“Análisis de Resultados de las Políticas Públicas en Salud Oral en Bogotá en el periodo comprendido entre 1999-2014."

\author{
Estudiantes Maestría Nubia Astrid Duarte Pinzón
}

Rutty Adriana Abril Vivas

Asesora

Ivonne Andrea Ordoñez Monack

\author{
Universidad Santo Tomas de Colombia \\ Facultad de Economía \\ Maestría de Protección Social \\ Bogotá D.C., Colombia
}

2016 
A Dios y la virgen que me han dado la fortaleza y oportunidad siempre, a mis padres Luis y Emma a mis hijos Brian, Christian, Stevens que fueron son y serán el norte de mi vida. 


\section{Tabla de contenido}

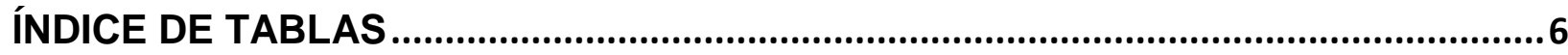

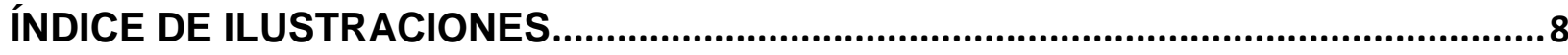

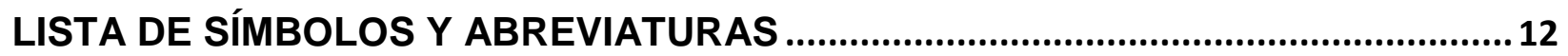

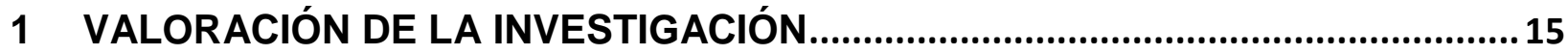

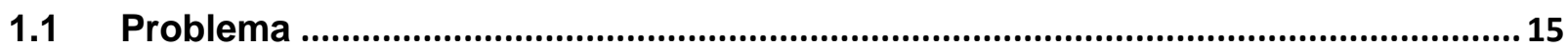

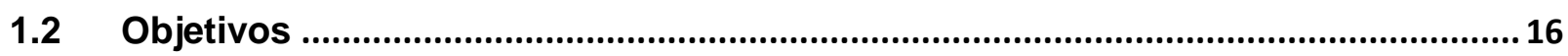





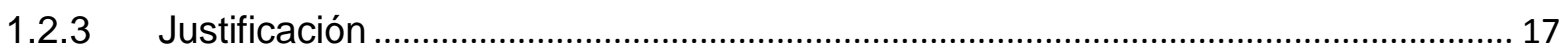

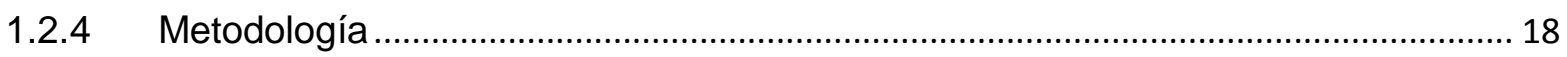

1.2.5 Limitaciones en la investigación ............................................................................. 19

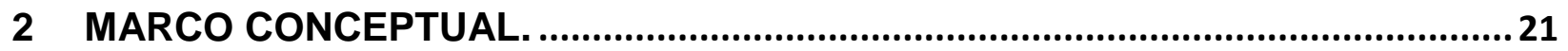

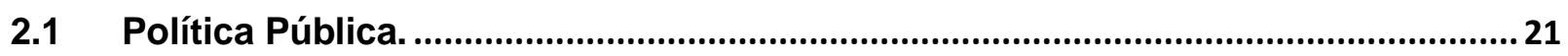

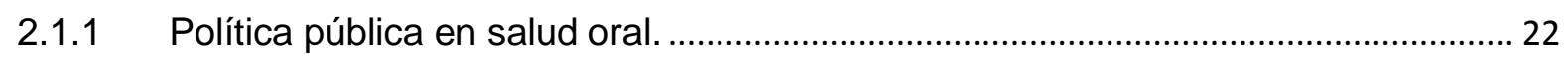

2.2 Definición de términos de patologías orales.............................................................23

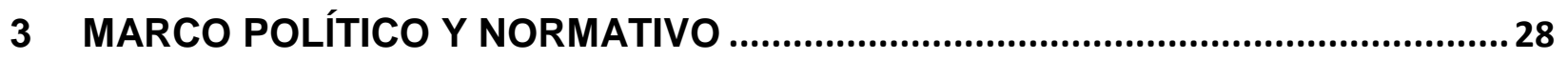

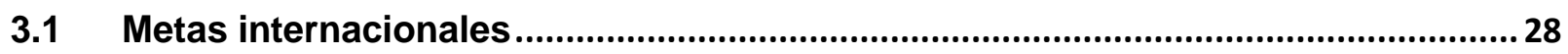

3.2 Marco normativo en Colombia..................................................................................

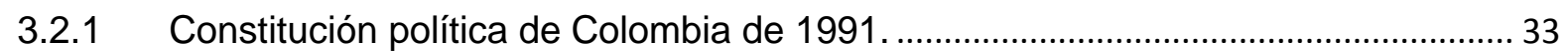



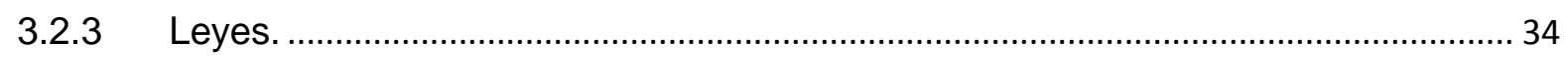

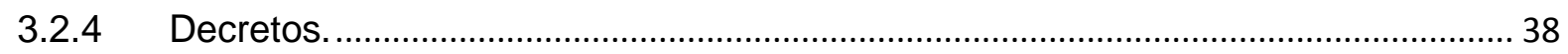

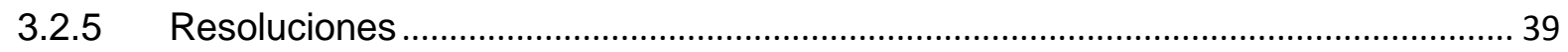

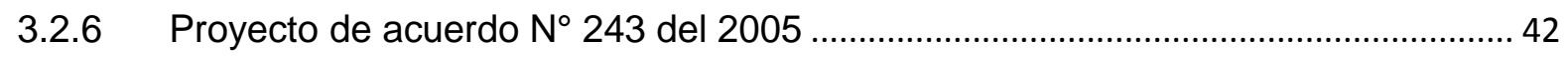

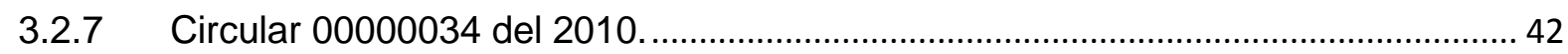

3.3 Metas en salud pública oral en Colombia y en Bogotá del 1999 al 2014.................43

3.3.1 El Plan Nacional de Salud adoptado mediante Resolución 3577 de 2006............. 44

3.3.2 Plan Decenal de Salud Pública, PDSP, 2012 - 2021 ............................................. 45

3.3.3 Plan decenal para el control de cáncer en Colombia, 2012-2021 ............................ 48

3.3.4 Política de salud oral 2004 en Bogotá....................................................................... 50 
3.3.5 Política de salud oral de Bogotá, D.C. con participación social para el decenio 2011-2021

3.3.6 Planes de desarrollo Bogotá....................................................................................... 52

3.3.7 Plan de atención básica, Plan de Intervenciones Colectivas. ................................... 53

\section{ANÁLISIS DE LA PERTINENCIA DE LAS POLÍTICAS DE SALUD ORAL EN} TÉRMINOS DE RESULTADOS Y DE PERFIL DE MORBILIDAD ORAL......................55

4.1 Percepción de la población frente al estado de salud oral 1999-2014. .................56

4.2 Análisis de la situación en salud en Colombia periodos 1999; 2002-2007; 2013-

2014. 65

4.3 Análisis resultados encuestas nacionales de salud bucal ENSAB III 1999, SISVESO 2013, APS 2011- 2012, ENSAB IV 2014, Colombia y Bogotá...........................69

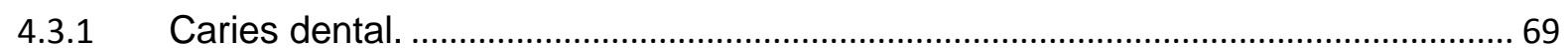

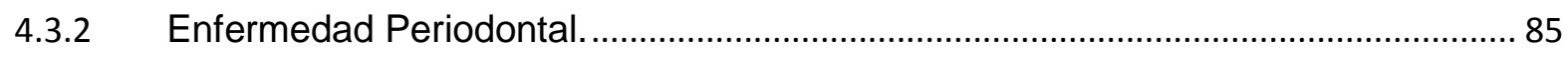

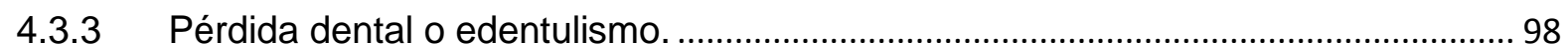

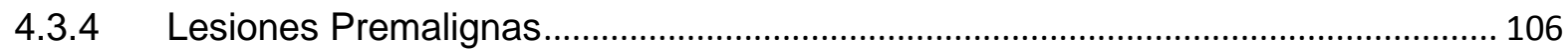

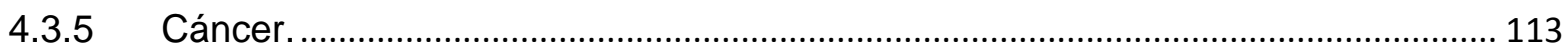

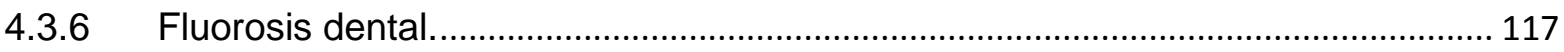

4.3.7 Consolidados eventos de salud oral e indicadores diferentes fuentes.................. 122

\section{EVOLUCION DE LOS INDICADORES DE COBERTURA EN SALUD} BUCODENTAL DE LA POBLACION Y DETERMINACION DE LAS NECESIDADES DE SALUD ORAL EN TERMINOS DEL PERFIL EPIDEMIOLOGICO ACTUALIZADO EN LA POBLACION DEL DISTRITO.- ...................................................................... 130

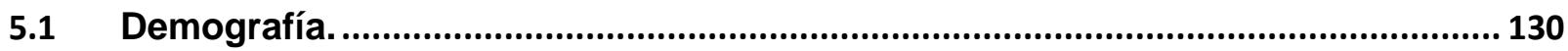

5.2 Regímenes de Afiliación Colombia 2014........................................................... 133

5.3 Oferta institucional de servicios de Salud. ..................................................... 136

5.3.1 Oferta institucional Colombia 2007....................................................................... 136

5.3.2 Oferta institucional Odontológica para Colombia y Bogotá 2013-2014 ............... 138

5.4 Metas distritales en salud oral Bogotá. .............................................................. 141

5.4.1 Cobertura de control de Placa Bacteriana Bogotá 2008- 2012 …......................... 142

5.4.2 Atención de consulta odontológica de primera vez............................................... 143

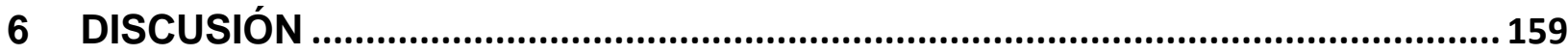

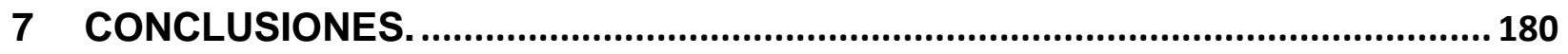

Página 4 de 228

Rutty Adriana Abril Vivas. Odontóloga. Especialista Administración Hospitalaria. Auditoria de la Calidad. Nubia Astrid Duarte Pinzón. Enfermera. Especialista en Gerencia de Salud. 


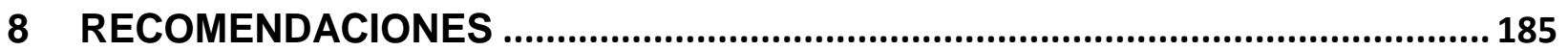

$9 \quad$ ANEXO

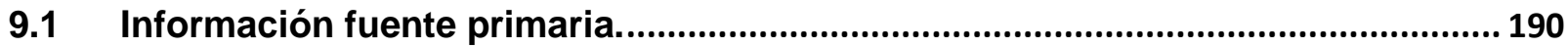

Rutty Adriana Abril Vivas. Odontóloga. Especialista Administración Hospitalaria. Auditoria de la Calidad. Nubia Astrid Duarte Pinzón. Enfermera. Especialista en Gerencia de Salud. 


\section{ÍNDICE DE TABLAS}

Tabla 1 Distribución de caries consulta externa Colombia 2002-2007.

Tabla 2 Distribución por grupos etarios de las primeras causas de morbilidad en consulta odontológica, Colombia 2013.

Tabla 3 Índice caries obturados perdidos ceo-d. SISVESO Distrito Capital 2013.

Tabla 4 Comparativo de la incidencia, mortalidad y prevalencia de cáncer por sexo Colombia y Bogotá vigencia 2007 a 2011.

Tabla 6 Comparativo consolidados indicadores de estado de salud oral menores 5 a 12años Colombia- Bogotá ENSAB III 1998.

Tabla 7 Estado de Aseguramiento Población de Bogotá 2014.

Tabla 8 Comparativo aseguramiento del 2000 al 2015.

Tabla 9 Número promedio de instituciones públicas y privadas de salud categoría especial, Colombia, 2007.

Tabla 10 Prestadores de Servicio Odontológico Habilitados Bogotá por Tipo de Prestador.2014.

Tabla 11 Metas Distritales, regímenes contributivo y subsidiado 2008-2012......

Tabla 12 Control de Placa Bacteriana por régimen de afiliación. Bogotá 2008- 2012.

Tabla 13 Cobertura de la atención en el menor de cinco años por régimen de afiliación

Tabla 14 . Visita al odontólogo primera infancia. SISVESO. Bogotá 2009 -2013. 145

Tabla 15 Cobertura consulta de primera vez régimen contributivo. Bogotá 2011 146

Tabla 16 Cobertura consulta de primera vez régimen subsidiado. Bogotá 2011. 147

Tabla 17 Cobertura de la atención en oral a la mujer gestante por régimen de afiliación. 148

Página 6 de 228

Rutty Adriana Abril Vivas. Odontóloga. Especialista Administración Hospitalaria. Auditoria de la Calidad. Nubia Astrid Duarte Pinzón. Enfermera. Especialista en Gerencia de Salud. 
Tabla 18 Metas Distritales de Salud Oral 2008-2011. Consolidado Régimen Subsidiado y Contributivo en Bogotá D.C .

Tabla 19 Comparativo año 2011 primer semestre 2012 del indicador consulta de primera vez.

151

Tabla 20 Seguimiento al indicador de oportunidad de porcentaje de asignación de citas odontológicas regímenes de afiliación. Colombia 2012- 2013. 


\section{ÍNDICE DE ILUSTRACIONES}

Ilustración 1 Distribución porcentual pregunta ¿qué es tener una boca sana? Bogotá, 1999.... 57 Ilustración 2 Distribución porcentual pregunta ¿qué es tener una boca sana? Bogotá, 2011 .2012 .

Ilustración 3 Distribución porcentual pregunta elementos utilizados para la limpieza de los dientes. Bogotá 1999.

Ilustración 4 Distribución porcentual pregunta elementos utilizados para la limpieza de los dientes. Bogotá, 2011 .2012.

Ilustración 5 Distribución porcentual de las razones por las cuales no se usa la seda dental Bogotá, 1999.

Ilustración 6 Distribución porcentual de las razones por las cuales no se usa la seda dental Bogotá 2011.2012.

Ilustración 7 Distribución porcentual pregunta frente a la pregunta de la supervisión de cepillado en menores. Bogotá 1999.

Ilustración 8 Distribución porcentual de la supervisión de cepillado en menores.

Bogotá.2011.2012.

Ilustración 9 Prevalencia de caries en dentición primaria en niños de 5 años Bogotá 1999 ...... 70

Ilustración 10 Ilustración 10 Historia y prevalencia de caries dentición permanente Colombia 1999.

Ilustración 11 Tendencia caries menor de 5 años y rango de edad 15 a 40 años periodos 19982014 Colombia

Ilustración 12 Prevalencia de caries no tratada Colombia 2013-2014. 74

Ilustración 13 Prevalencia de caries no tratada por región Colombia- Bogotá $2014 .$. 75

Ilustración 14 Prevalencia de caries no tratada comparativo por grupos etarios. Colombia 19992014. 
Ilustración 15 Comparativo Índice ceo-d, niños de 5 años, sub regiones Colombia, 1999

Ilustración 16 Índice COP-D según grupos de edad y mujeres gestantes, SISVESO 2007 ........ 79

Ilustración 17 Índice COP-D Subsistema de Vigilancia Epidemiológica por grupo de edad.

Bogotá 2013.

Ilustración 18 Índice de dientes con caries, obturados y perdidos por caries cavitacional por grupos de edad. Colombia 2014.

Ilustración 19 Comparativo promedio de Índice COP estudios nacionales. Colombia.2014 ........ 84

Ilustración 20 Índice de placa bacteriana (Silness \& Loe modificado) por etapa de ciclo vital, SISVESO 2009.

Ilustración 21 Estado de higiene oral primera infancia. Bogotá 2009-2013.

Ilustración 22 Extensión de la pérdida de inserción periodontal.ENSAB III.1999 ENSAB IV. 2014 Colombia.

Ilustración 23 Severidad de la pérdida de inserción periodontal.ENSAB III.1999 ENSAB IV.2014 Colombia.

Ilustración 24 Comparativo de la severidad de perdida soporte periodontal ENSAB III vs -IV.

Colombia 1999- 2014

Ilustración 25 Prevalencia de pérdida de soporte periodontal por curso de vida. 2014. Colombia.

Ilustración 26 Pérdida de inserción periodontal leve comparativo Bogotá. 1998-2014.

Ilustración 27 Prevalencia de enfermedad periodontal, comparativos estudios nacionales 1999-

2014.

Ilustración 28 Porcentaje de periodontitis por sexo y localidad. Bogotá 2011-2012.

Ilustración 29 Morbilidad (pérdida de dientes) en salud oral en la población vinculada, desplazada y del régimen subsidiado no POS, periodo 2011-2012. Bogotá.

Ilustración 30 Prevalencia de pérdida dental parcial. Colombia.2014. 101

Página 9 de 228

Rutty Adriana Abril Vivas. Odontóloga. Especialista Administración Hospitalaria. Auditoria de la Calidad. Nubia Astrid Duarte Pinzón. Enfermera. Especialista en Gerencia de Salud. 
Ilustración 32 Prevalencia edentulismo parcial y total por regiones. Bogotá. Colombia 20132014.

Ilustración 33 Presencia de prótesis por regiones. Bogotá. Colombia. 2013-2014. 103

Ilustración 34 Comparativo tendencia y uso de prótesis dental.Colombia-Bogotá 104

Ilustración 35 Prevalencia de lesiones pre malignas en la población de 20 a 79 años, Colombia, 2013-2014. 108

Ilustración 36 Prevalencia de lesiones asociadas al uso de prótesis según sexo en la población general. Colombia, 2013-2014. 108

Ilustración 37 Prevalencia de lesiones asociadas al uso de prótesis según régimen de afiliación en la población general. Colombia, 2013-2014. 110

Ilustración 38 Prevalencia de lesiones asociadas al uso de prótesis según grupos de edad en la población de 20 a 79 años. Colombia, 2013-2014.

Ilustración 39 Prevalencia de lesiones pre malignas en la población de 20 a 79 años, Colombia, 2013-2014.

Ilustración 40 Prevalencia de lesiones asociadas al uso de prótesis según sexo en la población general. Colombia, 2013-2014.

Ilustración 41 Porcentaje de mortalidad específica por edad cáncer oral en el 2008. Colombia.

Ilustración 42 Tasas de mortalidad específicas por edad cáncer oral en el 2008. Colombia. ... 114

Ilustración 43 Mortalidad por cáncer oral según regímenes de afiliación. Colombia. 2008. ..... 116

Ilustración 44 Presencia de fluorosis dental por grado de severidad en la población de 5 a 19 años. Colombia.

Ilustración 45 Índice Comunitario de Fluorosis - ICF por edad. Colombia 2013.2014. 
Ilustración 46 Índice Comunitario de Fluorosis - ICF por región. Bogotá. Colombia 2013.2014.

Ilustración 47 Comparativo Índice COP dentición permanente 1977-80, 1998, 2014 por grupo etario. Colombia.

Ilustración 48 Comparativo consolidados indicadores de salud oral ENSAB III- ENSAB IV población 5 años y adolescentes Bogotá.

Ilustración 49 Consolidado de la prevalencia por regiones de la salud oral. ENSAB IV 2014.Colombia. Bogotá.

Ilustración 50 Consolidado prevalencia eventos salud oral por edades. Colombia 2014. 125

Ilustración 51 Consolidado primeras causas de atención en salud oral, vinculados, desplazados, subsidiados. Bogotá 2011-2012.

Ilustración 52 Consolidado de diagnósticos principales de consulta de la población caracterizada por salud a su casa (PIC) según grupo de edad. Bogotá D.C., 2011-2012. 128

llustración 53 Pirámide poblacional de Bogotá año 2013.Bogotá, D.C. 132

llustración 54 Tendencia de las atenciones en salud oral por localidad y año en la población vinculada, desplazada y subsidiada no POSS. Bogotá, D.C., 2006-2012.

llustración 55 Consentimiento informado. 190

Página 11 de 228

Rutty Adriana Abril Vivas. Odontóloga. Especialista Administración Hospitalaria. Auditoria de la Calidad. Nubia Astrid Duarte Pinzón. Enfermera. Especialista en Gerencia de Salud. 


\section{LISTA DE SÍMBOLOS Y ABREVIATURAS}

Definición de Términos Básicos

APS. Atención Primaria en Salud.

ASIS Análisis de la Situación en Salud

COP-D Caries, obturados, perdidos en dientes permanentes

Ceo-d Caries, obturados, perdidos en dientes temporales

ENDS Encuesta Nacional Demográfica en Salud

ENSAB Encuesta Nacional de Salud Bucal

ENSIN Encuesta Nacional de Situación Nutricional Colombia

ENSP Encuesta Nacional de Salud Pública

EPS Empresa Promotora de Salud

ESE Empresa Social del Estado

FESP Funciones especiales de Salud Pública 
IPS Instituciones Prestadoras de Salud

MPS Ministerio de Protección Social

OPS Organización Panamericana de la Salud

OMS Organización Mundial de la Salud

PDA Proyecto de Autonomía

PCVS Enfoque Promocional de Calidad de Vida y Salud

PDSP Plan Decenal de Salud Pública

PIC Plan de Intervenciones Colectivas

PNSP Plan Nacional de Salud Pública

POA Plan Operativo Anual

POS Plan Obligatorio de Salud

PP Política Pública

PNUD Programa de las Naciones Unidas para el Desarrollo en Colombia 
RIPS Registro de información de Prestaciones en Salud

RISS Redes integradas de Servicios de Salud

SGSSS Sistema General de Seguridad Social en Salud

SISBEN Sistema de identificación de Beneficiarios de Programas sociales

SISVESO Sistema de Vigilancia Epidemiológica en Salud Oral

SP Salud Pública

SUPERSALUD Superintendencia Nacional de Salud. 


\section{VALORACIÓN DE LA INVESTIGACIÓN}

\subsection{Problema}

Las enfermedades de los dientes y tejidos de sostén, representan la primera causa de morbilidad de la población nacional y se encuentra entre las primeras causas de consulta en las instituciones de salud (Ministerio de Salud, 1999). En Bogotá dentro de las primeras causas de consulta ambulatoria, entre la población pobre no asegurada, se encontró como cuarta causa la caries de la dentina (Organización Mundial de la Salud OPS/OMS Colombia, 2009). Los diagnósticos de mayor consulta en Bogotá durante la vigencia 2011 fueron la caries de dentina, el sangrado de las encías o la gingivitis; mientras que los procedimientos registrados con mayor frecuencia fueron la consulta de primera vez y la consulta de urgencia; (Secretaria Distrital de Salud de Bogotá, Martha Lucía Hincapié Molina, \& Nirley Stella Vargas Díaz, 2014).

El Distrito Capital ha establecido políticas de salud que están basadas en los planes de desarrollo. Para el periodo 2008-2012,"Bogotá positiva: para vivir mejor", se desarrolló el proyecto salud a su casa, bajo el enfoque de la estrategia de atención primaria en salud APS.

Con el plan de gobierno "Bogotá Humana"; 2012-2016 se propuso como meta incrementar en el $25 \%$, la atención de primera vez en salud oral de los niños, niñas y jóvenes menores de 19 años en el Distrito Capital, mediante la estrategia promoción de prácticas en salud oral: técnicas de higiene oral, control odontológico, difusión de deberes y derechos, rol de los padres y cuidadores, factores protectores, entre otras acciones, dirigidas a la población dando prioridad al acceso en salud.

Bajo esta perspectiva y según lo observado al presentarse una alta carga de morbilidad del sistema estomatognático de la población del distrito capital es pertinente en un primer momento conocer y analizar los resultados de las acciones en salud oral con el fin de

Página 15 de 228

Rutty Adriana Abril Vivas. Odontóloga. Especialista Administración Hospitalaria. Auditoria de la Calidad. Nubia Astrid Duarte Pinzón. Enfermera. Especialista en Gerencia de Salud. 
establecer si las políticas, los programas y proyectos se encuentran orientados hacia los problemas más relevantes y poder establecer el impacto en términos de eficacia, efectividad y eficiencia de las acciones de promoción, prevención, tratamiento y rehabilitación en salud oral.

Por otra parte, no se evidenciaron estudios o evaluaciones oficiales que valoraran dichas políticas, teniendo en cuenta el perfil epidemiológico de la población del distrito, así como la existencia de barreras de acceso, la falta de integración de las acciones en salud oral.

Teniendo en cuenta lo anterior, La pregunta de investigación planteada en el trabajo de investigación fue ¿Cuál es la pertinencia de las Políticas Públicas en Salud oral en Bogotá en el periodo comprendido $1999-2014$ ?

\subsection{Objetivos}

\subsubsection{Objetivo General}

Analizar la pertinencia de las Políticas Públicas en Salud Oral establecidas a nivel Distrital a través de indicadores de salud bucal en el periodo comprendido entre 1999 a 2014.

\subsubsection{Objetivos Específicos}

- Identificar las Políticas Públicas de Salud Oral para el Distrito en el periodo del estudio. 
- Analizar la pertinencia de las políticas de salud oral a través de la evolución de los indicadores en salud bucodental de la población del Distrito en relación con su perfil de morbilidad oral.

- Determinar la cobertura de las políticas de salud oral en Bogotá en el periodo del estudio.

\subsubsection{Justificación}

El resultado evidenciado en el estado de salud oral, muestra que, en el Distrito Capital, prevalece una alta morbilidad oral, siendo necesario el cuestionamiento de que factores inciden en dicha situación de salud en la población. Por tal razón es importante generar un análisis más profundo del perfil epidemiológico oral, para poder identificar la morbilidad y analizar el modelo de atención existente y el resultado de las acciones realiza das en la comunidad.

El presente estudio pretendió analizar y cuestionar la fragmentación y segmentación de las políticas de salud oral, así como sus efectos en la población, ya que al parecer no se tienen en cuenta las acciones para la totalidad de los grupos poblacionales como muestran los hallazgos de las últimas encuestas nacionales de salud bucal (ENSAB III y ENSAB IV); las patologías de caries, gingivitis, periodontitis y pérdidas dentales 
prevalecen en todos los grupos poblacionales de la población siendo insuficientes e inadecuadas, .

Al verificar las fuentes bibliográficas se observó que existe poca bibliografía o estudios oficiales sobre análisis de resultados de las políticas públicas en salud oral en Bogotá, por lo que este estudio sería un aporte importante este sentido y siendo propositivo frente a un posible modelo de atención en salud oral.

\subsubsection{Metodología}

Investigación descriptiva mediante la búsqueda y revisión documental sistemática de información a través de fuentes secundarias, del Ministerio de la Protección Social , Secretaria Distrital de Salud, Alcaldía Mayor de Bogotá D.C, Encuestas Nacionales de Salud (ENSAB III y IV ), proyectos de desarrollo de autonomía de la Secretaria Distrital de Salud, registros individuales de prestación de servicios de salud ( RIPS ), bases de datos de vigilancia en salud pública así como informes técnicos, publicaciones nacionales e internacionales, revistas, libros entre otros, y entrevista con el fin de conocer, visualizar las características, la implementación, el desarrollo de las políticas públicas de salud oral. La información de la fuente primaria, fue obtenida mediante información suministrada por el Dr. Jairo Hernán Ternera, odontólogo egresado de la Universidad Nacional con maestría en administración de servicios de salud de la Universidad Javeriana y una

Página 18 de 228

Rutty Adriana Abril Vivas. Odontóloga. Especialista Administración Hospitalaria. Auditoria de la Calidad. Nubia Astrid Duarte Pinzón. Enfermera. Especialista en Gerencia de Salud. 
especialidad en seguros y seguridad social de la Universidad de la Sabana, y profesional especializado en el área de subdirección de aseguramiento de la S.D.S. (anexo )

Se analizaron las acciones ejecutadas desde la atención primaria, secundaria y terciaria de acuerdo a planes de beneficios establecidos y sus resultados frente a los diferentes grupos etarios de población.

\subsubsection{Limitaciones en la investigación}

A continuación, se relacionan algunas limitantes encontradas en la presente investigación:

$\checkmark$ El país cuenta con tres estudios nacionales de morbilidad oral; el primero corresponde a la investigación nacional de morbilidad años 1965-1966, seguido de la encuesta nacional de salud bucal realizada en el año 1998 y luego de 16 años se realizó la encuesta nacional de salud bucal 2014 ; estudios que permiten establecer el perfil epidemiológico oral de la población a nivel nacional, sin embargo no se encontraron estudios similares específicos para la población del distrito capital, lo que impidió realizar un comparativo sistemático de los diferentes periodos objeto de investigación, razón por la cual se toma de base el contexto nacional. 
$\checkmark$ Los sistemas de información en salud oral en el distrito no se encontraron unificados y presentaron inconsistencias y reportes inoportunos a los entes de control lo que genero sesgo en la información. 


\section{MARCO CONCEPTUAL.}

\subsection{Política Pública.}

La política pública se considera como las diferentes acciones que el gobierno como ente rector realiza en el marco de un objetivo público a través de un diagnóstico y análisis previo para la atención con efectividad de la problemática existente con participación comunitaria(Julio Franco Corzo, 2013).

Como afirma Molina (2013) "Ives Meny y Thoenig (1992:90) definen la Política Pública como "un programa de acción gubernamental en un sector de la sociedad o en un espacio geográfico". Para Thomas Dye (2002:1) una Política Pública "es todo aquello que los gobiernos deciden hacer o no hacer". De esta manera estos conceptos son formulados a raíz de las acciones realizadas por el ente de gobierno como respuesta a la problemática social. En este sentido, Salazar (1995:30) y Vargas (1999:57) definen las políticas públicas como las "iniciativas, decisiones y acciones del Estado frente a situaciones socialmente problemáticas, que buscan la resolución de las mismas 0 , al menos, llevarlas a niveles manejables" (Universidad de Antioquia Facultad Nacional de Salud Pública Héctor Abad Gómez \& COLCIENCIAS, 2014)

Para el presente trabajo se definió la política pública como el propósito y la acción de un gobierno como ente rector para realizar a través de políticas y programas la intervención

Página 21 de 228 Rutty Adriana Abril Vivas. Odontóloga. Especialista Administración Hospitalaria. Auditoria de la Calidad. Nubia Astrid Duarte Pinzón. Enfermera. Especialista en Gerencia de Salud. 
de las necesidades sentidas de los diferentes grupos poblacionales con el fin de dar respuesta a una problemática social especifica que deben ser abordadas y articuladas con los diferentes actores mediante procesos de construcción, decisión y acción con la mayor eficacia y efectividad.

\subsubsection{Política pública en salud oral.}

Según la OMS (Organización Mundial de la Salud, 2016) "La eficacia de las soluciones de salud pública contra las enfermedades bucodentales es máxima cuando se integran con otras enfermedades crónicas y con los programas nacionales de salud pública. Las actividades del Programa Mundial de Salud Bucodental de la OMS están alineadas con la estrategia de la Organización en materia de prevención de enfermedades crónicas y promoción de la salud. Se confiere especial prioridad a la elaboración de políticas mundiales de promoción de la salud bucodental y prevención de enfermedades de la boca ".

Como afirma la secretaria distrital de salud la política corresponde a la concertación con diferentes actores, quienes asumieron un rol de ciudadanía, comprometiéndose al trabajo por mejorar las condiciones de salud oral y calidad de vida de la población del distrito capital dando soporte a las actividades propuestas como solución a la necesidad sentida y detectada en los territorios (Secretaria Distrital de Salud, 2011a).

Página 22 de 228 Rutty Adriana Abril Vivas. Odontóloga. Especialista Administración Hospitalaria. Auditoria de la Calidad. Nubia Astrid Duarte Pinzón. Enfermera. Especialista en Gerencia de Salud. 


\subsection{Definición de términos de patologías orales.}

La salud oral es considerada por la Organización mundial de la salud (OMS) como ausencia de dolor, de lesiones orales, de alteraciones congénitas, periodontopatías, caries dental, perdida de dientes, cáncer oral y en general alteraciones de la boca sin afectar el bienestar general y psicosocial del individuo ni las capacidades biológicas y fisiologías como la masticación, el habla, la fonación, la deglución, el crecimiento maxilofacial entre otras (Secretaria de Salud de los Estados Unidos Mexicanos, 2012). Dentro de las principales patologías de origen dental se encuentran:

$\checkmark \quad$ La caries dental es una enfermedad de los tejidos calcificados de los dientes, que se caracteriza por desmineralización de la parte inorgánica y destrucción de la sustancia orgánica del diente (Hospital general de México., 2014).

$\checkmark \quad$ En relación con las patologías de las encías estas pueden variar desde una simple inflamación denominada gingivitis hasta una compleja patología, la periodontitis avanzada.

La gingivitis es una infección e inflamación de las encías las cuales destruyen los tejidos que soportan los dientes, es causada por la placa dental generada por bacterias, que corresponde a una película adherente que se acumula sobre la superficie de los dientes y las encías, y que produce ácidos y toxinas que pueden hacer que las encías sangren.

Página 23 de 228 Rutty Adriana Abril Vivas. Odontóloga. Especialista Administración Hospitalaria. Auditoria de la Calidad. Nubia Astrid Duarte Pinzón. Enfermera. Especialista en Gerencia de Salud. 
Afectan los tejidos blandos y los tejidos de soporte generando perdida dental, debido a la formación de bolsa por debajo de la línea de las encías, produciendo penetración y aumento de placa bacteriana inferior a la línea de la gingival involucrando finalmente fibras y tejido óseo destruyéndolo causando desplazamiento y movilidad dental.

La periodontitis es una condición inflamatoria progresiva que puede aparecer al no tratar la gingivitis y que destruye las fibras de los ligamentos periodontales y el hueso alveolar causando bolsas, activando el sistema inmunitario del cuerpo como mecanismo de defensa y puede, eventualmente ocasionar la pérdida de los dientes, con mayor frecuencia en adultos mayores de 35 años, la enfermedad periodontal presenta cuadro clínico de origen infeccioso produciendo lesiones de tipo inflamatorio con un potencial alto de destrucción local y compromiso sistémico como canceres, septicemias entre otros(National Institute of Dental and Craniofacial ResearchNational Oral Health Information Clearinghouse, 2013).

$\checkmark \quad$ En relación con la pérdida parcial o total denominada edentulismo, es la ausencia o la pérdida total o parcial de los dientes, y su causa puede ser congénita o adquirida. Los edentulismos congénitos totales son una manifestación de los síndromes congénitos muy graves y generalmente, no compatibles con la vida. El edentulismo adquirido, suele ser causado desde una deficiente higiene oral hasta traumatismos o diferentes patologías, incidiendo sobre la calidad de vida por dificultad para la ingesta de alimentos,

Página 24 de 228 Rutty Adriana Abril Vivas. Odontóloga. Especialista Administración Hospitalaria. Auditoria de la Calidad. Nubia Astrid Duarte Pinzón. Enfermera. Especialista en Gerencia de Salud. 
deficiente masticación, factores estéticos y problemas de autoestima, la ausencia de dientes naturales produce alteraciones del sistema estomatognático así como en las estructuras óseas del cráneo y la cara provocando alteraciones en la fonación y deglución, problemas masticatorios generando problemas del tracto digestivo , desnutrición y anemias, adicionalmente problemas de autoestima y psicológicos por factores estéticos (Souza Coelho Soares, Santos Gusmão, Soares Hordonho Santillo, \& Henriques Simoni, 2016)

Los fluoruros están constituidos por compuestos binarios elementos orgánicos e inorgánicos que contienen flúor que pueden ser sólidos, líquidos o gases, liberados de forma natural en el medio ambiente importante para las edades tempranas, debido a que en la cavidad oral se encuentran bacterias que combinadas con los azucares producen ácidos que causan daño en el esmalte dental, el fluoruro protege el tejido dental y colabora con la posible reversión de signos prematuros de caries pero su consumo excesivo en el periodo de formación dental provoca la fluorosis dental y esquelética, el hombre retiene en promedio de 60 a $90 \%$ de estos acumulándolo en huesos y dientes, en menores que consumen flúor en agua con 4ppm por periodos prolongados se produce fluorosis grave en dientes temporales. Toda la población está expuesta a fluoruros emitidos por fuentes naturales (minerales y agua) y/o por actividades humanas, una 
exposición excesiva ocasiona riesgo (Agencia para sustancias tóxicas y el registro de intoxicaciones., 2013)

$\checkmark \quad$ En lo relacionado con las lesiones de tejidos blandos de la cavidad oral se consideran las lesiones exofíticas sólidas, excrecentes y circunscritas, sobre de la mucosa bucal normal identificada en inspección exploración, de consistencia, elástica, duro elástica o blanda, clasificada según la patogénesis en malformaciones, hiperplasias reactivas o tumores(Bermejo Fenoll \& López Jornet, 2005).

$\checkmark \quad$ La Hiperplasia fibrosa inflamatoria (HFI), consiste en un aumento tisular asintomático de lento crecimiento lento, el cual aparece como mecanismo de defensa ante agentes físicos, normalmente por presencia de prótesis desadaptadas.

La estomatitis subprotésica produce inflamación mucosa por factores irritantes y crónicos asociada al uso de prótesis.

$\checkmark \quad$ Dentro de las lesiones pre malignas de la cavidad oral de mayor frecuencia se encuentran nevus, eritroplasias (mancha, rojo brillante aterciopelado), fibrosis submucosa, leucoplasias (mancha localizada blanca) y el liquen plano.

$\checkmark \quad$ Los canceres de cavidad oral y faringe se encuentra dentro de los canceres más comunes de cabeza y cuello, incluyendo labios, mejillas (mucosa bucal), encías, lengua, piso de boca, paladar, espacio retromolar zonas de gran importancia en las funciones masticatorias, respiración y habla.

Página 26 de 228

Rutty Adriana Abril Vivas. Odontóloga. Especialista Administración Hospitalaria. Auditoria de la Calidad. Nubia Astrid Duarte Pinzón. Enfermera. Especialista en Gerencia de Salud. 
Un porcentaje aproximado del $90 \%$ de los canceres corresponden a carcinomas de células escamosas es decir sus estadios primarios se encuentran en las células planas escamosas del revestimiento interno de la cavidad oral siendo la lengua, la encía y piso de boca los sitios más comunes de ubicación, se encuentran también otros tipos histológicos originados en glándulas salivares (Stambuk, H., Karimi,S., Lee S, Patel,S., 2007)

Dentro de los factores de riesgo considerados para la incidencia de la patología se encuentran: el tabaco, alcohol, cigarrillo, mala higiene presencia de restos radiculares, xerostomía, malnutrición y deficiencia de hierro entre otras. 


\section{$3 \quad$ MARCO POLÍTICO Y NORMATIVO}

\subsection{Metas internacionales}

Los antecedentes del marco normativo de la salud pública oral, pueden retomarse desde las declaraciones internacionales de salud, como la realizada por los pueblos de Alma Ata, en 1978 (Conferencia Internacional sobre Atención Primaria de Salud, 1978). En 1994, las Naciones Unidas establecieron la salud como derecho humano y la estableció como un compromiso de todas las naciones del mundo (Secretaria Distrital de Salud, 2011b). En 1997 se proponen los siguientes objetivos en salud oral pública con enfoque de atención primaria de salud derivados de lo establecido por la Organización Mundial de la Salud (OMS).

$\checkmark \quad$ Mejorar las condiciones de la salud oral en la población de América que tienen una alta morbilidad en patologías bucales.

$\checkmark \quad$ Establecer servicios de salud oral accesibles, eficaces y sostenibles(Organización Panamericana de la salud, 1997).

Posteriormente, el 8 de septiembre del 2000 se aprobó por los 189 estados miembros de las Naciones Unidas en la declaración del milenio, las políticas públicas en salud oral. En 1981 la Organización Mundial de la Salud (WHO) y la Federación Dental (FDI), de forma conjunta formularon las metas de salud bucal que esperaban fueran alcanzadas antes del año 2000

Página 28 de 228 Rutty Adriana Abril Vivas. Odontóloga. Especialista Administración Hospitalaria. Auditoria de la Calidad. Nubia Astrid Duarte Pinzón. Enfermera. Especialista en Gerencia de Salud. 
$\checkmark \quad$ El $50 \%$ de los niños de 5-6 años, libres de caries dental.

$\checkmark \quad$ Contar con un promedio mundial de COP menor de 3 a los 12 años.

$\checkmark \quad$ El $85 \%$ de la población debe conservar todos sus dientes a la edad de 18 años. .

$\checkmark \quad$ Una reducción del 50\% en el edentulismo en las personas entre 35-44 años, en comparación con los niveles de 1982.

$\checkmark \quad$ Una reducción de $25 \%$ en el edentulismo en las personas de 65 años y más, comparados con los niveles de 1982.

Un sistema de información (base de datos) para que el monitoreo de los cambios en salud bucal puedan ser establecidos (Ministerio de la Protección Social de Colombia, 2010) En el 2003, la Organización Mundial de la Salud, establece la salud oral como la incorporación del enfoque de promoción de la salud como un factor determinante en la calidad de vida y considera la necesidad de incluir la salud oral en las políticas de salud pública en las diferentes regiones del mundo(Secretaria Distrital de Salud, 2015)

Se estableció como prioridades en salud oral el control de las enfermedades bucodentales, como la caries dental, la periodontitis (enfermedad gingival), alteraciones funcionales, enfermedades infecciosas, cáncer orofaríngeo, las manifestaciones bucodentales de la infección por $\mathrm{VIH}$, noma o estomatitis gangrenosa, el trauma 0 anomalías cráneo faciales, reducción del dolor, anomalías de desarrollo de los dientes, enfermedades de la mucosa oral, alteraciones de las glándulas salivales, pérdida de 
dientes, servicios de atención sanitaria y sistemas de información para la atención sanitaria.

A partir de dichas metas se espera que las regiones, países y áreas locales, y los planificadores locales desarrollen programas de prevención dirigidos a las poblaciones y mejorar la calidad de los sistemas de salud bucal (Martin Hobdel, Poul Erik Petersen, John Clarkson, \& Newell Johnson, 2013)

Las metas internacionales definidas para el año 2020 fueron:

\section{- Para la caries dental:}

$\checkmark \quad$ Incrementar la proporción de niños de 6 años libres de caries, en X porcentaje

$\checkmark \quad$ Reducir el índice COP, particularmente en el componente C, a la edad de 12 años en un porcentaje $\mathrm{X}$ con especial atención en grupos poblacionales de alto riesgo.

$\checkmark \quad$ Reducir el número de dientes extraídos debido a caries dental en las edades de 18, 35 a 44 años y 65 a 74 años en una proporción X.

\section{- $\quad$ La enfermedad periodontal}

$\checkmark \quad$ Reducir el número de dientes perdidos debido a enfermedades periodontales en X\% en edades de 18,35 - 44 y 65 - 74 años reduciendo la exposición al riesgo a factores como el hábito de fumar, la mala higiene bucal, el estrés y enfermedades inter-sistémica. 
$\checkmark \quad$ Reducir la prevalencia de enfermedades periodontales necrotizantes en un X\% reduciendo la exposición al riesgo a factores como la mala nutrición, el estrés y la inmunosupresión

$\checkmark \quad$ Reducir la prevalencia activa de infección periodontal (con o sin pérdida de dientes) en todas las edades en un X\%

$\checkmark \quad$ Incrementar la proporción de la población de todas las edades con salud periodontal (encías y a estructura de soporte óseo) en un X\%

\section{- $\quad$ Edentulismo}

$\checkmark \quad$ Reducir el número de personas con edentulismo en un X\% en edades de $35-44$ y 65- 74 años

$\checkmark \quad$ Aumentar el número de los dientes naturales en un X\% en las edades de 18, 35 44 y $65-74$ años

$\checkmark \quad$ Aumentar el número de individuos con dentición funcional (21 o más dientes naturales) en un X\% en las edades de 35-44 y 65 - 74 años(Martin Hobdel et al., 2013).

\section{- Cáncer Oro faríngeo}

$\checkmark \quad$ Reducir la prevalencia de cáncer oro faríngeo en un X\%.

$\checkmark \quad$ Mejorar la sobrevida a cinco años de los casos tratados en un X\%

$\checkmark \quad$ Incrementar la detección temprana en un X\% 
$\checkmark \quad$ Incrementar la oportuna referencia en un X\%

$\checkmark \quad$ Reducir la exposición a factores de riesgo especialmente tabaco, alcohol y mala nutrición en un X\%.

$\checkmark \quad$ Incrementar cuidado multidisciplinario especializado en los pacientes afectados en un $\mathrm{X} \%$.

La OMS recomienda para el análisis del COP, en las edades de 5-6 años, 12, 15, 18, 3544,60-74 años, siendo la evaluación del índice CPO-D a los 12 años, usada como el principal referente de comparación internacional del estado de salud bucal.

La OMS definió una escala de gravedad para el COP-D (COP por diente) a los 12 años, que permite identificar el grado de severidad de la enfermedad al calcular el COP tradicional, y que tiene los siguientes rangos:

$\checkmark \quad$ Muy bajo: cuando el índice final está entre 0.0 y 1.1

$\checkmark \quad$ Bajo: cuando el índice final está entre 1.2 y 2.6

$\checkmark \quad$ Intermedio: al estar entre 2.7 y 4.4

$\checkmark \quad$ Alto: si se encuentra entre 4.5 y 6.5

$\checkmark \quad$ Muy alto: si llega a ser mayor de 6.5 


\subsection{Marco normativo en Colombia}

En Colombia se contextualiza todo lo anterior en la política pública con la elaboración del CONPES social 91 de 2005 y el CONPES social 140 de 2011 a través de las Metas y Estrategias los Objetivos de Desarrollo del Milenio (ODM)

El logro de los ODM se soporta en las actividades de promoción y prevención dadas en las actividades de salud pública plasmadas en la normatividad vigente, así como la estrategia de la atención primaria en salud (Departamento Nacional de Planeación DNP, 2015)

En este sentido, el marco normativo colombiano está definido por toda la legislación que desarrolla los fundamentos que rigen el Sistema General de Seguridad Social en Salud, las cuales están:

\subsubsection{Constitución política de Colombia de 1991.}

Define a "Colombia como un Estado Social de Derecho organizado en forma de República unitaria, descentralizada, con autonomía de sus entidades territoriales, democrática, participativa y pluralista, fundada en el respeto de la dignidad humana, en el trabajo y la solidaridad de las personas que la integran y en la prevalencia del interés general.

En su artículo 49 se define la atención de la salud y el saneamiento ambiental como servicios públicos a cargo del estado quien garantiza a todas las personas el acceso a 
los servicios de promoción, protección y recuperación de la salud, conforme a los principios de eficiencia, universalidad y solidaridad. También establece las políticas para la prestación de servicios de salud por entidades privadas, así como su vigilancia y control. Así mismo se establecen leyes para las competencias de la Nación, las entidades territoriales y los particulares".

\subsubsection{Sentencia T.760 de 2008.}

Por la cual la Corte Constitucional ordena unificar los planes de beneficios, universalización del aseguramiento, actualización anual del POS y mayor autonomía del Comité Técnico Científico de las EPS para autorizar procedimientos y medicamentos que el paciente requiera para el tratamiento integral. Las órdenes de la Corte Constitucional abren un espacio para que el odontólogo discuta la inclusión de procedimientos como: tratamiento integral de la enfermedad gingival, tratamiento integral de la patología labio y paladar hendido: inclusión de la cirugía ortognática.

\subsubsection{Leyes.}

$\checkmark \quad$ Ley 10 de 1962. Especifica los requisitos para ejercer la profesión de odontólogo en el territorio nacional y sus Decretos Reglamentarios.

$\checkmark \quad$ Ley 35 de 1989. Expresa principios y procesos de ética del odontólogo, así como los casos de infracción de estos al relacionarse con pacientes, colegas, personal auxiliar, 
instituciones, la sociedad y el Estado. Establece tribunales de ética. Su Decreto Reglamentario es el 491 de 1990.

$\checkmark \quad$ Ley 38 de enero de 1993. La cual unifica el Sistema de Dactiloscopia y se adopta la Carta Dental para fines de identificación. Dispone que a partir del $1^{\circ}$ de enero de 1993, todos los consultorios odontológicos, tanto públicos como privados, están obligados a levantar una carta dental y mantener su respectivo archivo.

$\checkmark \quad$ Ley 10 de 1990, ley 100 de 1993, ley 715 de 2001 y la ley 1122 de 2007: De estas se despliegan las bases que sostienen el Sistema General de Seguridad Social en Salud; así mismo, organizan y direccionan (con lineamientos de equidad, obligatoriedad, protección integral, libre escogencia, autonomía de las instituciones, descentralización administrativa, participación social, concertación y calidad) el accionar normas.

$\checkmark \quad$ Ley 10 de 1990. Por la cual se reorganiza el Sistema Nacional de Salud $\checkmark \quad$ Ley 100 de 1993 tiene como objeto el fortalecimiento del Sistema General de Seguridad Social en Salud, en el marco de la estrategia Atención Primaria en Salud que permita la acción coordinada del Estado, las instituciones y la sociedad. "El Sistema General de Seguridad Social en Salud estará orientado a generar condiciones que protejan la salud de los colombianos, siendo el bienestar del usuario el eje central y núcleo articulador de las políticas en salud.

$\checkmark \quad$ Ley 715 de 2001: "Por la cual se dictan normas orgánicas en materia de recursos y competencias de conformidad con los artículos 151, 288, 356 y 357 de la Constitución

Página 35 de 228

Rutty Adriana Abril Vivas. Odontóloga. Especialista Administración Hospitalaria. Auditoria de la Calidad. Nubia Astrid Duarte Pinzón. Enfermera. Especialista en Gerencia de Salud. 
Política y se dictan otras disposiciones para organizar la prestación de los servicios de educación y salud, entre otros".

$\checkmark \quad$ Ley 1122 de 2007. "Por la cual se hacen algunas reformas al Sistema General de Seguridad Social en Salud, se define el Plan Nacional de Salud Pública, se crea el sistema de inspección vigilancia y control del Sistema General de Seguridad Social en Salud, en cabeza de la Superintendencia de Salud que busca el Mejoramiento en la prestación de los servicios de salud"

$\checkmark \quad$ Ley 1164 del 3 de octubre de 2007: esta establece la articulación de diferentes actores que intervienen en la formación y capacitación del talento humano en salud pública, y lo relacionado con los procesos de planeación, formación, vigilancia y control del ejercicio para las Políticas, Planes, Programas y estrategias de salud pública y educación superior, con acciones a corto, mediano y largo plazo.

$\checkmark \quad$ Ley 1335 de 2009 se previene daños a la salud de los menores de edad, la población no fumadora y se estimulan políticas públicas para la prevención del consumo del tabaco y el abandono de la dependencia del fumador.

$\checkmark \quad$ Ley 1355 de 2009 se define la obesidad y las enfermedades crónicas no transmisibles asociadas a esta como una prioridad de salud pública y se dictan medidas para su prevención, atención y control.

$\checkmark \quad$ Ley 1384 de 2010 por la cual se establecen las acciones para la atención integral del cáncer.

Página 36 de 228

Rutty Adriana Abril Vivas. Odontóloga. Especialista Administración Hospitalaria. Auditoria de la Calidad. Nubia Astrid Duarte Pinzón. Enfermera. Especialista en Gerencia de Salud. 
$\checkmark \quad$ Ley 1388 de 2010 por el derecho a la vida de los niños con cáncer.

$\checkmark \quad$ Ley 1751 de 2015. Ley Estatutaria en Salud, que regula el derecho fundamental a la salud, el (art. 6), el cual debe tener continuidad, sin que este sea interrumpido por razones administrativas o económicas, de igual forma en el artículo 17 se consagra la autonomía médica, persiguiendo la seguridad del paciente, bajo esquemas de autorregulación, ética, racionalidad y evidencia científica.

$\checkmark \quad$ Ley 1438 de 2011. Por la cual se reforma el Sistema General de Seguridad Social en Salud y se establece a través de un modelo de prestación del servicio público en salud que en el marco de la Estrategia Atención Primaria en Salud permite la acción coordinada del Estado, las instituciones y la sociedad para el mejoramiento de la salud y la creación de un ambiente sano y saludable, que brinde servicios de mayor calidad, incluyente y equitativo, donde el centro y objetivo de todos los esfuerzos sean los residentes en el país. Fomenta el accionar intersectorial y transectorial, la participación social, ciudadana y comunitaria; y de la organización de Redes Integradas de Servicios de Salud (RISS).

Para esto concurrirán acciones de salud pública, promoción de la salud, prevención de la enfermedad y demás prestaciones que, en el marco de una estrategia de Atención Primaria en Salud, sean necesarias para promover de manera constante la salud de la población" (Ministerio de Salud y Protección Social, 2015)

Página 37 de 228

Rutty Adriana Abril Vivas. Odontóloga. Especialista Administración Hospitalaria. Auditoria de la Calidad. Nubia Astrid Duarte Pinzón. Enfermera. Especialista en Gerencia de Salud. 


\subsubsection{Decretos.}

$\checkmark \quad$ Decreto 2024 de 1984. Normaliza el contenido de yodo que debe dosificarse a la sal (entre 50 y 100 ppm), ordena la adición de flúor (entre 180 y 220 ppm) y establece sanciones a los empacadores que infrinjan la norma. Estas acciones de salud pública son de gran importancia para los ciudadanos y la odontología ya que es una medida masiva para la prevención de la caries dental.

$\checkmark \quad$ Con respecto a los decretos del marco normativo que rige a los profesionales de la salud, se encuentra, el Decretos 3616 de octubre 10 de 2005. Este decreto establece las denominaciones de los auxiliares en las áreas de la salud, se adoptan sus perfiles ocupacionales y de formación, los requisitos básicos de calidad de sus programas y se dictan otras disposiciones. En este Decreto se unifica al auxiliar de consultorio dental y al auxiliar de higiene oral en un solo perfil denominado Auxiliar de Salud Oral, el cual con un año de capacitación cumple con las funciones administrativas y clínicas que tenían los dos auxiliares anteriores.

$\checkmark \quad$ Decreto 1011 de 2006. Establece el Sistema Obligatorio de Garantía de Calidad de la Atención de Salud del Sistema General de Seguridad Social, se define calidad como "la prestación de servicios de salud accesibles, equitativos, con un nivel profesional óptimo que tiene en cuenta los recursos disponibles y logra la adhesión y satisfacción del usuario". 
$\checkmark \quad$ Decreto 3518 de 2006. Por el cual se crea y reglamenta el Sistema de Vigilancia en Salud Pública. Este Decreto determina los conceptos y aspectos operativos básicos del Sistema Nacional y sirve de referente para los Subsistemas de Vigilancia como el de salud oral, SISVESO.

$\checkmark \quad$ Decreto 19 de 2012. Define en su artículo $1^{\circ}$. Parágrafo $3^{\circ}$ "la asignación de las citas de odontología general y medicina general, no podrá exceder los tres días hábiles, contados a partir de la solicitud, salvo que el paciente las solicite de manera expresa para un plazo diferente"(Ministerio de Salud y Protección Social, 2015)

\subsubsection{Resoluciones}

$\checkmark \quad$ Resolución 6568 de 1992 por la cual se crea el Comité a nivel nacional y territorial para vigilancia de fluorización y yodación de sal de consumo humano, la Resolución 3997 de 1996 establece las actividades y los procedimientos para el desarrollo de las acciones de promoción y prevención en el SGSSS.

$\checkmark \quad$ Resolución 1995 de julio de 1999 por la cual el Ministro de Salud establece Normas para el Manejo de la Historia Clínica en literal a "es un documento privado, obligatorio y sometido a reserva, en el cual se registran cronológicamente las condiciones de salud del paciente, los actos médicos y los demás procedimientos ejecutados por el equipo de salud que interviene en su atención. Dicho documento únicamente puede ser conocido por terceros previa autorización del paciente o en los casos previstos por la Ley

Página 39 de 228 Rutty Adriana Abril Vivas. Odontóloga. Especialista Administración Hospitalaria. Auditoria de la Calidad. Nubia Astrid Duarte Pinzón. Enfermera. Especialista en Gerencia de Salud. 
$\checkmark \quad$ Resoluciones 4288 de 1996 hace referencia a Plan de Atención Básica (PAB) del Sistema General de Seguridad Social (SGSSS) y se dictan otras disposiciones.

$\checkmark$ Resolución 412 del 2000. Establece las actividades, procedimientos e intervenciones de demanda inducida y se adoptaron las normas técnicas y guías de atención, para el desarrollo de las acciones de protección específica y detección temprana, así como para la atención de las enfermedades de interés en salud pública. En esta Norma Técnica se incluyeron, para la atención preventiva en salud bucal, las siguientes actividades: control y remoción de placa bacteriana, aplicación de flúor, aplicación de sellantes de fosetas y fisuras; y el detartraje supragingival. Adicionalmente trata la delegación de funciones que se puede hacer al personal de higienista, siempre bajo la supervisión y responsabilidad del odontólogo. Tal como se recomienda en las Guías de manejo clínico, esta delegación debe partir del diagnóstico que realiza el profesional de odontología.

$\checkmark \quad$ Resolución 1043 de 2006. "por la cual se establecen las condiciones que deben cumplir los Prestadores de Servicios de Salud para habilitar sus servicios e implementar el componente de auditoría para el mejoramiento de la calidad de la atención y se dictan otras disposiciones".

$\checkmark \quad$ Resolución 3577de 2006. Permite la adopción del plan de salud bucal en el Plan Nacional. Aquí se incluye líneas estratégicas relacionadas como la garantía del acceso a 
los servicios, gestión de la salud bucal en los territorios, gestión integral del recurso humano, gestión de la información. Se consideran aspectos positivos: la inclusión de la salud bucal como una de las 7 prioridades nacionales de salud pública y su consecuente inclusión en los planes territoriales de acciones colectivas, la construcción de líneas de base para hacer seguimiento al cumplimiento de las metas del PNSP y el inicio del IV estudio nacional de salud bucal IV.

$\checkmark \quad$ Resolución 2680 de 2007. La cual modifica el artículo 1 de la Resolución 1043 de 2006, en relación a las condiciones que deben cumplir los prestadores de servicios de salud para habilitar sus servicios en cuanto a capacidad tecnológica y científica, suficiencia patrimonial y financiera y capacidad técnico-administrativa.

$\checkmark \quad$ Resolución 1101 de noviembre de 2009, establece la alianza por la salud pública. Entre sus objetivos está, el de construir conjuntamente, Secretaría Distrital de Salud, universidades, organizaciones académicas, Organización Panamericana de la Salud, Instituciones Prestadoras de Salud y otros actores sociales del Distrito Capital, propuestas para el fortalecimiento en la formación y capacitación del talento humano en salud pública, que articule las políticas, planes, programas y estrategias de salud pública y educación superior, con acciones a corto, mediano y largo plazo.

Página 41 de 228

Rutty Adriana Abril Vivas. Odontóloga. Especialista Administración Hospitalaria. Auditoria de la Calidad. Nubia Astrid Duarte Pinzón. Enfermera. Especialista en Gerencia de Salud. 
$\checkmark \quad$ Resolución 5521 de 2013. El plan obligatorio de salud cubre las tecnologías en tratamientos orales, operatoria dental, las obturaciones definitivas, las prótesis dentales mucosoportadas totales.

$\checkmark \quad$ Resolución 518 de 2015. Establece las disposiciones con la gestión de salud pública de intervenciones colectivas y determina las directrices para la formulación, ejecución, seguimiento y evaluación del Plan de Intervenciones Colectivas (PIC) con el fin de alcanzar las metas y objetivos de la salud pública. (Ministerio de Salud y Protección Social, 2015)

\subsubsection{Proyecto de acuerdo $\mathrm{N}^{\circ} 243$ del 2005}

En el distrito capital se tramitó el proyecto de acuerdo para la formulación de la política pública en salud oral hacia el año 2004, siendo la primera ciudad en Colombia que le apostó a la política pública del estado.

Este proyecto estableció como política pública en salud la atención y promoción preventiva en salud oral al menor de cero a catorce años de edad y atención asistencial al adulto mayor, en Bogotá distrito capital, y se dictaron otras disposiciones".

3.2.7 Circular 00000034 del 2010.

Página 42 de 228

Rutty Adriana Abril Vivas. Odontóloga. Especialista Administración Hospitalaria. Auditoria de la Calidad. Nubia Astrid Duarte Pinzón. Enfermera. Especialista en Gerencia de Salud. 
Estableció precisiones con relación a algunas acciones que benefician la salud bucal de la población: en el acuerdo 008 de diciembre 29 de 2009 se incluyó la educación grupal en salud por higiene oral (CUPS 990121), la educación individual en salud por odontología (CUPS 990203), así como los procedimientos contenidos en la norma técnica de la Resolución 412 del 2000.

\subsection{Metas en salud pública oral en Colombia y en Bogotá del 1999 al 2014.}

En Colombia las políticas públicas en el año 1948 se enmarcaron en la definición de la OMS" la salud es el estado de completo bienestar físico, mental y social del ser humano y no solo la ausencia de la enfermedad" para el año 1978 la declaración por la salud de los pueblos de ALMA ATA declara la importancia de la atención primaria en salud APS como estrategia para mejorar el nivel de salud de las comunidades se desarrollaban actividades de salud oral de acuerdo a la demanda mediante acciones de salud oral por parte de estado a través de instituciones públicas y del Instituto de Seguro Social mas no se evidenciaba existencia de políticas en salud oral.

Para el año 1996 mediante Resolución N4288 en su artículo 11 se establece la fluorización, aplicación de sellantes y detartraje,en el grupo poblacional comprendido en las edades de 5 a 14 años, la Resolución 412 del 2000 en su artículo 8 adopta las normas técnicas de la atención preventiva en salud bucal y la Resolución 3384 del 2000 establece

Página 43 de 228

Rutty Adriana Abril Vivas. Odontóloga. Especialista Administración Hospitalaria. Auditoria de la Calidad. Nubia Astrid Duarte Pinzón. Enfermera. Especialista en Gerencia de Salud. 
el cumplimiento de metas para los regímenes contributivo y subsidiado a nivel de placa bacteriana, detrartraje supragingival, aplicación tópica de flúor en gel y aplicación de sellantes de auto y fotocurado .

Las metas establecidas para la salud pública oral a nivel nacional y distrital durante el periodo del 2006 al 2014 fueron las siguientes:

\subsubsection{El Plan Nacional de Salud adoptado mediante Resolución 3577 de 2006.}

El plan nacional de salud, se incluyó la gestión de la salud bucal en los territorios, la gestión integral del recurso humano y la gestión de la información (Ministerio de Salud y Protección Social, 2015).

En el desarrollo de las competencias del Ministerio de la Protección Social, como ente rector del Sistema de Protección Social, del Sistema General de Seguridad Social en Salud - SGSSS y del sector salud, el cumplimiento de las metas establecidas en el nivel nacional, está relacionado con lo que realicen los prestadores, las entidades administradoras, los departamentos distritales y los municipios. Una buena parte de las entidades territoriales, han incorporado dentro de la formulación de sus planes territoriales de salud el componente de salud bucal y en concordancia con las metas nacionales han formulado estrategias con las cuales aportar a su cumplimiento. 
Para el Cuatrienio 2007 - 2010, la Salud Oral se encontró establecida como la tercera prioridad en el plan, allí se consignan las metas nacionales y las estrategias para mejorar la salud oral, en cuanto a promoción de salud, prevención de riesgos, recuperación de la salud y vigilancia en salud.

Las metas nacionales de salud oral establecidas fueron:

- Lograr un índice de COP promedio a los 12 años de edad menor de 2,3 (Línea de base: 2,3$)$.

- Lograr y mantener los dientes permanentes en el $60 \%$ de los mayores de 18 años (Línea de base: 50,2\%)(Ministerio de la Protección Social de Colombia, 2010)

\subsubsection{Plan Decenal de Salud Pública, PDSP, 2012 - 2021.}

Se adoptó mediante Resolución 1841 de 2013 en el cual se plantearon las estrategias de intervención colectiva e individual, de los diferentes sectores; dicho plan contempló una amplia participación social dentro del marco de la estrategia de atención primaria en salud en el cual confluyen las políticas sectoriales para mejorar el estado de salud de la población, garantizando que el proceso de participación social fuera eficaz, mediante la promoción de la capacitación de la ciudadanía y de las organizaciones sociales, por medio de la coordinación intersectorial y la conformación de un observatorio nacional de salud (Ministerio de Salud y Protección Social, 2015).

Página 45 de 228 Rutty Adriana Abril Vivas. Odontóloga. Especialista Administración Hospitalaria. Auditoria de la Calidad. Nubia Astrid Duarte Pinzón. Enfermera. Especialista en Gerencia de Salud. 
El Plan proyectó para el 2021 lograr una cobertura universal con acceso efectivo a los servicios de atención, implementación de un sistema de garantía de la calidad, aumento de la disponibilidad de información y evidencia sobre inequidades, desigualdades económicas y sociales en salud para de esta forma poder orientar políticas en los territorios y poblaciones vulnerables y contar con un sistema de información integrado.

En cuanto al tema específico de la salud oral, se establecieron metas a nivel nacional como incrementar prácticas de autocuidado para prevención y manejo de la salud bucal desde la primera infancia en un $20 \%$ y aumentar anualmente el número de organizaciones aliadas que se vinculan y promueven estilos de vida saludable. También se establecieron estrategias como el fortalecimiento de capacidades técnicas, científicas y operativas, para el ejercicio de la rectoría y autoridad sanitaria en el orden nacional y territorial para el manejo de la salud bucal y sus factores de riesgo.

Otra estrategia desarrollada fue la participación social activa para la construcción, monitoreo y evaluación de procesos que permitieran a la población incrementar el control sobre su salud y bienestar; tener incidencia política y ejercer el control social, para la promoción de la salud, la afectación de los determinantes sociales y el control de las enfermedades incluida la salud bucal.

Página 46 de 228

Rutty Adriana Abril Vivas. Odontóloga. Especialista Administración Hospitalaria. Auditoria de la Calidad. Nubia Astrid Duarte Pinzón. Enfermera. Especialista en Gerencia de Salud. 
Así como se establecieron estrategias para la salud oral, también se establecieron objetivos para mejorar la respuesta institucional del sistema y así fortalecer la prestación del servicio y su articulación interinstitucional para la atención integral de las necesidades en salud oral.

Dichos objetivos comprendieron el desarrollo de capacidades en cuanto a investigación en salud, vigilancia, control y la evaluación de gestión y efectos del mejoramiento de la salud oral.

Otro objetivo correspondió a la promoción de estrategias de servicios asistenciales enfocados a poblaciones prioritarias y así fortalecer en estas acciones de promoción y prevención en temas de salud oral.

Para el cumplimiento de los objetivos mencionados, se establecieron las siguientes metas:

- Lograr un incremento en las coberturas de detección temprana, prevención, de las alteraciones de la salud bucal y sus factores de riesgo en un $20 \%$ en el decenio, a partir de la línea de base que se defina en el 2014.

- Garantizar el acceso oportuno y de calidad al diagnóstico y tratamiento de las alteraciones de la salud bucal en el $100 \%$ de los casos. 
- $\quad$ Incrementar en el $20 \%$ la población del país sin caries, con énfasis en la primera infancia, niñez y adolescencia $(\mathrm{COP}=0)$

- Incrementar en el $20 \%$ la población mayor de 18 años sin pérdida dental por enfermedad bucodental prevenible.

- Contar con un sistema de análisis, seguimiento, monitoreo y evaluación de políticas, planes, programas y estrategias implementadas a nivel nacional y territorial para abordar los determinantes sociales de la salud bucal.

- Contar con al menos un nodo de investigación por región del país que permita la construcción de una agenda para el estudio de los determinantes sociales de la salud bucal(Ministerio de Salud y Protección Social., 2013).

3.3.3 Plan decenal para el control de cáncer en Colombia, 2012-2021

3.3.3.1 Línea estratégica control del riesgo de consumo y exposición a productos de tabaco y sus derivados.

A continuación, se enuncian las metas de esta línea estratégica:

- Disminuir la prevalencia de consumo de tabaco en jóvenes escolares de 13 - 15 años por debajo del 21,8\% (línea de base $21.8 \%$.).

Página 48 de 228 Rutty Adriana Abril Vivas. Odontóloga. Especialista Administración Hospitalaria. Auditoria de la Calidad. Nubia Astrid Duarte Pinzón. Enfermera. Especialista en Gerencia de Salud. 
- Disminuir la prevalencia de consumo de tabaco en jóvenes de 16 - 18 años por debajo del 17,36\% (línea de base 17,36\%).

- Posponer la edad de inicio de consumo de tabaco en los adolescentes colombianos por encima de 14 años (línea de base 11.9 años).

- $\quad$ Disminuir la prevalencia de tabaquismo en adultos de 18 a 69 años al $10 \%$ en los próximos 10 años (línea de base 12.8\%.)

- Garantizar el cumplimiento de ambientes $100 \%$ libres de humo de tabaco y sus derivados a nivel nacional, en los lugares definidos por la Ley 1335 de 2009.

3.3.3.2 Línea estratégica Control del riesgo del consumo nocivo de alcohol.

A continuación, se enuncian las metas de esta línea estratégica:

- Posponer la edad promedio de inicio de consumo de alcohol en los adolescentes colombianos por encima de 14 años (línea de base 12,44 años).

- Aumento del $100 \%$ en impuestos indexados al Índice de Precios al Consumidor (IPC) y al Producto Interno Bruto (PIB) para los productos de tabaco y sus derivados, antes del 2021.

- Aumentar a un $70 \%$ el tamaño de la advertencia sanitaria en las cajetillas de los productos de tabaco comercializados en el territorio colombiano antes del 2021, en 
consonancia con lo dispuesto en el convenio marco para el control del tabaco de la Organización Mundial de la Salud.(Secretaria Distrital de Salud, 2011a)

\subsubsection{Política de salud oral 2004 en Bogotá.}

Bogotá estableció la Política de salud oral con participación de diferentes actores a partir de octubre del año 2004, para la cual planteo la necesidad de redimensionar las acciones establecidas garantizando el acceso a la atención para la protección y recuperación de la salud oral, reorganizando la prestación de los servicios, garantizando el acceso y el financiamiento así como la calidad de los servicios(Secretaria Distrital de Salud, 2007).

Se reconoció la necesidad de actuar en los ámbitos político, económico, social y cultural; para incidir de manera significativa en el complejo proceso salud-enfermedad y avanzar en la promoción, prevención, protección, recuperación y mantenimiento de la salud oral.

Se proyectó para que los habitantes del Distrito Capital gozarán de un buen estado de salud oral, con el concurso de los distintos actores involucrados en la preservación de la misma, gracias a la garantía de condiciones que la favorecieran el acceso a los servicios preventivos, curativos y de mantenimiento, con especial énfasis en la población infantil de 5 a 14 años y mujeres gestantes en la búsqueda de garantizar progresivamente cobertura universal (Secretaria Distrital de Salud, 2011a)

Página 50 de 228

Rutty Adriana Abril Vivas. Odontóloga. Especialista Administración Hospitalaria. Auditoria de la Calidad. Nubia Astrid Duarte Pinzón. Enfermera. Especialista en Gerencia de Salud. 


\subsubsection{Política de salud oral de Bogotá, D.C. con participación social para el decenio}

2011-2021.

La presente política pretende" lograr una condición de salud oral sostenible a través de la promoción y generación de prácticas sociales protectoras, soportadas social y culturalmente; mediante el abordaje de los determinantes sociales y el fortalecimiento del ejercicio de la ciudadanía garantizando el acceso y calidad en la atención en los servicios de salud del Distrito Capital". (Secretaria Distrital de Salud, 2015)

La presente política de salud oral se ajusta a líneas de trabajo bajo el direccionamiento de la Secretaria distrital de salud con la participación de grupos, comunidad e instituciones a través de:

- Implementación de estrategias de promoción de la salud oral en diferentes ámbitos.

- Formulación participativa de las guías de práctica clínica de las patologías orales.

- Diseño y puesta en marcha del subsistema de vigilancia epidemiológica de Salud Oral, SISVESO

- Implementación de procesos de educación continúa del talento humano.

- Desarrollo de algunos proyectos de investigación.

- Desarrollo de programas de docencia-servicio con las universidades.

- Desarrollo de programas exitosos con la comunidad en algunas localidades. 


\subsubsection{Planes de desarrollo Bogotá.}

Dentro de las políticas públicas distritales incorporadas están las siguientes:

$\checkmark \quad$ Plan de Desarrollo Bogotá Positiva 2008-2012: estableció como meta al 2011 incrementar en un $25 \%$ la cobertura del programa de Salud Oral (Flúor, sellantes, control de placa y detartraje) en la población afiliada a los regímenes subsidiado y contributivo, sin detrimento de lo establecido por norma. Adicionalmente se propuso monitorear el acceso a los servicios de salud oral de los menores de cinco años y las mujeres gestantes para ello se espera que " A 2011, Incrementar en un 20 \% la cobertura en atención odontológica de la mujer gestante y población de menores de cinco años afiliados al Régimen Subsidiado y población pobre y vulnerable no asegurada"(Alcaldía Mayor de Bogotá, 2012b).

$\checkmark \quad$ Bogotá Humana 2012-2016: Al finalizar el 2016, se deberían haber logrado mejoras sustanciales en los resultados de salud de su población, por reducción significativa de brechas e inequidades, presentes entre localidades, territorios y grupos sociales. También, se debería haber propiciado condiciones ambientales y sanitarias seguras, satisfactorias, sostenibles y humanas para los habitantes y visitantes, que concurren cada año en procura de desarrollar actividades laborales, comerciales, turísticas, culturales, entre otras.

Página 52 de 228

Rutty Adriana Abril Vivas. Odontóloga. Especialista Administración Hospitalaria. Auditoria de la Calidad. Nubia Astrid Duarte Pinzón. Enfermera. Especialista en Gerencia de Salud. 
También estableció como meta incrementar al 25\% la atención de primera vez en salud oral de los niños, niñas y jóvenes menores de 19 años en el Distrito Capital, al 2016 (Alcaldía Mayor de Bogotá, 2012b).

\subsubsection{Plan de atención básica, Plan de Intervenciones Colectivas.}

El Plan de atención básica se estableció a partir de 1996 mediante la Resolución № 4288 el cual definió la realización de actividades, intervenciones y procedimientos, de promoción de la salud, prevención de la enfermedad, vigilancia en salud pública y control de factores de riesgo dirigidos a la colectividad (Ministerio de Salud y Protección Social, 2015). En el 2003 la organización mundial de la salud (OMS) planteó incorporar la promoción de la salud oral como factor determinante de la calidad de vida y su necesidad de incorporarla en la salud general.

El modelo de atención primaria en salud se inició en el país en el año 2004 con salud a su hogar como programa de gobierno del 2004 al 2007 continuando con el modelo de Salud a su casa realizado durante el periodo de 2008 a 2011 desde el contexto de ámbitos que incluían la familia, el escenario laboral, el comunitario, las instituciones educativas tanto escolares como universitarias, y las instituciones prestadoras de salud IPS para pasar al enfoque de territorios saludables en el que se tenían en cuenta los determinantes sociales con enfoques diferenciales de promocionar la calidad de vida

Página 53 de 228

Rutty Adriana Abril Vivas. Odontóloga. Especialista Administración Hospitalaria. Auditoria de la Calidad. Nubia Astrid Duarte Pinzón. Enfermera. Especialista en Gerencia de Salud. 
teniendo en cuenta el género el ciclo de vida con concepto de equidad, dentro de este contexto el Plan de Intervenciones Colectivas (PIC) .

Frente al PIC la red pública por intermedio de los catorce hospitales ha contado con asignación de recursos para la realización de actividades de salud oral a través de diferentes estrategias como son ámbitos y salud a su casa con el fin de disminuir la prevalencia de las patologías orales a través de actividades educación, comunicación e información (Secretaría Distrital de Salud de Bogotá D.C. Fondo Financiero Distrital de Salud de Bogotá D.C., 2013) adicionalmente la Secretaria Distrital de Salud a través de los proyectos de autonomía pretendió articular los diferentes programas establecidos como son prevención, resolución y salud pública con el fin de mejorar la eficacia, efectividad de los programas (Secretaria Distrital de Salud, 2011b), a la fecha no se cuenta con documentación amplia de resultados de estrategias A.P.S en salud oral .

Página 54 de 228

Rutty Adriana Abril Vivas. Odontóloga. Especialista Administración Hospitalaria. Auditoria de la Calidad. Nubia Astrid Duarte Pinzón. Enfermera. Especialista en Gerencia de Salud. 


\section{ANÁLISIS DE LA PERTINENCIA DE LAS POLÍTICAS DE SALUD ORAL EN TÉRMINOS DE RESULTADOS Y DE PERFIL DE MORBILIDAD ORAL.}

Frente al tema de morbilidad oral, Colombia cuenta con 4 estudios, dentro de las cuales encontramos: la primera investigación Nacional de Morbilidad oral realizada en los años 1965/1966, el segundo estudio de Morbilidad Oral realizada es $1977 / 1980$, el tercer estudio Nacional de Salud Bucal III realizado en 1998 y el cuarto estudio nacional de Salud Oral la ENSAB IV encuesta que se realizó luego de 16 años con el fin de contar con datos actualizados para la toma de decisiones que incidieran en la salud oral de la población colombiana. Para la presente investigación además de lo anterior se incluyó información registrada en: documento análisis de la situación en Salud (ASIS) 2002-2007, encuesta nacional de salud ENDS 2007, datos ASIS 2013, perfil epidemiológico de la población desplazada y vinculada de Bogotá periodo 2011 -2013, proyectos de autonomía de salud oral 2011, 2012 y 2015; adicionalmente se registraron datos relacionados con la caracterización de la oferta y la demanda de los servicios de salud, teniendo en cuenta la codificación de las causas de morbilidad en el sistema de la clasificación internacional de enfermedades (CIE 10) registradas en los registros individuales de prestación de servicios de salud (RIPS) así como los diferentes indicadores establecidos para conocer las condiciones de salud oral (caries, gingivitis,

Página 55 de 228

Rutty Adriana Abril Vivas. Odontóloga. Especialista Administración Hospitalaria. Auditoria de la Calidad. Nubia Astrid Duarte Pinzón. Enfermera. Especialista en Gerencia de Salud. 
periodontopatías, edentulismo, índice COP-d, copd e indicadores de consulta de primera vez.

Se incluyeron además la morbilidad sentida y la morbilidad general, la primera a partir de actitudes y prácticas de la población, y la segunda correspondiente a los usuarios atendidos en los servicios de salud oral de las instituciones del distrito.

\subsection{Percepción de la población frente al estado de salud oral 1999-2014.}

La morbilidad sentida o autoimagen del estado de salud corresponde a la información entregada por la persona en lo que se refiere a su salud, según sus ideas y sus interpretaciones, sin que esta opinión previamente sea establecida por personal de odontología (Ministerio de la Protección Social \& Universidad de Antioquia, 2010).

Los estudios realizados han pretendido conocer la percepción de la población sobre el estado de salud oral, las causas y consecuencias de la enfermedad bucodental, prácticas terapéuticas y de autocuidado; así como la demanda de los servicios odontológicos de la población entre otras; a continuación, se presenta el comparativo entre ENSAB III 1998 y la información tomadas de las fichas de caracterización de APS- de salud oral para la vigencia 2011 y 2012.

Página 56 de 228

Rutty Adriana Abril Vivas. Odontóloga. Especialista Administración Hospitalaria. Auditoria de la Calidad. Nubia Astrid Duarte Pinzón. Enfermera. Especialista en Gerencia de Salud. 
Ilustración 1 Distribución porcentual pregunta ¿qué es tener una boca sana? Bogotá, 1999.

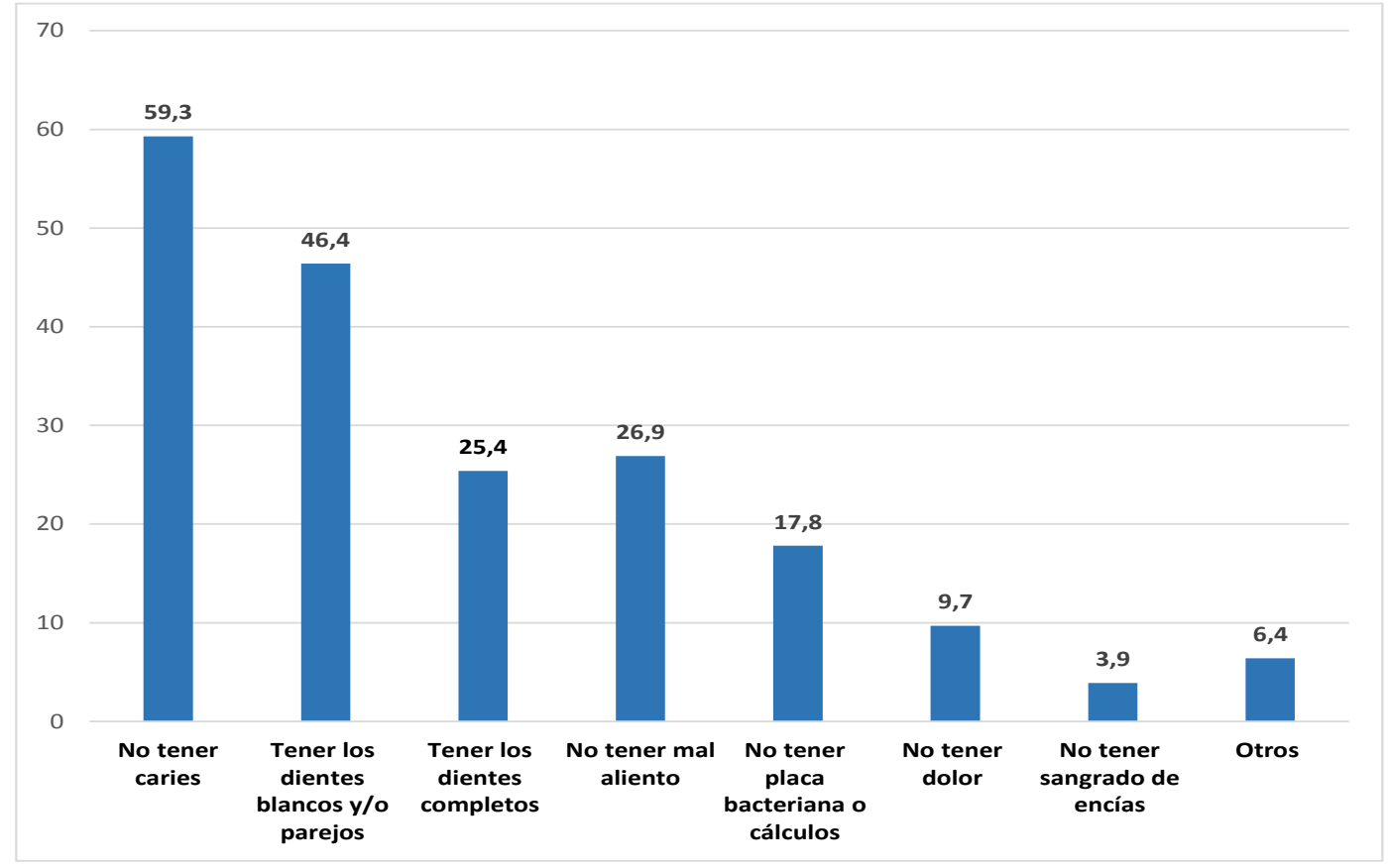

Fuente: ENSAB III 1999

Resultados: según estos datos, el predominio de la concepción de salud oral se encuentra en la ausencia de caries y la visibilidad de una dentadura estética, ya que el 59.3\% de la población considero que el tener una boca sana era no tener caries, seguida del $46.4 \%$ quienes consideraron el tener los dientes blancos.

Ilustración 2 Distribución porcentual pregunta ¿qué es tener una boca sana? Bogotá, 2011 .2012. 


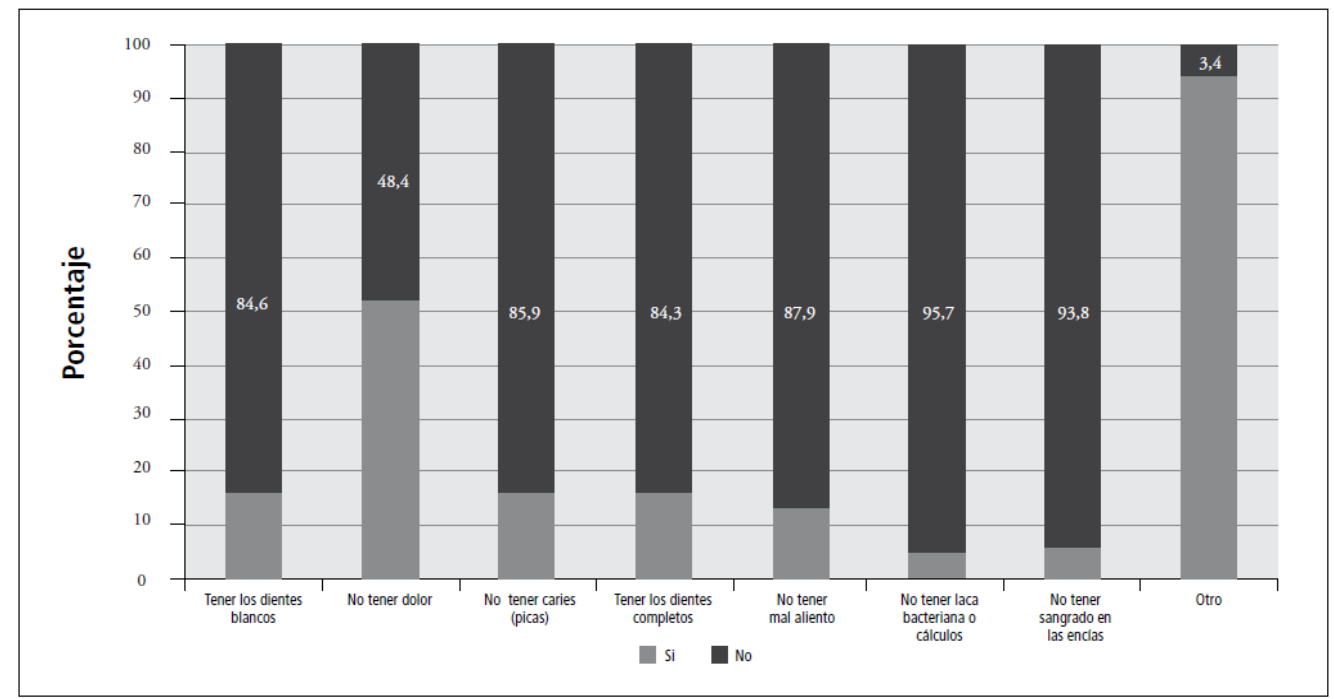

Fuente: Dirección de Planeación y Sistemas. RIPS 2011-2012-Fichas de caracterización de APS

Análisis: a diferencia de la ENSAB III, el 96\% de los encuestados a través de la estrategia APS del distrito manifestó otra respuesta no incluida en el listado de selección; el 51\% manifestó no sentir dolor, y el 15,7\% tener los dientes completos. Lo anterior indica que uno de los factores de mayor impacto frente a las problemáticas de salud oral, para tener la boca sana en la población caracterizada, fue la carencia de dolor, seguida de factores estéticos como dientes blancos, completos o mal aliento (aspecto coincidente con el ENSAB III). 
Ilustración 3 Distribución porcentual pregunta elementos utilizados para la limpieza de los dientes. Bogotá 1999.

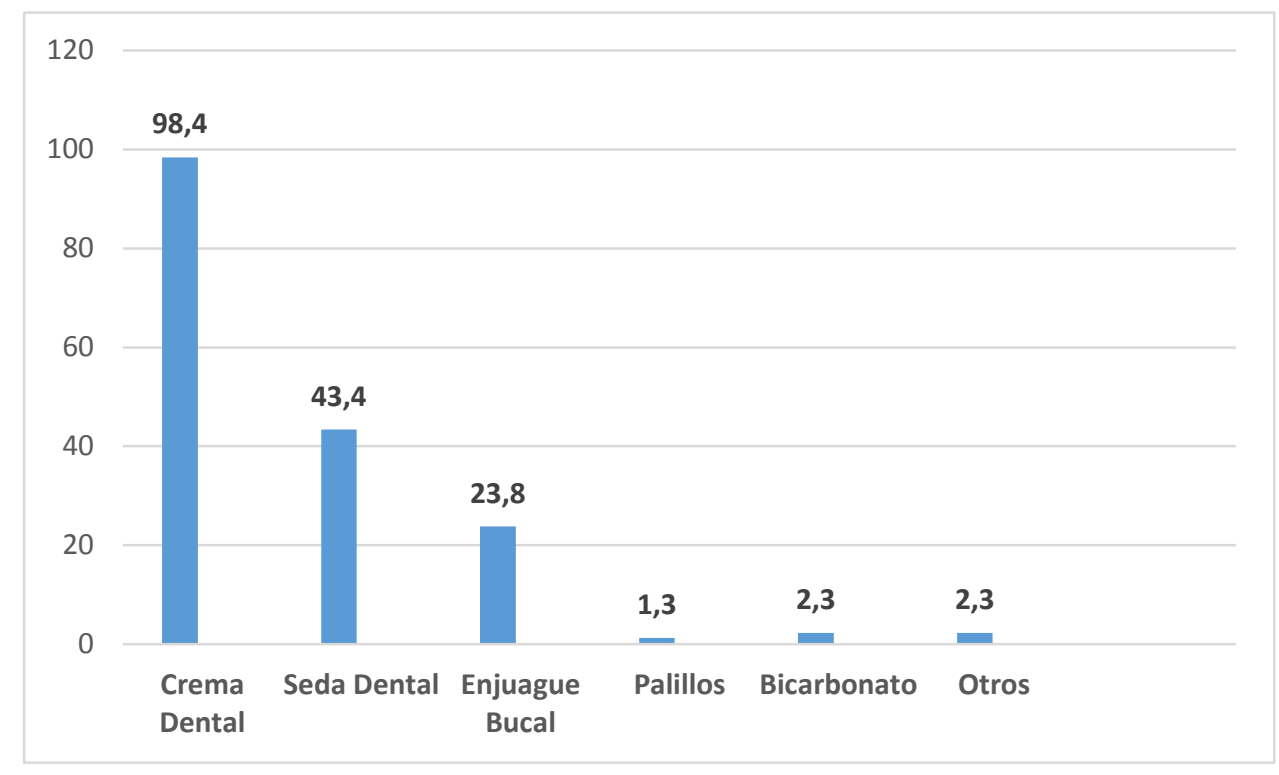

Fuente: ENSAB III 1999

Resultados: según la información, los principales elementos utilizados para la higiene dental fueron: la crema dental con un $98,4 \%$ de los encuestados; $43,4 \%$ para la seda dental y $23.8 \%$ en relación al enjuague bucal. 
Ilustración 4 Distribución porcentual pregunta elementos utilizados para la limpieza de los dientes. Bogotá, 2011 .2012.

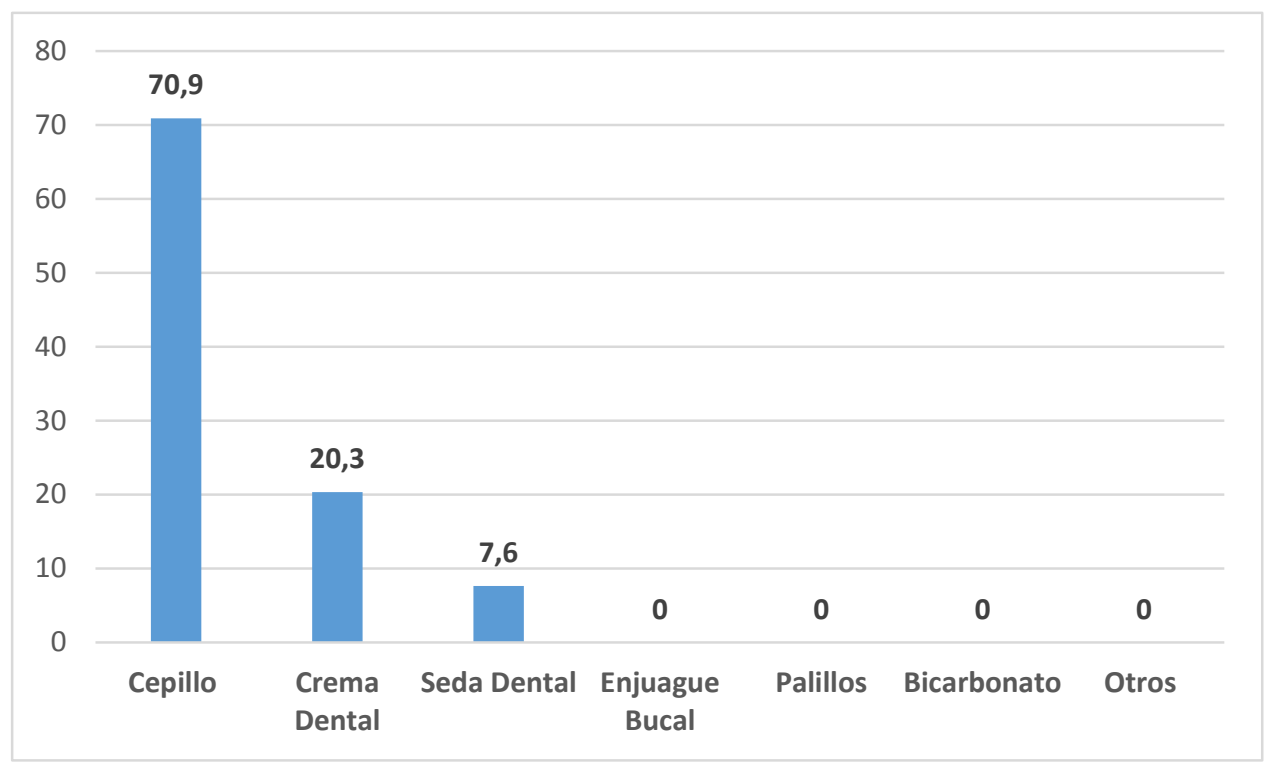

Fuente: Dirección de Planeación y Sistemas. RIPS 2011-2012-Fichas de caracterización de APS.

Análisis: según esta fuente, los principales elementos utilizados para la higiene dental en los encuestados fue $70,9 \%$ de el cepillo dental, $20.3 \%$ crema dental y $7.6 \%$. seda dental. Es interesante ver que con respecto a la ENSAB III, estos datos incluyen el cepillo de diente, pero no el uso de enjuague bucal, lo cual puede deberse a las opciones dadas a los encuestados en la ENSAB III, y a la posibilidad adquisitiva de la población caracterizada a través de APS. 


\section{Ilustración 5 Distribución porcentual de las razones por las cuales no se usa la seda dental Bogotá, 1999.}

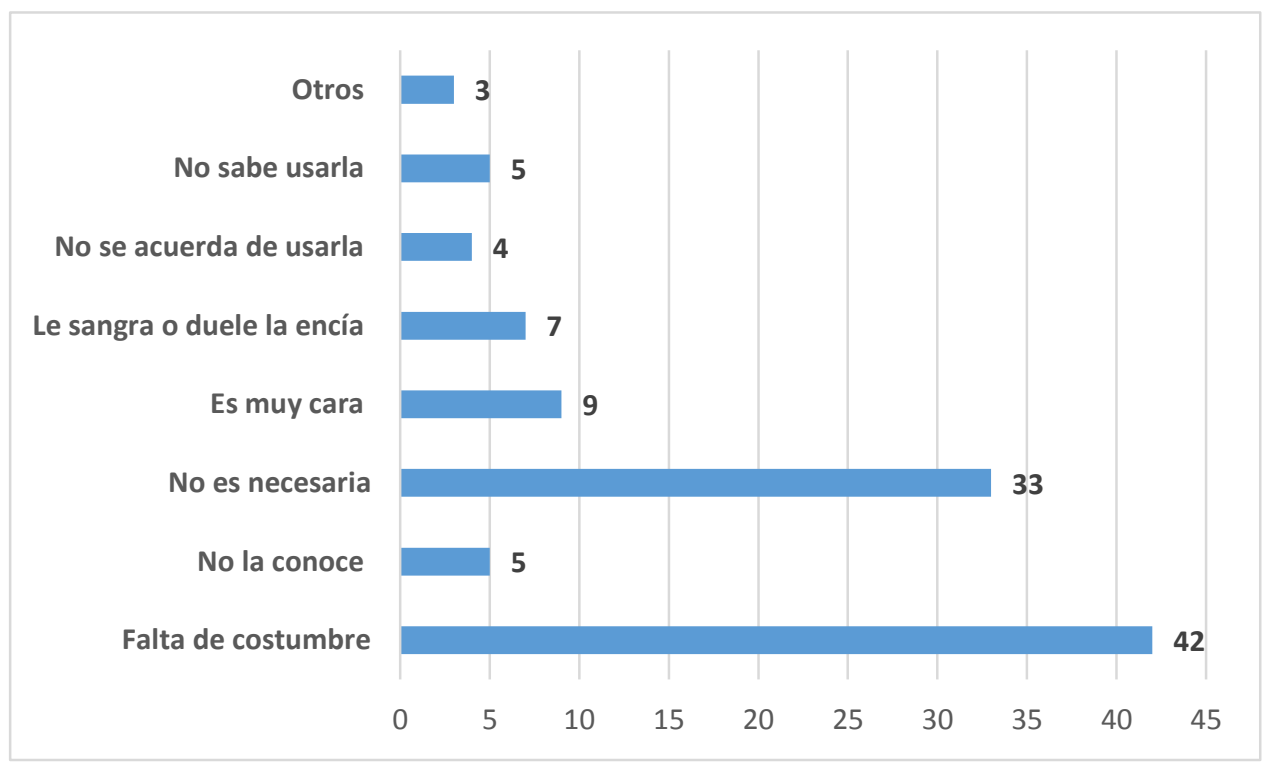

Fuente: ENSAB III 1999

Análisis: en cuanto al uso de la seda, las respuestas predominantes frente a los motivos para no hacerlo fueron: por falta de costumbre $42 \%$, y "no es necesaria" el $33 \%$, lo cual refleja una influencia cultural y educativa importante en los hábitos de salud oral de los encuestados. 
Ilustración 6 Distribución porcentual de las razones por las cuales no se usa la seda dental Bogotá 2011.2012.

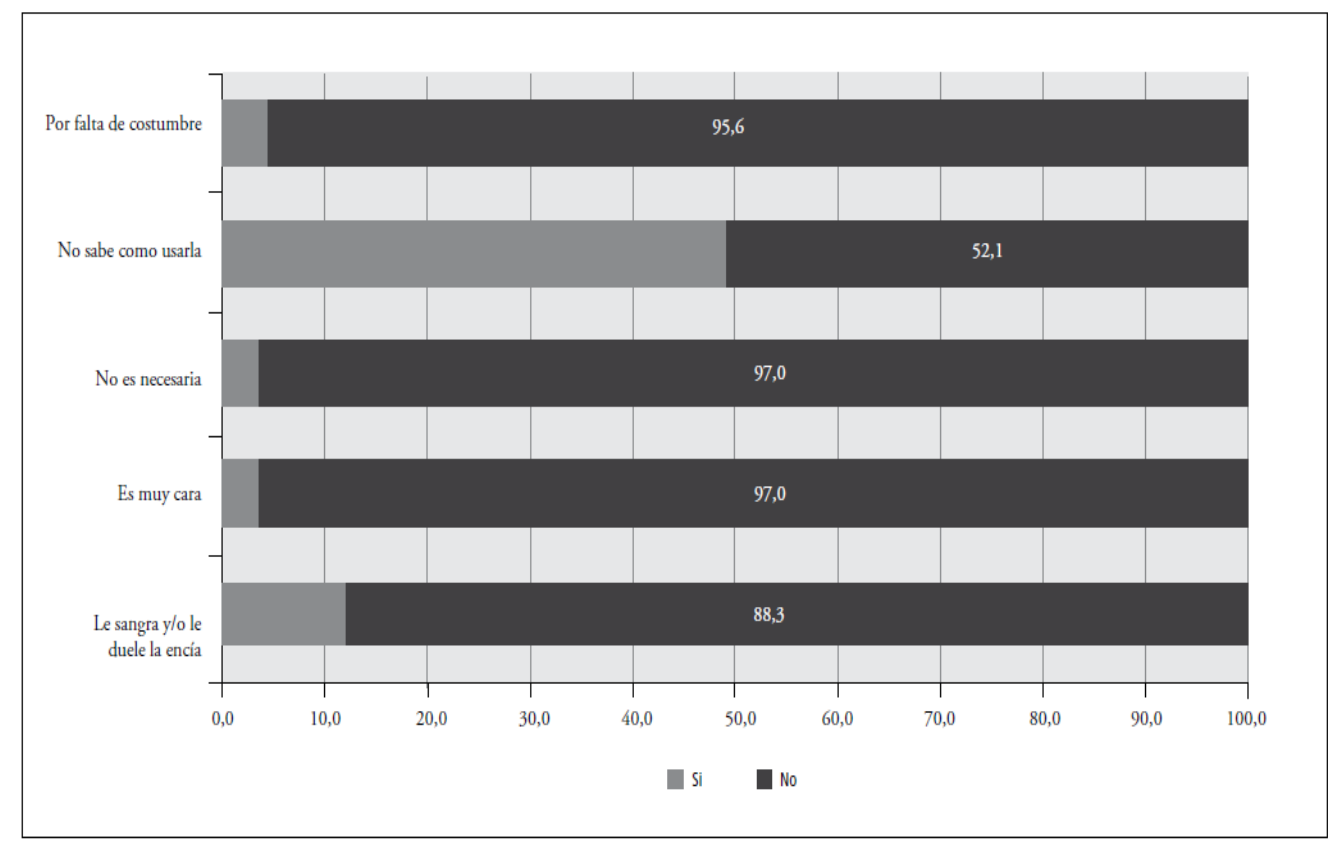

Fuente: Dirección de Planeación y Sistemas. RIPS 2011-2012-Fichas de caracterización de APS

Análisis: para esta fuente de datos, las respuestas principales en cuanto a los motivos para no utilizar la seda dental fueron: por no ser necesaria y por el costo en un $97 \%$, por falta de costumbre un 95,6\%, porque les sangraba o les dolía la encía 88,3\% y porque no sabían usarla 52.1\%, lo que nos indica el desconocimiento general de la población de que su uso disminuye los factores de riesgo que inciden en la salud oral y como los factores económicos intervienen en las prácticas de autocuidado. 
llustración 7 Distribución porcentual pregunta frente a la pregunta de la supervisión de cepillado en menores. Bogotá 1999.

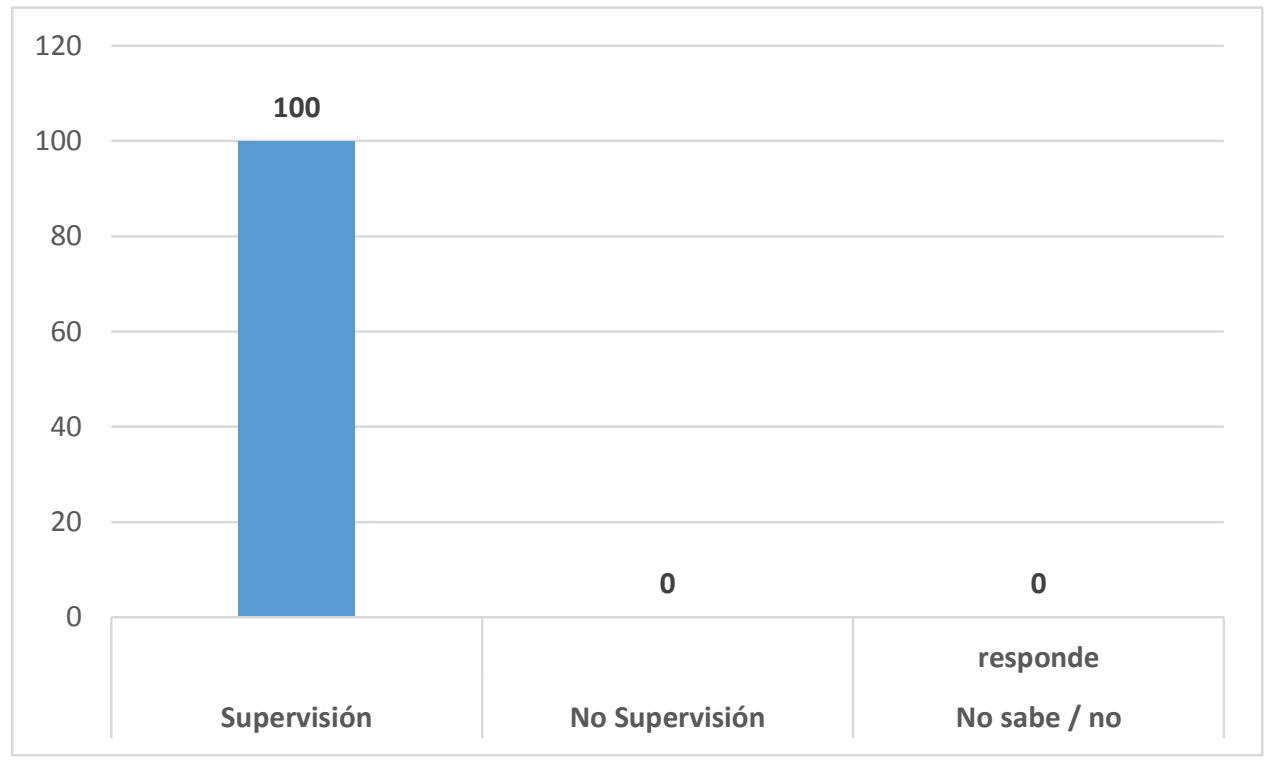

Fuente: ENSAB III 1999

Análisis: el 100\% de los encuestados supervisaron el cepillado de los menores de 10 años, lo cual deja algunas dudas en relación a la veracidad de las respuestas o la representatividad de la población encuestada. 
Ilustración 8 Distribución porcentual de la supervisión de cepillado en menores. Bogotá.2011.2012.

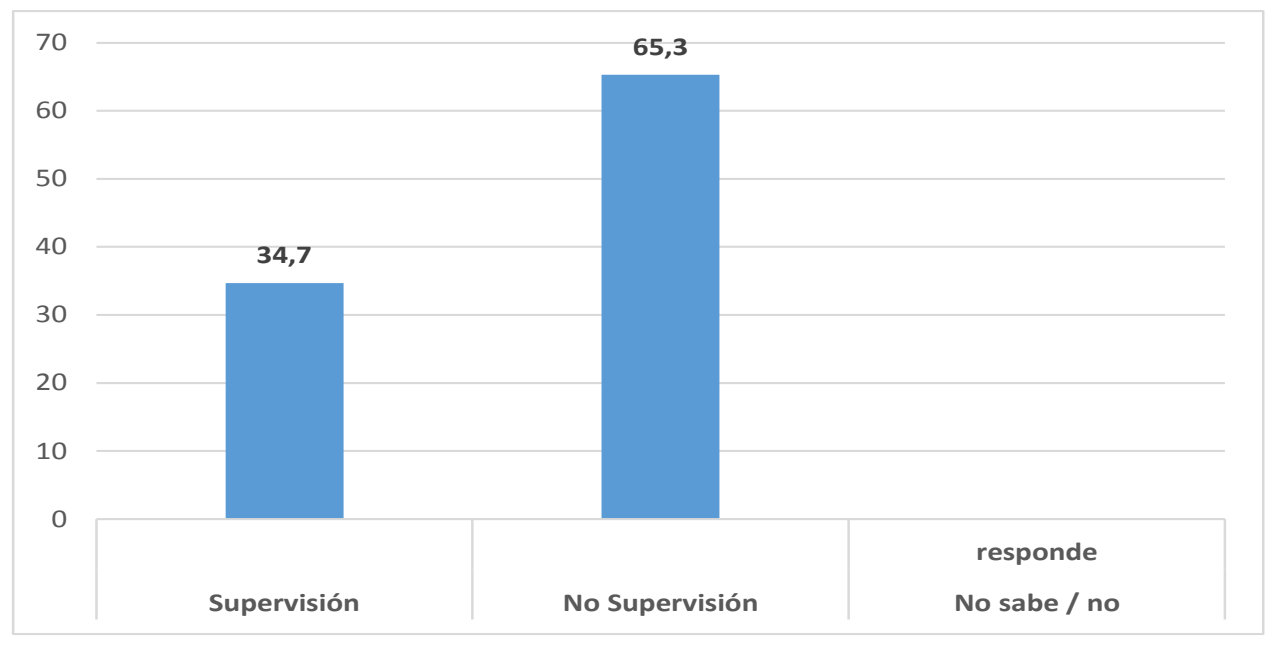

Fuente: Dirección de Planeación y Sistemas. RIPS 2011-2012-Fichas de caracterización de APS.

Análisis: el 34, 7\% de los encuestados afirmaron haber supervisado el cepillado de los menores de 10 años y el 65,3\% refirieron no hacerlo, lo cual comparado con la ENSAB III, parece ser más fiel a la realidad de los hábitos de salud oral de los cuidadores con respecto a los menores.

Según la encuesta nacional de demografía y salud 2007 (ENDS) en Bogotá el 28\% de los usuarios de consulta odontológica tiene problemas orales los cuales requieren tratamiento, del anterior porcentaje el $72,2 \%$ de los pacientes refirieron el inicio del tratamiento dentro los 30 días posteriores a la consulta, el porcentaje restante $(27,8 \%)$ refirió no haber iniciado el tratamiento, por el costo o por la falta de dinero(Ministerio de 
la Protección Social, COLCIENCIAS, Cendex, S.E.I. S.A, \& Pontificia Universidad Javeriana, 2009).

Lo anteriormente descrito demostró débil conocimiento frente a lo relacionado con la necesidad de una atención periódica, uso de seda dental y prácticas de autocuidado.

Se observó una inadecuada higiene oral lo que indicaba la importancia de fortalecer programas de promoción y prevención en salud oral tanto a nivel individual como colectivo y de realizar tratamientos oportunos con el fin de minimizar factores de riesgo que aumentaran la morbilidad de las patologías bucodentales.

\subsection{Análisis de la situación en salud en Colombia periodos 1999; 2002-2007; 2013-2014.}

Para el año 1999 se presentó en el país los resultados del tercer estudio nacional de salud bucal y el segundo estudio nacional de factores de riesgo para enfermedades crónicas en el cual se incluyó el componente de morbilidad oral, para esta fecha las enfermedades orales en menores de 5 a 14 años representaban las primeras causas de consulta externa(Ministerio de Salud, 1999).

En Colombia según fuente del ASIS, las enfermedades crónicas en los adultos y adultos mayores, aparecían dentro de las 10 primeras causas de consulta externa en los servicios de salud; la hipertensión esencial o primaria y la diabetes desplazan progresivamente

Página 65 de 228

Rutty Adriana Abril Vivas. Odontóloga. Especialista Administración Hospitalaria. Auditoria de la Calidad. Nubia Astrid Duarte Pinzón. Enfermera. Especialista en Gerencia de Salud. 
otras atenciones, a medida que aumenta la edad, también los problemas de salud mental, se van registrando con mayor frecuencia en las consultas institucionales (Ministerio de la Protección Social \& Universidad de Antioquia, 2010), (Ministerio de Salud y Protección Social, 2014) ,siendo similar el comportamiento distrital.

La transición demográfica evidenciada en el distrito con el aumento de la población mayor de 40 años y la disminución de la población menor ha generado un cambio en el perfil epidemiológico de la ciudad, el ambiente, el estilo de vida así como las formas de producción y de consumo; evidenciándose un aumento de morbimortalidad con énfasis en enfermedades crónico degenerativas en el grupo de adultos mayores siendo necesario ajustar las estrategias de salud para el abordaje de las diferentes patologías. (Organización Mundial de la Salud OPS/OMS Colombia, 2009).

Frente a la morbilidad atendida según registros del presente análisis, las enfermedades orales se encontraron reportadas dentro de las diez primeras causas del servicio de consulta externa; en el grupo de edad de 5 a 9 años las caries se registraron como las causas de enfermedad de mayor frecuencia ocupando el tercer puesto y en el séptimo lugar otros trastornos de los dientes y de las estructuras de sostén; en el grupo de 15 a 19 años, ocupó la caries el tercer lugar, para las edades de 20 a 29 años ocupó el cuarto puesto; de los 30 a 34 el segundo lugar, de los 35 a 39 años el tercero; de 40 a 44 años,

\footnotetext{
Página 66 de 228

Rutty Adriana Abril Vivas. Odontóloga. Especialista Administración Hospitalaria. Auditoria de la Calidad. Nubia Astrid Duarte Pinzón. Enfermera. Especialista en Gerencia de Salud.
} 
en mujeres el quinto lugar y en hombres ocupó el cuarto lugar (Ministerio de la Protección Social \& Universidad de Antioquia, 2010)

Tabla 1 Distribución de caries consulta externa Colombia 2002-2007.

\begin{tabular}{|l|l|}
\hline Edad & $\begin{array}{l}\text { Puesto de } \\
\text { enfermedad } \\
\text { de mayor } \\
\text { frecuencia }\end{array}$ \\
\hline $5-9$ años & 3 \\
\hline $15-19$ años & 3 \\
\hline 20-29 años & 4 \\
\hline 30-34 años & 2 \\
\hline 35-39 años & 3 \\
\hline $40-44$ años & $4-5$ \\
\hline
\end{tabular}

Fuente: ASIS 2002-2007. Colombia

Análisis: la población que en mayor porcentaje consultó fueron los grupos etarios de adultos y adultos mayores por consulta externa lo que indicaba la necesidad de fortalecer las estrategias en la política pública para la atención de estos grupos poblacionales.

Según reportes para el año 2013 las siguientes fueron las causas de mayor porcentaje de atención con respecto a la problemática salud oral: 
Tabla 2 Distribución por grupos etarios de las primeras causas de morbilidad en consulta odontológica, Colombia 2013.

\begin{tabular}{|c|c|c|c|c|c|c|c|}
\hline Edad años & $\begin{array}{l}\text { Atenciones } \\
\text { Caries } \\
\text { KO21 }\end{array}$ & $\begin{array}{l}\text { Personas } \\
\text { Caries KO21 }\end{array}$ & $\begin{array}{l}\text { Atenciones } \\
\text { Gingivitis } \\
\text { aguda K050 }\end{array}$ & $\begin{array}{l}\text { Personas } \\
\text { Gingivitis } \\
\text { aguda } \\
\text { K050 }\end{array}$ & $\begin{array}{l}\text { Total } \\
\text { atenciones } \\
\text { odontológicas }\end{array}$ & $\begin{array}{l}\text { Total } \\
\text { general de } \\
\text { atenciones }\end{array}$ & $\begin{array}{l}\text { Total } \\
\text { general de } \\
\text { personas }\end{array}$ \\
\hline $0-4$ & 34.422 & 15.311 & 7126 & 5.243 & 41.548 & 780.148 & 265.533 \\
\hline $5-9$ & 146.539 & 64.179 & 20.098 & 13.831 & 166.637 & 570.718 & 224.001 \\
\hline $10-14$ & 82.544 & 41.014 & 20.754 & 14.157 & 103.298 & 317.420 & 148.541 \\
\hline $15-19$ & 85.212 & 41.708 & 22.764 & 15.863 & 107.976 & 329.503 & 154.194 \\
\hline $20-24$ & 84.099 & 42.072 & 19.092 & 13.263 & 103.191 & 444.149 & 184.279 \\
\hline $25-29$ & 106.580 & 49.851 & 22.480 & 15.475 & 129.060 & 522.372 & 205.107 \\
\hline $20-34$ & 108.595 & 49.300 & 22.318 & 15.183 & 130.913 & 497.876 & 195.141 \\
\hline $35-39$ & 90.648 & 39.619 & 17.088 & 11.602 & 107.736 & 398.062 & 154.910 \\
\hline $40-44$ & 84.184 & 35.536 & 14.760 & 9.808 & 98.944 & 377.513 & 11.224 \\
\hline $45-49$ & 77.212 & 32.047 & 12.671 & 8.295 & 89.883 & 387.968 & 10.634 \\
\hline $50-54$ & 58.527 & 24.357 & 9.767 & 6.182 & 68.294 & 383.808 & 9.257 \\
\hline $55-59$ & 39.149 & 16.289 & 6.632 & 4.174 & 45.781 & 347.861 & 7320 \\
\hline $60-64$ & 26.133 & 10.677 & 4.774 & 2.905 & 30.907 & 318.176 & 96.602 \\
\hline $65-69$ & 16.607 & 6.623 & 2.813 & 1.737 & 19.420 & 272.688 & 81.190 \\
\hline $70-74$ & 10.755 & 4.274 & 1.652 & 1.003 & 12.407 & 242.203 & 69.414 \\
\hline $75-79$ & 5.520 & 2.296 & 870 & 535 & 6.390 & 193.493 & 54.025 \\
\hline 80 y mas & 6.173 & 2.619 & 1.187 & 716 & 7.360 & 249.536 & 70695 \\
\hline
\end{tabular}

Fuente. ASIS 2013 CIE 10

Análisis: según reportes para el año 2013 las caries y los problemas de las encías se registraron como las patologías de mayor frecuencia y se encontraron registradas dentro de las primeras causas de consulta externa de los servicios de salud. 


\subsection{Análisis resultados encuestas nacionales de salud bucal ENSAB III 1999, SISVESO 2013, APS 2011- 2012, ENSAB IV 2014, Colombia y Bogotá.}

La caries dental y la enfermedad periodontal históricamente se han considerado las patologías orales más frecuentes en la población, el presente estudio incluyo el edentulismo, fluorosis dental, las lesiones premalignas y el cáncer oral a pesar de no contar con información completa para la totalidad del periodo objeto del estudio debido a que contribuyen con el bienestar y la calidad de vida de la población. Así mismo estas últimas son consideradas enfermedades ruinosas y catastróficas que generan altos costos para el paciente, su familia, así como para el sector salud al no realizarse su detección temprana.

\subsubsection{Caries dental.}

Según registro de la ENSAB III para Colombia la prevalencia de caries presentó una tendencia muy similar a la historia para el año de 1998; a los 12 años el 57\% de los niños presentó una o más lesiones cavitarias no tratadas y el máximo valor $(76,0 \%)$ se alcanzó en el grupo de 30 a 34 años, edad en la cual todas las personas presentaron experiencia de caries. Al comparase la historia de caries con la prevalencia, se observa una relación de 3:2, lo que significa que de cada tres personas con historia de caries, dos tienen lesiones no tratadas al momento del examen(Ministerio de Salud, 1999).

Página 69 de 228

Rutty Adriana Abril Vivas. Odontóloga. Especialista Administración Hospitalaria. Auditoria de la Calidad. Nubia Astrid Duarte Pinzón. Enfermera. Especialista en Gerencia de Salud. 
llustración 9 Prevalencia de caries en dentición primaria en niños de 5 años Bogotá .1999

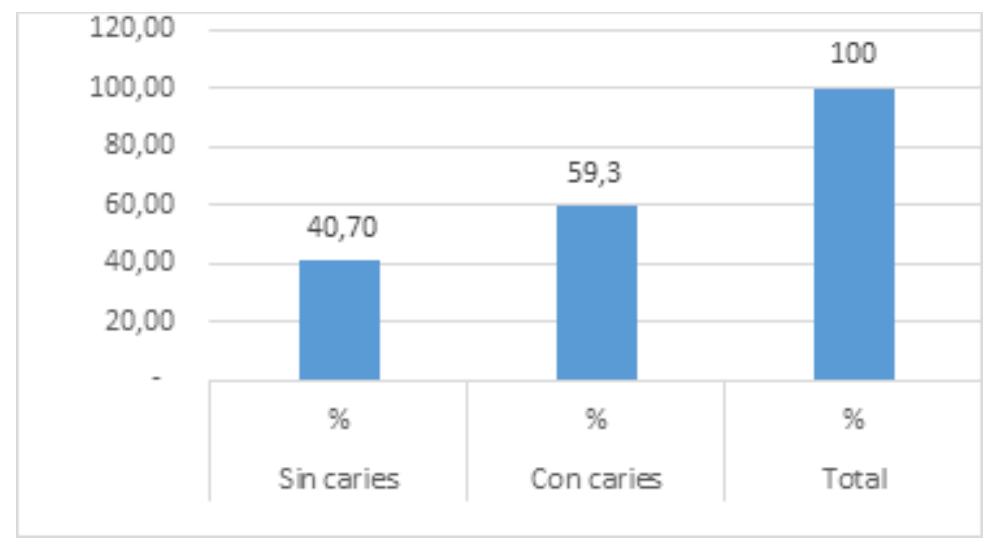

Fuente III Estudio Nacional de salud bucal 1998

Resultados: Bogotá presento una un 59,3\% de prevalencia de caries en la población de niños de 5 años para 1.998. 
Ilustración 10 llustración 10 Historia y prevalencia de caries dentición permanente Colombia 1999.

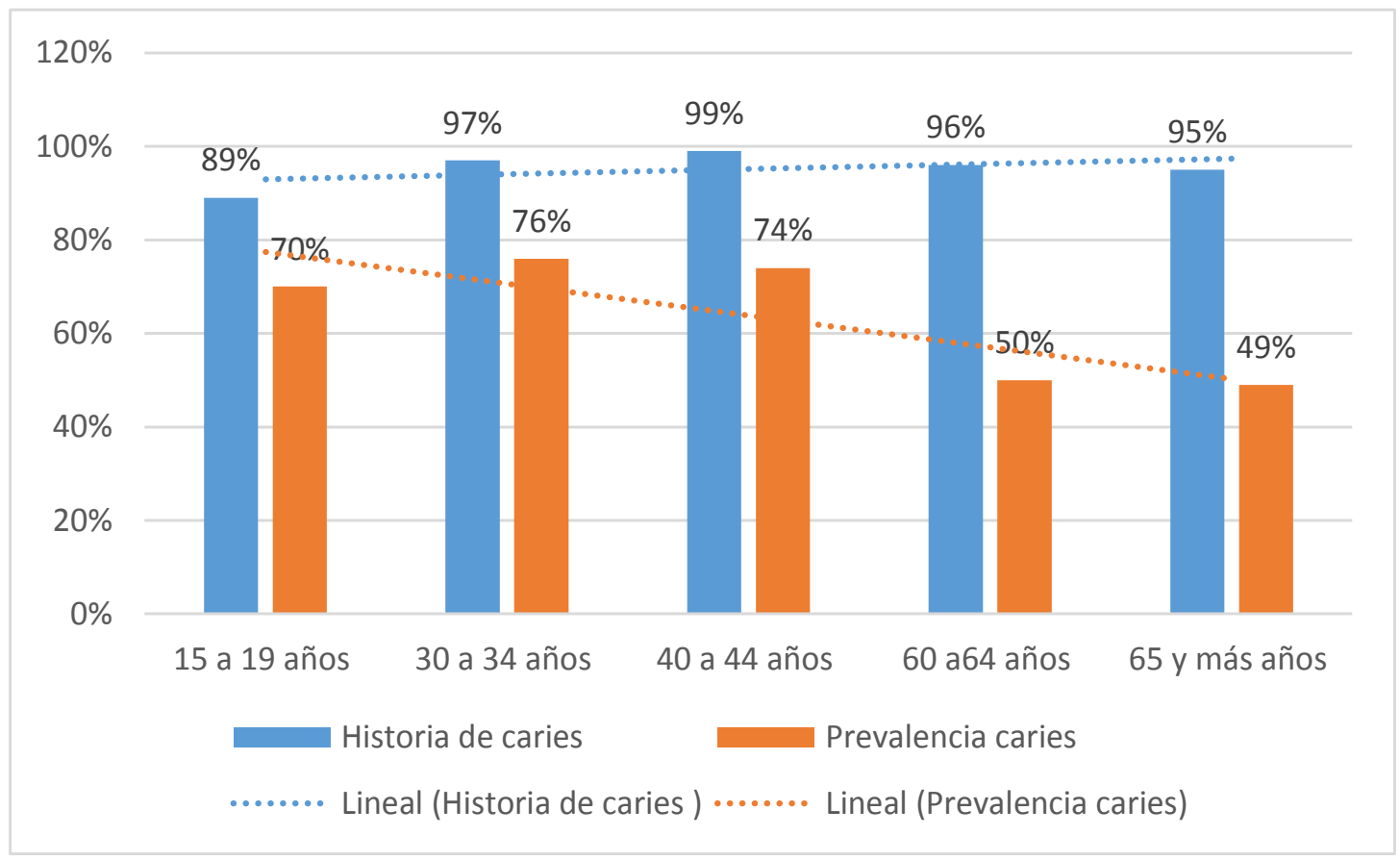

Fuente. Proyecto de desarrollo de autonomía salud oral 2011

Análisis: la población comprendida entre el rango de 15 a 44 años presentó el mayor porcentaje de prevalencia de caries seguida de la población de adultos mayores, frente a la historia de caries la totalidad de los grupos poblacionales presentaron una distribución porcentual elevada con más del 89\%. 
En investigación de 2004 de la Secretaria Distrital de Salud en el marco del plan de atención básica en lo que respecta a la dentición decidua el 74,8\% presentaron historia de caries con prevalencia de 68,3. En informe de SISVESO para la vigencia de 2009 más de la mitad de los menores (52,9\%) presento caries cavitacional (Secretaria Distrital de Salud, 2011b).

Según información de la ENSAB IV para Colombia los niños menores de 5 años presentaron prevalencia de caries de $6.02 \%$ en la dentición temporal; aumentando a los 3 y 5 años siendo un $47.10 \%$ y $62.10 \%$ respectivamente y al tener en cuenta la dentición permanente se presentó en un $54.16 \%$, a los 12 años aumentándose en $75.21 \%$, a los 18 años, llegando a $96.26 \%$ en adultos mayores.

En la población con dentición permanente, los indicadores registrados en la ENSAB IV no dan cuenta de mejoras sustanciales frente a los resultados presentados en el ENSAB III con relación a la experiencia de caries, pero se observó que pasó de 10.3 en 1998 a 10.48 en 2013-2014 mientras que la prevalencia se redujo al pasar de $65.3 \%$ en ENSAB III a $55.82 \%$ en el ENSAB IV.

Frente a las estadísticas referente a la caries, no guardan diferencias significativas por sexo, por tipo de afiliación y por región a excepción de la cantidad promedio de dientes cariados, que registró para el régimen subsidiado en 2.07 dientes(Ministerio de Salud y Protección social. \& Pontificia Universidad Javeriana, 2014).

Página 72 de 228 Rutty Adriana Abril Vivas. Odontóloga. Especialista Administración Hospitalaria. Auditoria de la Calidad. Nubia Astrid Duarte Pinzón. Enfermera. Especialista en Gerencia de Salud. 
Ilustración 11 Tendencia caries menor de 5 años y rango de edad 15 a 40 años periodos 19982014 Colombia
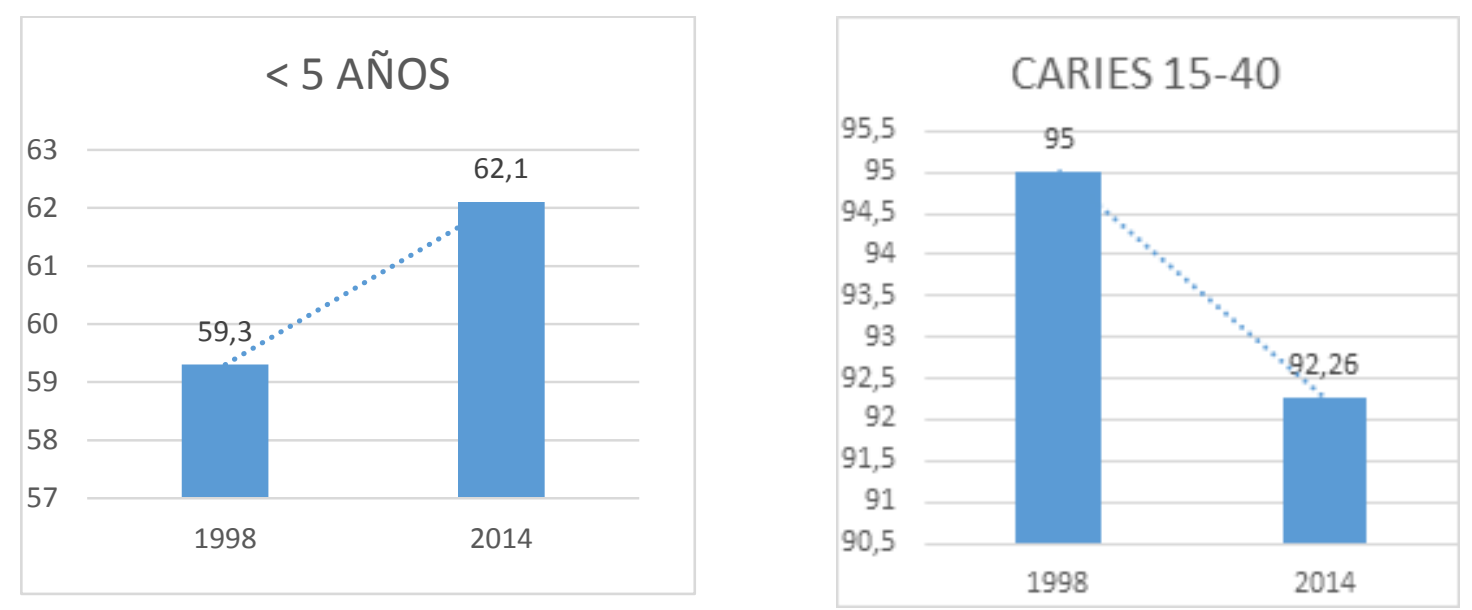

Fuente: ENSAB III- ENSAB IV

Resultados: la tendencia observada de la presencia de caries dental para el grupo poblacional de menores de 5 años fue mayor para el estudio del año 2014 con respecto a la vigencia 1999, mientras que para el grupo poblacional de 15 a 40 años disminuyo para el 2014.

\subsubsection{Prevalencia de caries no tratada Colombia 2013-2014.}

La siguiente información corresponde al ENSAB IV: 
Ilustración 12 Prevalencia de caries no tratada Colombia 2013-2014.

Prevalencia considerando caries cavitada

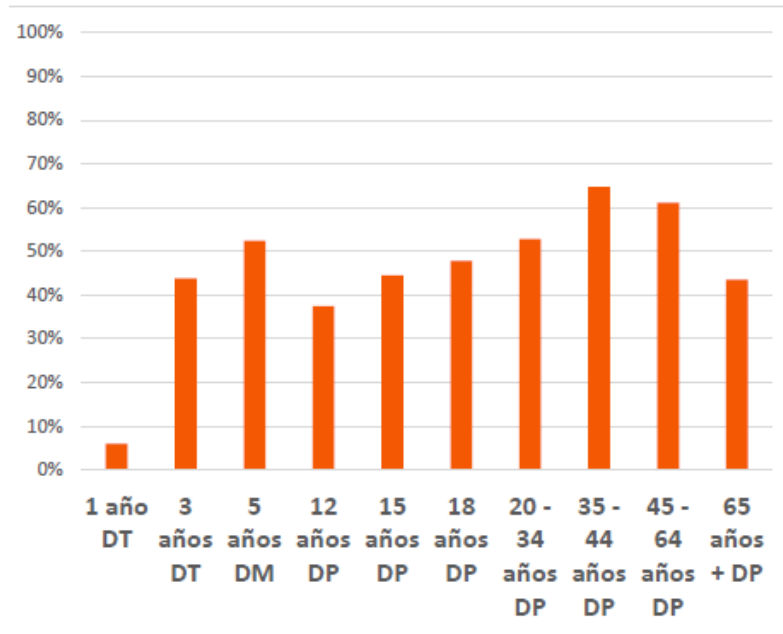

DT: Dentición temporal
Prevalencia considerando además la caries incipiente



DP: Dentición permanente

Fuente: IV-MPS, estimaciones UT SEI- PUJ CENDEX, 2013-2014

Análisis: la prevalencia de caries cavitacional se encontró en mayor proporción en las edades de adultos de 35 y 45 años en el $65 \%$ y $60 \%$ respectivamente seguida por población de 5 años con un $52 \%$, aumentándose en un alto porcentaje al considerar la caries incipiente para un resultado promedio entre $90 \%$ y $70 \%$ para las edades de 15 y 18 años.

\subsubsection{Prevalencia de caries no tratada por región Colombia 2014.}

Con respecto a la prevalencia de caries no tratada por región según reporte de la ENSAB IV se encontró lo siguiente: 
llustración 13 Prevalencia de caries no tratada por región Colombia- Bogotá 2014.

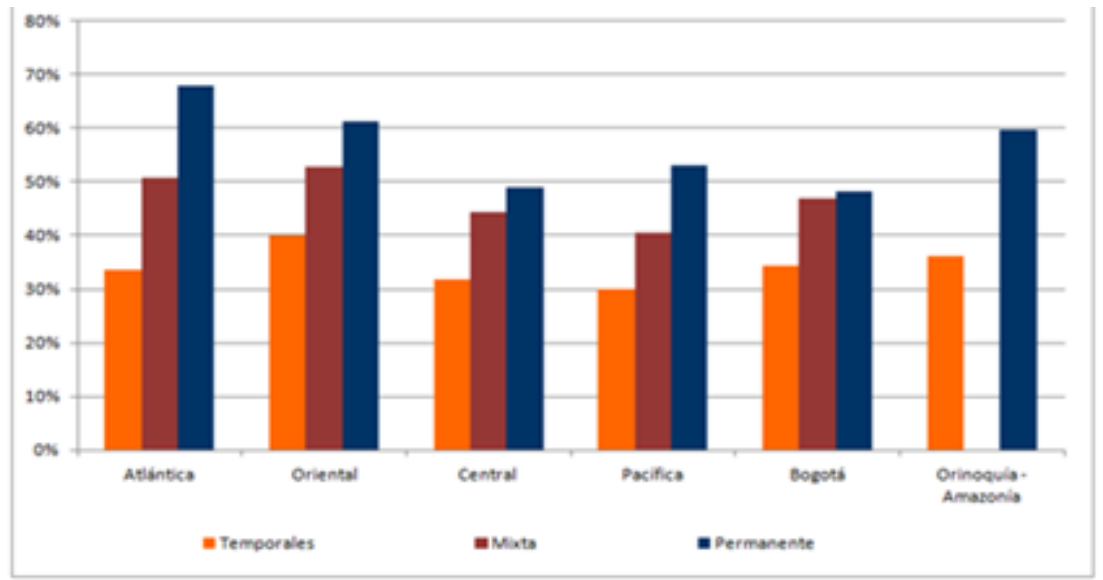

Fuente: IV-MPS, estimaciones UT SEI- PUJ CENDEX, 2013-2014

Análisis: Bogotá, ocupó el tercer lugar con caries no tratada en dientes temporales luego de la zona oriental y Orinoquia- Amazonia. También ocupó el tercer lugar en dentición mixta, luego de las zonas Atlántica y Oriental.

\subsubsection{Prevalencia de caries no tratada según ENSAB III -ENSAB IV por grupos etarios. Colombia.}

La siguiente comparación de los diferentes estudios realizados en el país corresponde a la encuesta nacional de salud bucal ENSAB IV. 
Ilustración 14 Prevalencia de caries no tratada comparativo por grupos etarios. Colombia 19992014.

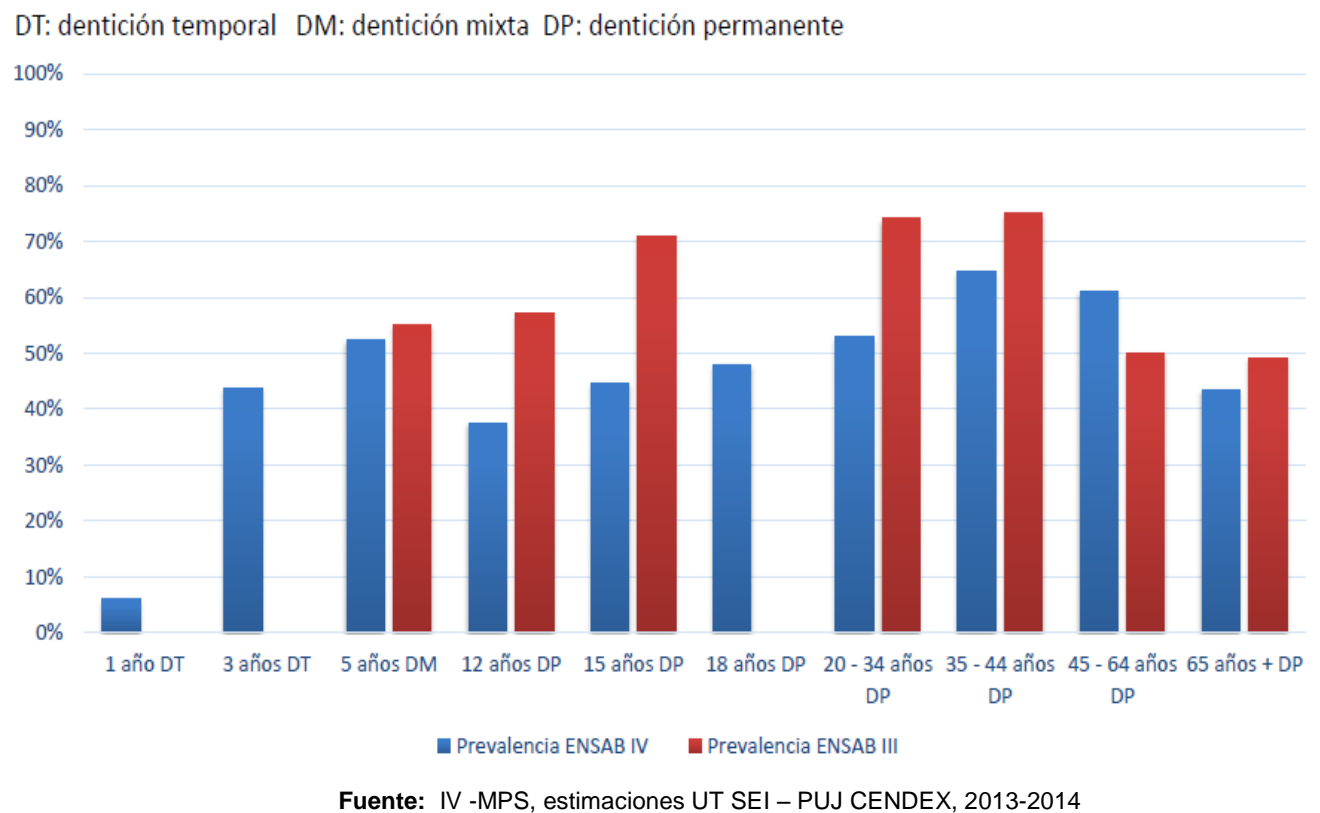

Análisis: la prevalencia de caries al realizar la comparación entre la ENSAB III y IV mostró disminución en todos los grupos etarios con excepción del grupo de 45 a 64 años, adicionalmente los grupos etarios comprendidos entre 1 y 3 años y el grupo de 18 años no cuentan con comparativo, lo cual sugiere una debilidad de la política frente a estos grupos poblacionales. 


\subsubsection{4 Índices COP-D y ceo-d indicadores de medición de caries Colombia y Bogotá.}

4.3.1.4.1 Índice ceo-d. COP-D Colombia .1998.

La severidad del problema de caries dental en la dentición temporal se estima a través del índice de ceo-d (número promedio de dientes con antecedentes de caries) y por el índice de COP-D para dentición permanente.

Para el año 1998 de observó a nivel nacional que el 84,4\% de los dientes presentes en los menores de 5 años se encontraban sanos sin presentar incrementos importantes en los 6 y 7 años (Ministerio de Salud, 1999).

En los datos registrados por ENSAB III para la dentición permanente la población de 15 a 19 años la historia de caries es el $89 \%$, ósea que de cada 10 adolescentes 9 ya había tenido historia de caries a los 40 años el $99 \%$ de la población ya había sufrido el evento(Secretaria Distrital de Salud, 2011b)

Página 77 de 228

Rutty Adriana Abril Vivas. Odontóloga. Especialista Administración Hospitalaria. Auditoria de la Calidad. Nubia Astrid Duarte Pinzón. Enfermera. Especialista en Gerencia de Salud. 
llustración 15 Comparativo Índice ceo-d, niños de 5 años, sub regiones Colombia, 1999

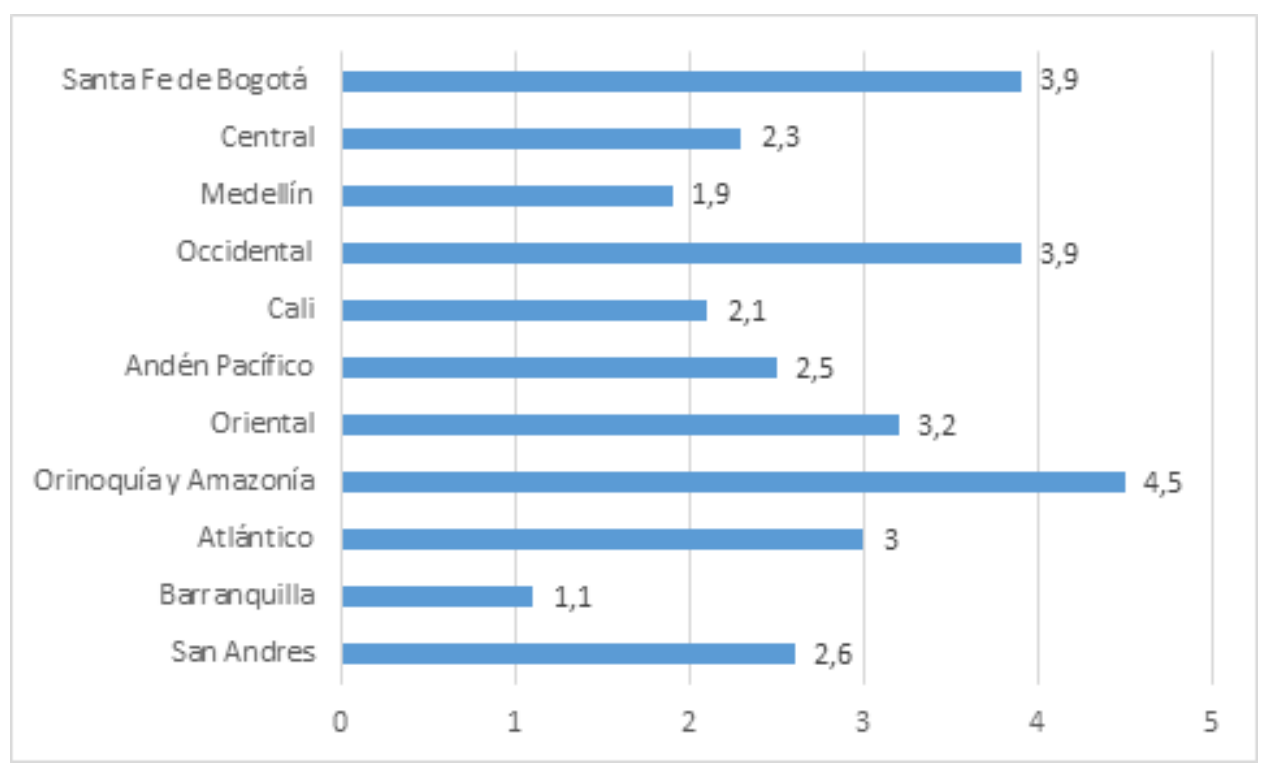

Fuente: Estudio Nacional de Salud Bucal .1999

Resultados: los niños de 5 años que habitaban en Bogotá presentaron un índice de ceo-d de 3,9; el segundo índice más alto después de la Orinoquia y Amazonia que registraron el 4,5\% con 167 niños. (Ministerio de Salud, 1999)

En investigación de 2004 de la Secretaria Distrital de Salud en lo que respecta a la dentición decidua el $74,8 \%$ presentaron historia de caries con prevalencia de $68,3 \%$, el ceo-d fue de $3,8 \%$.

4.3.1.4.2 Índice COP-D según grupo etario y mujeres gestantes, SISVESO 2007-2013. Bogotá. 
Cuando se analizó la trayectoria de la prevalencia de caries dental y del índice COP-D a los12 años, a nivel nacional y distrital, a partir de los tres estudios nacionales, mostraron un mayor deterioro de la situación para el distrito capital comparada con el promedio nacional y aunque se logró mejoramiento en Bogotá, este no seguía la misma magnitud que en el país. El índice COP-D para todas las edades encontrado por el SISVESO 2007 fue de 8,3(Secretaria Distrital de Salud, 2011b).

Ilustración 16 Índice COP-D según grupos de edad y mujeres gestantes, SISVESO 2007

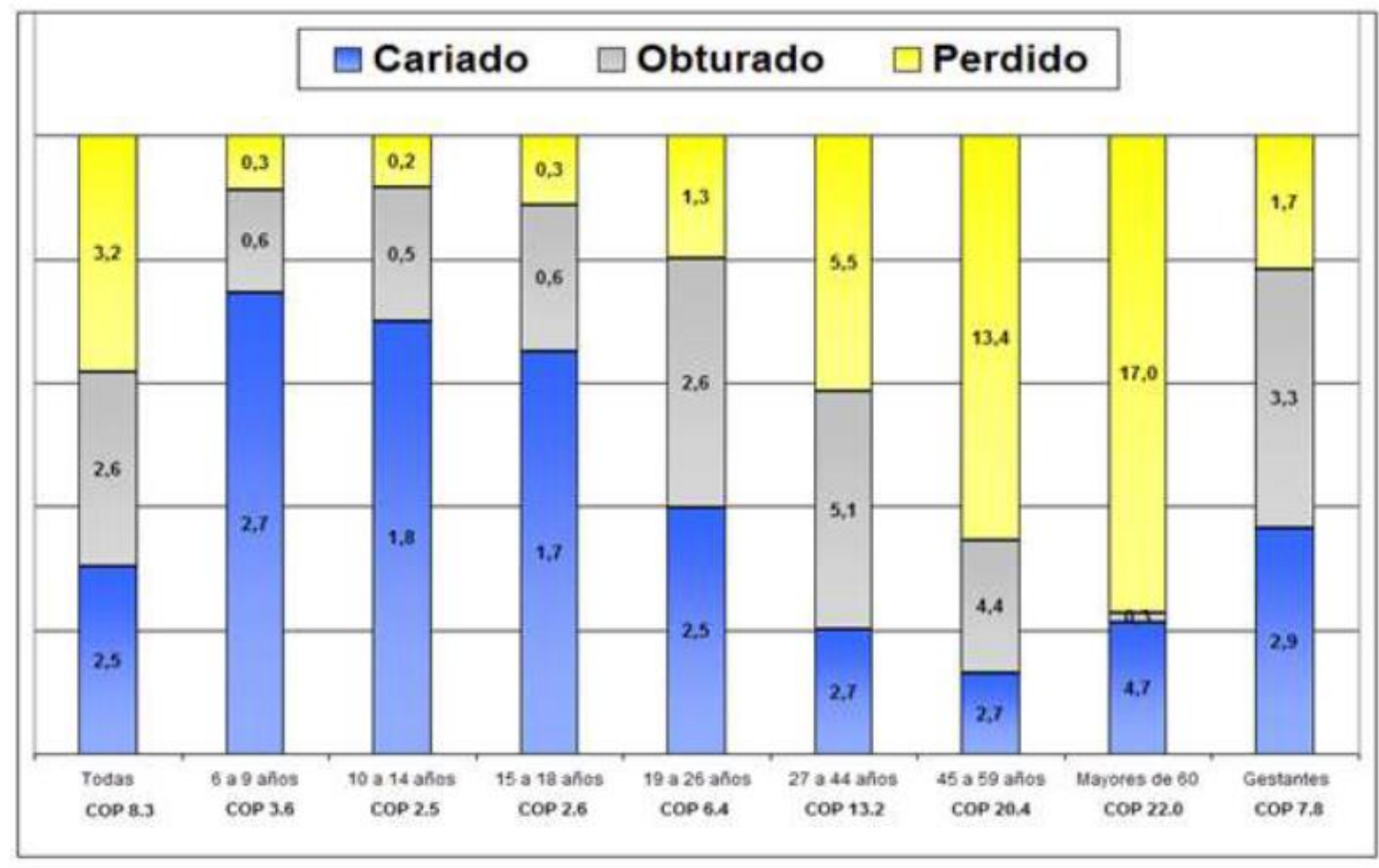

Fuente: Estudio piloto de la estrategia de vigilancia centinela. SISVESO 2007. Bogotá. 
Análisis: se observó el mayor porcentaje de dientes cariados en el grupo poblacional de 6 a 9 años y el menor porcentaje al grupo poblacional de 45 a 59 años.

El mayor porcentaje de obturados correspondió a las edades de 27 a 44 años y el menor al grupo poblacional mayor de 60 años

El porcentaje mayor de dientes perdidos se presentó en la población de los mayores de 60 registraron seguido por la población de 45 a 69 años.

El mayor índice COP correspondió al grupo poblacional mayor de 60 años, seguido de la población de 45 a 59 años de edad.

En investigación realizada por la Secretaría Distrital de Salud en el 2004 en el marco del, Plan de atención básica en relación con caries dental, en dentición temporal el ceo-d registrado de 3,8 .

En el estudio piloto del SISVESO del 2007, el ceo-d para niños entre 1 a 5 años fue de 2,5 y para niños entre los 6 y 9 años fue de 3,6. El reporte de SISVESO 2009 se evidenció en la infancia lesiones de caries tipo mancha blanca en un 37,9\% y mancha café en un 41,2\%(Secretaria Distrital de Salud, 2011b).

Página 80 de 228

Rutty Adriana Abril Vivas. Odontóloga. Especialista Administración Hospitalaria. Auditoria de la Calidad. Nubia Astrid Duarte Pinzón. Enfermera. Especialista en Gerencia de Salud. 
Ilustración 17 Índice COP-D Subsistema de Vigilancia Epidemiológica por grupo de edad. Bogotá 2013.

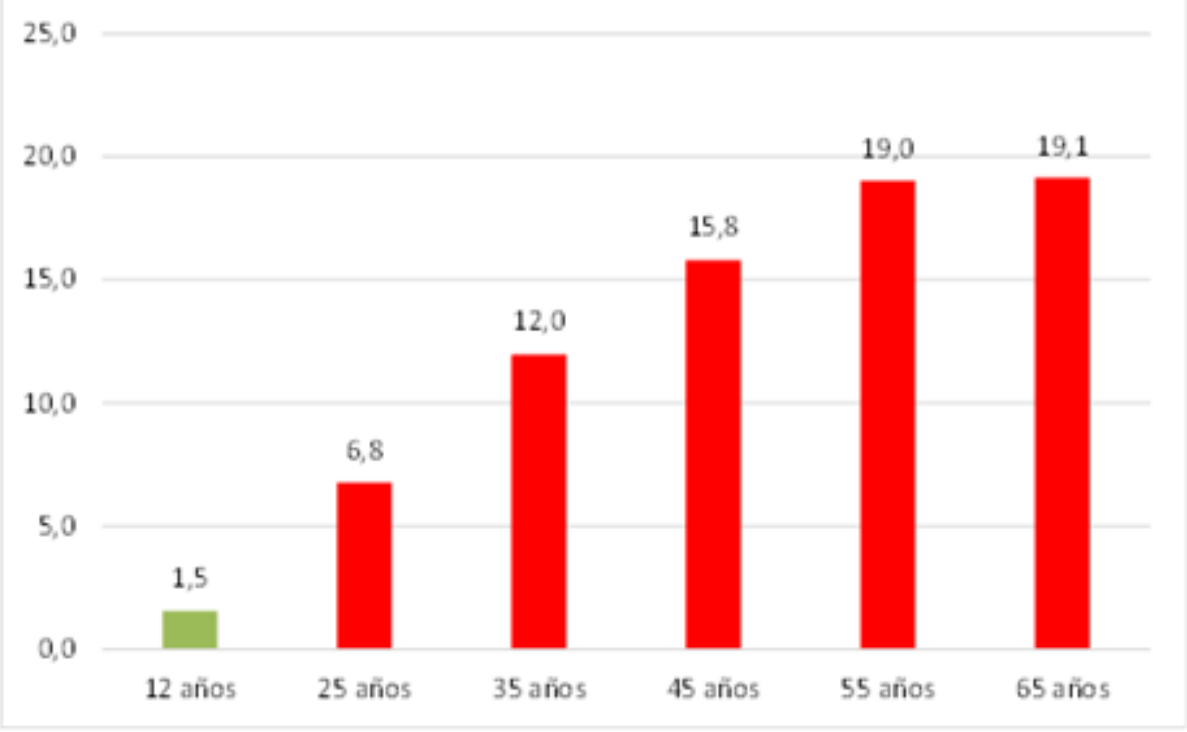

Fuente: SISVESO 2013

Análisis: el índice COP se encontró por fuera del estándar establecido para la población de 25 años en adelante por la OMS que corresponde muy alto $(>6,5)$, lo que requería la intervención en los grupos de edad a partir de los 25 años, lo cual sugiere deficiencias en la política frente a estos grupos poblacionales situación similar a la registrada a nivel nacional. 
Tabla 3 Índice caries obturados perdidos ceo-d. SISVESO Distrito Capital 2013.

\begin{tabular}{|c|c|c|c|c|c|c|c|c|c|}
\hline \multicolumn{10}{|c|}{ Aho 2013} \\
\hline Edad & Pobbción & $\begin{array}{c}\text { No. } \\
\text { dedinis } \\
\text { tamponiks } \\
\text { Carbos }\end{array}$ & $\begin{array}{l}\text { Ponedode } \\
\text { dints } \\
\text { mponies } \\
\text { cardos }\end{array}$ & $\begin{array}{c}\mathrm{Na} \\
\text { dedertes } \\
\text { troponiles } \\
\text { Oturnds }\end{array}$ & $\begin{array}{l}\text { Porido de } \\
\text { dents } \\
\text { torponiks } \\
\text { Ottrindos }\end{array}$ & 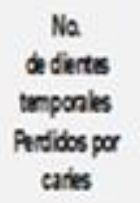 & 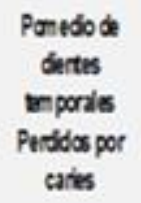 & 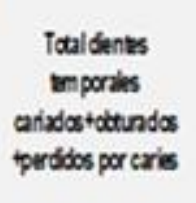 & $\begin{array}{l}\text { hdice } \\
\text { ceod }\end{array}$ \\
\hline Uenorde 1 xौ० & 3 & 9 & 0,3 & 10 & 0,3 & 1 & 0,0 & 20 & 1 \\
\hline 125 ahlos & 3180 & 6661 & 20 & 978 & 0,3 & 30 & 0,1 & 752 & 2 \\
\hline ToblGenenal & 3285 & 6270 & 20 & 968 & 0,3 & 34 & 0,1 & $75 \mathscr{Q}$ & 2 \\
\hline
\end{tabular}

Fuente: Base de datos Distrital de vigilancia centinela SISVESO. S.D.S

Análisis: se observó un índice ubicado a muy temprana edad y aumentándose en el grupo de 1 a 5 años lo que indica la necesidad de incluir estos grupos poblacionales en el fortalecimiento de la política pública de salud oral para el año 2013.

4.3.1.4.3 Índice COP-D. Encuesta nacional de salud bucal. ENSAB IV Colombia 2014.

Página 82 de 228

Rutty Adriana Abril Vivas. Odontóloga. Especialista Administración Hospitalaria. Auditoria de la Calidad. Nubia Astrid Duarte Pinzón. Enfermera. Especialista en Gerencia de Salud. 
Ilustración 18 Índice de dientes con caries, obturados y perdidos por caries cavitacional por grupos de edad. Colombia 2014.

DT: dentición temporal DM: dentición mixta DP: dentición permanente

23

18

13

Valor referencia OMS en edad

indice :

COP de 3,0

3

1 año DT 3 años DT 5 años DM
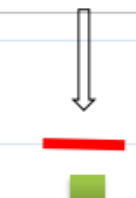

Análisis: según datos reportados por la IV Encuesta Nacional de Salud Oral 2014 el Índice COP-D promedio a los 12 años: es de 1,51, mejorando el promedio internacional establecido por la OMS para este grupo de edad sin embargo se observó que en la población de la primera infancia aumenta progresivamente así como para los grupos etarios comprendidos entre el rango de 20 a 79 años; lo que indica la necesidad de fortalecer y controlar las acciones de la política frente a estos grupos poblacionales. 
4.3.1.4.4 Comparativo promedio índice COP dentición permanente 1977-80, 1999, 1914 por grupo etario. Colombia.

Ilustración 19 Comparativo promedio de Índice COP estudios nacionales. Colombia.2014



Fuente: Estudio de Morbilidad Oral 1965/1966: Estudio Morbilidad Oral 1997/80: ENASB III; IV -MPS.

Análisis: se observó un incremento en los obturados por caries en el periodo 1965 a 2014, con su correspondiente disminución de los perdidos por caries lo que indicó efectividad de la política frente a las actividades de obturaciones, sin embargo, es necesario fortalecer la política oral frente a las actividades con el fin de minimizar riesgos que potencialicen la perdida dental ya que se han mantenido a través del tiempo. 
Bogotá no cuenta con información estadística consolidada para todo el periodo objeto de estudió, se realizó análisis con base a la información existente.

\subsubsection{Enfermedad Periodontal.}

\subsubsection{1 Índice de higiene oral simplificada medición de estado periodontal Colombia y Bogotá.}

El hábito de la higiene oral debe establecerse desde la etapa de gestación y desde las conductas establecidas en la familia con el fin de que los menores adquieren comportamientos que garanticen una salud oral óptima y que ayuden a disminuir los avances de la enfermedad hacia los tejidos periodontales. El estado de higiene oral se estable mediante la medición cuantitativa de placa bacteriana a través del indicador de índice de higiene oral simplificado IHOS; a continuación, se analizan los resultados de acuerdo a la información existente:

4.3.2.1.1 Índice de placa blanda, estudio nacional de salud 1999.

Para la vigencia el $81,6 \%$ de la población presentó placa bacteriana. En el grupo etario comprendido entre el rango de 4 de 20 años se presentó en más del 95\% de esta población; a partir de los 21 años se produjo una leve reducción en el porcentaje,

Página 85 de 228

Rutty Adriana Abril Vivas. Odontóloga. Especialista Administración Hospitalaria. Auditoria de la Calidad. Nubia Astrid Duarte Pinzón. Enfermera. Especialista en Gerencia de Salud. 
disminución que en las personas adultas mayores estaba influenciada por la pérdida dentaria.

El índice de placa blanda presentó valores muy similares en los menores de 5, 6,7 y 12 años, con el valor más bajo a los 12 años de 1,2 (98,8\%) y el más alto a los 7 años de 1,6(99,6\%). En los jóvenes de 15 a 19 años el índice se redujo a 0,8(95,0\%).El comportamiento en los adultos de 20 a 44 años fue similar al del grupo de jóvenes y para los adultos mayores se presentó en $0,5(47,3 \%)$ y 0.3 y $(26,9 \%)$ posiblemente influenciado por la pérdida dentaria (Ministerio de Salud, 1999).

4.3.2.1.2 Índice de placa blanda, SISVESO. Bogotá 2009-2013.

Según informe del SISVESO 2009 para el periodo comprendido entre 2009 y 2013 en todas las etapas del ciclo vital y en las mujeres gestantes se presentó un alto porcentaje de placa bacteriana, siendo deficiente en un $90,5 \%$ en la edad adulta y un $87,5 \%$ en los jóvenes, según el índice de Silness \& Loe modificado el cual valora la presencia de placa bacteriana, factor de riesgo para la presencia de la enfermedad periodontal, (Secretaria Distrital de Salud, 2011b). 
Ilustración 20 Índice de placa bacteriana (Silness \& Loe modificado) por etapa de ciclo vital, SISVESO 2009.

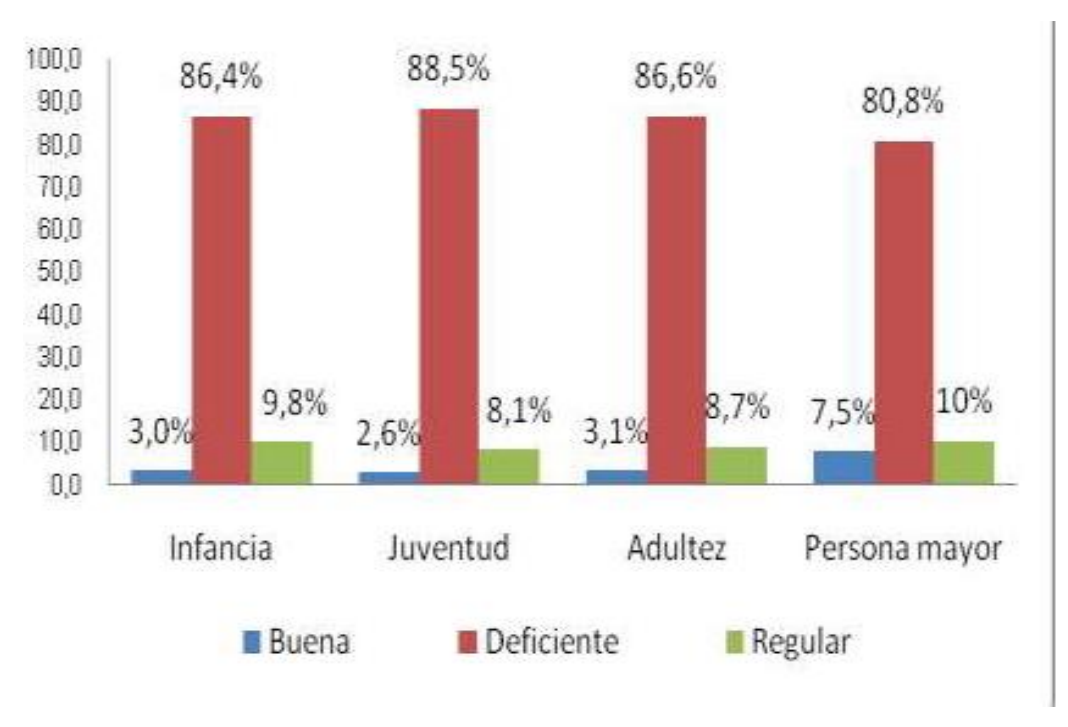

Fuente: Análisis de la estrategia de vigilancia centinela, SISVESO-VSP-DSP-SDS año 2009

Resultado: se observó registro del índice de placa similar para la totalidad de la población siendo ligeramente mayor para el grupo de edad de jóvenes y menor para el grupo de adultos mayores. 
Ilustración 21 Estado de higiene oral primera infancia. Bogotá 2009-2013.



Fuente: SISVESO. S.D.S Bogotá años 2009 a 2013.

Análisis: se observó una disminución en el índice de higiene oral clasificado como deficiente para el grupo poblacional de la primera infancia para el periodo 2009- 2011 en Bogotá con incremento para el 2012 disminuyendo para el periodo 2013; sin embargo para esta vigencia se presentó un alto porcentaje de población con higiene oral deficiente $54,7 \%$ lo que indicaba la necesidad de redefinir y fortalecer estrategias de promoción, prevención y educación en la política pública para este grupo etario. 
No fue posible establecer el comportamiento del indicador comprendido antes del año 2009 tanto a nivel nacional como distrital ya que los estudios encontrados manejan diferentes muestras y variables.

\subsubsection{Extensión y severidad de la pérdida de inserción periodontal. Colombia.ENSAB III 1998.ENSAB IV 2014.}

Frente a la pérdida de soporte periodontal se apreció la tendencia al aumento de la extensión y severidad; al realizar comparativo entre la vigencia 1998 y la 2014, se observó que la población adulta mayor es la que presenta el mayor porcentaje (79.01\%) de pérdida para el 2014(Ministerio de Salud y Protección social. \& Pontificia Universidad Javeriana, 2014).

Del total de población incluida en la valoración periodontal de la ENSAB III, el 50,1\% de la población nacional presentó extensión de pérdida de inserción, siendo mayor la tasa en el sexo masculino $(52,6 \%)$ que en mujeres $(47,6 \%)$.El $42,0 \%$ presentaron pérdida localizada y el $8,2 \%$ generalizada. La pérdida leve estuvo presente en el $41,1 \%$; moderada en el 7,7\% y severa en el 1,2\%. La pérdida de inserción guardo relación inversa con la escolaridad, la proporción registrada aumentaba con la edad y afectó el 32,8 de la 
población de 15 a 19 años y el $87 \%$ a los grupos poblacionales mayores de 55 años y más.

Para el distrito capital la pérdida se presentó en el 58,8 del total de la población intervenida(Ministerio de Salud, 1999).

Según información a la ENSAB IV más del 50 \% de la población objeto del estudio presento una extensión generalizada de la pérdida del nivel de inserción clínico, 51.27\%, mientras que en el $44.02 \%$ se presentó una extensión localizada, y sólo el $4.41 \%$ no presentaron ninguna pérdida del nivel de inserción clínico al momento de la valoración.

\section{Ilustración 22 Extensión de la pérdida de inserción periodontal.ENSAB III.1999 ENSAB IV. 2014} Colombia.

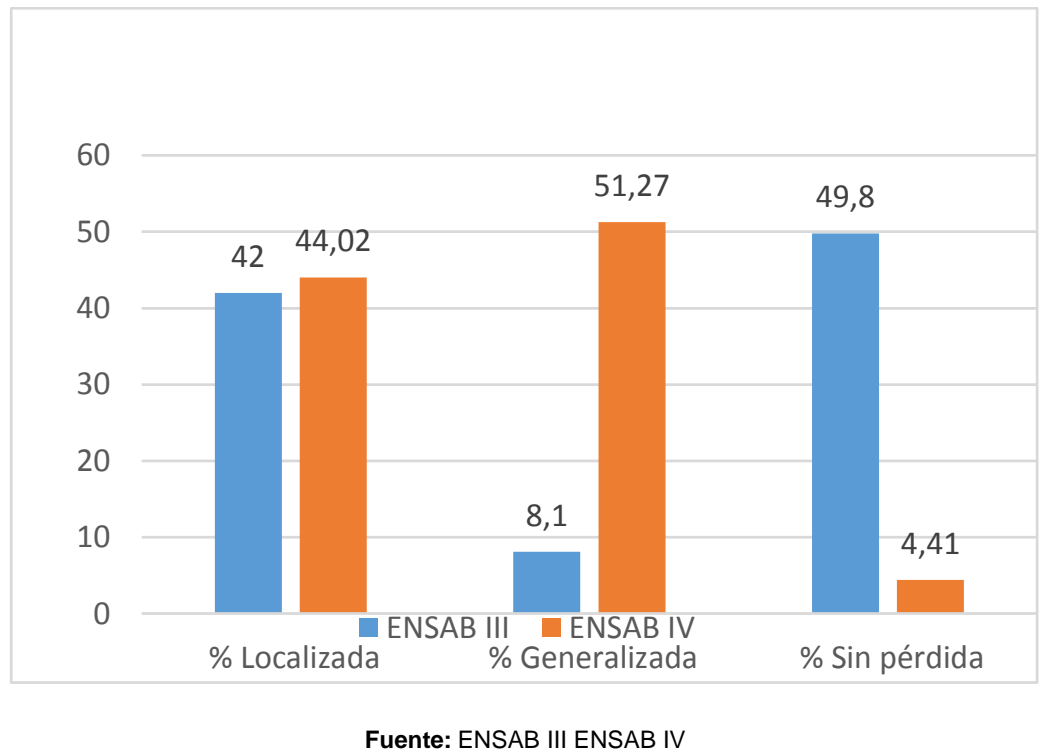

Página 90 de 228

Rutty Adriana Abril Vivas. Odontóloga. Especialista Administración Hospitalaria. Auditoria de la Calidad. Nubia Astrid Duarte Pinzón. Enfermera. Especialista en Gerencia de Salud. 
Análisis: al comparar el comportamiento de la extensión de pérdida de inserción periodontal se observó un aumento en la pérdida generalizada con un registro de $51,27 \%$ para el 2014 frente a la reportada 8,1\% para el año 1999, disminuyendo el porcentaje de la población registrada sin pérdida de inserción periodontal $(4,41 \%)$.

\section{llustración 23 Severidad de la pérdida de inserción periodontal.ENSAB III.1999 ENSAB IV.2014} Colombia.

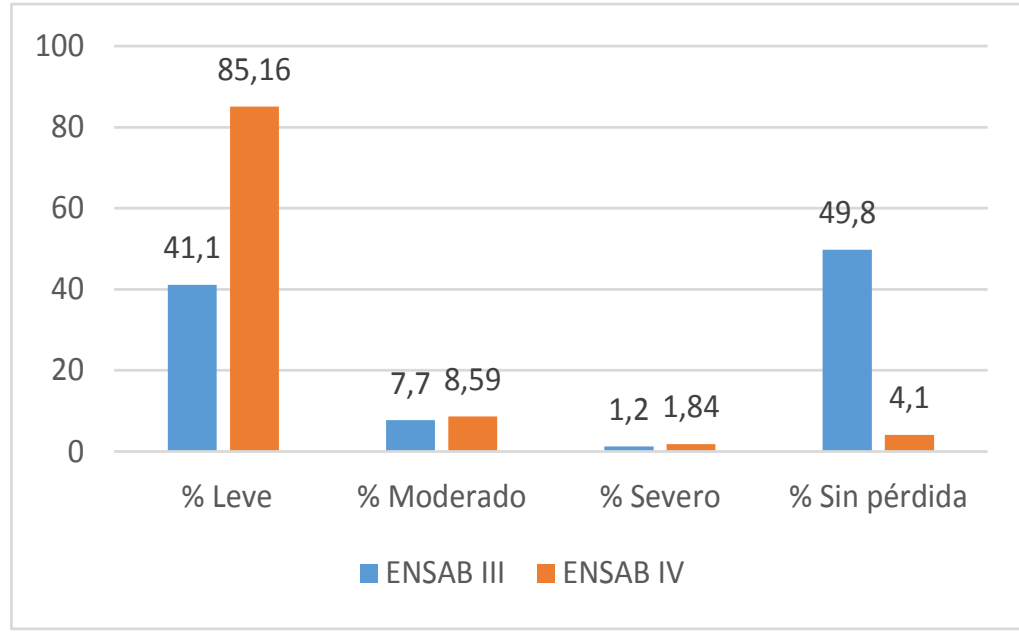

Fuente: ENSAB III ENSAB IV

Análisis: frente a la severidad de la pérdida de inserción periodontal se observó el aumento registrando $86,16 \%$ de perdida leve para la vigencia 2014 frente a una 
distribución porcentual de 41,1\% para el año 1999 y disminuyo el porcentaje de no perdida $4,1 \%$ en el reporte de la ENSAB IV frente a la ENSAB III reportando en $49,8 \%$.

\section{llustración 24 Comparativo de la severidad de perdida soporte periodontal ENSAB III vs -IV. Colombia 1999- 2014.}

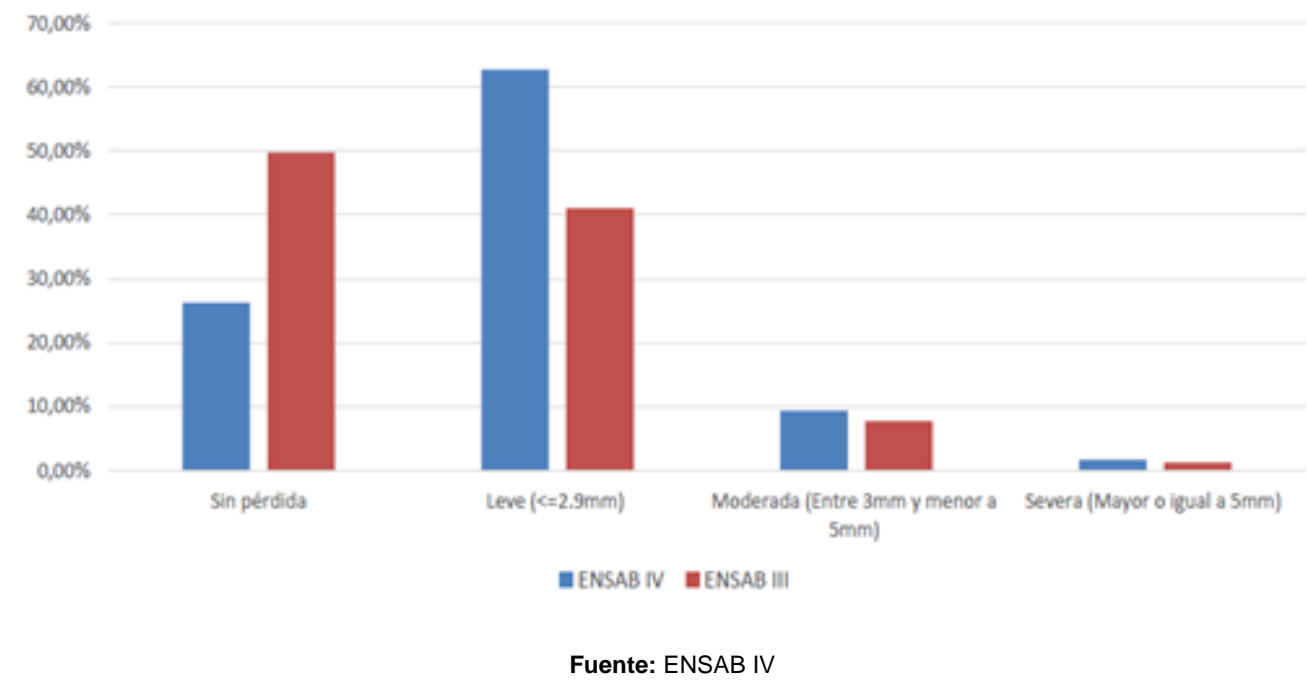

Análisis: la severidad de pérdida de soporte periodontal leve demuestra disminución al realizar comparación de las dos encuestas, pero se sigue presentando para el 2014 en un $62 \%$ de la población, la pérdida moderada y severa permanecen constantes en el tiempo lo que sugiere debilidad en la formulación de las políticas que intervengan los tejidos periodontales de la población. 
Ilustración 25 Prevalencia de pérdida de soporte periodontal por curso de vida. 2014. Colombia.

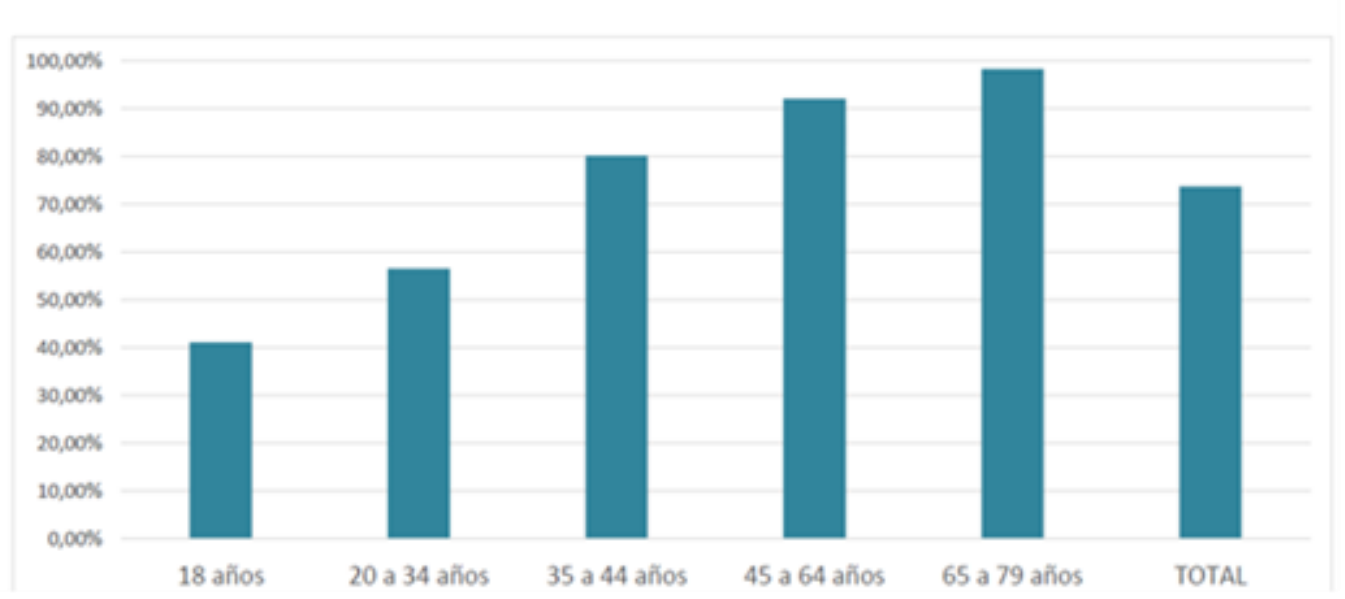

Fuente: IV -MPS, estimaciones UT SEI-PU CENDEX, 2013-2014

Análisis: los reportes del ENSAB IV registraron prevalencia de pérdida de soporte periodontal presentando mayor proporción en el grupo etario de 65-79 años con un 98\% siguiendo la población de 45 a 64 años con 92\% y el grupo etario de 35 a 44 con $80 \%$.

4.3.2.2.1 Pérdida de inserción periodontal leve. Bogotá. 1998- 2014.

A continuación, se referencia el resultado solamente de la comparación de la pérdida de inserción periodontal leve debido a que solamente se cuenta con esta variable en el distrito. 
Ilustración 26 Pérdida de inserción periodontal leve comparativo Bogotá. 1998-2014.

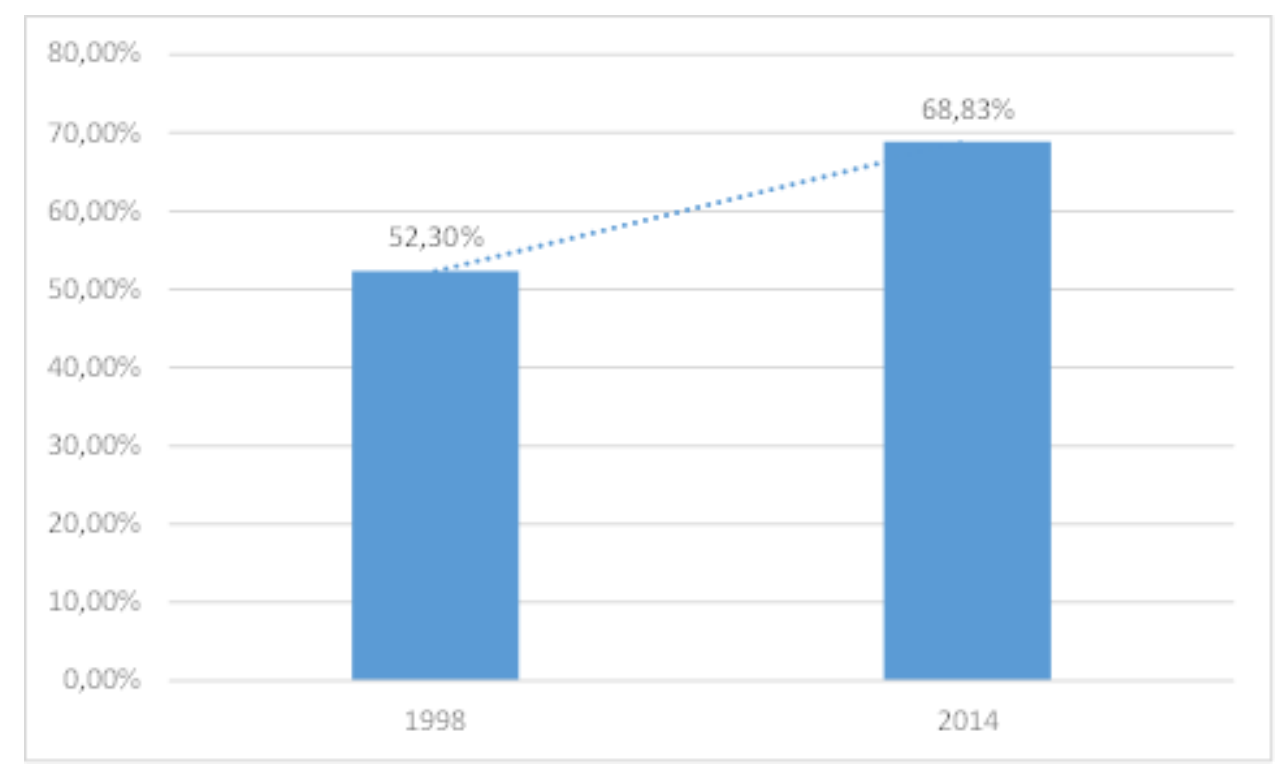

Fuente: ENSAB III- ENSAB IV

Análisis: se observó aumento de pérdida de inserción periodontal leve para el distrito capital registrando un 52,30\% para el año 1998 frente a una distribución porcentual de $68,83 \%$ para el año 2014.

\subsubsection{Prevalencia de enfermedad periodontal. Colombia 2014.}


Un alto porcentaje de la población colombiana (61.8\%) presentó periodontitis mientras un 38,2\% se clasificó sin periodontitis(Ministerio de Salud y Protección social. \& Pontificia Universidad Javeriana, 2014).

4.3.2.3.1 Comparativo de la prevalencia de enfermedad periodontal. Colombia 1998 2014.

La siguiente información corresponde a la comparación realizada frente a los diferentes estudios realizados en el país y reportados por la ENSAB IV (Ministerio de Salud. Colombia, 2014):

llustración 27 Prevalencia de enfermedad periodontal, comparativos estudios nacionales 19992014.

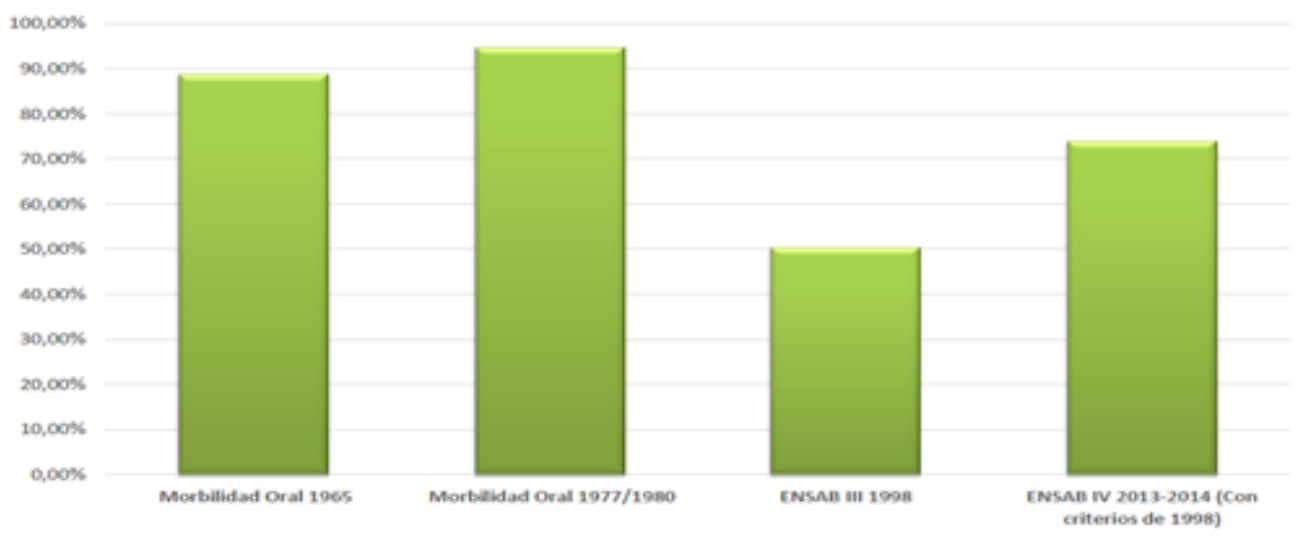

Fuente: Estudio de Morbilidad Oral 1965/1966: Estudio Morbilidad Oral 1997/80: ENSAB III; IV -MPS, estimaciones UT SEI - PUJ CENDEX, 2013-2014 
Análisis: se observó una disminución significativa de enfermedad periodontal desde año 1965 al 1968; para la vigencia 2013 a 2014 se observó un incremento en el aumento en la prevalencia de un $30 \%$ lo que indicaba la necesidad de mejorar los procesos de atención dirigidos a mitigar las acciones existentes en la política de salud oral relacionados con los tejidos periodontales de la población colombiana.

4.3.2.3.2 Prevalencia de enfermedad periodontal. Perfil epidemiológico población vinculada, desplazada y subsidiada. Bogotá 2011- 2012.

Para la población de Bogotá, según perfil epidemiológico de la población vinculada, desplazada y subsidiada realizado por la Secretaria de salud del distrito capital para el periodo comprendido entre los años 2011 y 2012 se encontraron los siguientes datos relacionados con la distribución por localidades y sexo para el distrito capital para la enfermedad periodontal (Secretaria Distrital de Salud de Bogotá et al., 2014) .

Página 96 de 228

Rutty Adriana Abril Vivas. Odontóloga. Especialista Administración Hospitalaria. Auditoria de la Calidad. Nubia Astrid Duarte Pinzón. Enfermera. Especialista en Gerencia de Salud. 
Ilustración 28 Porcentaje de periodontitis por sexo y localidad. Bogotá 2011-2012.



Fuente: S.DS.Subdirección de Vigilancia en Salud Pública

Análisis: se observó mayor porcentaje de periodontitis en hombres en las localidades de Sumapaz seguido de Antonio Nariño y Rafael Uribe presentando bolsa periodontal mayor de 3,5 mm, inflamación gingival, edema, sangrado, presencia de cálculo y movilidad dentaria, lo que sugiere debilidad de las acciones de promoción y prevención en estas localidades, presentándose en una distribución porcentual mayor con un 7,4 \% en hombres frente a un 5,7\% correspondiente a mujeres.

A través del tiempo se han producido cambios importantes en los parámetro que definen la enfermedad periodontal y los métodos de diagnóstico lo que dificultad realizar análisis 
de la tendencia; sin embargo los problemas periodontales se constituyen en la segunda causa de consulta de los servicios de salud oral ya que el $50,1 \%$ de la población presenta alguna pérdida periodontal y el $94.4 \%$ presenta algún tipo de marcador de enfermedad periodontal (Ministerio de la Protección social, 2005).

\subsubsection{Pérdida dental o edentulismo.}

El edentulismo genera disminución de la función masticatoria y aparece como un proceso secundario a los eventos de patologías orales anteriormente descritas, generando anomalías en la función general del sistema estomatognático.

\subsubsection{Prevalencia de pérdida dental o edentulismo.}

4.3.3.1.1 Prevalencia edentulismo periodos 1999 - 2005- 2013 Colombia y Bogotá.

Para el periodo 1999 y según reporte de la ENSAB III el edentulismo a nivel nacional se presentó en el $25 \%$ en los dos maxilares y del $7 \%$ en el maxilar inferior (Universidad de Antioquia. Facultad de Odontología, 2014).

Según estudio nacional de salud bucal en el año 1999; en el maxilar superior el 51,9 \% de las personas de los grupos de edad de 15 a 44 años y más de 55 años mantenían la dentición completa y en el inferior el 46,4\%; el uso de prótesis en el maxilar superior se observaba en el $25,8 \%$ mientras que en el inferior solamente el $7.0 \%$ presentándose con 
mayor frecuencia en los mayores de 55 años. La necesidad de usar prótesis era del 22,3\% para el maxilar superior y 46,6 para el inferior(Ministerio de Salud, 1999), situación igualmente registrada en el Plan nacional de salud bucal 2005-2008(Ministerio de la Protección social, 2005).

Según reporte de la secretaria distrital de salud en el perfil epidemiológico de la población vinculada, desplazada y del régimen subsidiado no POS (2011-2012) la pérdida de dientes ocupó el cuarto lugar en la distribución del diagnóstico principal para una población registrada de 104.885 personas.

llustración 29 Morbilidad (pérdida de dientes) en salud oral en la población vinculada, desplazada y del régimen subsidiado no POS, periodo 2011-2012. Bogotá.

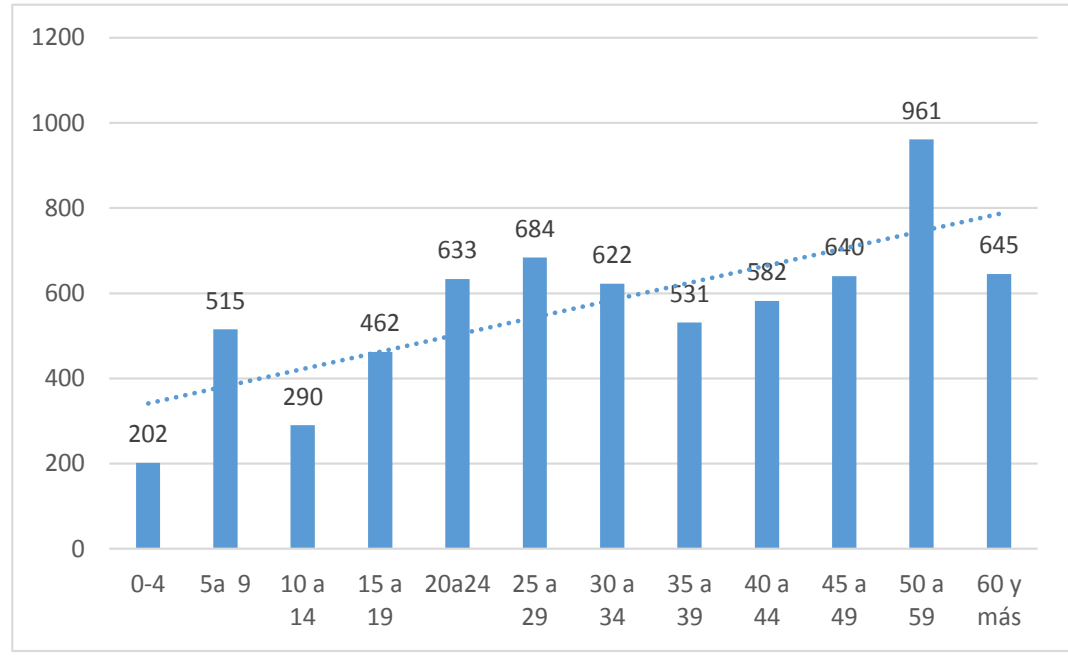

Fuente: Dirección de Planeación y Sistemas. RIPS 2011-2012. Fecha de generación del reporte: 31 de enero de 2013.

Página 99 de 228

Rutty Adriana Abril Vivas. Odontóloga. Especialista Administración Hospitalaria. Auditoria de la Calidad. Nubia Astrid Duarte Pinzón. Enfermera. Especialista en Gerencia de Salud. 
Análisis: la población con mayor distribución porcentual de perdida dental para el distrito capital correspondió a los adultos de 50 a 59 años con 961 casos, seguido del grupo poblacional de 25 a 29 años con 684 casos y en tercer lugar los grupos de 45 a 49 , se observó que el grupo de 20 a 24 presenta un alto porcentaje de pérdida con 633 casos, lo que indicaba la necesidad de fortalecer las políticas orales para estos grupos poblacionales.

4.3.3.1.2 Prevalencia de pérdida dental parcial ENSAB IV. 2014. Colombia.

De acuerdo a resultados de la última encuesta de salud bucal la pérdida parcial de dientes se encontró presente en similares porcentajes tanto en hombres como en mujeres y mayor proporción en el régimen subsidiado, requiriendo el uso de prótesis en un $75.13 \%$ de la población nacional (Ministerio de Salud y Protección social. \& Pontificia Universidad Javeriana, 2014) .

Página 100 de 228

Rutty Adriana Abril Vivas. Odontóloga. Especialista Administración Hospitalaria. Auditoria de la Calidad. Nubia Astrid Duarte Pinzón. Enfermera. Especialista en Gerencia de Salud. 
Ilustración 30 Prevalencia de pérdida dental parcial. Colombia.2014.

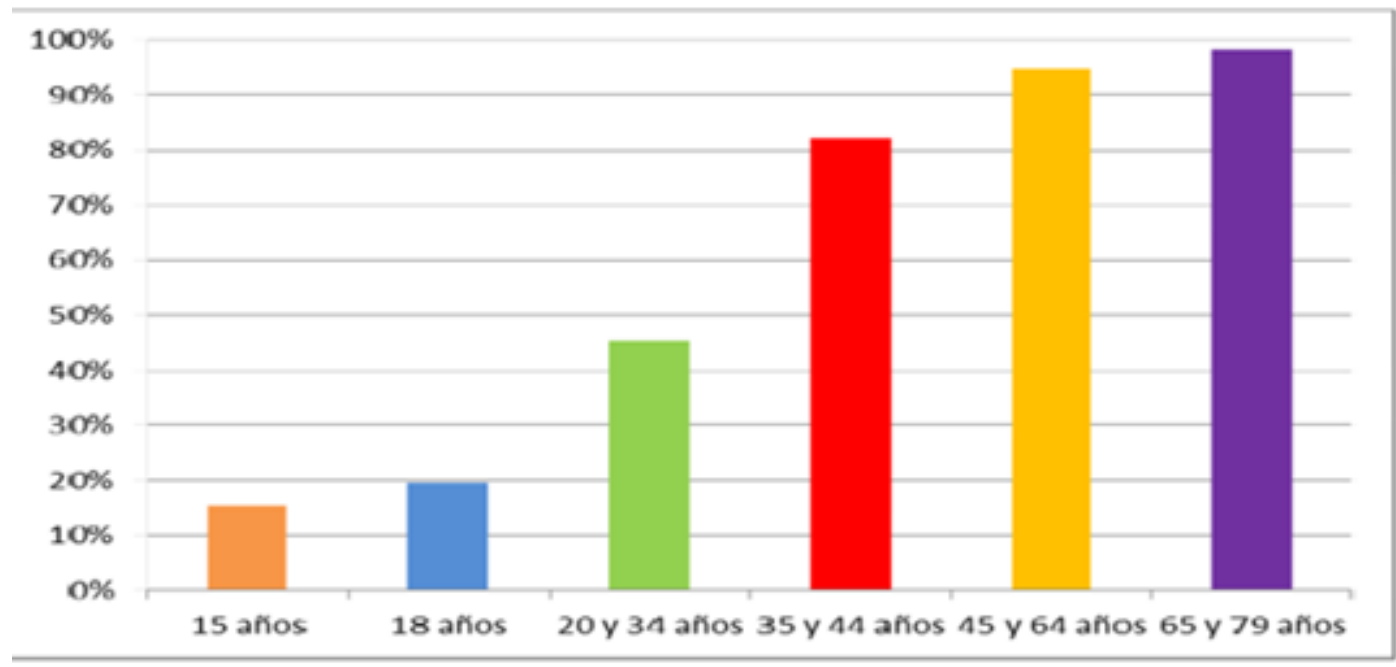

Fuente: IV -MPS, estimaciones UT SEI - PUJ CENDEX, 2013-2014

Análisis: la prevalencia de pérdida dental parcial (al menos 1 diente) para población de 20-34 fue de 45\%, población de 35-44 años 82\%, población de 45 y 64 años $92 \%$, población de 65 y 79 años $98 \%$ evidenciándose un significativo porcentaje de pérdida parcial dental después de los 35 años indicando la necesidad de fortalecer la política frente a las acciones de tipo preventivo, curativo y de rehabilitación.

\subsection{Prevalencia de pérdida dental total 2014 Colombia.}

El grupo poblacional de la tercera edad es propenso a factores de riesgo tanto de la salud general, como de la salud oral, afectando considerablemente su calidad de vida, 
integralidad y bienestar. La población del rango comprendido entre 65 a 79 años presentó edentulismo total, presentándose en mayor porcentaje en mujeres (37.78\%) frente a los hombres (26.97\%); los usuarios del régimen contributivo corresponden al $35 \%$, en Bogotá presenta un porcentaje de 48.43\% (Ministerio de Salud y Protección social. \& Pontificia Universidad Javeriana, 2014)

Ilustración 31 Prevalencia de pérdida dental total Colombia. 2014.

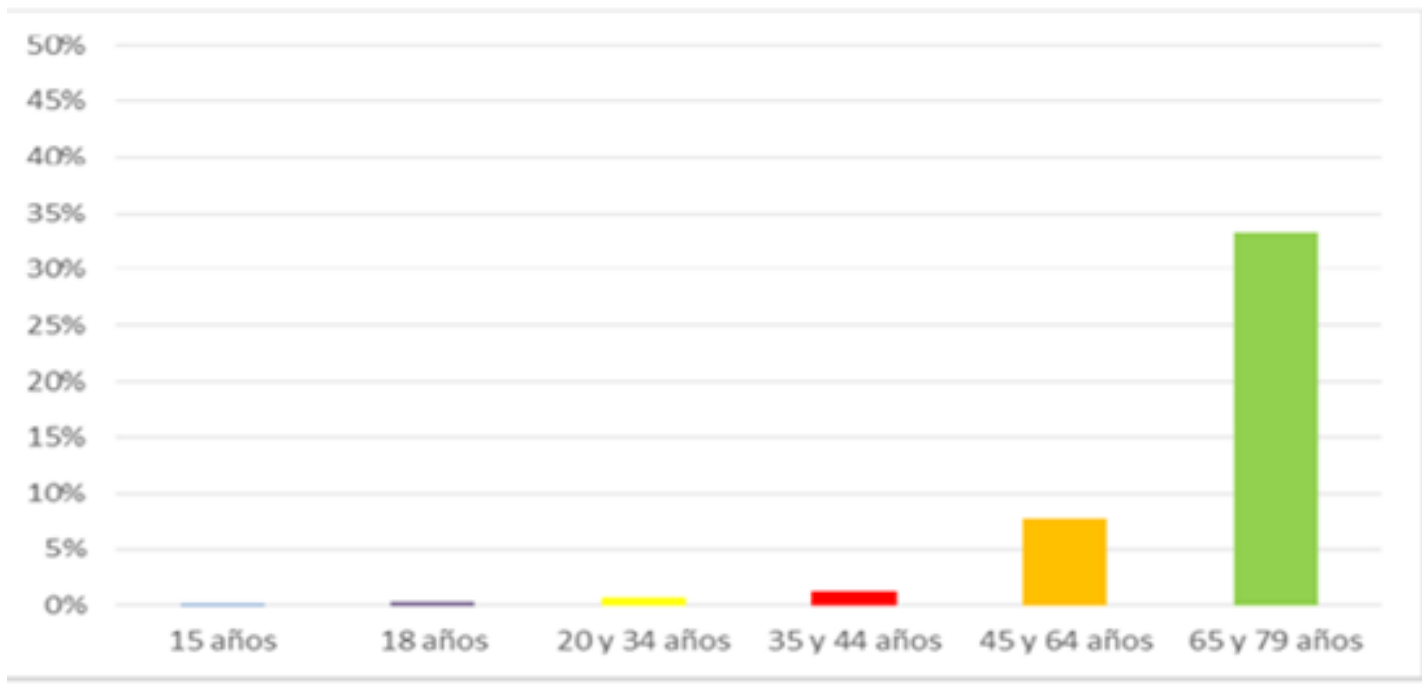

Fuente: IV -MPS, estimaciones UT SEI - PUJ CENDEX, 2013-2014

Análisis: el grupo de adultos mayores de 65 a 79 años registró el mayor porcentaje de prevalencia de pérdida dental total con un 34\%; seguido por la población de 45 a 64 
años con un $8 \%$, aunque a la fecha el POSS incluye las prótesis dentales demostrando avance en la política pública frente a la problemática, se hace necesario fortalecer la política de salud oral favoreciendo a los adultos mayores en una atención oportuna de tal manera que minimice los factores de riesgos a los cuales se encuentran expuestos, debido a los cambios sociales biológicos y sociales de la población .

Ilustración 32 Prevalencia edentulismo parcial y llustración 33 Presencia de prótesis por total por regiones. Bogotá. Colombia 2013-2014. regiones. Bogotá. Colombia. 2013-2014.
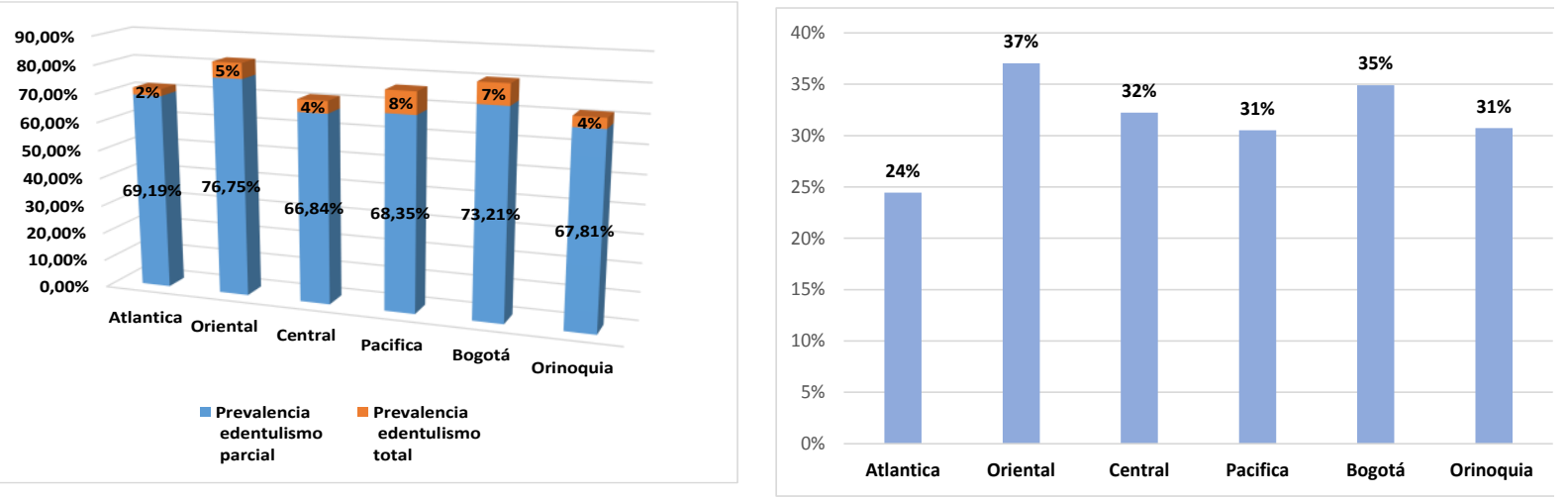

Fuente: ENSAB IV - MSPS, estimaciones UT SEI - PUJ Cendex, 2013-2014

Análisis: Bogotá ocupó el segundo lugar de las regiones evaluadas en el estudio, frente a la prevalencia de edentulismo tanto parcial como total superada por la zona oriental.

Página 103 de 228

Rutty Adriana Abril Vivas. Odontóloga. Especialista Administración Hospitalaria. Auditoria de la Calidad. Nubia Astrid Duarte Pinzón. Enfermera. Especialista en Gerencia de Salud. 


\subsubsection{Comparativo y tendencia en el uso de prótesis dental ENSAB 1999 -}

ENSAB IV 2014.Colombia.

llustración 34 Comparativo tendencia y uso de prótesis dental.Colombia-Bogotá

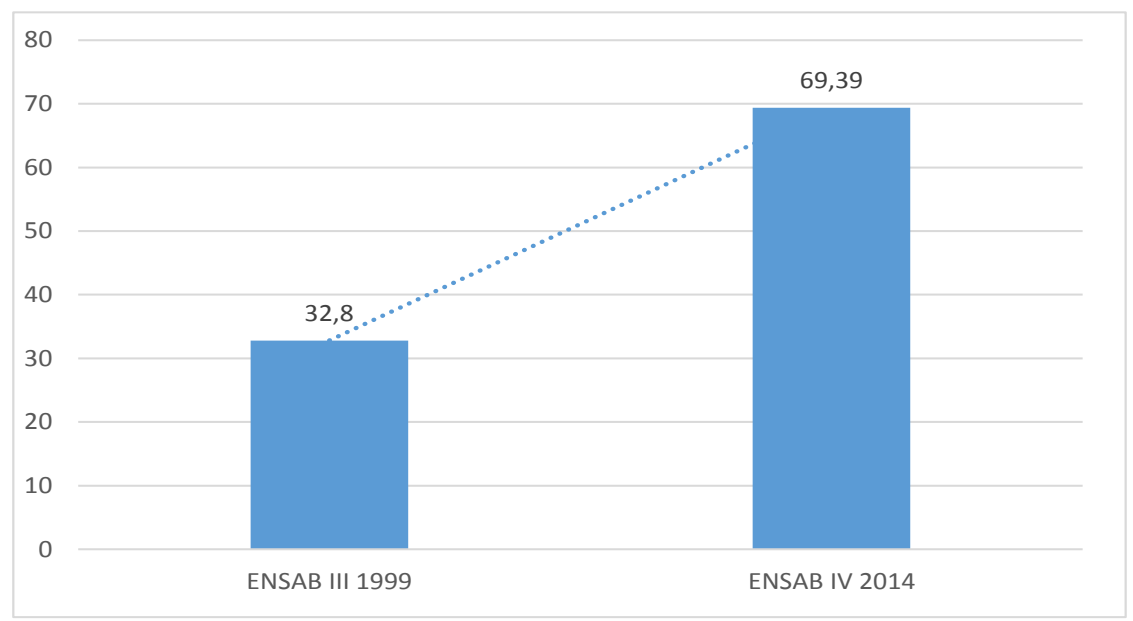

Fuente: Datos extraídos de ENSAB III ENSAB IV.

Análisis: se observó a nivel nacional una distribución porcentual mayor de uso de prótesis $69 \%$ tanto fija como removible para el 2014 frente a un 32,8\% para el estudio del año 1999 situación más frecuente en adultos y adultos mayor, lo que indica mayor porcentaje de edentulismo, situación que nos demuestra la necesidad de fortalecer las acciones de la política para esta población. 
No se cuenta con información estadística documentada para el periodo comprendido entre 1999 al 2012, según registro del diagnóstico de adultos mayores en Colombia (Fundación Saldarriaga Concha, 2007) a pesar de haberse realizado tres estudios nacionales de morbilidad oral: 1965, 1980 y el último en 1998, para la fecha anterior a la realización de la ENSAB IV no se especificaba la situación oral de las personas mayores, la poca información existente correspondía a estudio realizado por el servicio de odontogeriatría de la Universidad Nacional de Bogotá el cual encontró que el paciente promedio que asistía era de sexo femenino, con un rango de edad entre 61 y 65 años, con un nivel de ingresos mensuales de un salario mínimo, con escolaridad primaria completa, pensionado y perteneciente al régimen contributivo; el edentulismo parcial fue el hallazgo más frecuente; el número de dientes remanentes fue de 10.7 por persona; el COP- D de 27, a expensas en su mayoría, del componente perdido; del total de prótesis encontradas el $63 \%$ estaba en mal estado, lo cual se relaciona con la alta prevalencia de estomatitis protésica; la necesidad protésica más importante fue la inferior .

Para el grupo comprendido entre las edades de 35 a 44 años se identificó una disminución importante de la cantidad de dientes perdidos, debido a que en el periodo de 1998 estuvo alrededor de 8 dientes y, el 2014, se identificó en 3.5 dientes perdidos(Ministerio de Salud y Protección social. \& Pontificia Universidad Javeriana, 2014).

\footnotetext{
Página 105 de 228

Rutty Adriana Abril Vivas. Odontóloga. Especialista Administración Hospitalaria. Auditoria de la Calidad. Nubia Astrid Duarte Pinzón. Enfermera. Especialista en Gerencia de Salud.
} 


\subsubsection{Lesiones Premalignas}

A pesar de que la prevalencia de lesiones pre malignas se consideró baja; las lesiones de la mucosa oral representan una gran importancia tanto clínicamente como epidemiológicamente y presentan un alto potencial para progresar a patologías complejas como el carcinoma escamo celular.

\subsubsection{Prevalencia de lesiones premalignas en Colombia.}

Las patologías de tejidos blandos fueron consideradas bajas en el estudio nacional de salud bucal de 1999 , pero era importante la presencia de procesos infecciosos de origen dental las leucoplasias y las hiperplasias tisulares producidas por la presencia de trauma protésico(Ministerio de Salud, 1999). Frente al aumento tisular se consideró asociado a prótesis desadaptadas y a otros hábitos; lo que indicaba la falta de control en la elaboración y uso de las rehabilitaciones así como la necesidad de fortalecer las acciones de atención al grupo de adultos mayores(Ministerio de Salud, 1999).

Los resultados registrados para la vigencia 2014 para Colombia correspondieron a el 0.10\% para leucoplasias; $0.14 \%$ para eritroplasias; $0.18 \%$ para queratosis actínica y $0.25 \%$ para lesiones palatinas del fumador invertido.

Página 106 de 228

Rutty Adriana Abril Vivas. Odontóloga. Especialista Administración Hospitalaria. Auditoria de la Calidad. Nubia Astrid Duarte Pinzón. Enfermera. Especialista en Gerencia de Salud. 
Resultaron relevantes las lesiones asociadas al uso de prótesis dentales removibles, al observar como resultado la prevalencia de aumento tisular en el $2.18 \%$ del total de la población referenciada: pero cuando se analizó en solo las personas con uso de prótesis, se encontró una distribución porcentual del $0.02 \%$ en grupos poblacionales de 20 a 34 años; un $0.30 \%$ para grupos de 35 a 44 años; un $3.6 \%$ de las personas entre 45 y 64 años y en el $10.55 \%$ en poblaciones de 65 a 79 años. Por otro lado la estomatitis subprotésica en la población de 20 a 79 años, se encontró en el $14.56 \%$ del total de la población y analizando solo las personas con uso de prótesis, se encontró una distribución porcentual del $53.06 \%$ en el grupo de 20 a 34 años; aumentando a $61.84 \% \%$ en las personas de 35 a 44 años, y en el $65.11 \%$ y $57.11 \%$ del grupo poblacional de 45 a 64 años y 65 a 79 años respectivamente, para llegar a que el $62.17 \%$ del total de personas que usan prótesis la presencia de estomatitis subprotésica (Ministerio de Salud y Protección social. \& Pontificia Universidad Javeriana, 2014)

Página 107 de 228

Rutty Adriana Abril Vivas. Odontóloga. Especialista Administración Hospitalaria. Auditoria de la Calidad. Nubia Astrid Duarte Pinzón. Enfermera. Especialista en Gerencia de Salud. 
llustración 35 Prevalencia de lesiones pre llustración 36 Prevalencia de lesiones asociadas malignas en la población de 20 a 79 años, al uso de prótesis según sexo en la población Colombia, 2013-2014. general. Colombia, 2013-2014.

\section{g}
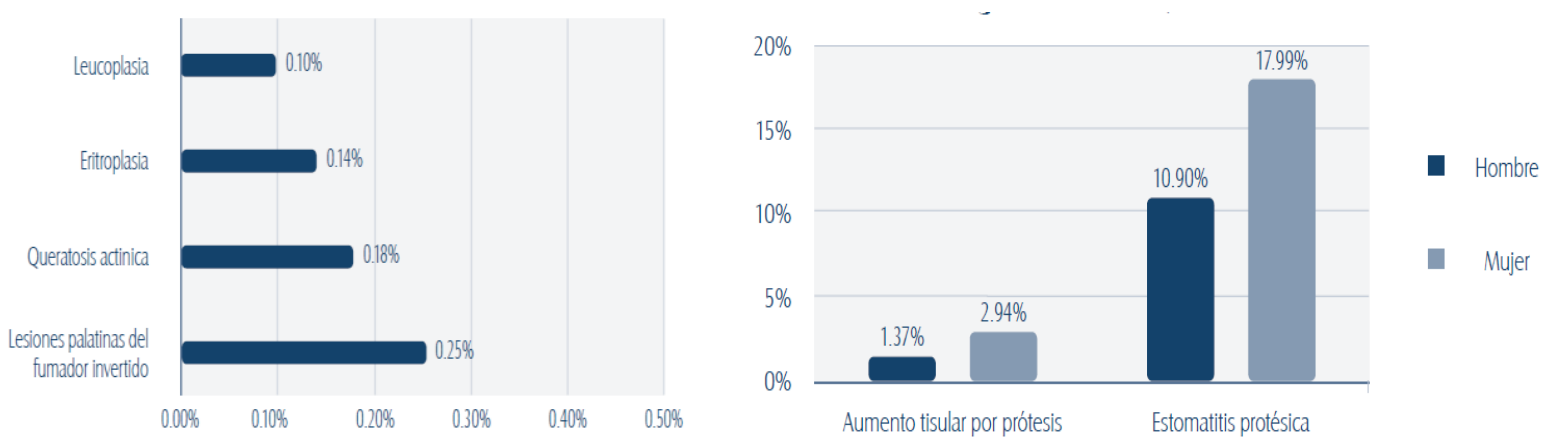

Fuente: IV -MPS, estimaciones UT SEI - PUJ CENDEX, 2013-2014

Análisis: a pesar de que el país cuenta con normatividad cumpliendo con los lineamientos de la OMS a través de una Política Pública frente al control de tabaquismo y la realización de acciones tanto a nivel individual como colectivo en el marco de la ley 1122 de 2007 se evidenció la prevalencia de lesiones pre malignas en la población de 20 a 79 años en el periodo $2013-2014$; de las cuales un 0,25\% correspondiente a lesiones palatinas del fumador invertido seguido de queratosis actínica en un 0,38\% a nivel nacional.

Página 108 de 228

Rutty Adriana Abril Vivas. Odontóloga. Especialista Administración Hospitalaria. Auditoria de la Calidad. Nubia Astrid Duarte Pinzón. Enfermera. Especialista en Gerencia de Salud. 
Según lo reportado por la ENSAB IV la población que presentó una mayor proporción con un $0,99 \%$ de lesiones palatinas no se encontraban aseguradas a algún régimen de afiliación lo que nos mostró la necesidad de incluir acciones dirigidas a esta problemática en la Política de Salud oral.

Frente al comportamiento distrital no fue posible la documentación de información estadística de la incidencia y prevalencia de estas patologías orales lo que impidió realizar un análisis comparativo para Bogotá.

En lo que respecta al resultado del aumento tisular por prótesis corresponde al $2.18 \%$ del total de la población, con prevalencia mayor en mujeres con una distribución porcentual del $2.94 \%$ y en hombres correspondió al $1.37 \%$, mientras que la estomatitis protésica correspondió en mayor proporción al sexo masculino con una distribución porcentual de 17.99\%. Estos resultados nos indicaban la necesidad de fortalecer en la política pública oral el control y la educación acerca de los factores de riesgo existentes con el fin de garantizar factores protectores que minimizaran la aparición de patologías de mayor complejidad en la cavidad oral y/ o detección en estadios tempranas lesiones malignas asociadas a síntomas y signos orales.

Página 109 de 228

Rutty Adriana Abril Vivas. Odontóloga. Especialista Administración Hospitalaria. Auditoria de la Calidad. Nubia Astrid Duarte Pinzón. Enfermera. Especialista en Gerencia de Salud. 
llustración 37 Prevalencia de lesiones llustración 38 Prevalencia de lesiones asociadas al uso de prótesis según régimen asociadas al uso de prótesis según grupos de afiliación en la población general. de edad en la población de 20 a 79 años. Colombia, 2013-2014.

Colombia, 2013-2014
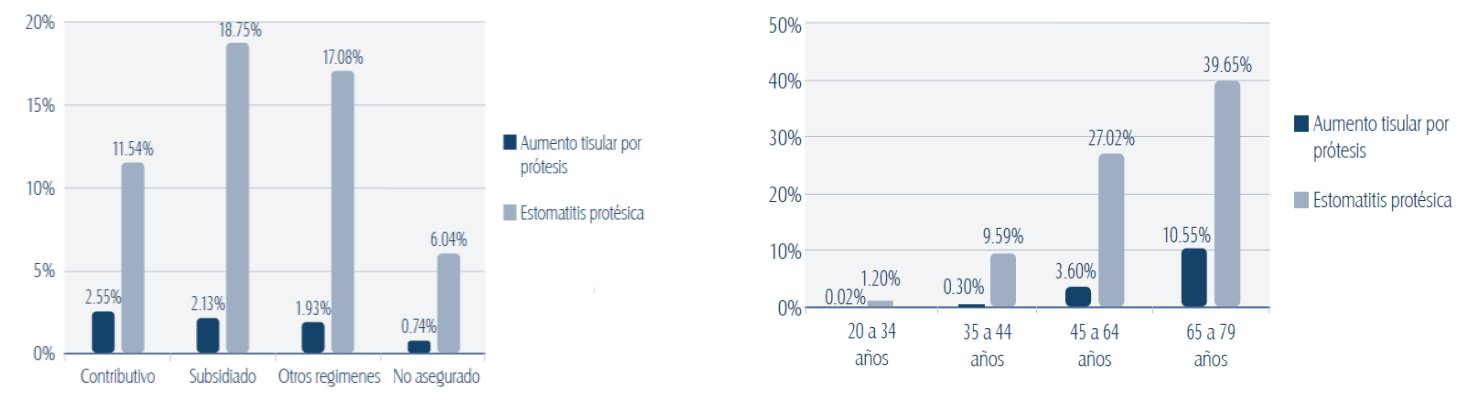

Fuente: IV -MPS, estimaciones UT SEI - PUJ CENDEX, 2013-2014

Análisis: en el grupo de 65 a 79 años se presentó mayor aumento tisular con 10.55\%; en lo que se refiere a la procedencia, la distribución fue similar para zona urbana con $2.05 \%$ y rural $2.61 \%$, capitales $2.76 \%$; frente a los regímenes de afiliación fue mayor en el contributivo con distribución porcentual $2.55 \%$, el subsidiado con $2.13 \%$, otros regímenes $1.93 \%$ y no asegurados el $0.74 \%$. 
La estomatitis subprotésica se presenta con mayor frecuencia en los regímenes subsidiado con $18.75 \%$ y otros regímenes con $17.08 \%$; ésta presentaba mayor prevalencia en usuarios de prótesis en las edades de 35 a 44 años con una distribución porcentual de 65.11\%; en un 64.32\% de las mujeres (Ministerio de Salud y Protección social. \& Pontificia Universidad Javeriana, 2014).

Ilustración 39 Prevalencia de lesiones pre malignas en la población de 20 a 79 años, Colombia, 2013-2014.

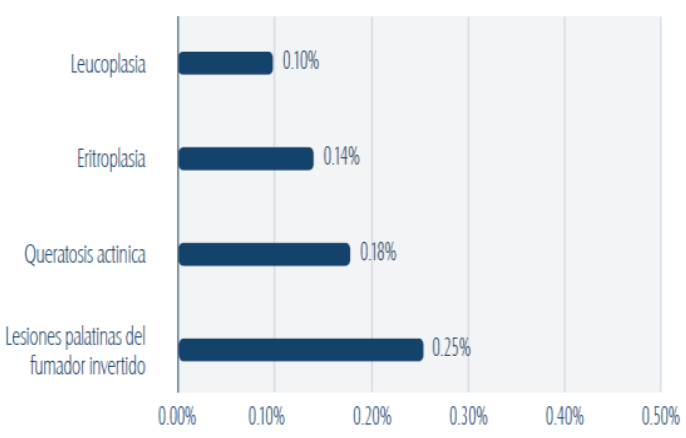

Fuente: IV -MPS, estimaciones UT SEI - PUJ CENDEX, 2013-2014
Ilustración 40 Prevalencia de lesiones asociadas al uso de prótesis según sexo en la población general. Colombia, 2013-2014.

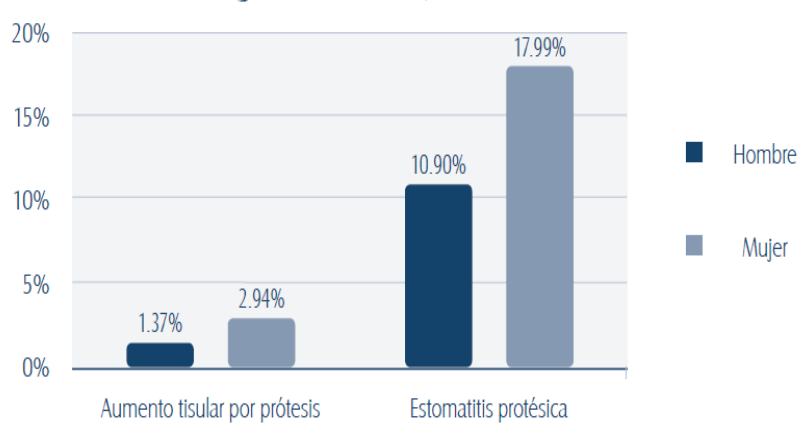

Resultados: se observó que las lesiones de mayor prevalencia correspondierón a las lesiones premalignas de fumador invertido.

La prevalencia con mayor distribución porcentual correspondió a estomatitis prótesica.

\subsubsection{Prevalencia de lesiones premalignas. Distrito Capital.}


Para Bogotá, según reporte de la ENSAB IV el comportamiento del aumento tisular generado por la presencia de prótesis frente a las demás regiones nacionales, es similar registrando un 2,66\% ocupando el segundo lugar después de la región Central con 2,74\%; la regiones de Orinoquía-Amazonía presentan un 1.98\%, región Atlántica un $1.96 \%$ región Oriental presenta $1.95 \%$; y región Pacífica registra $1.38 \%$, frente al comportamiento de la estomatitis sub-protésica Bogotá representa un $9.69 \%$, siendo las regiones del oriente y la central las de mayor distribución porcentual con $19.34 \%$ y 16.84\% respectivamente(Ministerio de Salud. Colombia, 2014) (Ministerio de Salud y Protección social. \& Pontificia Universidad Javeriana, 2014).

Las patologías de tejidos blandos se registraron con mayor frecuencia en las localidades de Usaquén con un $16 \%$ de casos, la localidad de Suba con 12,2 \%, Bosa con registro del $11 \%$ y los de menor registro reportado corresponde a las localidades de Sumapaz con $0,2 \%$ y Antonio Nariño y Teusaquillo con $0,1 \%$ (Secretaria Distrital de Salud de Bogotá et al., 2014)

A pesar de que se observó un porcentaje bajo de la presencia de lesiones pre malignas de la cavidad oral se puede considerar que pudiese existir un subregistro de estos eventos lo que hace necesario fortalecer la política pública de salud oral para detectar e intervenir estas patologías que pueden generar patologías de alto costo al no detectarse en estadios tempranos de la enfermedad.

Página 112 de 228

Rutty Adriana Abril Vivas. Odontóloga. Especialista Administración Hospitalaria. Auditoria de la Calidad. Nubia Astrid Duarte Pinzón. Enfermera. Especialista en Gerencia de Salud. 
No se encontraron documentados informes estadísticos para los periodos anteriores por lo cual no fue posible presentar tendencias de indicadores de estas lesiones a nivel nacional y distrital.

\subsubsection{Cáncer.}

La mayoría de los cánceres de cabeza y cuello inician en los tejidos que circunscriben la boca, nariz y la garganta e incluyen los cánceres de cavidad oral, de nariz, de senos paranasales, de glándulas salivares de garganta y de ganglios linfáticos(U.S. National Library of Medicine, 2015).

\subsubsection{Prevalencia de cáncer oral Colombia 2007-2011.}

Según reporte del Instituto nacional de cancerología para el año 2008 el cáncer de cabeza y cuello representó el $42 \%$ de los tejidos orales: lengua con un 13\%, labio representa el $11 \%$, piso de la boca $7 \%$ mucosa oral y encía $4 \%$ y paladar representa el $3 \%$. En cuanto a los maxilares los osteosarcomas equivalen al $20 \%$ de la totalidad de los sarcomas. La mayor incidencia se presentó en el sexo masculino en el rango de 10 y 20 años y de mayor incidencia en el maxilar inferior.

En Colombia, para el 2008, se reportaron 528 defunciones debido a cáncer oral, representando una tasa de 1,2 casos por cien mil habitantes. El 59,4\% de estas muertes

Página 113 de 228

Rutty Adriana Abril Vivas. Odontóloga. Especialista Administración Hospitalaria. Auditoria de la Calidad. Nubia Astrid Duarte Pinzón. Enfermera. Especialista en Gerencia de Salud. 
se presentaron en el género masculino, y en mujeres la tasa correspondió a 1,0 por cada 100.000 habitantes en una edad promedio de 67 años con un porcentaje de 62,9\%(Juan Carlos Uribe López, 2011)

llustración 41 Porcentaje de mortalidad llustración 42 Tasas de mortalidad específica por edad cáncer oral en el 2008. específicas por edad cáncer oral en el 2008. Colombia. Colombia.
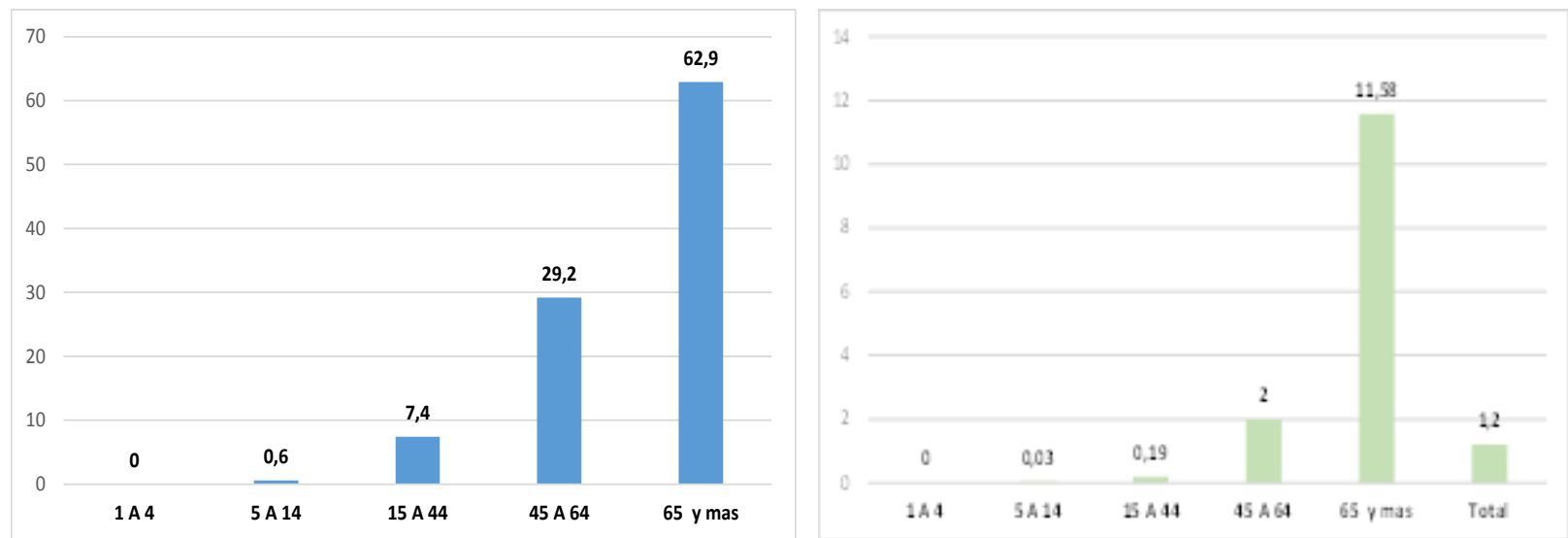

Fuente: Mortalidad en Colombia por cáncer oral en el 2008.I.N.C

Análisis: la edad promedio en que se presentaron las muertes por cáncer oral correspondió a los 67 años, el grupo etario con mayor número de defunciones correspondió a la edad de 67 y más años con un 62,9\%, lo que indica la necesidad de fortalecer las actividades tempranas en esta población.

\subsubsection{Incidencia, mortalidad y prevalencia de cáncer por régimen de afiliación y sexo Colombia- Bogotá 2007-2011.}


A continuación se presenta comparativo de la incidencia, mortalidad y prevalencia de cáncer por sexo (Constanza Pardo Ramos \& , Ricardo Cendales Duarte, 2015):

Tabla 4 Comparativo de la incidencia, mortalidad y prevalencia de cáncer por sexo Colombia y Bogotá vigencia 2007 a 2011.

Incidencia, mortalidad y prevalencia de cáncer Incidencia , mortalidad y prevalencia de cáncer , , hombres, Colombia ,2007-2011 mujeres, Colombia ,2007-2011

\begin{tabular}{|c|c|c|c|c|c|c|c|c|}
\hline \multicolumn{3}{|c|}{$\begin{array}{c}\text { Incidencia } \\
\text { estimada anual }\end{array}$} & \multicolumn{3}{|c|}{$\begin{array}{c}\text { Mortalidad } \\
\text { observada } \\
\text { anual }\end{array}$} & \multicolumn{3}{|c|}{$\begin{array}{c}\text { Prevalencia } \\
\text { estimada } \\
\text { (casos) }\end{array}$} \\
\hline $\begin{array}{c}\text { Caso } \\
5\end{array}$ & $\begin{array}{c}\text { Tasa } \\
\text { crud } \\
\text { a }\end{array}$ & $\begin{array}{c}\text { TA } \\
E\end{array}$ & $\begin{array}{c}\text { Muerte } \\
\text { s }\end{array}$ & $\begin{array}{c}\text { Tasa } \\
\text { crud } \\
\text { a }\end{array}$ & $\begin{array}{c}\text { TA } \\
E\end{array}$ & $\begin{array}{c}1 \\
\text { añ } \\
0\end{array}$ & $\begin{array}{c}3 \\
\text { años }\end{array}$ & $\begin{array}{c}5 \\
\text { años }\end{array}$ \\
\hline 787 & 3,5 & 4 & 295 & 1,3 & 1,5 & $\begin{array}{c}53 \\
6\end{array}$ & $\begin{array}{c}1.35 \\
4\end{array}$ & $\begin{array}{c}2.02 \\
0\end{array}$ \\
\hline
\end{tabular}

\begin{tabular}{|c|c|c|c|c|c|c|c|c|}
\hline \multicolumn{2}{|c|}{$\begin{array}{c}\text { Incidencia } \\
\text { estimada anual }\end{array}$} & \multicolumn{3}{c|}{$\begin{array}{c}\text { Mortalidad } \\
\text { observada } \\
\text { anual }\end{array}$} & \multicolumn{2}{c|}{$\begin{array}{c}\text { Prevalencia estimada } \\
\text { (casos) }\end{array}$} \\
\hline & Tasa & & & Tasa & & & & \\
Casos & $\begin{array}{c}\text { crud } \\
\text { a }\end{array}$ & $\begin{array}{c}\text { TA } \\
\text { E }\end{array}$ & $\begin{array}{c}\text { Muerte } \\
5\end{array}$ & $\begin{array}{c}\text { crud } \\
\text { a }\end{array}$ & $\begin{array}{c}\text { TA } \\
\mathrm{E}\end{array}$ & 1 año & $\begin{array}{c}3 \\
\text { años }\end{array}$ & $\begin{array}{c}5 \\
\text { años }\end{array}$ \\
\hline 707 & 3,1 & 3,1 & 206 & 0,9 & 0,9 & 475 & $\begin{array}{c}1.20 \\
8\end{array}$ & $\begin{array}{c}1.80 \\
4\end{array}$ \\
\hline
\end{tabular}

Incidencia, mortalidad y prevalencia de cáncer Incidencia, mortalidad y prevalencia de cáncer , mujeres, Bogotá ,2007-2011 , hombres, Bogotá ,2007-2011

\begin{tabular}{|c|c|c|c|c|c|c|c|c|}
\hline \multicolumn{3}{|c|}{$\begin{array}{c}\text { Incidencia } \\
\text { estimada anual }\end{array}$} & \multicolumn{3}{|c|}{$\begin{array}{c}\text { Mortalidad } \\
\text { observada anual }\end{array}$} & \multicolumn{3}{|c|}{$\begin{array}{c}\text { Prevalencia } \\
\text { estimada } \\
\text { (casos) }\end{array}$} \\
\hline $\begin{array}{c}\text { Caso } \\
s\end{array}$ & $\begin{array}{l}\text { Tasa } \\
\text { crud } \\
\text { a }\end{array}$ & $\begin{array}{c}\text { TA } \\
E\end{array}$ & $\begin{array}{c}\text { Muerte } \\
\text { s }\end{array}$ & $\begin{array}{l}\text { Tasa } \\
\text { crud } \\
\text { a }\end{array}$ & $\begin{array}{c}\text { TA } \\
E \\
\end{array}$ & $\begin{array}{c}1 \\
\text { año }\end{array}$ & $\begin{array}{c}3 \\
\text { año } \\
5\end{array}$ & $\begin{array}{c}5 \\
\text { año } \\
5\end{array}$ \\
\hline 119 & 3,4 & 4 & 45 & 1,3 & 1,5 & 80 & 204 & 305 \\
\hline
\end{tabular}

\begin{tabular}{|c|c|c|c|c|c|c|c|c|}
\hline $\begin{array}{c}\text { Incidencia estimada } \\
\text { anual }\end{array}$ & \multicolumn{3}{|c|}{$\begin{array}{c}\text { Mortalidad } \\
\text { observada anual }\end{array}$} & \multicolumn{3}{c|}{$\begin{array}{c}\text { Prevalencia estimada } \\
\text { (casos) }\end{array}$} \\
\hline & Tasa & & & Tasa & & & & \\
Casos & $\begin{array}{c}\text { crud } \\
\text { a }\end{array}$ & $\begin{array}{c}\text { TA } \\
\text { E }\end{array}$ & Muertes & $\begin{array}{c}\text { crud } \\
\text { a }\end{array}$ & $\begin{array}{c}\text { TA } \\
\text { E }\end{array}$ & 1 año & $\begin{array}{c}5 \\
\text { año } \\
\text { año } \\
\text { s }\end{array}$ \\
\hline 109 & 2,9 & 2,8 & 32 & 0,9 & 0,8 & 74 & 189 & 282 \\
\hline
\end{tabular}

Fuente: INC, 2007-2011

Análisis: Bogotá para el periodo 2007-2011 presentó una incidencia estimada anual de 228 casos de cáncer oral y faringe que correspondía al 15\% de la totalidad de 1.794 casos presentados a nivel nacional y 72 muertes que correspondían al $14 \%$ de la 
mortalidad por cáncer frente a la mortalidad nacional; presentándose en mayor proporción en hombres, situación muy similar a los reportes para Colombia.

\subsubsection{Mortalidad por cáncer oral según regímenes de afiliación. Colombia} 2008.

El mayor porcentaje de muertes debido al cáncer oral pertenece al régimen subsidiado con una distribución porcentual del $45 \%$, y para el contributivo una distribución del $40 \%$ para vinculados se presentó en un 15\%, predominando el nivel socio-económico de estratos 1, 2 y 3(Juan Carlos Uribe López, 2011).

Ilustración 43 Mortalidad por cáncer oral según regímenes de afiliación. Colombia. 2008.

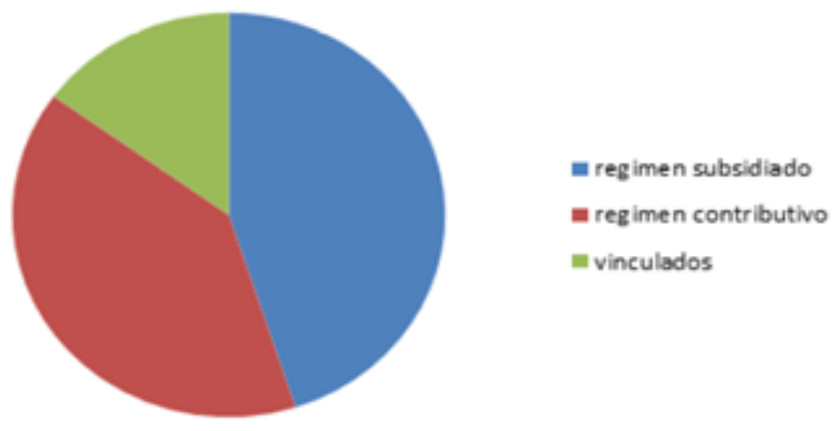

Fuente: Mortalidad en Colombia por cáncer oral en el 2008.I.N.C

Análisis: la población con mayor mortalidad de cáncer oral a nivel nacional pertenecía al régimen subsidiado, seguido del régimen contributivo, sin embargo, al unificar el régimen subsidiado con el vinculado generó un aumento significativo de mortalidad del $60 \%$ de la 
población pobre y vulnerable lo que indicaba la necesidad de incorporar acciones en la política de salud oral frente a esta problemática.

Los departamentos de Antioquia y Bogotá fueron las regiones que presentaron el mayor porcentaje de muertes por cáncer oral con una distribución porcentual de 15,7\% y 13,8\% respectivamente en el año 2008(Juan Carlos Uribe López, 2011).

El Ministerio de Salud y el Instituto Nacional de Cancerología a partir del 2012 plantearon intervenciones a través del Plan Decenal para el control integral del cáncer (Ministerio de Salud . \& Protección Social - Instituto Nacional de Cancerología, ESE., 2012) con el fin de minimizar la incidencia de esta patología; y aunque el cáncer oral no se encontró dentro de los cánceres de mayor incidencia en la población, las manifestaciones orales si correspondieron a un signo de gran importancia en la detección temprana de diferentes tipos de cáncer. No se evidenció en la política pública oral la inclusión de acciones encaminadas para este fin.

\subsubsection{Fluorosis dental.}

Para la evaluación de la fluorosis se utilizó la Escala de Dean la cual evalúa la presencia de estados de fluorosis leves y cambios de color en el esmalte dental con los siguientes ponderaciones normal 0.5; cuestionable 1.0; muy leve 2.0; leve, 3.0 y moderado, 4.0 (Ana Cristina Mafla, Doris Lucía Córdoba Urbano, \& Maritza Natalia Rojas Caicedo, 2014).

Página 117 de 228

Rutty Adriana Abril Vivas. Odontóloga. Especialista Administración Hospitalaria. Auditoria de la Calidad. Nubia Astrid Duarte Pinzón. Enfermera. Especialista en Gerencia de Salud. 
La prevalencia de fluorosis a nivel nacional según información de la ENSAB III, se presentó en el $11,5 \%$ de niños y jóvenes de 6 a 19 años registrados en niveles de dudoso y leve(Ministerio de la Protección social, 2005).

Para el año 1999 para el nivel nacional según registro de la ENSAB III la prevalencia total de fluorosis en Bogotá fue de 22.9\% para las edades de 6, 7,12 años. Por grados de severidad, la prevalencia de fluorosis leve fue de $18.4 \%$ y la fluorosis moderada a severa fue de 4.5\%. En las edades de 15-19 años la fluorosis leve se presentó en 3\% de la población y la moderada a severa en $0.5 \%$ para un total general de 3,5 .

En el informe SISVESO de 2009 se evidenció una mayor prevalencia de fluorosis en la juventud y la infancia con un $13,4 \%$ y $25,4 \%$ respectivamente(Secretaria Distrital de Salud, 2011b).

Según la encuesta nacional de salud bucal para el 2014 la fluorosis se incrementó, aunque de forma no sobresaliente, en general los grupos poblacionales que mayor porcentaje presentan corresponden a los comprendidos entre los rangos de 5 a 12 años del régimen subsidiado. (Ministerio de Salud y Protección social. \& Pontificia Universidad Javeriana, 2014).

Para el distrito capital en el año 2014 los niños con dentición mixta el rango se encontraron en $22,96 \%$ y para los menores de 5 años se encontraron en $5,68 \%$ presentando la mayor prevalencia.

Página 118 de 228

Rutty Adriana Abril Vivas. Odontóloga. Especialista Administración Hospitalaria. Auditoria de la Calidad. Nubia Astrid Duarte Pinzón. Enfermera. Especialista en Gerencia de Salud. 
No fue posible la comparación de la tendencia del indicador de fluorosis debido a que los estudios existentes contemplan variables y muestra poblacional diferentes.

Ilustración 44 Presencia de fluorosis dental por grado de severidad en la población de 5 a 19 años. Colombia.

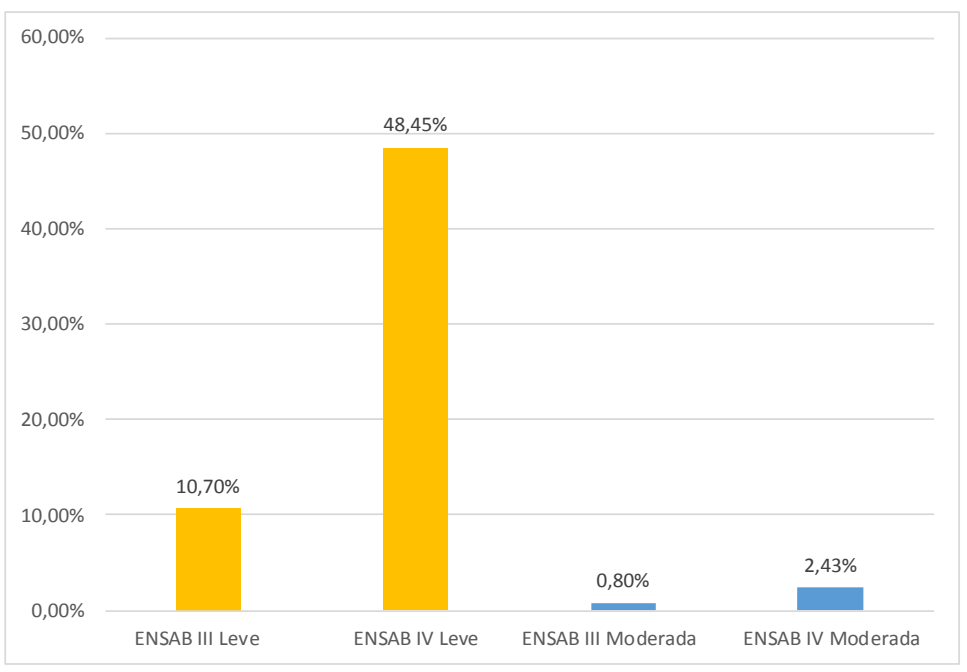

Fuente: ENSAB III ENSAB IV

Análisis: se evidenció que el grado de severidad leve y moderada de fluorosis presentó aumento en el año 1999 y 2014.

\subsubsection{1 Índice Comunitario de Fluorosis de Dean - ICF Colombia-ENSAB IV} 2014.

La prevalencia de fluorosis dental, se reportó en el $8.43 \%$ de la población de 5 años (dientes temporales), a los 12 años es de 62.15\% pasando a los 15 años a un 56.05\%, 
y el Índice Comunitario de fluorosis (ICF) se encontró para la población de 12 años en un $\quad 0.90 \%$ y en un $0.84 \%$ para la población de 15 años; considerándose un problema leve de salud pública, el cual requiere intervención en este grupo de edad (Ministerio de Salud. Colombia, 2014).

llustración 45 Índice Comunitario de Fluorosis - ICF por edad. Colombia 2013.2014.

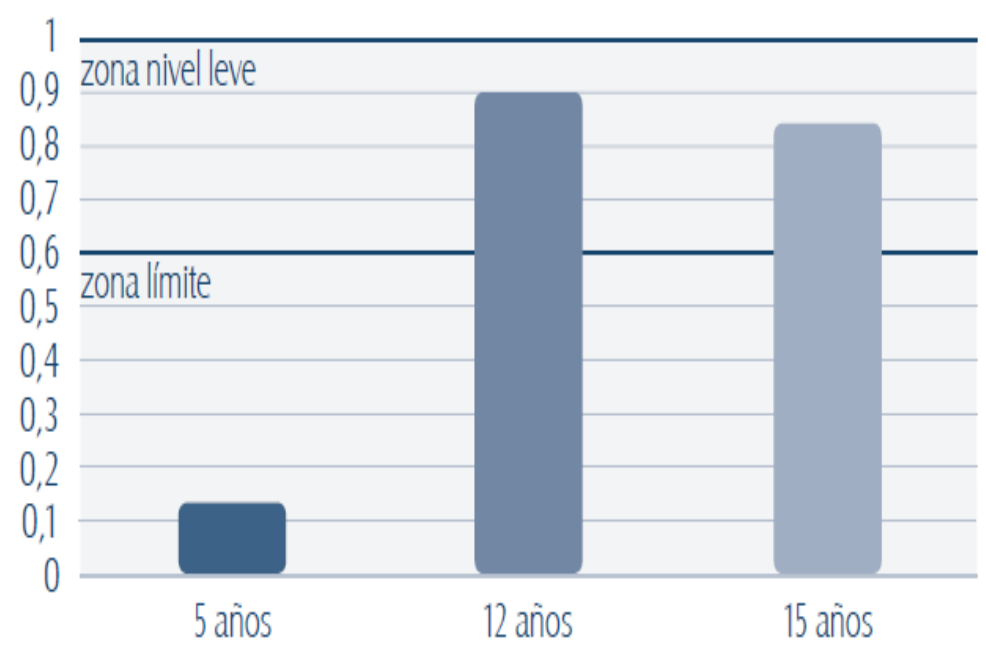

Fuente: IV -MPS, estimaciones UT SEI - PUJ CENDEX, 2013-2014

Análisis: en general en la población se encontró en un índice comunitario de fluorosis leve, presentándose mayor incidencia en la población de 12 años, lo que indica la necesidad de realizar seguimiento a las actividades de aplicaciones de flúor e ingesta de esta desde la misma política para control de factores de riesgo teniendo en cuenta que este grupo poblacional se encuentra priorizado en la misma. 


\subsubsection{2 Índice Comunitario de Fluorosis - ICF por región. Bogotá. Colombia}

\subsection{4.}

El distrito capital es la región que presenta la mayor proporción de prevalencia, seguida de la región Oriental (5.57\%) y Central (4.50\%), con un 5.68\%, considerándose como un problema leve de salud pública (Ministerio de Salud y Protección social. \& Pontificia Universidad Javeriana, 2014).

Ilustración 46 Índice Comunitario de Fluorosis - ICF por región. Bogotá. Colombia 2013.2014.

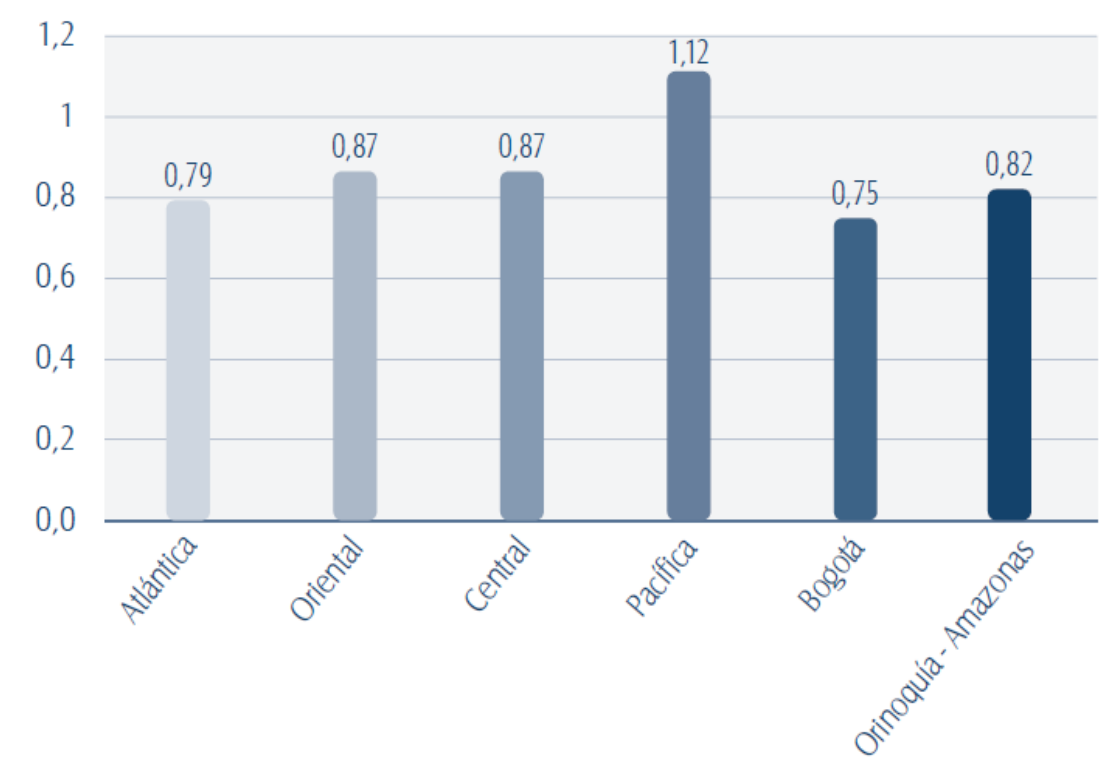

Fuente: IV -MPS, estimaciones UT SEI - PUJ CENDEX, 2013-2014 
Análisis: Bogotá es la región que menor Índice Comunitario de fluorosis presentó con un valor de $0,75 \%$, encontrándose mayor porcentaje en la zona Pacífica, central y oriental, sin embargo, Bogotá es la región que presentó mayor prevalencia de fluorosis (5.68\%).

No se encontró documentación para el periodo del indicador de índice comunitario de fluorosis para Bogotá en estudios preliminares en comparativo ENSABIII - ENSABIV

No se cuenta con información estadística documentada para el periodo comprendido entre 1999 al 2012 para el distrito capital sin embargo se puede considerar una tendencia similar a la nacional.

\subsubsection{Consolidados eventos de salud oral e indicadores diferentes fuentes.}

Tabla 5 Comparativo consolidados indicadores de estado de salud oral menores 5 a 12años Colombia- Bogotá ENSAB III 1998.

\begin{tabular}{|c|c|c|}
\hline & HACIONAL & BOGOTA D.C. \\
\hline Porcentaje de niños con caries activa en dentición temporal alos 5 años & $54,8 \%$ & $59,3 \%$ \\
\hline Promedio de dientes cariados, entraidos y obturados por caries en dertición temporal a los 5 años & 3,0 & 3,9 \\
\hline Parcentaje de niños que han tenido àquna vez caries en la dertición permanente & $\approx, 7 \%$ & $90,7 \%$ \\
\hline Porcentaje de niños con caries activa en dentición permanente & $65,3 \%$ & $68,1 \%$ \\
\hline Promedio de dientes cariados, chturados y perdiclos por caries en dentición pemnanerte a los 12 an̂́os & 2,3 & 3,1 \\
\hline Porcentaje de perscnas sanas periodortalmente & $7,6 \%$ & $5,0 \%$ \\
\hline Parcentaje de perscnas que necesitan tratanierto periodonta (higjene oral ydetartraje) & $83,6 \%$ & $86,5 \%$ \\
\hline Porcentaje de niños y addiescentes con fluorosis muy leve a leve & $10,7 \%$ & $9,3 \%$ \\
\hline Porcentaje de niños y addescentes con fluorosis moderada a severa & $0,8 \%$ & $2,2 \%$ \\
\hline
\end{tabular}

Fuente: ENSAB III (1998)

Análisis: se observó que el comportamiento del distrito capital se encuentra por encima del promedio nacional en los indicadores de caries, cop-d y fluorosis en menores de 5 a 12 años. 
Con respecto al índice de COP la población adulta es la que en mayor porcentaje presenta antecedentes de caries a través del índice COP y para cada uno de sus componentes; los grupos de edad de 35 a 44 demostraron una disminución en el número de dientes perdidos pasando de 8 dientes en 1999 a 3.5 dientes, sin embargo se siguen presentando debido a la baja oportunidad, resolutividad y efectividad de las acciones, incrementando el edentulismo la necesidad de utilizar, lesiones de tejidos blandos prótesis y discapacidad afectando la calidad de vida(Ministerio de Salud y Protección social. \& Pontificia Universidad Javeriana, 2014) .

Ilustración 47 Comparativo Índice COP dentición permanente 1977-80, 1998, 2014 por grupo etario. Colombia.

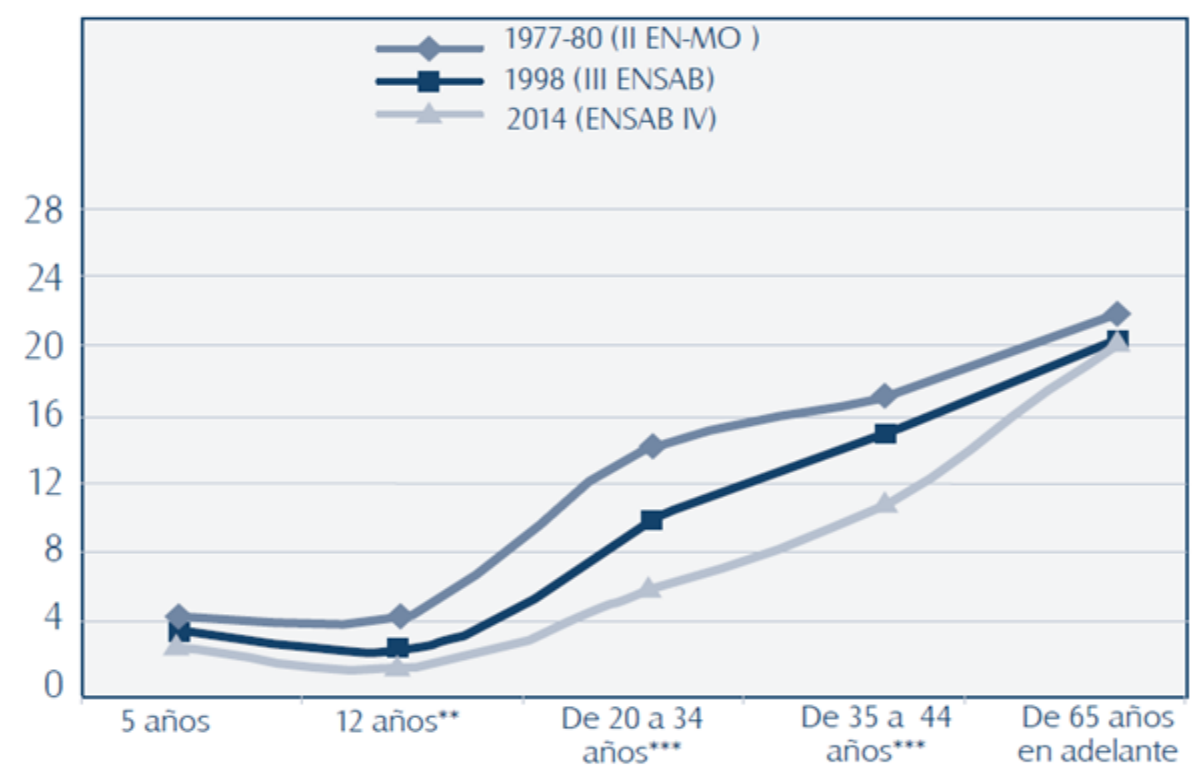

Página 123 de 228

Rutty Adriana Abril Vivas. Odontóloga. Especialista Administración Hospitalaria. Auditoria de la Calidad. Nubia Astrid Duarte Pinzón. Enfermera. Especialista en Gerencia de Salud. 
Resultados: al realizar comparación de los diferentes estudios realizados en el país y teniendo en cuenta la diferencias en las muestras tomadas para cada estudio y los diferentes métodos aplicados se evidenció la reducción de población con prevalencia de eventos orales.

\section{Ilustración 48 Comparativo consolidados indicadores de salud oral ENSAB III- ENSAB IV población 5 años y adolescentes Bogotá.}

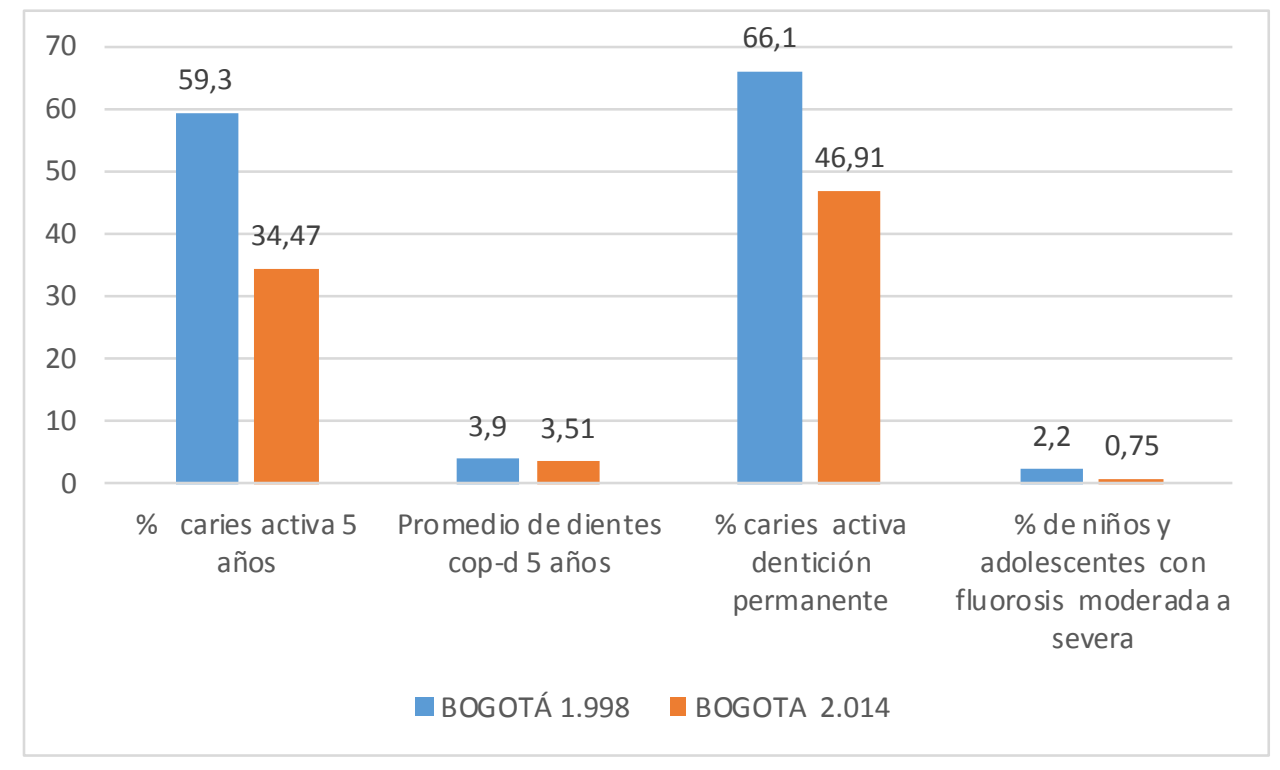

Fuente: ENSAB III ENSAB IV

Análisis: se evidenció disminución de los indicadores de caries, cop-d y fluorosis en niños de 5 años y adolescentes en el año 2014 frente al año 1999. 
Ilustración 49 Consolidado de la prevalencia por regiones de la salud oral. ENSAB IV 2014.Colombia. Bogotá.

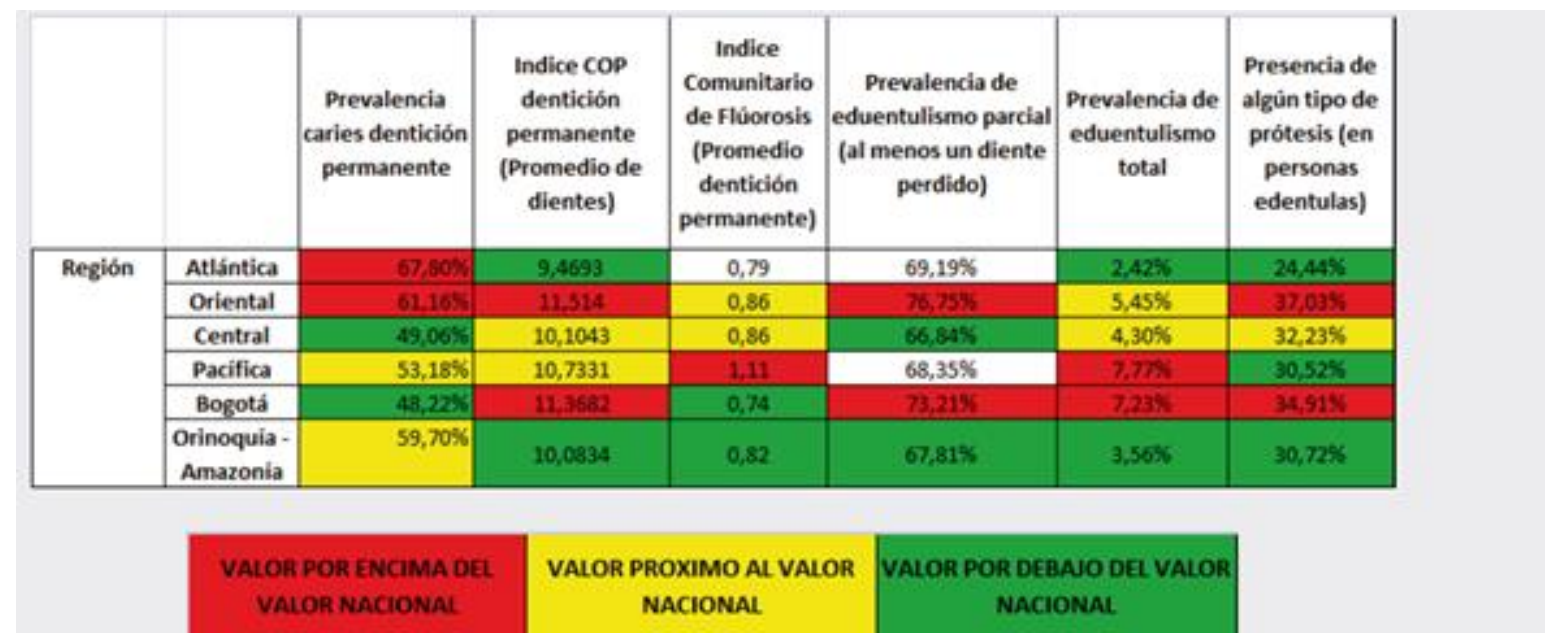

Fuente: ENSAB IV - MSPS, estimaciones UT SEI - PUJ Cendex, 2013-2014

Análisis: Bogotá presentó un 48,22\% de prevalencia de caries y un $0,74 \%$ de índice comunitario de fluorosis, ubicándose por debajo del valor promedio nacional ; el índice COP en dentición permanente y la prevalencia de edentulismo tanto parcial como total con presencia de prótesis se encuentran por encima del promedio nacional. A pesar de contar con una política pública oral con acciones definidas en el Distrito Capital es necesaria la revisión, análisis seguimiento y/ o reorientación de esta para garantizar una disminución del valor de los indicadores que aseguren la disminución de eventos del sistema estomatognático.

Ilustración 50 Consolidado prevalencia eventos salud oral por edades. Colombia 2014. 

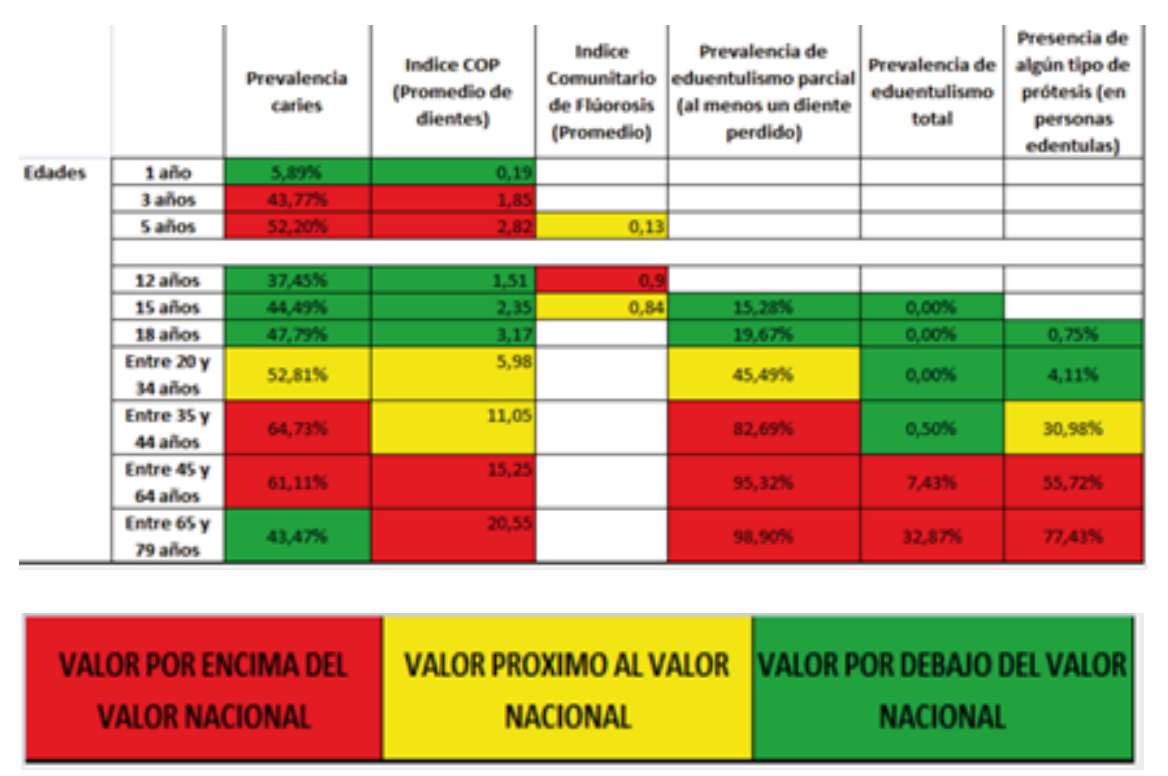

Fuente: IV - MSPS, estimaciones UT SEI - PUJ Cendex, 2013-2014

Análisis: las edades donde se concentraron cifras por encima del valor nacional frente a la prevalencia de caries son los grupos de edad de 3 a 5 años y de 35 a 64 años. Referente a los valores más altos por evento, llama la atención el promedio de índice comunitario de fluorosis a los 12 años, la prevalencia de edentulismo parcial entre 35 y 79 años, edentulismo total en el grupo de 45 a 79 años y la presencia de prótesis de 45 a 79 años. Se observa la necesidad de incluir en la política acciones para el grupo de edad de adultos y adultos mayores, así como el grupo poblacional de 3 a 5 años en Bogotá, ya que se encontraron por encima del promedio nacional. 
La siguiente información fue analizada a partir de los datos registrados del perfil epidemiológico realizado por la Secretaria distrital de salud de Bogotá a la población de vinculados desplazados, subsidiados:

Ilustración 51 Consolidado primeras causas de atención en salud oral, vinculados, desplazados, subsidiados. Bogotá 2011-2012.

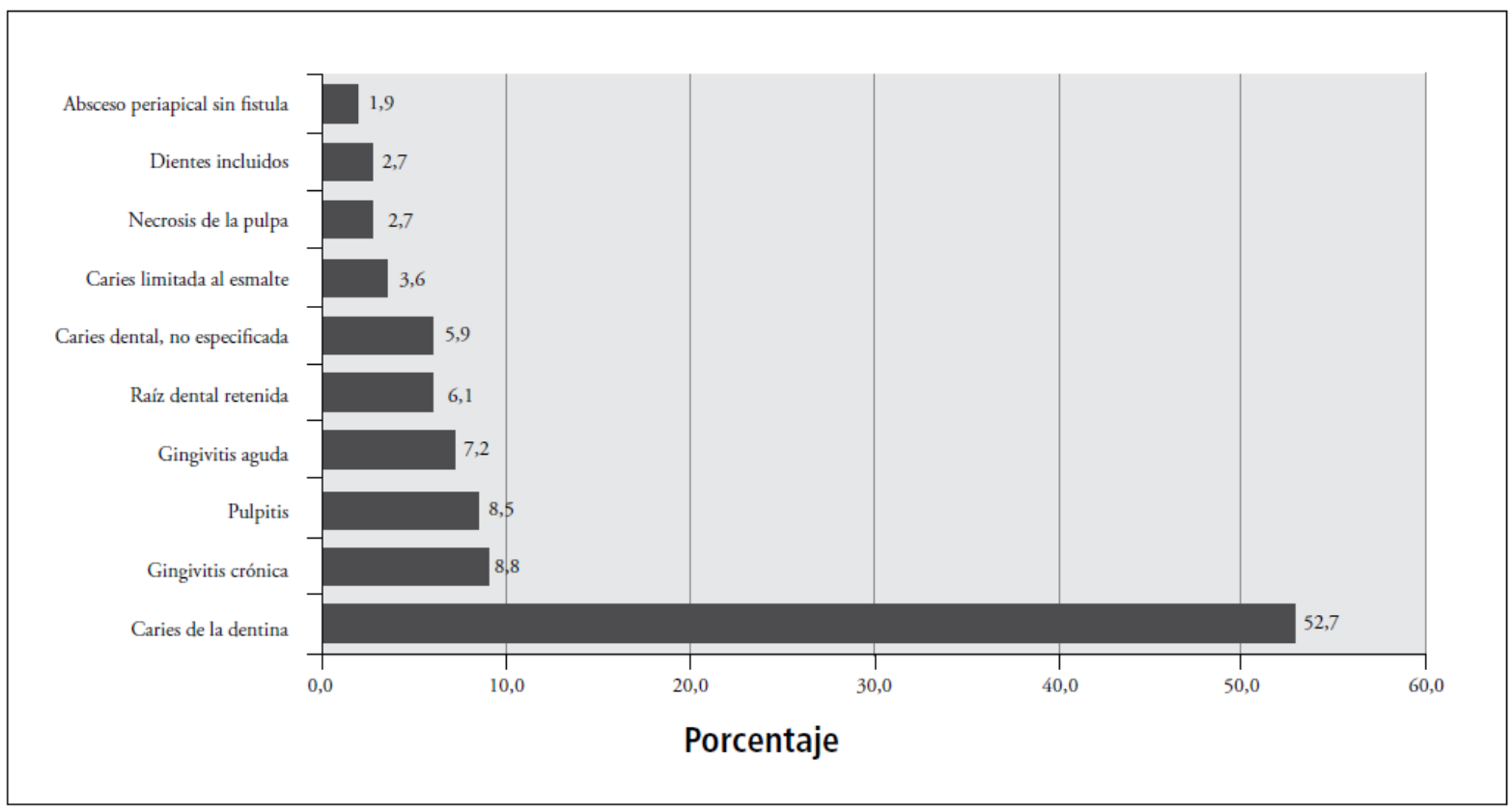

Fuente: Dirección de planeación y sistemas RIPS 2006-2012. Reporte 2013

Análisis: para la población vinculada, desplazada y subsidiada no POSS en Bogotá las primeras causas de consulta correspondieron a caries $52.7 \%$ y gingivitis $8.8 \%$ similar al diagnóstico nacional. 
Ilustración 52 Consolidado de diagnósticos principales de consulta de la población caracterizada por salud a su casa (PIC) según grupo de edad. Bogotá D.C., 2011-2012.

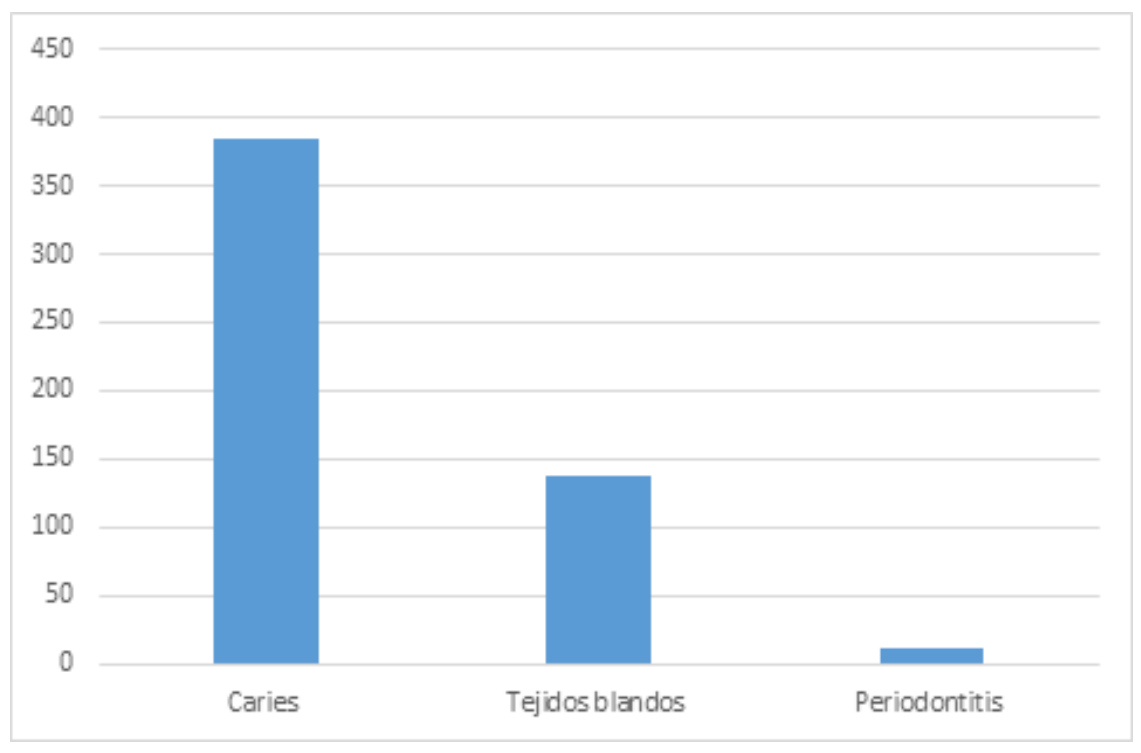

Fuente: Dirección de planeación y sistemas RIPS 2006-2012. Fichas de caracterización de APS -Ficha salud oral. Información preliminar

Análisis: los principales diagnósticos realizados por el plan de intervenciones colectivas mediante la estrategia de salud a su casa correspondieron a las enfermedades de los tejidos duros con 367 casos que corresponde al $47.6 \%$ seguidos de las patologías de los tejidos blandos con 137 casos que corresponde al $17.7 \%$.

Frente al tema de $\mathrm{VIH}$ / sida para el año 2013 se reportaron 17,4 casos de $\mathrm{VIH} /$ sida por 100.000 habitantes, después del 2008 la tasa de incidencia de VIH/sida en hombres pasó de 16,7 a 25,6 casos por 100.000 en 2013. Mientras que, la tasa de incidencia de $\mathrm{VIH} /$ sida en mujeres se mantuvo constante en 9,0 casos por cada 100.000 (Ministerio de Salud y Protección Social, 2014) 
De acuerdo con los datos de la cuenta de alto costo, a 31 de enero de 2013, las prevalencias en VIH más altas en población de 15 a 49 años por ciudades capitales fueron Medellín (0,34\%), Cali $(0,30 \%)$, Pereira $(0,28 \%)$, Cúcuta $(0,27 \%)$, Montería $(0,26 \%)$, Barranquilla y Manizales $(0,25 \%)$, Bogotá y Villavicencio $(0,24 \%)$ y Armenia y Bucaramanga $(0,22 \%)$, concentrando en estas 11 ciudades el $63 \%$ de los casos reportados (Fondo Colombiano de enfermedades de alto costo, 2014)

En relación a la discapacidad en Colombia, ésta es una condición que no se aborda desde ninguna perspectiva en las políticas de salud oral del Distrito. Esto es un aspecto importante, ya que en el 2014, el 50,38\% (564.931) de las personas registradas presentaron alteraciones del movimiento del cuerpo, manos, brazos, piernas; el $41,84 \%$ (469.180) tiene discapacidad del sistema nervioso y el 39,13\% (438.711) discapacidad de los ojos(Ministerio de Salud y Protección Social, 2014)., lo que indica que éste grupo poblacional requiere orientación diferencial en las políticas que supla sus necesidades funcionales en pro de la garantía de su derecho a la salud oral.

En lo referente a indicadores de tratamientos terminados en odontología no se evidencia información estadística de la población en general ni para la que padece de enfermedades crónicas ni con algún tipo de discapacidad por lo tanto no fue posible realizar revisión ni análisis.

Página 129 de 228

Rutty Adriana Abril Vivas. Odontóloga. Especialista Administración Hospitalaria. Auditoria de la Calidad. Nubia Astrid Duarte Pinzón. Enfermera. Especialista en Gerencia de Salud. 
5 EVOLUCION DE LOS INDICADORES DE COBERTURA EN SALUD BUCODENTAL DE LA POBLACION Y DETERMINACION DE LAS NECESIDADES DE SALUD ORAL EN TERMINOS DEL PERFIL EPIDEMIOLOGICO ACTUALIZADO EN LA POBLACION DEL DISTRITO.-

Los indicadores de cobertura de los servicios de salud oral miden la atención recibida de las necesidades sentidas de la población. En el presente estudio se tuvieron en cuenta aspectos relacionados con los habitantes del distrito, en lo referente a sus características, la georreferenciación, así como la oferta y demanda institucional entre otros.

\subsection{Demografía.}

Para Colombia y el distrito las tendencias esperadas dentro del proceso de transición demográfica y epidemiológica, han determinado descensos en la tasa global de fecundidad y en las tasas de mortalidad infantil así incremento en las esperanzas de vida y cambios en las probabilidades de sobrevivencia, entre otros (Departamento Administrativo Nacional de Estadística .DANE, 2009).

El Departamento Administrativo Nacional de Estadísticas DANE para el año 2005, registro 41.468.384 habitantes a nivel nacional con proyección al año 2010 de 45.508.205 habitantes en Colombia a nivel nacional. La población de Bogotá D.C. pasó de 5.699 .655 personas en 1995 a 6.840 .116 en el 2005; se proyectaron 7.363 .782 personas, para el 2010 y una población de 7.878 .783 para el 2015. Para la vigencia de 2005 la localidad

Página 130 de 228

Rutty Adriana Abril Vivas. Odontóloga. Especialista Administración Hospitalaria. Auditoria de la Calidad. Nubia Astrid Duarte Pinzón. Enfermera. Especialista en Gerencia de Salud. 
de mayor volumen poblacional fue Kennedy con 951.073 personas y la de menor fue Sumapaz con 5.792 habitantes (Secretaria Distrital de Salud de Bogotá et al., 2014).

De acuerdo con la distribución de la población por localidades se observó que la mayor cantidad de habitantes se concentran en: Suba, Kennedy, Engativá, Ciudad Bolívar y Bosa, las cuales albergan el $56 \%$ del total de Bogotá. Las localidades de Sumapaz y la Candelaria tienen la menor cantidad de personas de la ciudad.

El Distrito capital para el 2013, llegó a los 7.674.366 habitantes, representando un 16,29\% del total de la población nacional. Su tasa de crecimiento promedio anual fue estimada en $1,14 \%$ para para los años $2009-2013$.

Referente a la distribución porcentual de acuerdo a género y edad; el cálculo realizado correspondió a $51,70 \%$ la población femenina y 48,30\% la población masculina. Del total de la población del distrito los menores de 15 años correspondieron al 24\%, la población económicamente activa (15 y 64 años) represento el $64 \%$ de la población y el grupo de edad de 65 años correspondió al 7\%. Según proyecciones, se determinó que Bogotá cuenta con un constante crecimiento de población adulta y adulta mayor y una disminución de la población infantil y la población de adolescentes comportamiento similar de la población nacional. En lo que se refiere a la distribución poblacional, el grupo etario de mayor concentración correspondió a los pertenecientes a las edades de 15 a 24 años siendo la población masculina los de mayor densidad, en cuanto a las mujeres 
su mayor concentración correspondió a las edades de 25 a 34 años representando el $42 \%$ del total de la población; por otro lado los menores de 25 años en un alto porcentaje corresponde a hombres, tendencia invertida para los mayores de esta edad (Secretaria de educación, 2013).

llustración 53 Pirámide poblacional de Bogotá año 2013.Bogotá, D.C.

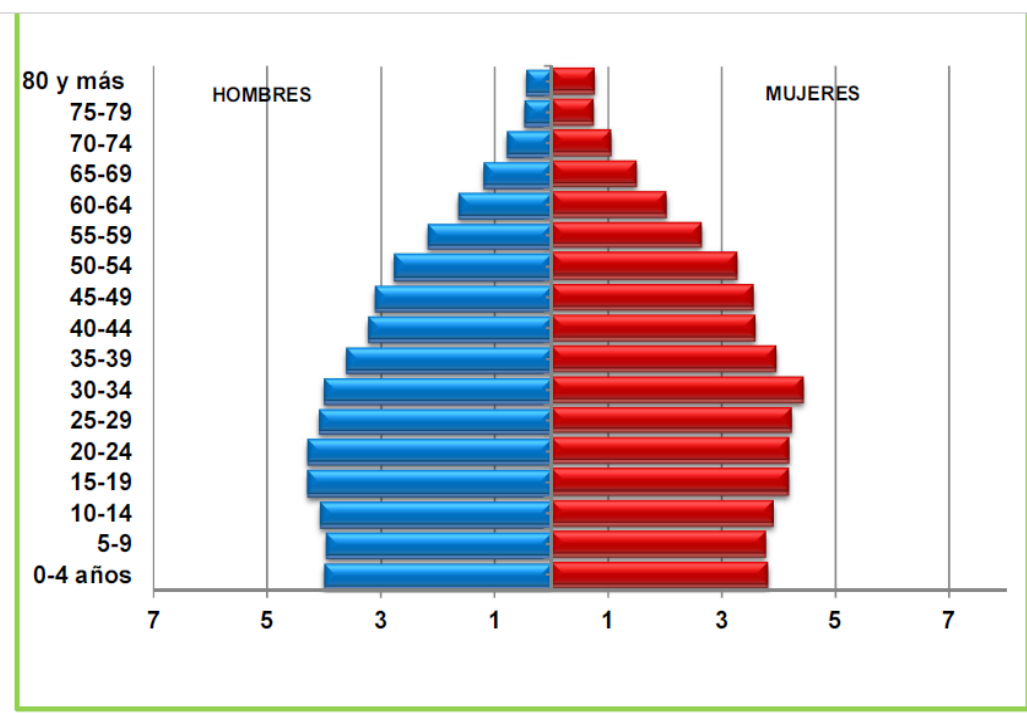

Fuente: Proyecciones de población DANE-SDP

Elaboración y cálculos: Oficina Asesoría de Planeación. Grupo de Análisis y Estadística.

La comparación entre las pirámides poblacionales de la ciudad mostró evidencias de transición demográfica, pues, aunque predominó la población joven adulta, existe una tendencia al aumento progresivo de la proporción de adultos mayores. 


\subsection{Regímenes de Afiliación Colombia 2014.}

El plan obligatorio de salud (POS) es ofertado por las Entidades Promotoras de Salud ya sean públicas o privadas con recursos del fondo de solidaridad y garantía (FOSYGA), a través de los diferentes regímenes de afiliación; contributivo, subsidiado, vinculado, desplazados y regímenes especiales.

Frente a la afiliación de la población en los regímenes de seguridad social; según información del FOSYGA a septiembre de 2014 las personas afiliadas al contributivo eran 5.675.507 personas de las cuales correspondían al 73 \% a la población total de Bogotá. Las personas pertenecientes al régimen subsidiado eran 1.277.631 con una distribución porcentual de $16.4 \%$, la población no asegurada correspondió a 336.55 personas equivalentes al 4,3\% y las pertenecientes a regímenes especiales fueron 271.261 personas correspondientes al 3,5\% de la población, para un total de 7.776 .854 personas en Bogotá.

Tabla 6 Estado de Aseguramiento Población de Bogotá 2014.

\begin{tabular}{|l|l|l|}
\hline Afiliados por Régimen & Cantidad & \% Total \\
\hline Régimen Contributivo & 5.675 .507 & $73 \%$ \\
\hline Régimen Subsidiado & 1.277 .631 & $16,4 \%$ \\
\hline
\end{tabular}

Página 133 de 228

Rutty Adriana Abril Vivas. Odontóloga. Especialista Administración Hospitalaria. Auditoria de la Calidad. Nubia Astrid Duarte Pinzón. Enfermera. Especialista en Gerencia de Salud. 


\begin{tabular}{|l|l|l|}
\hline $\begin{array}{l}\text { Regímenes de excepción } \\
\text { (estimado) }\end{array}$ & 271.261 & $3.5 \%$ \\
\hline No afiliados & 336.559 & $4,3 \%$ \\
\hline Total & 7.560 .958 & $100 \%$ \\
\hline
\end{tabular}

Fuente: BDUA-FOSYGA Maestro subsidiado S.D.S. Base de datos certificada DNP corte 30 junio 2014.

Resultados: en Colombia la cobertura de salud se ha incrementado significativamente en la población al pasar de 58,3\% en el año 2.000 a un 94,44\% para el año 2015 , lo que significa que 45.547.641 personas cuentan con cubrimiento de servicios. Se observó que en el país se incrementó la población cubierta en el régimen subsidiado el cual pasó de un 23\% del año 2.000 a un 48,19\% en el año 2015 (Fundación Corona \& Fundación Santa Fe de Bogotá, 2015)

La afiliación al régimen subsidiado se incrementó con respecto al régimen contributivo pasando de un porcentaje de población afiliada de 35,22\% en el 2000 a un porcentaje de 43,56\% en el 2014 , de igual manera se evidenció disminución en la afiliación del contributivo pasando de un $41,17 \%$ de población no afiliada al sistema en el año 2000 a un 4,55\% en el año 2014. En el 2014 un total de 1.849 .615 personas se encontraron afiliadas al régimen de excepción o especial.

Página 134 de 228

Rutty Adriana Abril Vivas. Odontóloga. Especialista Administración Hospitalaria. Auditoria de la Calidad. Nubia Astrid Duarte Pinzón. Enfermera. Especialista en Gerencia de Salud. 
La tendencia que se observó en afiliación contradijo lo planteado en la ley 100 de 1993 cuando se esperaba tener cerca del $70 \%$ de las personas en el régimen contributivo y $30 \%$ en el régimen subsidiado. La consecuencia directa es la desfinanciación del sistema de salud debido a que se requieren más los recursos públicos que los pagos de los trabajadores formales a causa del desempleo o la informalidad laboral lo que afecta el recaudo de las cotizaciones en salud.

La Ley 797 de 2003 obligó a cotizar a quienes se encuentren vinculados a través de contratos de trabajo, y la Ley 1250 de 2008 que autorizó a cotizar solamente a salud a trabajadores independientes de bajos ingresos pueden tener incidencia en el aumento del porcentaje de afiliados al régimen contributivo en los últimos cuatro años (Fundación Corona \& Fundación Santa Fe de Bogotá, 2015)

Tabla 7 Comparativo aseguramiento del 2000 al 2015.

\begin{tabular}{|l|l|l|l|l|l|}
\hline Año & $\begin{array}{l}\text { \% afiliación } \\
\text { Régimen } \\
\text { Contributivo }\end{array}$ & $\begin{array}{l}\text { \%efiliación } \\
\text { Régimen } \\
\text { Subsidiado }\end{array}$ & $\begin{array}{l}\text { \% de } \\
\text { Aseguramiento } \\
\text { en salud }\end{array}$ & $\begin{array}{l}\text { Población } \\
\text { no Afiliación a a } \\
\text { asegurada }\end{array}$ & $\begin{array}{l}\text { Régimen de } \\
\text { excepción }\end{array}$ \\
\hline 2000 & 35.22 & 23.6 & 58.83 & 41.17 & 0 \\
\hline 2001 & 32.68 & 27.12 & 59.8 & 40.2 & 0 \\
\hline 2002 & 31.86 & 27.69 & 59.55 & 40.45 & 0 \\
\hline 2003 & 32.99 & 28.36 & 61.35 & 38.25 & 0 \\
\hline 2004 & 35.07 & 36.71 & 71.78 & 28.22 & 0 \\
\hline 2005 & 36.31 & 43.32 & 79.63 & 20.37 & 0 \\
\hline
\end{tabular}

Página 135 de 228

Rutty Adriana Abril Vivas. Odontóloga. Especialista Administración Hospitalaria. Auditoria de la Calidad. Nubia Astrid Duarte Pinzón. Enfermera. Especialista en Gerencia de Salud. 


\begin{tabular}{|l|l|l|l|l|l|}
\hline 2006 & 37.67 & 46.32 & 84 & 16 & 0 \\
\hline 2007 & 38.91 & 49.19 & 88.1 & 11.9 & 0 \\
\hline 2008 & 38.77 & 50.59 & 89.36 & 10.64 & 0 \\
\hline 2009 & 40.16 & 46.64 & 86.8 & 13.2 & 0 \\
\hline 2010 & 41.08 & 47.63 & 88.71 & 11.29 & 0 \\
\hline 2011 & 42.61 & 48.26 & 91.67 & 8.33 & 0.81 \\
\hline 2012 & 42.84 & 48.53 & 92.21 & 7.79 & 0.84 \\
\hline 2013 & 42.76 & 48.11 & 91.69 & 8.31 & 0.82 \\
\hline 2014 & 43.56 & 48.01 & 95.45 & 4.55 & 3.88 \\
\hline 2015 & 42.44 & 48.19 & 94.49 & 5.51 & 3.86 \\
\hline
\end{tabular}

Fuente. Así vamos en salud 2015.

Análisis: para la vigencia 2015 se encontró una distribución porcentual del 94.49\% de ase

guramiento poblacional frente a un $5.51 \%$ de población no asegurada lo que demostró una cobertura en salud de acuerdo a lo establecido normativamente en lo que se refiere a la cantidad de personas afiliadas a un tipo de régimen.

\subsection{Oferta institucional de servicios de Salud.}

\subsubsection{Oferta institucional Colombia 2007.}

Según datos registrados en la encuesta nacional de salud del 2007 con relación a la oferta de instituciones públicas y privadas para la atención en salud, existían en promedio 35,8 instituciones públicas hospitalarias en los municipios de categoría especial, 88 centros de salud, 22 puestos de salud, 51 clínicas privadas con hospitalización, 62,6 
centros de atención ambulatoria de EPS y 1.721 profesionales independientes registrados en el sistema de habilitación (Ministerio de la Protección Social et al., 2009)

Tabla 8 Número promedio de instituciones públicas y privadas de salud categoría especial, Colombia, 2007.

\begin{tabular}{|l|l|}
\hline VARIABLE Categoría & \multicolumn{1}{|c|}{ Especial } \\
\hline $\begin{array}{l}\text { Hospitales y clínicas } \\
\text { públicas }\end{array}$ & 35,8 \\
\hline Centros de Salud & 88,8 \\
\hline Puestos de Salud & 22,4 \\
\hline $\begin{array}{l}\text { Otras entidades } \\
\text { Públicas de Salud }\end{array}$ & 2,4 \\
\hline $\begin{array}{l}\text { Clínicas Privadas con } \\
\text { hospitalización }\end{array}$ & 51,2 \\
\hline $\begin{array}{l}\text { Centros de atención } \\
\text { ambulatorias EPS o } \\
\text { ARs de }\end{array}$ & 1721,6 \\
\hline $\begin{array}{l}\text { Profesionales } \\
\text { Independientes } \\
\text { registrados }\end{array}$ & 1721,6 \\
\hline $\begin{array}{l}\text { en Sistema } \\
\text { Habilitación }\end{array}$ & 172,6 \\
\hline
\end{tabular}

Fuente. Encuesta Nacional de Salud 2007

Resultados: en Colombia para el año de 2007 se registraron 1.721 profesionales e instituciones habilitadas, evidenciándose que los municipios de categorías 1,2 y 3 contaban con una oferta amplia de instituciones tanto públicas como privadas, 
contrastando con municipios de categorías 4,5 y 6 con oferta menor (Blanca M. Chávez G \& Luis E. Velásquez, 2011)

En cuanto a la estructura de la atención para el 2007; el 82,1\% (499) de las 608 IPS's correspondieron a instituciones de naturaleza privada o mixta y el 69\% (388) de las 562 a IPS de naturaleza pública y contaban con registro especial de prestadores de salud para ofertar atenciones, intervenciones y procedimientos contenidos en las normas y guías de atención de enfermedades de interés en salud pública de la Resolución 412 de 2000.

\subsubsection{Oferta institucional Odontológica para Colombia y Bogotá 2013-2014.}

Al nivel nacional para el año 2013 se encontraban 29.044 profesionales independientes los cuales correspondían a 16.649 odontólogos generales habilitados $(57,3 \%)$ y 12.395 especialistas $(42,7 \%)$, de los cuales el $77,2 \%$ eran prestadores privados con la siguiente distribución : Bogotá presentó el 46,6\%, Valle el 9,2\%, Antioquía el 8,1\%, Santander el 3,5\%, Atlántico y Bolívar el 3,4\% respectivamente , y Cundinamarca 3,0\% (Ministerio de Salud y Protección Social, 2013).

Para el Distrito Capital para el mismo año, según información preliminar de la secretaria de salud se encontraban habilitados 11.914 prestadores en servicios de salud oral distribuidos en 4.701 IPS, de las cuales 18 correspondían a instituciones con objeto social

Página 138 de 228

Rutty Adriana Abril Vivas. Odontóloga. Especialista Administración Hospitalaria. Auditoria de la Calidad. Nubia Astrid Duarte Pinzón. Enfermera. Especialista en Gerencia de Salud. 
diferente, 5.106 profesionales independientes laborando en 7029 sedes, lo que demostró que cerca del $28,6 \%$ de odontólogos ofertaban sus servicios en más de un consultorio.

Las localidades que ofertaban a la fecha el mayor porcentaje la atención en servicios odontológicos en su orden fueron: Chapinero con un 19,7\%, Suba con 9,1\%, Kennedy con $8,2 \%$, Teusaquillo con 7,9\%, Engativá con 7,6\%; en lo referente a las localidades que ofertan menores servicios habilitados sobresalen San Cristóbal y Tunjuelito con 1,7\%, Ciudad Bolívar y Mártires con 1,6\%, Santa Fe con 1,0\%, Usme con 0,8\% y Candelaria con 0,5\% (Grupo funcional de salud oral, 2014).

Tabla 9 Prestadores de Servicio Odontológico Habilitados Bogotá por Tipo de Prestador.2014.

\begin{tabular}{|l|l|l|l|l|l|}
\hline Localidad & IPS & $\begin{array}{l}\text { Objeto social } \\
\text { diferente }\end{array}$ & $\begin{array}{l}\text { Profesional } \\
\text { Independiente }\end{array}$ & $\begin{array}{l}\text { Total, } \\
\text { General }\end{array}$ & $\%$ \\
\hline $\begin{array}{l}\text { Antonio } \\
\text { Nariño }\end{array}$ & 231 & 10 & 81 & 322 & 2,7 \\
\hline $\begin{array}{l}\text { Barrios } \\
\text { Unidos }\end{array}$ & 169 & 10 & 180 & 359 & 3 \\
\hline Bosa & 91 & 1 & 171 & 263 & 2,2 \\
\hline Chapinero & 611 & 32 & 1.703 & 2.346 & 19,7 \\
\hline $\begin{array}{l}\text { Ciudad } \\
\text { Bolívar }\end{array}$ & 73 & 1 & 117 & 191 & 1,6 \\
\hline Engativá & 412 & 3 & 487 & 902 & 7,6 \\
\hline Fontibón & 272 & 3 & 204 & 479 & 4 \\
\hline Kennedy & 522 & 2 & 453 & 977 & 8,2 \\
\hline $\begin{array}{l}\text { La } \\
\text { Candelaria }\end{array}$ & 35 & 11 & 16 & 62 & 0,5 \\
\hline Los Mártires & 86 & 8 & 96 & 190 & 1,6 \\
\hline
\end{tabular}

Página 139 de 228

Rutty Adriana Abril Vivas. Odontóloga. Especialista Administración Hospitalaria. Auditoria de la Calidad. Nubia Astrid Duarte Pinzón. Enfermera. Especialista en Gerencia de Salud. 


\begin{tabular}{|l|l|l|l|l|l|}
$\begin{array}{l}\text { Puente } \\
\text { Aranda }\end{array}$ & 118 & 2 & 197 & 317 & 2,7 \\
\hline Rafael Uribe & 101 & 1 & 156 & 258 & 2,2 \\
\hline $\begin{array}{l}\text { San } \\
\text { Cristóbal }\end{array}$ & 51 & 2 & 155 & 208 & 1,7 \\
\hline Santa Fe & 48 & 14 & 58 & 120 & 1 \\
\hline Suba & 523 & 13 & 543 & 1079 & 9,1 \\
\hline Sumapaz & 4 & & & 4 & 0 \\
\hline Teusaquillo & 322 & 24 & 590 & 936 & 7,9 \\
\hline Tunjuelito & 107 & 4 & 92 & 203 & 1,7 \\
\hline Usaquén & 229 & 3 & 341 & 573 & 4,8 \\
\hline Usme & 43 & & 56 & 99 & 0,8 \\
\hline (en blanco) & 653 & 40 & 1.333 & 2.026 & 17 \\
\hline $\begin{array}{l}\text { Total, } \\
\text { general }\end{array}$ & 4.701 & 184 & 7.029 & 11.914 & 100 \\
\hline
\end{tabular}

Fuente: Dirección de desarrollo de Servicios. IVC Prestadores habilitados corte septiembre 9 de 2014

Análisis: la mayor concentración de oferta de los servicios de salud oral se encontraron en las localidades de Chapinero y Suba y la menor en la localidad de Ciudad Bolívar siendo insuficiente para la población proyectada por el DANE mostrando relación de 9.253 habitantes por IPS y 5.773 habitantes por profesional, seguidas de Mártires, Santa Fe, Usme y Candelaria, lo que indica la necesidad de revisión y análisis para la toma de decisiones del nivel central que incluye en la política la cobertura a poblaciones de mayor vulnerabilidad en el Distrito Capital.

El $70 \%$ de los profesionales se encontraron concentrados al norte de Bogotá, el 15\% en el sur occidente, el $7.5 \%$ se encontraron en la zona centro oriente y en la zona sur el 7.1\%. Se reportó la apertura de 189 consultorios de profesionales independientes en la 
localidad de Chapinero, siguiendo Suba con 150 y la localidad de Engativá con 107 consultorios (Grupo funcional de salud oral, 2014)

\subsection{Metas distritales en salud oral Bogotá.}

En el periodo de 2008-2011 según registro en documento consolidado de metas distritales se encontró que los análisis realizados por la SDS se basaron en informes parciales debido al no reporte oportuno de la información por la totalidad de instituciones prestadoras de servicios de salud lo que generó sesgos en los resultados.

El porcentaje de metas de cumplimiento de los procedimientos incluidos en las Normas técnicas de protección específica y detección temprana según Resoluciones 412 y 3384 del 2000 para el Régimen Contributivo en salud oral correspondió a $20 \%$ y $50 \%$ subsidiado.

El Plan Distrital de Salud Bogotá Positiva, en las metas estructurales planteó “A 2011 incrementar en un $25 \%$ la cobertura del programa de Salud Oral (Flúor, sellantes, control de placa y detartraje) en la población afiliada a los regímenes subsidiado y contributivo, sin detrimento de lo establecido por norma" (Grupo técnico de la Secretaria Distrital de Salud, 2012) 
A continuación, se presenta la información relacionada con cobertura establecida para los regímenes contributivo y subsidiado en las atenciones de salud oral para el periodo encontrado documentado:

Tabla 10 Metas Distritales, regímenes contributivo y subsidiado 2008-2012.

\begin{tabular}{|l|l|l|}
\hline $\begin{array}{c}\text { Procedimien } \\
\text { to }\end{array}$ & $\begin{array}{l}\text { Régimen } \\
\text { Contributivo }\end{array}$ & $\begin{array}{l}\text { Régimen } \\
\text { Subsidiado }\end{array}$ \\
\hline $\begin{array}{l}\text { Control de } \\
\text { Placa dental }\end{array}$ & $20 \%$ & $50 \%$ \\
\hline $\begin{array}{l}\text { Detartraje } \\
\text { supragigival. }\end{array}$ & $20 \%$ & $50 \%$ \\
\hline $\begin{array}{l}\text { Topicación } \\
\text { de flúor gel }\end{array}$ & $20 \%$ & $80 \%$ \\
\hline $\begin{array}{l}\text { Aplicación e } \\
\text { Sellantes de } \\
\text { autocurado }\end{array}$ & $20 \%$ & $80 \%$ \\
\hline $\begin{array}{l}\text { Aplicación e } \\
\text { Sellantes de } \\
\text { autocurado }\end{array}$ & $20 \%$ & $80 \%$ \\
\hline
\end{tabular}

Fuente: Primer análisis metas 2008-2012

\subsubsection{Cobertura de control de Placa Bacteriana Bogotá 2008- 2012.}

El siguiente es el resultado del periodo de la cobertura alcanzada para el control de placa bacteriana para el distrito. 
Tabla 11 Control de Placa Bacteriana por régimen de afiliación. Bogotá 2008- 2012

\begin{tabular}{|c|c|c|c|c|c|c|c|c|c|c|c|c|c|}
\hline \multirow[b]{2}{*}{ Regimen } & \multicolumn{3}{|c|}{2008} & \multicolumn{3}{|c|}{2009} & \multicolumn{3}{|c|}{2010} & \multicolumn{3}{|c|}{2011} & \multirow[b]{2}{*}{$\begin{array}{l}\text { Porcentaje de } \\
\text { Cumplimiento }\end{array}$} \\
\hline & Intervenida & Programada & Cobertura & Intervenida & Programada & Cobertura & Intervenida & Programada & Cobertura & Intervenida & Programada & Cobertura & \\
\hline Contributivo & 1.572 .326 & 4.665 .583 & $34 \%$ & 925.882 & 4.479 .215 & $21 \%$ & 1.045 .942 & 4.816 .997 & $22 \%$ & 791.784 & 3.267 .047 & $24 \%$ & $25 \%$ \\
\hline Subsidiado & 52.268 & 1.041 .122 & $5 \%$ & 88.249 & 1.025 .074 & $9 \%$ & 119.412 & 1.239 .302 & $10 \%$ & 142.962 & 915.868 & $16 \%$ & $10 \%$ \\
\hline Total & 1.624 .594 & 5.706 .705 & $28 \%$ & 1.014 .131 & 5.504 .289 & $18 \%$ & 1.165 .354 & 6.056 .299 & $19 \%$ & 934.746 & 4.182 .915 & $22 \%$ & $22 \%$ \\
\hline
\end{tabular}

Fuente: Secretaria Distrital de Salud. Dirección de aseguramiento

Análisis: para el periodo el control de placa alcanzó niveles por encima del 20\% para el contributivo siendo mayor a la alcanzada al régimen subsidiado que registro un $10 \%$ no logrando la meta establecida en la política de salud oral para el régimen subsidiado.

En relación con la programación vs la intervención para cada uno de los años no se logró la meta planteada lo que indica la necesidad de realizar seguimiento, análisis y replanteamiento de la política con base a resultados de control de placa.

\subsubsection{Atención de consulta odontológica de primera vez.}

\subsubsection{Atención de Primera Vez al Menor de cinco años.}

El Plan Distrital de Salud Bogotá Positiva, en las metas estructurales planteó "A 2011 incrementar en un $20 \%$ la cobertura de la población de menores de 5 años en la población afiliada a los regímenes subsidiado, contributivo y vinculado". 
Las siguientes fueron las actividades realizadas en el periodo frente a las metas programadas:

Tabla 12 Cobertura de la atención en el menor de cinco años por régimen de afiliación

\begin{tabular}{|l|c|c|l|l|l|l|l|l|l|l|l|l|l|}
\hline \multirow{2}{*}{ Regimen } & \multicolumn{3}{|c|}{2008} & \multicolumn{3}{c|}{2009} & \multicolumn{3}{c|}{2010} & \multicolumn{3}{c|}{2011} & \\
\cline { 2 - 15 } & Intervenida & Programada & Cobertura & Intervenida & Programada & Cobertura & Intervenida & Programada & Cobertura & Intervenida & Programada & Cobertura & $\begin{array}{l}\text { Porcentaje de } \\
\text { Cumplimiento }\end{array}$ \\
\hline Contributivo & 81.551 & 326.022 & $25 \%$ & 94.035 & 647.651 & $15 \%$ & 151.714 & 418.636 & $36 \%$ & 105.196 & 234.956 & $45 \%$ & $26 \%$ \\
\hline Subsidiado & 616 & 85.452 & $1 \%$ & 14.364 & 27.251 & $53 \%$ & 12.388 & 117.395 & $11 \%$ & 21.845 & 63.529 & $34 \%$ & $16 \%$ \\
\hline Total & 82.167 & 411.474 & $20 \%$ & 108.399 & 674.902 & $16 \%$ & 164.102 & 536.031 & $31 \%$ & 127.041 & 298.485 & $43 \%$ & $25 \%$ \\
\hline
\end{tabular}

Fuente: Secretaria Distrital de Salud. Dirección de aseguramiento

Análisis: en el periodo 2008-2011, la meta en régimen contributivo fue del $26 \%$ y para el subsidiado el $16 \%$ de cumplimiento en la cobertura el menor de cinco años evidenciándose el incumplimiento del régimen subsidiado frente a lo establecido en la política de salud oral.

Al comparar la población programada frente a la intervenida por año tanto en el régimen contributivo como subsidiado se observó para el 2008 una cobertura del 20\%, para el 2009 un 16\%, para el 2010 un 31\%, y para el 2011 y un 43\%, lo que indicaba la necesidad de realizar seguimiento, análisis y replanteamiento con base a resultados con el fin de realizar ajuste para lograr una cobertura útil de la población menor de cinco años.

Frente a la información extraída del SISVESO periodo 2009 a 2012 con lo relacionado con la visita al servicio de salud oral en la primera infancia se presentó lo siguiente: 
Tabla 13 . Visita al odontólogo primera infancia. SISVESO. Bogotá 2009 -2013.

\begin{tabular}{ccccccccccc}
\hline & \multicolumn{10}{c}{ Año } \\
\cline { 2 - 11 } Visita al od ontólogo & $\begin{array}{c}2009 \\
\mathrm{n}=604\end{array}$ & $\%$ & $\begin{array}{c}2010 \\
\mathrm{n}=2018\end{array}$ & $\%$ & $\begin{array}{c}2011 \\
\mathrm{n}=3409\end{array}$ & $\%$ & $\begin{array}{c}2012 \\
\mathrm{n}=2608\end{array}$ & $\%$ & $\begin{array}{c}2013 \\
\mathrm{n}=3215\end{array}$ & $\%$ \\
\hline \hline No visita & 365 & 60,4 & 1053 & 52,2 & 1711 & 50,2 & 1316 & 50,5 & 1641 & 51,0 \\
Una vez en el año & 177 & 29,3 & 766 & 38,0 & 1255 & 36,8 & 1050 & 40,3 & 1311 & 40,8 \\
Dos veces en el año & 47 & 7,8 & 165 & 8,2 & 398 & 11,7 & 226 & 8,7 & 263 & 8,2 \\
\hline
\end{tabular}

Fuente: SISVESO.S.D. S Dirección de Salud Pública. Área de Vigilancia.

Análisis: se observó que en promedio del 50 \% de la población de la primera infancia no asistió a consulta de odontología lo que indicó la débil respuesta a esta actividad que está definida en la política de salud oral por lo que se debe realizarse seguimiento a las acciones realizadas desde los niveles individual, colectivo y resolutivo.

\subsubsection{Frecuencia de uso de consultas de primera vez de odontología régimen contributivo. Bogotá. 2011.}

La Secretaría Distrital de Salud, incluyo en el objetivo 3 del plan territorial de salud el "Diseñar e implementar un sistema de evaluación de resultados en salud de la población, por regímenes de afiliación en el Distrito Capital, ordeno incrementar al 25\% la atención

Página 145 de 228

Rutty Adriana Abril Vivas. Odontóloga. Especialista Administración Hospitalaria. Auditoria de la Calidad. Nubia Astrid Duarte Pinzón. Enfermera. Especialista en Gerencia de Salud. 
de primera vez en salud oral de los niños, niñas y jóvenes menores de 19 años en el Distrito Capital, al 2016" (Secretaria Distrital de Salud, 2012b)

Para el 2011 las EPS del régimen contributivo reportaron un total de 295.292 consultas de primera vez realizadas para la vigencia(Jairo Hernán Ternera, 2012)

Tabla 14 Cobertura consulta de primera vez régimen contributivo. Bogotá 2011.

\begin{tabular}{|c|c|c|c|c|c|c|c|}
\hline Grupo etareo & SALUD COLPATRIA & COMPENSAR & HUMANA VIVIR & NUEVA EPS & ALIANSALUD & SURA EPS & TOTAL \\
\hline Menor de un Año & $0,0 \%$ & $0,5 \%$ & $0,0 \%$ & $0,3 \%$ & $26,7 \%$ & $0,0 \%$ & $11,1 \%$ \\
\hline 1 a 4 & $14,6 \%$ & $27,8 \%$ & $4,1 \%$ & $23,8 \%$ & $26,5 \%$ & $14,4 \%$ & $24,2 \%$ \\
\hline $5-9$ & $21,9 \%$ & $31,3 \%$ & $5,1 \%$ & $33,8 \%$ & $25,7 \%$ & $31,9 \%$ & $29,8 \%$ \\
\hline $10-14$ & $12,7 \%$ & $24,0 \%$ & $3,6 \%$ & $24,4 \%$ & $27,6 \%$ & $24,6 \%$ & $23,4 \%$ \\
\hline 15-19 & $25,0 \%$ & $19,4 \%$ & $3,6 \%$ & $21,7 \%$ & $24,1 \%$ & $22,1 \%$ & $20,1 \%$ \\
\hline $20-24$ & $11,7 \%$ & $20,2 \%$ & $11,5 \%$ & $17,2 \%$ & $21,0 \%$ & $19,5 \%$ & $19,1 \%$ \\
\hline $25-29$ & $14,4 \%$ & $20,5 \%$ & $4,6 \%$ & $20,9 \%$ & $20,4 \%$ & $21,1 \%$ & $20,0 \%$ \\
\hline $30-34$ & $15,5 \%$ & $17,8 \%$ & $5,9 \%$ & $18,8 \%$ & $21,8 \%$ & $20,9 \%$ & $18,4 \%$ \\
\hline $35-39$ & $18,4 \%$ & $16,3 \%$ & $3,8 \%$ & $20,9 \%$ & $21,2 \%$ & $19,3 \%$ & $17,6 \%$ \\
\hline $40-44$ & $14,8 \%$ & $15,0 \%$ & $4,7 \%$ & $19,9 \%$ & $33,7 \%$ & $18,4 \%$ & $18,1 \%$ \\
\hline $45-49$ & $15,2 \%$ & $12,8 \%$ & $4,0 \%$ & $17,9 \%$ & $20,3 \%$ & $18,2 \%$ & $15,5 \%$ \\
\hline $50-54$ & $15,4 \%$ & $10,7 \%$ & $3,6 \%$ & $15,4 \%$ & $19,6 \%$ & $17,9 \%$ & $13,8 \%$ \\
\hline $55-59$ & $14,3 \%$ & $8,7 \%$ & $2,4 \%$ & $13,4 \%$ & $21,1 \%$ & $15,6 \%$ & $12,4 \%$ \\
\hline $60-64$ & $15,9 \%$ & $7,7 \%$ & $2,5 \%$ & $11,7 \%$ & $22,0 \%$ & $15,9 \%$ & $11,4 \%$ \\
\hline $65-69$ & $11,3 \%$ & $6,5 \%$ & $2,1 \%$ & $10,6 \%$ & $19,4 \%$ & $15,6 \%$ & $10,2 \%$ \\
\hline $70-74$ & $10,1 \%$ & $5,6 \%$ & $1,9 \%$ & $8,7 \%$ & $19,9 \%$ & $13,3 \%$ & $8,8 \%$ \\
\hline $75-79$ & $8,6 \%$ & $4,2 \%$ & $6,5 \%$ & $6,9 \%$ & $12,4 \%$ & $13,1 \%$ & $7,1 \%$ \\
\hline 80 y más & $4,0 \%$ & $2,8 \%$ & $0,3 \%$ & $4,8 \%$ & $1,2 \%$ & $9,3 \%$ & $4,2 \%$ \\
\hline Total & $14,2 \%$ & $17,6 \%$ & $4,8 \%$ & $15,7 \%$ & $22,8 \%$ & $12,2 \%$ & $17,5 \%$ \\
\hline
\end{tabular}

Fuente: Primer análisis de metas 2012-2016. Secretaria Distrital de Salud.

Análisis: se observó una cobertura general del 17,5\% para la consulta de primera vez en odontología, para un cumplimiento en menores de 19 años para el régimen contributivo. 
Frente a la cobertura en el año 2011 las EPSS afiliaron 627.185 habitantes del distrito de los cuales 252.906 correspondieron a menores de 18 años reportando 36.854 consultas de primera vez(Secretaria Distrital de Salud, 2012a).

Tabla 15 Cobertura consulta de primera vez régimen subsidiado. Bogotá 2011.

\begin{tabular}{|c|c|c|c|c|c|c|c|c|c|c|c|c|c|}
\hline \multirow[b]{2}{*}{ Grupo etareo } & \multicolumn{3}{|c|}{ HUMANA VMR EPSS } & \multicolumn{3}{|c|}{ COLSUBSIDIO EPSS } & \multicolumn{3}{|c|}{ UNICAJAS EPSS } & \multicolumn{3}{|c|}{ TOTAL } & \multirow[b]{2}{*}{$\begin{array}{l}\text { Estimación } \\
\text { Meta Distrital }\end{array}$} \\
\hline & $\mid \begin{array}{c}\mathrm{N}^{0} \text { Afiliados } \\
\text { a Dic-11 }\end{array}$ & $\begin{array}{c}\mathbf{N}^{\circ} \\
\text { Consultas } \\
\text { de Primera } \\
\text { Vez Por } \\
\text { Odont. Año } \\
2011\end{array}$ & $\begin{array}{c}\text { Cobertura } \\
\%\end{array}$ & $\begin{array}{c}N^{0} \text { Afiliados a } \\
\text { Dic-11 }\end{array}$ & \begin{tabular}{|c|}
$\mathrm{N}^{\circ}$ \\
Consultas \\
de Primera \\
Vez Por \\
Odont. Año \\
2011 \\
\end{tabular} & $\begin{array}{c}\text { Cobertura } \\
\%\end{array}$ & $\begin{array}{c}N^{0} \text { Afiliados } \\
\text { a Dic-11 }\end{array}$ & \begin{tabular}{|c|}
$\mathbf{N}^{\circ}$ \\
Consultas \\
de Primera \\
Vez Por \\
Odont. Año \\
2011 \\
\end{tabular} & $\begin{array}{c}\text { Cobertura } \\
\%\end{array}$ & $\begin{array}{c}N^{\circ} \text { Afiliados } \\
\text { a Dic-11 }\end{array}$ & \begin{tabular}{|c|}
$\mathbf{N}^{\circ}$ \\
Consultas \\
de Primera \\
Vez Por \\
Odont. Año \\
2011 \\
\end{tabular} & $\begin{array}{c}\text { Cobertura } \\
\%\end{array}$ & \\
\hline Menores de 1 año & 13 & - & $0,0 \%$ & 2.475 & 108 & $4,3 \%$ & 944 & 1.558 & $165,1 \%$ & 3.432 & 1.685 & $48,5 \%$ & $25 \%$ \\
\hline $1 \mathrm{a} 4$ & 21.387 & 2.378 & $11,1 \%$ & 11.323 & 2462 & $21,6 \%$ & 4.220 & 2.312 & $54,8 \%$ & 37.000 & \begin{tabular}{|l|}
7.152 \\
\end{tabular} & $18,3 \%$ & $25 \%$ \\
\hline $5 \mathrm{a} 8$ & 34.858 & 4.154 & $11,9 \%$ & 15.874 & 3.076 & $18,4 \%$ & 7.789 & 3.874 & $47,2 \%$ & 58.521 & 10.804 & $18,6 \%$ & $25 \%$ \\
\hline $15 a 18$ & 43.483 & 2.884 & $6,6 \%$ & 21.737 & 2580 & $11,9 \%$ & 12.814 & 2.302 & $18,0 \%$ & 78.034 & 7.786 & $10,0 \%$ & $25 \%$ \\
\hline 20 a 24 & 30.831 & 1.731 & $5,7 \%$ & 16.502 & 1.673 & $10,1 \%$ & 8.150 & 1.473 & $18,1 \%$ & 55.283 & 4.877 & $8,8 \%$ & $22 \%$ \\
\hline $25 a 29$ & 21.688 & 1.480 & $6,7 \%$ & 12298 & 1.188 & $9,7 \%$ & 5.535 & 1.164 & $21,0 \%$ & 39.500 & 3.812 & $8,7 \%$ & $22 \%$ \\
\hline 30 a 34 & 18.532 & 1.407 & $7,2 \%$ & 11.379 & 1.265 & $11,1 \%$ & 4.533 & 1.053 & $23,2 \%$ & 35.444 & 3.725 & $10,5 \%$ & $21 \%$ \\
\hline $35 a 39$ & 18.476 & 1.379 & $7,1 \%$ & 11.036 & 1.180 & $10,8 \%$ & 4.328 & 1.200 & $27,7 \%$ & 34.838 & \begin{tabular}{ll|}
3.780 \\
\end{tabular} & $10,8 \%$ & $20 \%$ \\
\hline 40 a 44 & 21.496 & 1.392 & $6,5 \%$ & 12.586 & 1.327 & $10,6 \%$ & 4.852 & 985 & $19,9 \%$ & 39.014 & 3.704 & $8,5 \%$ & $20 \%$ \\
\hline 45 a 49 & 22.118 & 1.377 & $6,2 \%$ & 13.478 & 1.303 & $9,7 \%$ & 5.451 & 858 & $15,7 \%$ & 41.045 & 3.538 & $8,6 \%$ & $15 \%$ \\
\hline 50 a 54 & \begin{tabular}{l|l}
18.424 \\
\end{tabular} & 1.081 & $5,6 \%$ & 11.967 & 1.017 & $8,5 \%$ & 4.887 & 629 & $12,6 \%$ & 36.378 & 2.727 & $7,5 \%$ & $15 \%$ \\
\hline 55 a 50 & 14.890 & 624 & $4,2 \%$ & 8.048 & 670 & $7,4 \%$ & 3.804 & 349 & $8,7 \%$ & 27.832 & 1.643 & $5,8 \%$ & $15 \%$ \\
\hline 70 a 74 & \begin{tabular}{ll|}
6.315 \\
\end{tabular} & 200 & $3,3 \%$ & 3.847 & 185 & $4,8 \%$ & 1.779 & 71 & $4,0 \%$ & 11.841 & 465 & $3,8 \%$ & $15 \%$ \\
\hline 75 a 78 & 4.645 & 110 & $2,4 \%$ & 2.748 & 86 & $3,5 \%$ & 1.288 & 68 & $5,1 \%$ & 8.680 & 272 & $3,1 \%$ & $15 \%$ \\
\hline 80 y más & 5.162 & 75 & $1,5 \%$ & 3.021 & 76 & $2,5 \%$ & 1.454 & 22 & $1,5 \%$ & 9.707 & 173 & $1,8 \%$ & $15 \%$ \\
\hline Total & 346.420 & 24.467 & $7,1 \%$ & 191.444 & 21.788 & $11,4 \%$ & 89.321 & 21.290 & $23,8 \%$ & 627.185 & 67.545 & $10,8 \%$ & $20,0 \%$ \\
\hline
\end{tabular}

Fuente: Primer análisis de metas 2012-2016. Secretaria Distrital de Salud.

Análisis: para el año 2011 la cobertura general alcanzada para todo el grupo, poblacional del régimen subsidiado correspondió a 10,8\% y para los menores alcanzó una cobertura global de $14,6 \%$ siendo necesario fortalecer la demanda en consulta para dar cumplimiento a la política establecida en el grupo poblacional.

Página 147 de 228

Rutty Adriana Abril Vivas. Odontóloga. Especialista Administración Hospitalaria. Auditoria de la Calidad. Nubia Astrid Duarte Pinzón. Enfermera. Especialista en Gerencia de Salud. 


\subsubsection{Atención Odontológica a la Mujer Gestante.}

El Plan Distrital de Salud Bogotá Positiva, en las metas estructurales planteó que "A 2011 incrementar en un $20 \%$ la cobertura de la atención odontológica de mujeres gestantes en la población afiliada a los regímenes subsidiado, contributivo y vinculado (Grupo técnico de la Secretaria Distrital de Salud, 2012).

Tabla 16 Cobertura de la atención en oral a la mujer gestante por régimen de afiliación.

\begin{tabular}{|l|c|c|l|l|l|l|l|l|l|l|l|l|l|}
\hline \multirow{2}{*}{ Regimen } & \multicolumn{3}{|c|}{2008} & \multicolumn{3}{c|}{2009} & \multicolumn{3}{c|}{2010} & \multicolumn{3}{c|}{2011} & \\
\cline { 2 - 16 } & Intervenida & Programada & Cobertura & Intervenida & Programada & Cobertura & Intervenida & Programada & Cobertura & Intervenida & Programada & Cobertura & $\begin{array}{l}\text { Porcentaje de } \\
\text { Cumplimiento }\end{array}$ \\
\hline Contributivo & 43.708 & 75.126 & $58 \%$ & 46.395 & 74.388 & $62 \%$ & 52.627 & 725.916 & $72 \%$ & 41.471 & 72.115 & $58 \%$ & $19 \%$ \\
\hline Subsidiado & 7.945 & 23.862 & $33 \%$ & 6.372 & 23.522 & $27 \%$ & 7.839 & 24.040 & $33 \%$ & 6.574 & 22.930 & $29 \%$ & $30 \%$ \\
\hline Total & 51.653 & 98.988 & $52 \%$ & 52.767 & 97.910 & $54 \%$ & 60.466 & 96.956 & $62 \%$ & 48.045 & 95.045 & $51 \%$ & $55 \%$ \\
\hline
\end{tabular}

Fuente: Secretaria Distrital de Salud. Dirección de aseguramiento

Análisis: se observó cumplimiento en la cobertura de gestantes en los dos regímenes en el periodo 2008-2011 de acuerdo a lo establecido en la Política de Salud oral, sin embargo al comparar la población programada frente a la intervenida por año tanto en el régimen contributivo como vinculado se observó para el 2008 una cobertura del 52\%, para el 2009 un 54\%, para el 2010 un $62 \%$ y para el 2011 un $51 \%$ lo que indicaba la necesidad de aumentar la cobertura de atención de la gestante en los regímenes contributivo y subsidiado ya que se observó un porcentaje del 45 \% por atender de esta población, de igual forma se hacía necesario realizar seguimiento, análisis y replanteamiento con base 
a resultados con el fin realizar ajuste a los lineamientos establecidos en la Política Pública de salud oral. .

\subsubsection{Cobertura consulta Odontológica de primera vez menores de 19 años Régimen Contributivo y Subsidiado Bogotá.2011.}

La población especial perteneciente a menores de 19 años presentó el siguiente comportamiento para el primer semestre del 2012 frente a las atenciones de primera vez para los dos regímenes de afiliación:

Tabla 44 Cobertura de consulta de primera vez en regímenes contributivo y subsidiado población menor de 19 años en Bogotá. Corte junio 30 de 2012.

\begin{tabular}{|l|l|l|l|}
\hline Régimen & Afiliados < 19 años & $\begin{array}{l}\mathbf{N}^{\circ} \text { de consultas } \\
\text { primera } \\
\text { odontología }\end{array}$ & Cobertura \\
\hline Subsidiado & 252.906 & 36.854 & $14,6 \%$ \\
\hline Contributivo & 461.971 & 108.076 & $23,4 \%$ \\
\hline Total & 714.877 & 144.930 & $20,3 \%$ \\
\hline
\end{tabular}

Fuente. Secretaria Distrital de Salud. Dirección de aseguramiento.

Análisis: se observó que las coberturas de consulta de primera vez en menores de 19 años se encontraban en un porcentaje bajo frente a las metas establecidas para el final del periodo lo que hacía necesario el fortalecimiento de la asignación de citas para lograr alcanzar la meta proyectada de ciudad.

Página 149 de 228

Rutty Adriana Abril Vivas. Odontóloga. Especialista Administración Hospitalaria. Auditoria de la Calidad. Nubia Astrid Duarte Pinzón. Enfermera. Especialista en Gerencia de Salud. 


\subsubsection{Consolidado Ciudad Bogotá 2008 - 2011 .}

La cobertura en los dos regímenes de afiliación en Bogotá en el periodo comprendido 2008-2011 mostró mejores coberturas de las acciones preventivas en salud oral y en el acceso para la atención de primera vez para el grupo de menores de cinco años (contributivo) y gestantes (Grupo técnico de la Secretaria Distrital de Salud, 2012)

Tabla 17 Metas Distritales de Salud Oral 2008-2011. Consolidado Régimen Subsidiado y Contributivo en Bogotá D.C

\begin{tabular}{|l|r|r|r|r|r|r|}
\hline \multirow{2}{*}{} & \multicolumn{3}{|c|}{ Año 2008 } & \multicolumn{3}{|c|}{ Año 2011 } \\
\cline { 2 - 7 } & $\begin{array}{l}\text { Población } \\
\text { Intervenida }\end{array}$ & $\begin{array}{l}\text { Población } \\
\text { Programada }\end{array}$ & Cobertura & $\begin{array}{l}\text { Población } \\
\text { Intervenida }\end{array}$ & $\begin{array}{l}\text { población } \\
\text { Porgramada }\end{array}$ & Cobertura \\
\hline Control de Placa Bacteriana & 1.886 .120 & 5.944 .510 & $31,7 \%$ & 934.746 & 4.182 .915 & $22 \%$ \\
\hline Fluorización & 225.759 & 1.574 .578 & $14,3 \%$ & 247.613 & 1.086 .941 & $23 \%$ \\
\hline Aplicación de Sellantes & 175.319 & 1.355 .790 & $12,9 \%$ & 195.699 & 874.455 & $22 \%$ \\
\hline Detartraje Supragingival & 647.611 & 4.806 .685 & $13,5 \%$ & 502.603 & 3.450 .598 & $15 \%$ \\
\hline Atención Odontologica a la Gestante & 47.827 & 93.131 & $51,4 \%$ & 48.045 & 68.840 & $70 \%$ \\
\hline Atención a Niños y Niñas Menores de Cinco Años & 82.167 & 411.474 & $20,0 \%$ & 127.041 & 298.485 & $43 \%$ \\
\hline
\end{tabular}

Fuente: Secretaria Distrital de Salud. Dirección de aseguramiento

Análisis: a pesar de evidenciarse aumento de la cobertura del año 2008 frente al 2011 para los dos regímenes de las actividades preventivas a excepción del control de placa bacteriana que disminuyó, se observó un alto porcentaje de incumplimiento de actividades programadas frente a las actividades realizadas para el periodo 2008-2011, lo que indica la necesidad de realizar seguimiento, análisis y replanteamiento con base a resultados con el fin realizar ajuste a los lineamientos establecidos en la Política Pública de Salud oral incluyendo todos los grupos etarios.

Página 150 de 228

Rutty Adriana Abril Vivas. Odontóloga. Especialista Administración Hospitalaria. Auditoria de la Calidad. Nubia Astrid Duarte Pinzón. Enfermera. Especialista en Gerencia de Salud. 


\subsubsection{Comparativo de cobertura de consulta de primera vez Bogotá 2011-}

2012.

La siguiente información se realizó un comparativo de la atención de primera vez del año 2011 y el primer semestre del 2012.

Para el primer semestre del 2012, según información de las EPS que reportaron de forma oportuna, el régimen contributivo afilió a 1.733 .751 bogotanos, el cual representaba el $32.30 \%$ del total de los afiliados y realizó 171.948 consultas de primera vez; en lo que respecta al régimen subsidiado afilió a 579.444 personas y realizó un total de 31.772 consultas. (Secretaria Distrital de Salud, 2012b)

Tabla 18 Comparativo año 2011 primer semestre 2012 del indicador consulta de primera vez.

\begin{tabular}{|l|l|l|l|l|}
\hline & Contributivo 2011. & $\begin{array}{l}\text { Contributivo } \\
\text { primer semestre } \\
2012 .\end{array}$ & Subsidiado 2011. & $\begin{array}{l}\text { Subsidiado primer } \\
\text { semestre 2012. }\end{array}$ \\
\hline Consulta 1 vez & 295.292 & 171.948 & 67.545 & 31.772 \\
\hline Cobertura & $17,5 \%$ & $9.9 \%$ & $10,8 \%$ & $6,9 \%$ \\
\hline
\end{tabular}

Fuente. Secretaria Distrital de Salud. Dirección de aseguramiento.

Análisis: se observó para el régimen contributivo una cobertura de $9.9 \%$ de consultas de primera vez y para el subsidiado una cobertura de 6,9\% evidenciándose débil incremento

Página 151 de 228

Rutty Adriana Abril Vivas. Odontóloga. Especialista Administración Hospitalaria. Auditoria de la Calidad. Nubia Astrid Duarte Pinzón. Enfermera. Especialista en Gerencia de Salud. 
frente al 2011, por la cual se deberían haber buscado estrategias para mejorar la demanda en este aspecto.

\subsubsection{Perfil epidemiológico población vinculada, desplazada y subsidiada.}

\section{Bogotá. 2006-2012.}

La información registrada en perfil epidemiológico 2006-2012 realizado para la población vinculada, desplazada y subsidiada por la Secretaria Distrital de Salud tomando los datos reportados en los registros individuales de servicios de salud RIPS registró lo siguiente: (Secretaria Distrital de Salud de Bogotá et al., 2014):

llustración 54 Tendencia de las atenciones en salud oral por localidad y año en la población vinculada, desplazada y subsidiada no POSS. Bogotá, D.C., 2006-2012.

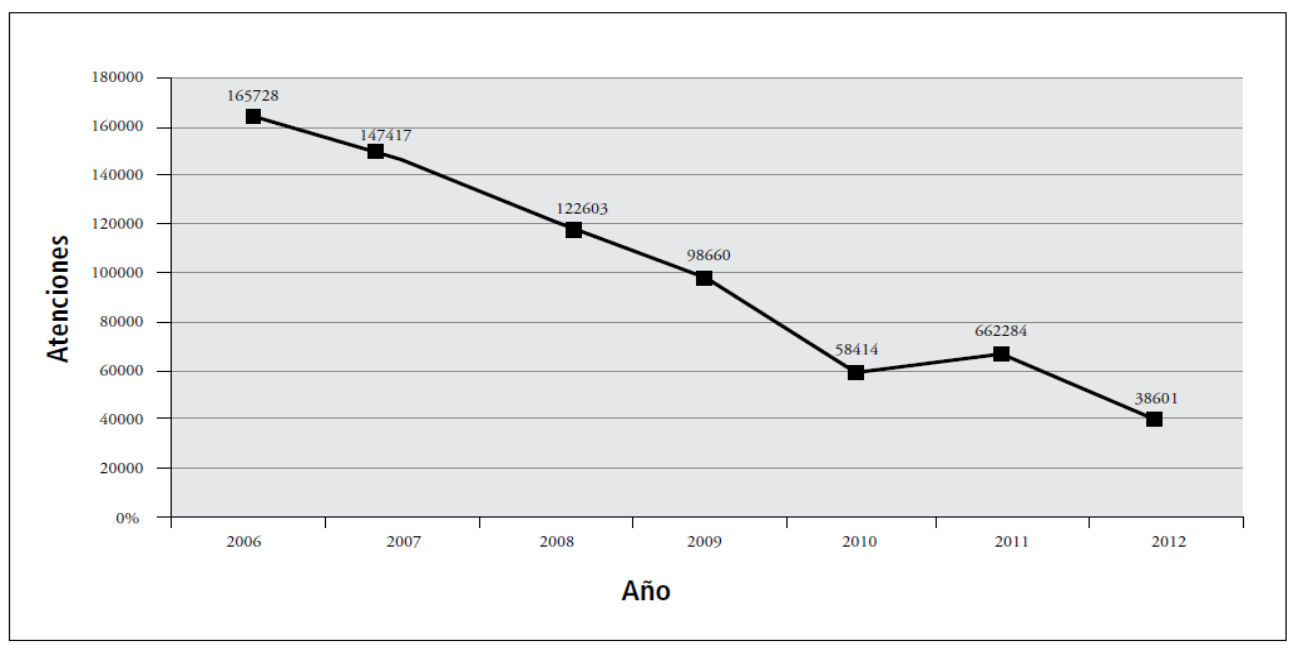


Análisis: se evidencio tendencia a la disminución en la atención a la población vinculada, desplazada y subsidiada no POSS en Bogotá lo que sugiere el fortalecimiento de la política frente a esta población en la totalidad de los eventos en salud oral.

\subsubsection{Indicadores de alerta temprana vigencia Colombia Superintendencia Nacional de Salud 2013.}

Frente a los indicadores de alerta temprana, específicamente de oportunidad para la asignación de citas de consulta general para el 2013 se encontraron entre 1,8 y 5,2 días. El promedio de oportunidad en la asignación de citas de odontología general, de manera global, a nivel nacional se encontró entre 2,2 y 3,7 días, con una desviación estándar entre 2,87 y 6,7 días.

Para el indicador oportunidad de asignación de citas odontológicas a nivel nacional (datos pertenecientes a las EPS que reportaron oportunamente con fecha primer semestre del 2013), el 26,3\% de las EPS asignaron en menos de 3 días las citas y el 73,7\% reportaron una desviación de más de tres días ofreciendo la atención a más de tres días después de que fue solicitada; para el régimen contributivo al observar la distribución porcentual promedio en la red de cada EPS solamente el 10,5\% contó con oportunidad de atención inicial en el primer nivel. 
Para el subsidiado, se observó una distribución porcentual de $71 \%$ en promedio con oportunidad inferior a 3 días y 29\% realizaron la atención a más de tres días, donde el $38,7 \%$ de estas realizaron el servicio en su atención inicial de forma oportuna

Frente a las EPS que prestan el servicio a las comunidades indígenas el 66,6\% cuentan con una distribución porcentual promedio de oportunidad menor de 3 días, y el 33,3\% registro una desviación estándar la oportunidad de atención, ofreciendo en el 66,6\% de sus servicios en la red de primer nivel la atención inicial.

Tabla 19 Seguimiento al indicador de oportunidad de porcentaje de asignación de citas odontológicas regímenes de afiliación. Colombia 2012- 2013.

\begin{tabular}{|l|l|l|l|}
\hline $100 \%$ EPS & $\begin{array}{l}\text { Indicador de } \\
\text { oportunidad de } \\
\text { asignación en menos } \\
\text { de 3 días }\end{array}$ & $\begin{array}{l}\text { Indicador } \\
\text { oportunidad de } \\
\text { asignación } \\
\text { desviación a más de } \\
3 \text { días }\end{array}$ & $\begin{array}{l}\text { Oportunidad incial en } \\
\text { atención inicial } \\
\text { primer nivel }\end{array}$ \\
\hline Contributivo & $26,3 \%$ & $73,7 \%$ & $10,5 \%$ \\
\hline Subsidiado & $71 \%$ & $29 \%$ & $38,7 \%$ \\
\hline Indígena & $66,6 \%$ & $33,3 \%$ & $66,6 \%$ \\
\hline
\end{tabular}

Análisis: se observó que el $100 \%$ de la red de prestadores que ofertan la atención de odontología general no cumplió con los estándares designados por norma generando inoportunidad en la prestación de los servicios de la población asegurada.

Página 154 de 228

Rutty Adriana Abril Vivas. Odontóloga. Especialista Administración Hospitalaria. Auditoria de la Calidad. Nubia Astrid Duarte Pinzón. Enfermera. Especialista en Gerencia de Salud. 
De acuerdo al seguimiento global de la Superintendencia Nacional de Salud (SNS) del Decreto 019 de 2012 para la vigencia 2012-2013 se encontró un elevado porcentaje de inoportunidad para la atención de los servicios para los usuarios del régimen contributivo, mientras que para el régimen subsidiado un $42 \%$ de la red presentó oportunidad en la prestación del servicio; sin embargo teniendo en cuenta que el mayor porcentaje de afiliados pertenecen a este grupo se observa un elevado número de usuarios sin cubrimiento. Se evidenció que la red prestadora de servicios de las EPS indígenas cumplió con el estándar establecido, y a pesar de que en general un $60 \%$ de las IPS cumplieron con el promedio del estándar de tres días establecido para la consulta, el número de entidades prestadoras con desviación en este estándar es alto, a pesar de que ha mejorado con respecto al 2012.

El seguimiento realizado a la asignación de citas de odontología general dio como resultado en el régimen contributivo la oportunidad de 2,3 a 5,1 días, para el subsidiado de 2,3 a 3,6 días y para las EPS indígenas de 1,8 a 3,8 días.

Al comparar con la vigencia 2012, los promedios para la consulta de odontología en los diferentes regímenes se encontró dentro de los establecido en el decreto 019 de 2.012, observándose una mejoría tanto en los tiempos como en el reporte institucional de las diferentes EPS, pero se presentaron entidades con asignación de citas de hasta 2 meses

\footnotetext{
Página 155 de 228

Rutty Adriana Abril Vivas. Odontóloga. Especialista Administración Hospitalaria. Auditoria de la Calidad. Nubia Astrid Duarte Pinzón. Enfermera. Especialista en Gerencia de Salud.
} 
lo que índice directamente sobre el servicios (Superintendencia Nacional de Salud ., 2012)

\subsubsection{Cobertura establecida en Programa de acciones colectivas (PIC) Distrital.}

Para el periodo 2010, se abordaron 228 sedes de Instituciones educativas del distrito y 143 Jardines infantiles, con el fin de mejorar las prácticas de cepillado en este programa participaron 101.537 estudiantes y 3010 docentes, así como 15.230 pre-escolares y 580 profesores de estos grados.

En el ámbito familiar, se registró el abordaje de 4.456 familias en condición de vulnerabilidad con participación de población de menores de 9 años, gestantes, así como población desplazada con el concurso de 13.368 personas.

En el ámbito institucional, se realizó el abordaje de 58 Instituciones de protección de menores, con participación de 1200 adolescentes y niños, y participación de 1953 adultos mayores de 125 Instituciones y 212 cuidadores de este grupo etario ubicados de 17 localidades. 
En el ámbito comunitario se registró una atención de 179 Organizaciones sociales (FAMIS, comedores comunitarios, clubes juveniles, HOBIS) implementando prácticas protectoras en salud oral con la participación de 7.118 personas.

En el ámbito laboral se registró participación de 159 unidades de trabajo informal, en las localidades de Ciudad Bolívar, Suba, Kennedy, Puente Aranda y Engativá, con la participación de 175 trabajadores informales.

En el ámbito IPS, se reportaron 123 puntos de atención en salud oral de las ESE desarrollando acciones de competencias ciudadanas con la participación de 179 odontólogos, 71 auxiliares de consultorio y 48 higienistas, fortaleciendo herramientas conceptuales y técnicas actualizadas mejorando la atención.

Para el año 2011 el proyecto de autonomía oral contó con la participación de 129.911 escolares realizando seguimiento al $82,92 \%$ de la población intervenida; de los cuales un $85,16 \%$ mejoraron las prácticas de salud oral; en lo referente al aseguramiento se contó con 86.823 escolares correspondiendo a $60 \%$ del régimen contributivo, el $26 \%$ del régimen subsidiado y el $12 \%$ escolares no asegurados y $2 \%$ del régimen especial, se encontró que 14.987 escolares clasificados con alta necesidad de atención accedieron al servicio; de un total de 38.062 menores, la población que no accedió al servicio fue debido a los siguientes factores: falta de tiempo $19 \%$, por factor aseguramiento el $15,4 \%$ 
,por temas económicos el 10,46\%, por temas económicos el 4\%, por tema geográfico el $2 \%$, por considerar la calidad del servicio deficiente, $1 \%$ consideraron que no era importante la visita a la consulta (Secretaria Distrital de Salud. Bogotá, 2012).

En el ámbito familiar se registró la participación de 14.559 familias (43.677 personas aproximadamente) de las cuales el $80 \%$ mejoraron las prácticas en salud oral

Para la vigencia 2012 de la Secretaria Distrital de Salud; abordó la población por intermedio de equipos de salud oral integrados por odontólogos y auxiliares de salud oral en los hospitales de primer nivel del Distrito, Chapinero, Usaquén, San Cristóbal, Centro Oriente, Fontibón, Usme, Tunjuelito, Engativá, Rafael Uribe, Sur, Suba, Nazaret, Pablo VI, Vista Hermosa, así como los espacios de instituciones educativas, las familias, los comedores comunitarios, las unidades de trabajo informal, HOBIS, FAMIS, los institutos de protección de adolescentes y niños y en los consultorios de las diferentes ESE, con el fin de realizar estrategias promocionales en salud oral (Secretaria Distrital de Salud, 2012)

Página 158 de 228

Rutty Adriana Abril Vivas. Odontóloga. Especialista Administración Hospitalaria. Auditoria de la Calidad. Nubia Astrid Duarte Pinzón. Enfermera. Especialista en Gerencia de Salud. 


\section{DISCUSIÓN}

En Colombia con la reforma del sistema de salud a raíz de la implementación de la Ley 100 de 1993, se evidenciaron dificultades en las acciones de salud pública al contar con limitantes desde su propia estructura influenciadas por el mercado del sistema de aseguramiento generando segmentación institucional y fragmentación operativa afectándose de igual forma el criterio de los profesionales en su ética desincentivando el ejercicio profesional que va en contra de los principios individuales y colectivos tal y como lo afirman Franco, 2013:273-277; Ruiz et al, 2011:1; Vega y Carrillo, 2006:2; Yepes et al, 2010 citado por Molina (Universidad de Antioquia Facultad Nacional de Salud Pública Héctor Abad Gómez \& COLCIENCIAS, 2014), afectándose de igual forma la autonomía profesional de los trabajadores de la salud, sus principios morales, éticos y sus derechos laborales, lo que desestimula el buen desempeño y va en contra de los derechos individuales y comunitarios (Universidad de Antioquia Facultad Nacional de Salud Pública Héctor Abad Gómez \& COLCIENCIAS, 2014)

Para la construcción de la política de salud oral del distrito se tuvieron en cuenta los lineamientos emitidos por la nación, el perfil epidemiológico, los problemas sociales de mayor importancia, las estadísticas nacionales y las metas establecidas en el milenio. EI distrito utilizo la estrategia enfocada en los determinantes social es basado en la Atención Primaria en Salud, con énfasis en la participación comunitaria, como lo definió la OPS “ 
la APS como: "la asistencia esencial, basada en métodos y tecnologías prácticos, científicamente fundados y socialmente aceptables, puesta al alcance de todos los individuos y familias de la comunidad mediante su plena participación, y a un costo que la comunidad y el país puedan soportar, en todas y cada una de las etapas de su desarrollo, con espíritu de auto responsabilidad y autodeterminación" (OPS, 2008)

En Bogotá a pesar de que la dirección de salud pública definió estrategias para su cumplimiento se generaron varios cambios a través de los diferentes programas de gobierno como: Salud a su Hogar en el periodo 2004-2007, Salud a su Casa años 2008 a 2011 y a partir del 2012 se realizó cambio en su enfoque, estrategia y operativización a través de Territorios Saludables.

De acuerdo a Molina (Universidad de Antioquia Facultad Nacional de Salud Pública Héctor Abad Gómez \& COLCIENCIAS, 2014) dentro de una de las limitaciones observadas en estos programas se encontró el conflicto que ocurrió entre las aseguradoras y la Secretaria distrital de salud de Bogotá, debido a que la demanda inducida pudo afectar los intereses financieros de las EPS por lo que generó freno en el desarrollo de estas estrategias blindando el interés económico de las aseguradoras; de igual forma los regímenes de afiliación permitieron la segmentación de los grupos poblacionales y la realización de una atención fragmentada influyendo en la atención integral de la familia.

Página 160 de 228

Rutty Adriana Abril Vivas. Odontóloga. Especialista Administración Hospitalaria. Auditoria de la Calidad. Nubia Astrid Duarte Pinzón. Enfermera. Especialista en Gerencia de Salud. 
El cambio continuó de abordajes y sus respectivos lineamientos permitieron no contar con una contextualización y alcance de la estrategia APS y de las acciones de salud pública.

La priorización de poblaciones y la focalización de los programas de salud pública liderado por la Secretaria de salud de Bogotá enfocada a la población del régimen subsidiado o pobres no afiliados, generaron formas de exclusión de la población pobre y vulnerable del régimen contributivo que también requieren los programas de salud pública, pero que deben ser cubiertas por la EPS y dado que estas han evadido su responsabilidad, esta 'población queda casi sin cobertura, de igual forma las prioridades establecidas por el Ministerio de salud se antepone con las prioridades del distrito (Universidad de Antioquia Facultad Nacional de Salud Pública Héctor Abad Gómez \& COLCIENCIAS, 2014).

Los diferentes estudios a nivel nacional y en el distrito capital concluyeron que la educación en salud bucal y su refuerzo permanente es la única garantía para que la población se mantenga sana ; según Montenegro, la educación temprana a los padres y a los niños acerca de las buenas prácticas de higiene bucal reduce la incidencia de caries y les permite adquirir hábitos saludables (Gino Montenegro Martínez, Ana Lucia Sarralde Delgado, \& Claudia Patricia Lamby Tovar, 2013), afirma Montenegro, que la información y la educación que reciban las comunidades deben estar de acuerdo a sus necesidades y representaciones sociales, y no sólo desde la mirada científica impositiva. Por lo tanto, 
son prioritarios programas de promoción de prácticas que favorezcan la salud oral, que integren no sólo al individuo objeto de la intervención, sino la familia, vecino y amigos al tiempo que se reconocen las condiciones sociales donde se efectúa la educación. Para tal fin se requiere de estrategias que anticipe el desarrollo de las enfermedades de boca y promuevan las prácticas de acciones que favorezcan la salud oral y que sean culturalmente sostenibles, liderada por el equipo de odontología y con el apoyo en casa del cuidador de los niños; el odontólogo debe formar parte de equipos de trabajo interdisciplinarios de salud e intersectoriales con otros actores de la sociedad. Es necesario avanzar en la construcción de ambientes y contextos saludables, lo que a largo plazo puede influir en la reducción de los costos de los servicios de salud oral (Gino Montenegro Martínez, 2011) de acuerdo a lo anterior es cuestionable la calidad de la educación de los programas preventivos en salud oral de acuerdo a la morbilidad sentida y a los indicadores de salud oral evidenciados en el presente estudio.

De acuerdo a la ENSAB IV, se ha reducido la cantidad de personas con edentulismo, sin embargo, quienes la padecen siguen siendo víctimas de una baja oportunidad, resolutividad y efectividad de las atenciones, $y$ han tenido que rendirse ante el incremento del edentulismo al uso de prótesis que desencadenan disfuncionalidad, lesiones de tejidos blandos como la estomatitis subprotésica (presente en el $62.17 \%$ de quienes usan prótesis) y discapacidad, que afectan su calidad de vida y su bienestar. (Ministerio de

\footnotetext{
Página 162 de 228

Rutty Adriana Abril Vivas. Odontóloga. Especialista Administración Hospitalaria. Auditoria de la Calidad. Nubia Astrid Duarte Pinzón. Enfermera. Especialista en Gerencia de Salud.
} 
Salud y Protección social. \& Pontificia Universidad Javeriana, 2014), esta misma encuesta estableció la presencia de lesiones consideradas como premalignas a partir de identificación de leucoplasias, queilitis actínicas, eritroplasias y lesiones palatinas del fumador invertido, que en conjunto se identifican como de menor frecuencia frente a las cifras internacionales.

A pesar que se tiene la política en salud oral la disminución del edentulismo ,no se evidencia la monitorización de este indicador, que permita lograr un diagnóstico, pronóstico y un plan de tratamiento protésico correcto, según Varón, la pérdida de los dientes naturales genera una serie alteraciones oclusales y cambios en el sistema estomatognático y en las estructuras cráneo-faciales (Amparo Constanza Varón de Gaitán, Juan Carlos Bustamante Mesa, Ana Catalina Hoyos Galvis, Andrés Felipe Zapata Suárez, \& Sonia Patricia Plaza Ruiz, 2014)

Se evidenció que es necesario definir una fuerte política en salud bucal y un plan de contingencia con varios componentes desde los territorios y los servicios de salud, pensados desde el mantenimiento así como generación de acciones resolutivas como la atención en red, sitio de trabajo para el desempeño de los equipos básicos de salud como parte de un nuevo modelo de atención, con rutas específicas de atención que operen en lo urbano y en zona rurales con el fin de reducir la causa de carga de enfermedad bucal para la población del distrito capital, sin desconocer los principios de la promoción y prevención que han regido a través del tiempo y que no han logrado los

Página 163 de 228

Rutty Adriana Abril Vivas. Odontóloga. Especialista Administración Hospitalaria. Auditoria de la Calidad. Nubia Astrid Duarte Pinzón. Enfermera. Especialista en Gerencia de Salud. 
efectos deseados por la cual es necesario que las instituciones prestadoras de servicios de salud cuenten con recurso humano idóneo y suficiente para formar equipos multidisciplinarios que conozcan ampliamente el perfil local ; adicionalmente es necesario realizar una revisión y ajuste desde la misma norma que permita la prestación de los servicios desde el enfoque de derechos donde prime la atención de los usuarios y no favorezca los intereses financieros institucionales apoyados de la veeduría ciudadana, COPACOS, asociación de usuarios y entes de control .

La prevención de los riesgos asociados y la identificación oportuna y seguimiento a la detección temprana de las lesiones premalignas constituyen el elemento esencial para la atención temprana, la prevención y detección temprana del cáncer bucal en procura de reducir la letalidad por la atención inoportuna, teniendo en cuenta que este tipo de lesiones son más frecuentes a partir de los 45 años de edad, en personas del régimen subsidiado, no aseguradas y de grupos provenientes de la región Pacífica y Atlántica, se hace necesario fortalecer las acciones de educación, autocuidado y atención oportuna.

El equipo odontológico tiene la responsabilidad en la educación, detección precoz, el diagnóstico y la remisión al especialista de pacientes con cáncer oral. El cumplimiento de esta responsabilidad por parte del odontólogo proporcionará una tasa de supervivencia mayor para los pacientes y una marcada reducción en las tasas de morbilidad y mortalidad (García García V \& Bascones Martínez A, 2009)

\footnotetext{
Página 164 de 228
}

Rutty Adriana Abril Vivas. Odontóloga. Especialista Administración Hospitalaria. Auditoria de la Calidad. Nubia Astrid Duarte Pinzón. Enfermera. Especialista en Gerencia de Salud. 
Es posible reducir simultáneamente la carga de enfermedades bucodentales y la de otras enfermedades crónicas si se abordan los factores de riesgo comunes, como el consumo de tabaco y las dietas malsanas, la reducción de la ingesta de azúcares y una alimentación bien equilibrada previenen la caries dental y la pérdida prematura de dientes. Dejar de fumar y reducir el consumo de alcohol disminuye el riesgo de cánceres de la cavidad bucal, periodontopatías y pérdida de dientes. El consumo de frutas y verduras protege contra el cáncer de la cavidad bucal. El uso de equipos en la protección en la práctica de deportes y el uso de vehículos automóviles reduce las lesiones faciales y perdidas de dientes. Por ultimo unos buenos hábitos de higiene (Bascones Martínez A, 2009) ,razón por la cual es necesario generar una cultura educativa con acciones transformadoras que involucren todos los actores : prestadores, usurarios estudiantes, docentes, directivos realizando revisión, análisis y acciones de mejora basadas en información, para minimizar la morbilidad oral de la población del distrito .

Es posible reducir la carga de enfermedades bucodentales si se implementan políticas públicas en la población en general con el fin de disminuir y prevenir la caries dental, promoviendo actividades como la fluorización del agua de bebida, la sal, la leche, el uso de dentífricos; según la OMS la exposición a largo plazo a niveles óptimos de fluoruros reduce el número de caries tanto en los niños como en los adultos. Usando esas estrategias de prevención se pueden evitar tratamientos dentales muy costosos (Organización Mundial de la Salud, 2012), sin embargo es necesario realizar un control

\footnotetext{
Página 165 de 228

Rutty Adriana Abril Vivas. Odontóloga. Especialista Administración Hospitalaria. Auditoria de la Calidad. Nubia Astrid Duarte Pinzón. Enfermera. Especialista en Gerencia de Salud.
} 
estricto, educación y recomendación a la población sobre su uso ya que actualmente existen estudios en los que la aplicación sistémica de flúor están relacionados con efectos adversos como aumento de riesgo de fracturas óseas, hipotiroidismo, disminución del coeficiente Intelectual IQ, enfermedades de tipo artrítico, fluorosis dental y posiblemente sarcoma óseo (CDC de Atlanta, 2002).

Se observa deficiencia en la política de salud oral para los pacientes con enfermedades crónicas, con VIH, con enfermedades sistémicas (como la inmunosupresión) y enfermedades genéticas; de acuerdo a Arévalo son factores de riesgo en la gingivitis y enfermedad periodontal.

No se dispone de información de los pacientes crónicos que son tratados por equipos interdisciplinario; según Arévalo el tratamiento interdisciplinario de las enfermedades crónicas con una visión integral de la persona mejoran el pronóstico en la salud bucal (Catalina Arévalo et al., 2012)

En la actualidad se desconoce información de los pacientes tratados por odontología en los pacientes con VIH-SIDA por lo que podemos concluir que el estado de salud oral de este grupo de sujetos es inferior al de la población general colombiana al mostrar porcentajes superiores de la mayor parte de las patologías analizadas. Por tanto, se hace evidente la falta de tratamiento bucodental y atención oportuna. Esto podría ayudar la prevención de alteraciones orales no relacionadas con el SIDA, conllevando atenciones

Página 166 de 228

Rutty Adriana Abril Vivas. Odontóloga. Especialista Administración Hospitalaria. Auditoria de la Calidad. Nubia Astrid Duarte Pinzón. Enfermera. Especialista en Gerencia de Salud. 
en tratamiento odontológico (María del Carmen Jiménez Malagón, Luis Fang, \& Antonio Díaz Caballero, 2012)

A través de este estudio se evidencia la existencia de problemas estructurales ya que como se presentó en los diferentes estudios realizados a nivel nacional y distrital las enfermedades del sistema estomatognático se siguen presentando, viéndose afectadas las metas establecidas tanto a nivel distrital como nacional, la atención en salud oral no se concibe por niveles de complejidad, no se observa una atención integral con niveles de referencia y contrarreferencia que solucionen el problema a la población (Secretaria Distrital de Salud, 2011) la estructura organizacional actual no permite una real coordinación entre las acciones individuales y colectivas así como las de promoción y prevención.

Es necesario que las políticas de salud oral del distrito se establezcan de manera integral con enfoque desde la promoción prevención, tratamiento y rehabilitación en todos los grupos poblacionales realizando un diagnóstico previo con el fin de prestar una atención de acuerdo a la necesidad sentida, con actitudes, competencias y prácticas clínicas de los servicios de salud de forma conjunta con los diferentes actores sociales y comunidad. Considerando el marco normativo generado a nivel nacional y distrital los diferentes estudios relacionados en la presente investigación muestran que las condiciones de salud oral de los habitantes del distrito no han logrado el bienestar general de la población en lo que respecta a su salud oral mirada de forma integral en el sistema estomatognático,

\footnotetext{
Página 167 de 228

Rutty Adriana Abril Vivas. Odontóloga. Especialista Administración Hospitalaria. Auditoria de la Calidad. Nubia Astrid Duarte Pinzón. Enfermera. Especialista en Gerencia de Salud.
} 
a pesar de que la Secretaria Distrital de salud en cumplimento con lo establecido en la línea operativa de la gestión de la salud Pública del plan decenal 2012- 2021 ha formulado diferentes estrategias, planes, programas, políticas, observándose excesiva demanda frente a la oferta ,inadecuado cumplimiento de la norma establecida, ausencia de sistemas de medida para conocer la continuidad y terminación de tratamientos con el fin de establecer estrategias de intervención para mejoramiento de los servicios, problemas de calidad en los servicios de salud oral, desinformación del acceso a los servicios, afectación de los atributos de calidad en la atención, debilidades en la información del reporte de indicadores de alerta temprana dada por los prestadores evidenciada como insuficiente, irregular e inadecuada, adicionalmente no se cuenta con instrumentos para el monitoreo continúo de los indicadores establecidos (Ministerio de la Protección Social de Colombia, 2010)

Según lo referenciado por Rocha en el estudio de Martins, las consultas odontológicas, al contrario de las consultas médicas en efecto tienden a disminuir en la medida en que aumenta la edad de los habitantes, por tanto, la utilización de los servicios odontológicos aumenta durante la adultez mayor, de acuerdo al autor en el estudio de Lima atribuyen la alta prevalencia de pérdida de dientes naturales entre adultos mayores y las dificultades de acceso a servicios odontológicos. En la revisión realizada por Rocha, en el estudio de Moreira se identificaron como principales barreras que afectan a la utilización de servicios odontológicos: la baja escolaridad, los bajos ingresos económicos

\footnotetext{
Página 168 de 228

Rutty Adriana Abril Vivas. Odontóloga. Especialista Administración Hospitalaria. Auditoria de la Calidad. Nubia Astrid Duarte Pinzón. Enfermera. Especialista en Gerencia de Salud.
} 
y la escasa oferta de servicios públicos de atención en salud bucal para población (Anderson Rocha Buelvas, 2013), esta situación demuestra la fuerte influencia de los intereses económicos que prevalecen sobre las necesidades reales de los usuarios.

En el Sistema General de Seguridad Social en Salud (SGSSS), la cobertura del régimen contributivo, como del subsidiado, se ha incrementado; sin embargo, se observa que cerca del $66.6 \%$ de la población pertenece al régimen subsidiado y solamente el $33.4 \%$ se encontró afiliado al régimen contributivo, lo cual es contrario a lo planteado en la ley 100 de 1993 cuando se esperaba tener cerca del 70\% de las personas en el régimen contributivo y $30 \%$ en el régimen subsidiado. La consecuencia de esta disparidad es que la financiación del sistema tiende a aumentar en los recursos públicos y disminuye en las contribuciones de los trabajadores formales de la economía, ya que factores como el desempleo o la informalidad laboral afecta directamente el monto de las cotizaciones en salud. A pesar que se han promulgados leyes como: la Ley 797 de 2003 donde se obliga a cotizar a quienes se encuentren vinculados a través de contratos de trabajo y la Ley 1250 de 2008 que autorizaba a cotizar solamente a salud a trabajadores independientes de bajos ingresos pudo tener incidencia en el aumento del porcentaje de afiliados al régimen contributivo en los últimos cuatro años y a pesar que se generó mecanismos de control, como la planilla integrada de liquidación de aportes (PILA) en la que se unió la contribución a pensiones con la de salud, con el fin de disminuir la evasión de la afiliación al régimen contributivo (Fundación Corona \& Fundación Santa Fe de Bogotá, 2015), se

\footnotetext{
Página 169 de 228

Rutty Adriana Abril Vivas. Odontóloga. Especialista Administración Hospitalaria. Auditoria de la Calidad. Nubia Astrid Duarte Pinzón. Enfermera. Especialista en Gerencia de Salud.
} 
pudo inferir que a pesar del aumento de la cobertura en salud es innegable las barreras de acceso a los servicios, de acuerdo a informe preliminar de la defensoría del pueblo se han generado que continuamente se interpongan en los últimos 5 años un alto porcentaje de acciones de tutela incrementándose en un 25,2\% para garantizar el derecho fundamental a la salud(2015), igualmente el estudio realizado por Martín, refirió que en Colombia los usuarios presentaron barreras en las autorizaciones desde la entrada a los servicios de salud y la atención oportuna por fallas en la comunicación con las EPS e IPS; continuidad del servicio, falta de oportunidad para citas médicas especializadas, procedimientos quirúrgicos y entrega de medicamentos (Jorge Martín Rodríguez Hernández, Diana Patricia Rodríguez Rubiano, \& Juan Carlos Corrales Barona, 2013), de igual manera la Secretaria distrital de salud detecto barreras de acceso como cobro de copagos y gastos de bolsillo; los problemas de traslado por barreras de tipo geográfico y de seguridad; ausencia de información, no disponibilidad de servicios o insuficiencia de capacidad resolutiva frente a las necesidades de los ciudadano (Alcaldía Mayor de Bogotá, 2012a), lo que ocasiona demoras en la atención en salud general y por ende de salud oral con efectos perjudiciales para los pacientes y sus familias. Las barreras de acceso son generadas principalmente por el modelo de atención del SGSSS y prácticas indebidas de algunas EPS. Varios funcionarios de éstas, consideraron que el acceso a los servicios de salud, se relaciona con el nivel adquisitivo, lo cual no coincide con los principios de equidad en salud y con la realidad social de la mayoría de la

\footnotetext{
Página 170 de 228

Rutty Adriana Abril Vivas. Odontóloga. Especialista Administración Hospitalaria. Auditoria de la Calidad. Nubia Astrid Duarte Pinzón. Enfermera. Especialista en Gerencia de Salud.
} 
población colombiana, adicionalmente se evidenció desconocimiento de los derechos que la normatividad en Colombia ofrece a los usuarios, lo que ocasionó que fueran usuarios manipulados por las EPS e IPS (Jorge Martín Rodríguez Hernández et al., 2013)

Según estudio realizado por la Universidad Nacional de Colombia y Secretaria Distrital de salud, los habitantes de las localidades con mayor población cuentan con una disponibilidad mucho menor de servicios de consulta externa general odontológica y especializada en las IPS por cada 100.000 habitantes, se evidencia una inequitativa distribución de la oferta en la población del sur ,occidente de la ciudad y centro oriente, donde se conoce un mayor número de necesidades en salud de esta población, lo que implica una necesidad de desplazamiento para obtener los servicios concentrados en otras localidades que tienen un excedente de estos servicios para su población, lo que en resumen constituye una doble barrera, geográfica y económica para el acceso a los servicios (Universidad Nacional de Colombia, 2012)

Frente a la implementación y desarrollo del Sistema de vigilancia Epidemiológica SIVESO se observó el trabajo de la Secretaria Distrital de Salud, sin embargo existen dificultades que no permiten el alcance de logros importantes en Bogotá, la academia no ha adoptado como parte de formación integral a los profesionales para el conocimiento, aplicación y desarrollo de este sistema (entrevista Dr. Ternera anexa), lo que fortalecería el establecimiento de un perfil epidemiológico completo y actualizado del Bogotá para 
definir con exactitud los planes y programas que realmente requiere la población del distrito de acuerdo a su necesidad sentida ya que como se describió la transición demográfica del distrito capital mostro un avanzado descenso de los grupos poblacionales a los cuales están dirigidas las políticas públicas orales, incrementándose la población adulta y adulta mayor y con mayor porcentaje de mujeres, con mayor prevalencia en el régimen subsidiado, viéndose la necesidad de implementar programas de salud oral para estas edades.

Los registros individuales de prestación de servicios de salud -RIPS son instrumentos que se tienen en cuenta para el análisis de la morbilidad atendida y para la toma de decisiones, se ha reportado cuestionamientos sobre su calidad y oportunidad en lo referente a que va dirigida hacia la facturación y no hacia la atención propiamente dicha y/o caracterización epidemiológica (Instituto Nacional de Salud, 2015), adicionalmente nos registra la demanda espontánea y demanda atendida y no las necesidades poblacionales, por esta razón se presentan sesgos en la información para el planteamiento de las políticas, motivo por el cual es indispensable tomar medidas para la calidad del dato con el fin de generar datos de referencia que sirvan para establecer objetivos, acciones y metas eficaces ,así como medir avances y resultados, estableciendo un perfil epidemiológico real con el fin de establecer estrategias y procesos administrativos con una adecuada planeación en los servicios de salud oral tal y como lo propone el Plan de desarrollo 2010-2104, de igual forma para establecer

\footnotetext{
Página 172 de 228

Rutty Adriana Abril Vivas. Odontóloga. Especialista Administración Hospitalaria. Auditoria de la Calidad. Nubia Astrid Duarte Pinzón. Enfermera. Especialista en Gerencia de Salud.
} 
indicadores para considerar la frecuencia de uso por patología y el promedio de procedimientos por usuario.

Como sabemos la oportunidad en la prestación de los servicios y por lo tanto la accesibilidad a los servicios de salud oral y la resolutividad de la problemática existente es de gran importancia para que un sistema se considere eficiente ya que direcciona y racionaliza la atención como el costo, realizándose una oportuna respuesta con la respectiva atención y tratamiento primario de la patología favoreciendo la no aparición de secuelas, generación de incapacidades y descongestionando y racionalizando los servicios de salud oral.

Se cuenta con soporte conceptual tanto a nivel internacional, nacional y distrital que ha permitido implementar estrategias para fortalecer las acciones dirigidas a la población del distrito tanto a nivel promocional, preventivo, resolutivo y de rehabilitación; desde un abordaje tanto individual como colectivo sin embargo y de acuerdo a lo evidenciado en el presente estudio se hace necesario fortalecer la rectoría del ente rector frente a la conducción institucional, mejorar el desarrollo y capacidad de respuesta institucional ; ejercer las funciones de vigilancia y control de forma efectiva, así como del control social.

El presente estudio se basó en información fragmentada ya que como se ha descrito las instituciones no reportaron de forma oportuna ya que los consolidados estadísticos de la ciudad se ven altamente afectados no mostrando la realidad de la situación distrital.

\footnotetext{
Página 173 de 228

Rutty Adriana Abril Vivas. Odontóloga. Especialista Administración Hospitalaria. Auditoria de la Calidad. Nubia Astrid Duarte Pinzón. Enfermera. Especialista en Gerencia de Salud.
} 
Frente al acceso no se está cumpliendo con los estándares establecidos generando inoportunidad en la atención ; se evidenció que en el distrito capital las aseguradoras han venido realizando un alto porcentaje de actividades preventivas sin embargo se considera necesario realizar un seguimiento y control de estas con el fin de evaluar la calidad y efectividad de estas, ya que como se evidenció en el presente estudio no hay cumplimento de las metas programadas frente a las establecidas, por otro lado es evidente que los diseños institucionales facilitan las barreras de acceso a los servicios de salud oral, permiten la fragmentación de los servicios no permitiendo la atención integral de la población y facilitando las barreras de acceso a los servicios de salud oral.

Al realizar el análisis de los resultados permite establecer que existen diferencias en el perfil de salud oral de la población del distrito por consiguiente necesidades de atención diferente en cuanto a lugar de residencia, trabajo, nivel educativo entre otros por lo tanto deben tenerse en cuenta estas variables para la planeación y programación local, no se desconoce el mejoramiento de algunos indicadores debido a la implementación de acciones de promoción y prevención en poblaciones de niños y jóvenes pero se ha evidenciado el incremento de los mismos en poblaciones de adultos y adultos mayores lo que nos indica la necesidad de analizar y replantear las acciones con base a los resultados y teniendo en cuenta las proyecciones poblacionales establecidas por el departamento administrativo nacional de estadística DANE de igual forma es evidente

\footnotetext{
Página 174 de 228

Rutty Adriana Abril Vivas. Odontóloga. Especialista Administración Hospitalaria. Auditoria de la Calidad. Nubia Astrid Duarte Pinzón. Enfermera. Especialista en Gerencia de Salud.
} 
que la mayoría de la población distrital sigue presentando patologías orales en alto porcentaje mastranto a través del tiempo un problema de salud pública.

No se cuenta con un sistema de información unificado por unidades de costos que permitan identificar las necesidades reales de los diferentes servicios de salud oral en el distrito, por lo tanto se hace necesario el mejoramiento en los sistemas y reportes de información de las diferentes EPS, estandarizando desde el ente rector el tipo de información, realizando análisis, y seguimiento continuo, en Bogotá la información sobre prestadores y prestaciones de servicio de salud se encuentra fragmentada y no corresponde a las reales necesidades poblacionales. El sistema integral de la información de salud y su componente de prestación de servicios es incipiente, situación que limita el direccionamiento, la planeación y la gestión de los prestadores de servicios, como lo afirma la Procuraduría general de la nación de Colombia (2012) no se dispone de un sistema de rendición de cuentas cuyos ejes sean indicadores y resultados en salud y la gestión en la prestación de los servicios a nivel de las entidades territoriales, aseguradoras y prestadoras de salud.

Frente a la gestión de la Política en salud oral (2011-2021) se ha identificado una problemática específica en cuanto a la respuesta comunitaria considerada como insuficiente, ausencia de articulación y debilidades en la coordinación interinterinstitucional a pesar de evidenciarse algunos avances en instituciones públicas, lo 
que amerita analizar y en dado caso replantear procesos de identificación planeación y ejecución de acciones en salud oral desde una perspectiva multidimensional, para la generación de planes distritales, así como el replantear el objetivo de rentabilidad económica del sistema de salud lo que incide directamente en la generación de barreras de acceso, concepto de atención primaria en salud desvirtuado entre otros (Secretaria Distrital de Salud, 2012)

Se observa el direccionamiento en lo relacionado con la atención de la salud oral en los diferentes servicios de salud la necesidad de la articulación de las acciones PIC y POS en el marco del sistema obligatorio de garantía de calidad Decreto 1011 de 2006 se observan diferentes barreras de accesos de tipo organizacional, geográfico y económico, desconocimiento de la población en solicitud de servicios que por derecho tienen ,así como ausencia de indicadores de accesibilidad para la toma de decisiones relacionadas con el este atributo de calidad, de igual forma se ha identificado problemática en la oportunidad de atención tanto de la institución como de los usuarios ; la pertinencia y la integralidad se ven afectadas por la existencia de diferentes planes de beneficios condicionados a la capacidad de pago así como su falta de articulación incidiendo directamente sobre la calidad en la atención de los servicios de salud oral, de igual forma las debilidades en los procesos de planeación afecta el desarrollo de la política establecida .

Página 176 de 228

Rutty Adriana Abril Vivas. Odontóloga. Especialista Administración Hospitalaria. Auditoria de la Calidad. Nubia Astrid Duarte Pinzón. Enfermera. Especialista en Gerencia de Salud. 
Un factor a considerar en la implementación de la política de salud oral y que esta tuvo en cuenta fue el fortalecimiento de la gestión del talento humano, sin embargo no es desconocido el tipo de contratación del personal de la salud y por ende los relacionados con la salud oral donde intervienen factores de flexibilidad laboral, que genera alta rotación en los diferentes escenarios afectando la continuidad y avances en los diferentes procesos y en la cual no se aprecian avances en el distrito esto sumado a las múltiples funciones asignadas a los profesionales en odontología ,evidenciándose la ausencia de una coordinación de salud oral no contando con un liderazgo que garantice una adecuada planeación, seguimiento y evaluación, reorientación en la atención de los diferentes Planes y programas(Grupo técnico de la Secretaria Distrital de Salud, 2012)

Adicionalmente en lo referente al campo de investigación a pesar de existir análisis de política de salud oral existen grandes vacíos, no se encuentran documentados análisis de resultados de los planes operativos de las diferentes instituciones ni en lo referente a los resultados de las acciones individuales y colectivas además en temas relacionados con la salud oral no se encuentra documentado grupos inscritos en COLCIENCIAS que generen conocimientos relacionados con la problemática existente (Secretaria Distrital de Salud, 2011)

En Colombia y por ende en el distrito se evidencia ausencia de estadísticas en la atención en salud oral de los pacientes con tratamiento oncológicos ya que en diversos estudios estos pacientes requieren atención interdisciplinaria integral incluyendo el profesional de

\footnotetext{
Página 177 de 228

Rutty Adriana Abril Vivas. Odontóloga. Especialista Administración Hospitalaria. Auditoria de la Calidad. Nubia Astrid Duarte Pinzón. Enfermera. Especialista en Gerencia de Salud.
} 
odontología, con estándares de calidad con el fin de disminuir complicaciones y secuelas que pueden ser graves o letales y que es causada antes, durante y posterior al tratamiento oncológico; debido a la existencia previa de enfermedades orales y que se agudizan en estos tratamientos afectando los tejidos periodontales generando alteraciones locales y sistémicas, el tratamiento odontológico mejora la calidad de vida de los pacientes. (Damián Guillermo Lanza Echeveste, 12d. C.)

La Política pública de salud oral en Bogotá focaliza la atención en menores comprendidos en los rangos de 5- 19 años y gestantes; se observó que para las edades de 20 años en adelante existe debilidad en las acciones de la política pública de salud oral; ya que se evidenció la alta prevalencia de morbilidad oral de acuerdo a la pirámide poblacional de Colombia la cual es similar a lo observado en Bogotá mostró cambios importantes en su forma de acuerdo a los datos poblacionales, pasando de más expansiva a una un poco más constrictiva lo que significa el avance de la transición demográfica ha generado un proceso de envejecimiento, de acuerdo a PROFAMILIA, la esperanza de vida al nacer es de 74 años y la esperanza de vida a partir de los 60 años es de 20 más, ambas superiores en las mujeres que en los hombres. En el año 2013 se observó que un gran porcentaje de la población adultas mayores viven en zonas urbanas y en más de un 60 \% se concentran en Bogotá, así como en los departamentos Valle, Atlántico y Quindío, que son departamentos con niveles altos de desarrollo social y transiciones demográficas más avanzadas, se evidenció que la política oral a nivel nacional y distrital (Secretaria

\footnotetext{
Página 178 de 228

Rutty Adriana Abril Vivas. Odontóloga. Especialista Administración Hospitalaria. Auditoria de la Calidad. Nubia Astrid Duarte Pinzón. Enfermera. Especialista en Gerencia de Salud.
} 
Distrital de Salud, 2011) no ha logrado la articulación funcional de las acciones de promoción de estilos de vida sana, prevención, recuperación y rehabilitación que requiere el individuo ;la asistencia que demanda la elaboración de guías de atención del adulto mayor, que incluyan acciones desde diferentes disciplinas; y que articulen acciones individuales de atención que promuevan un envejecimiento sano y una vejez activa, considerando los cambios y retos demográficos de la sociedad y estrategias que permitan articular y coordinar acciones interdisciplinares, intersectoriales, con apropiación de la misma y promover los estados de salud en las personas en los diferentes ámbitos: social, político, económico, geográfico y cultural (PROFAMILIA, 2013) 


\section{CONCLUSIONES.}

$\checkmark \quad$ Las políticas de salud oral a nivel nacional y distrital, conceptualmente contienen una idea de empoderamiento, inclusión, horizontalidad, planeación y eficacia que, realmente, están muy lejos de observarse en su ejecución.

$\checkmark \quad$ Se observó que el gobierno nacional delega la responsabilidad constitucional del mantenimiento de la salud (oral) a las EPS y entes territoriales, la vinculación de las comunidades en la política de salud oral, aún está muy lejos de ser perceptible corresponde más a un ejercicio simbólico de legitimación.

$\checkmark \quad$ Se observó que a pesar de la existencia de políticas públicas en salud oral en Bogotá su alcance es limitado debido en gran medida, a cambios en los gobiernos locales que implementan planes y programas específicos de acuerdo a sus intereses y necesidades, dejando de lado muchas veces las prioridades de la salud bucodental de la población del distrito, evidenciándose de igual forma la falta de continuidad de programas establecidos.

$\checkmark \quad$ Se demuestra que la capacidad del estado es frágil para organizar los múltiples actores en el sistema de salud para el desarrollo de políticas públicas y programas en salud oral. Se denota, una limitada capacidad de rectoría y de gobernanza en las políticas

Página 180 de 228

Rutty Adriana Abril Vivas. Odontóloga. Especialista Administración Hospitalaria. Auditoria de la Calidad. Nubia Astrid Duarte Pinzón. Enfermera. Especialista en Gerencia de Salud. 
de salud oral por parte del Ministerio de Salud y de la Secretaría de Salud de Bogotá, lo que puede explicar el deterioro o estancamiento de los indicadores de salud oral.

$\checkmark \quad$ Las políticas públicas en salud oral en Bogotá responden a las necesidades de los grupos etarios de 5 a 19 años y gestantes; sin embargo este tipo de políticas no soluciona de manera efectiva la morbilidad oral en la población general debido a que excluye a los grupos de edad de menores de cinco años, mayores de 20 y grupos vulnerables como son los pacientes crónicos, alto costo, discapacidad y, enfermedad mental, no es una política incluyente y articulada con las políticas internacionales que pueda garantizar una atención adecuada y que responda a los determinantes sociales ,que influyen en la salud oral de los individuos, las familias y las comunidades.

$\checkmark \quad$ Se observó la fragmentación y segmentación de los servicios de salud oral; la oferta del servicio se encuentra distribuida en las localidades de forma inequitativa generando una menor oportunidad de atención para la población pobre y vulnerable incidiendo en la prevalencia de las patologías del sistema estomatognático. En relación con la programación vs la intervención para cada uno de los periodos estudiados se observó que no se logró la meta planteada por la Secretaría Distrital de Salud lo que 
indica la necesidad de realizar seguimiento, análisis y replanteamiento de la ejecución de la política con base a resultados de las actividades de promoción y prevención.

$\checkmark \quad$ El envejecimiento, el género femenino, vivir en zonas del sur y rural en Bogotá, pertenecer a las fracciones sociales menos favorecidas y pertenecer al régimen subsidiado, fueron variables asociadas a mayor prevalencia de patologías orales, lo cual indica que está lejos de las metas que trazó la OMS en salud bucal para el año 2000.

$\checkmark \quad$ Se observó la necesidad de fortalecer las estrategias educativas así como la atención de eventos que afectan la salud bucal encaminadas a las prácticas de autocuidado con el fin de minimizar los factores de riesgo de las enfermedades orales.

$\checkmark$ La cobertura desde la salud pública se proyectó de forma amplia pero no ha logrado la meta de canalizaciones efectivas en salud oral esperada desde el Plan de Intervenciones Colectivas (PIC), la educación en salud oral, aunque funciona presentan vacíos de tipo estructural y estratégico, lo que se manifiesta en no obtener el resultado deseado.

$\checkmark$ Se observó que, en el país se le resta importancia a las acciones de 
promoción y prevención de la salud así como al manejo de los riesgos y se incentivan el manejo curativo quizás por el enfoque rentista y el sistema morbicéntrico, que se enfoca en atender la enfermedad no en mejorar las condiciones debidas para mantener la salud bucal en la población.

$\checkmark \quad$ Se evidenciaron avances frente a los indicadores establecidos en el COP, registrados en la ENSAB III y ENSAB IV que dan como resultado una reducción en prevalencia y severidad; pasando de 2.3 a 1.51 dientes involucrados en el grupo de niños de 12 años, encontrándose por debajo del referente internacional definido por la OMS de 3.0.

$\checkmark \quad$ La accesibilidad al servicio odontológica en Bogotá para los diferentes periodos fue menor para el régimen subsidiado frente al régimen contributivo, se observa que Bogotá no escapa a los criterios de priorización de la población y de focalización, que restringe la cobertura de otros grupos poblacionales generando nuevas formas de exclusión en la salud oral.

$\checkmark \quad$ A pesar que el Ministerio de Salud, publica anualmente los indicadores para el país, se evidenciaron deficiencias en los registros de prestación de servicios RIPS que

Página 183 de 228

Rutty Adriana Abril Vivas. Odontóloga. Especialista Administración Hospitalaria. Auditoria de la Calidad. Nubia Astrid Duarte Pinzón. Enfermera. Especialista en Gerencia de Salud. 
impiden conocer la demanda real y la realización de un análisis profundo y desagregado de morbilidad oral. Por otro lado, en muchos casos la información disponible no es analizada ni publicada, de igual forma se observó el reporte inoportuno por parte de las EPS e IPS prestadoras de servicios de salud oral de la información de la Resolución 412 de 2000, en los procedimientos de protección específica: sellantes, flúor en gel de aplicación profesional, higiene por profesional y detartraje y la Resolución 5521 de 2013 que incluye la aplicación de flúor, lo que genera sesgos en los análisis.

$\checkmark \quad$ Colombia y el Distrito no cuentan con sistemas de información estadístico de tratamientos odontológicos para pacientes con patologías crónicas y pacientes con discapacidad que garanticen una oportuna atención, detección temprana de complicaciones en la salud bucodental y mejoramiento de la calidad de vida, debido a que estos eventos en salud generan consecuencias en la salud, a nivel social, financiero y emocional en el paciente y su familia.

Página 184 de 228

Rutty Adriana Abril Vivas. Odontóloga. Especialista Administración Hospitalaria. Auditoria de la Calidad. Nubia Astrid Duarte Pinzón. Enfermera. Especialista en Gerencia de Salud. 


\section{RECOMENDACIONES}

$\checkmark \quad$ El Estado Colombiano a través del Ministerio de Salud de Colombia y la Secretaría Distrital de Salud debe garantizar y difundir el derecho a la salud bucal para todos desde cada una de las acciones que involucre a los diferentes actores de la sociedad y profesionales de la salud; con el fin de promocionar la salud, prevenir las enfermedades bucales y mejorar la atención de las alteraciones en la cavidad bucal que permitan que la población mantenga altos niveles de salud bucal durante el curso de vida.

$\checkmark \quad$ El Ministerio de Salud de Colombia y la Secretaría Distrital de Salud debe definir y fortalecer una política pública en salud bucal y un plan de contingencia con varios componentes, desde los territorios y los servicios de salud incluyendo el mantenimiento, el tratamiento odontológico en el resolutivo con una red prestadora que incluya el trabajo de los equipos básicos de salud como parte del nuevo modelo de atención, con rutas específicas de atención que operen en áreas urbanas y rurales con participación comunitaria, para la reducción de la carga de morbilidad de la cavidad bucal para el país y el distrito.

$\checkmark \quad$ La Secretaría Distrital de Salud de Bogotá debe establecer en todos los niveles de atención en el Sistema de Salud como una prioridad la conservación y protección de la cavidad bucal, con programas específicos de acuerdo al perfil epidemiológico de las

Página 185 de 228

Rutty Adriana Abril Vivas. Odontóloga. Especialista Administración Hospitalaria. Auditoria de la Calidad. Nubia Astrid Duarte Pinzón. Enfermera. Especialista en Gerencia de Salud. 
diferentes localidades con criterios de calidad y continuidad la cual debe privilegiarse y medirse a partir de tratamientos completos odontológicos, logrados a partir de las atenciones integradas e integrales en la red de servicios, lo que implica que el odontólogo general, será el eje fundamental para prevenir y atender los diferentes aspectos de la salud bucal que determinan la carga de enfermedad bucal.

$\checkmark \quad$ El ente rector en conjunto con las diferentes EPS e IPS, deben generar modelos de atención y servicios que posibiliten el acceso real a los diferentes servicios desde los primeros meses de vida, tanto a nivel individual como colectivo, con el fin de mejorar los indicadores establecidos.

$\checkmark \quad$ La atención integral en salud bucal debe convertirse en política pública prioritaria bajo parámetros de calidad y de carácter obligatorio, con el fin de mejorar la cobertura en el tratamiento de tejidos duros, lesiones periodontales, lesiones por prótesis y estomatitis, así como edentulismo, para disminuir su incidencia y prevalencia en la población distrital para la totalidad de las etapas de ciclo vital.

$\checkmark \quad$ Es necesario establecer un modelo de atención donde no se genere fragmentación ni segmentación en el servicio de salud con el fin de lograr una atención eficiente y solidaria ; el estado desde el nivel central debe asegurar los recursos para activar la

Página 186 de 228

Rutty Adriana Abril Vivas. Odontóloga. Especialista Administración Hospitalaria. Auditoria de la Calidad. Nubia Astrid Duarte Pinzón. Enfermera. Especialista en Gerencia de Salud. 
política pública la cual debe estar sujeta a cumplimiento de metas, bajo monitoreo de principios fundamentales de eficiencia y equidad; desde la Secretaria distrital se deben desarrollar estrategias para lograr el cumplimento de las metas programadas abordando los diferentes escenarios tanto preventivos, resolutivos y de rehabilitación

$\checkmark \quad$ El ministerio y la S.D.S debe realizar un enfoque diferencial en las políticas públicas de salud oral ; es un imperativo ético que grupos excluidos ya sea por su participación o por modo de vida, en razón a su etnia, raza, sexo, identidad de género, etapa de ciclo vital y discapacidad, reivindicar el ejercicio de una ciudadanía con capacidad de disfrutar y participar activamente en todas las actividades encaminadas al restablecimiento de la salud oral; con el fin de mejorar la cobertura en el tratamiento de las lesiones de tejidos duros, lesiones periodontales, lesiones por prótesis y estomatitis, así como establecer rehabilitación para los casos de edentulismo, para disminuir la incidencia y prevalencia en la población distrital comprendida en el rango de 20 años en adelante.

$\checkmark \quad$ Desde la academia se debe formar al profesional de odontología de manera integral para promover el trabajo interdisciplinario en los diferentes programas de salud realizando actividades bajo parámetros de calidad; el odontólogo, tiene la obligación de educar e informar a los pacientes, sobre responsabilidad individual en el mantenimiento 
de la salud bucal y del tratamiento odontológico cuando se necesite; las instituciones por su parte debe facilitar los medios necesarios para el cumplimiento de los diferentes planes y programas establecidos.

$\checkmark \quad$ Los gobernantes y los entes rectores deben realizar una reorientación y cambios estructurales en el sistema de salud con el fin de promover la prevención en salud bajo la aplicación efectiva de la estrategia de APS para el logro de los objetivos de la salud oral.

$\checkmark \quad$ Es necesario que las EPS y su red de prestadores mejoren el acceso real a la asignación de atención odontológica tanto para todos los regímenes de afiliación con el fin de lograr disminución de la morbilidad oral y de esta forma gradualmente ir construyendo cohortes de poblaciones sanas, o rehabilitadas.

$\checkmark \quad$ El ministerio de salud y la S.D.S debe fortalecer el seguimiento a la calidad del mecanismo de captura del dato, reporte oportuno, procesamiento y análisis de los indicadores y apoyen el desarrollo de una cultura de intercambio e interacción entre las diferentes organizaciones, con miras a aumentar la utilización de la información en 
Colombia, para la toma de decisiones informadas y el diseño de políticas que apunten al real mejoramiento de la salud oral de la población del distrito.

$\checkmark \quad$ Se hace necesario incluir mediciones de las acciones en salud oral realizadas a la población con prevalencia de enfermedades crónicas, y discapacidad con el fin de contribuir al mejoramiento de la calidad de vida de esta población. 


\section{$9 \quad$ ANEXO}

\subsection{Información fuente primaria.}

Ilustración 55 Consentimiento informado.

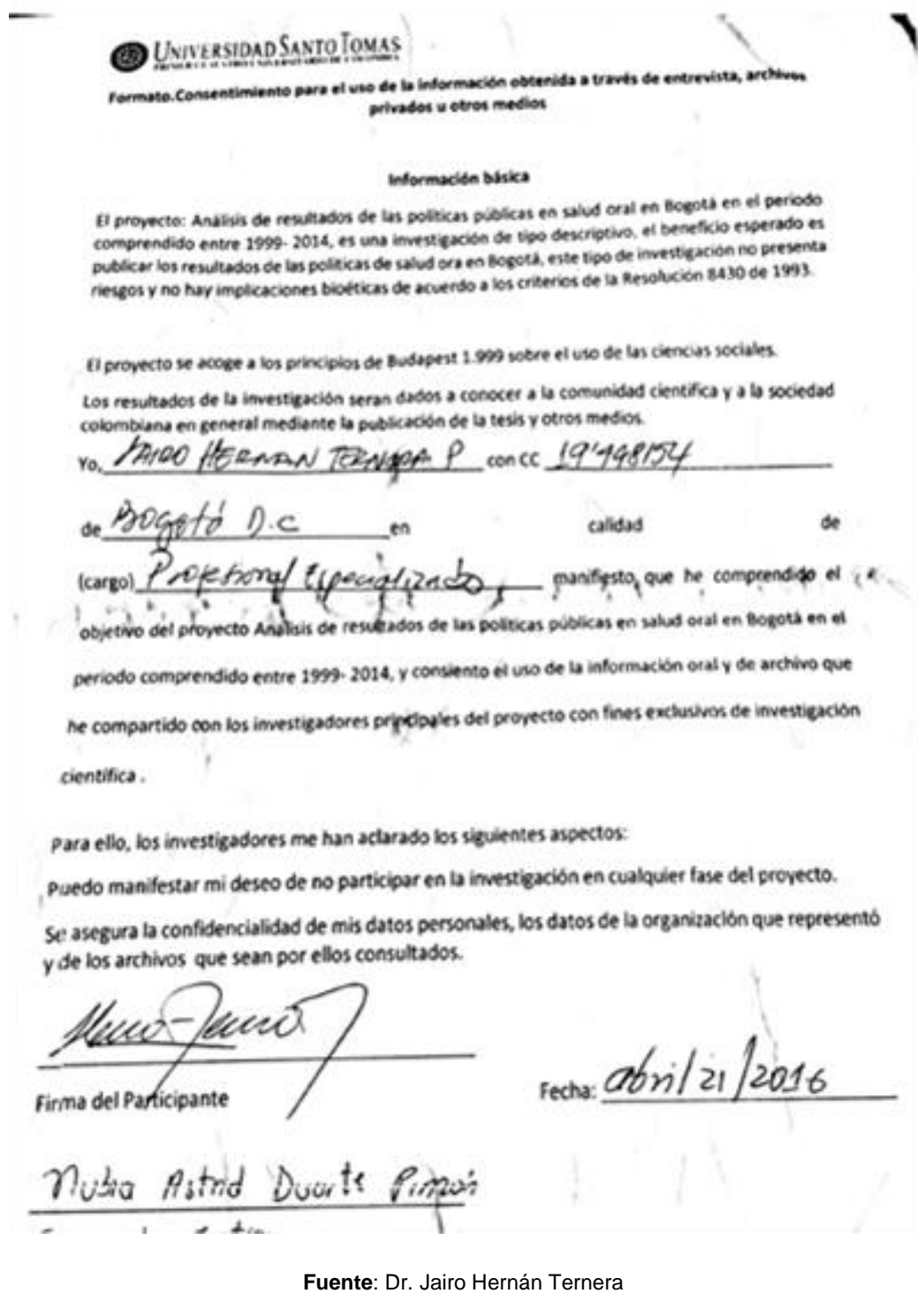

Página 190 de 228

Rutty Adriana Abril Vivas. Odontóloga. Especialista Administración Hospitalaria. Auditoria de la Calidad. Nubia Astrid Duarte Pinzón. Enfermera. Especialista en Gerencia de Salud. 
El Dr. Jairo Hernán Ternera es Odontólogo Universidad Nacional, Magister en Administración de Servicios de Salud Universidad Javeriana. Especialista en Seguros y Seguridad Social Universidad de la Sabana. Profesional Especializado. En el área de Administración de Aseguramiento S.D. S

Profesional prestigioso en el medio pertenece a la comisión interna de trabajo del observatorio Nacional de Salud Bucal y la práctica odontológica, ha realizado un gran número de ensayos y artículos de opinión, en revista y periódicos reconocidos

Entrevistador: Dr. Jairo buenas tardes quiero agradecerle la disponibilidad de atenderme ya que considero que sus aportes son muy valiosos para el desarrollo de la investigación que como es de su conocimiento estoy adelantando. Soy fuerte crítica del Sistema de Salud ya que he tenido la oportunidad de conocer el sector en el área clínica, de salud pública, así como de aseguramiento sin desconocer los esfuerzos que se han realizado desde para intervenir la problemática existente, de nuevo le agradezco por su atención ya que Ud. Ya que como es de conocimiento general usted ha contribuido a los avances existentes en los temas de salud oral en el distrito.

Entrevistado: Para eso estamos, entonces como hacemos

Página 191 de 228

Rutty Adriana Abril Vivas. Odontóloga. Especialista Administración Hospitalaria. Auditoria de la Calidad. Nubia Astrid Duarte Pinzón. Enfermera. Especialista en Gerencia de Salud. 
Entrevistador: Dr. quiere presentarse por favor

Soy odontólogo egresado de la Universidad Nacional con una Maestría en Administración de Servicios de Salud de la Universidad Javeriana y una Especialidad en Seguros y Seguridad Social de la Universidad de la Sabana, ah y profesional especializado en el área de Administración de Aseguramiento de la S.D.S.

Entrevistado: Quisiera conocer su concepto de los antecedentes y comparativos de los planes de gobierno y las políticas públicas para conocer su accionar a través del tiempo.

Entrevistado. ¿Desde qué fecha arrancaste?

Entrevistador. 2010- 2014. Pero realmente la información no se encuentra continuo la ENSB 3 de 1998 y pasa a ENSB 4 del 2014,

Entrevistado. Hay baches, incluso acá en la biblioteca se encuentra información del año 60 de Odontología Sanitaria de los servicios, luego no aparece información, se encuentra a pedazos.

Entrevistador. Bueno Dr.

1.-Podría definir los programas actuales de Salud Oral, desde Distrito, y si estas dan respuesta Plan de Desarrollo 2010 - 2014; 2012 -2016 
El periodo comprendido 2010- 2014 corresponde a Bogotá Positiva , Construir Ciudad corresponde al Periodo Mockus, que ocurre que al final del periodo de Mockus se inicia la Formulación de la Política de Salud Oral y en el Periodo de Luis Eduardo Garzón se hace explicita la Política Bogotá sin indiferencia y se lanza en octubre de 2004 y digamos a partir del gobierno Bogotá Positiva aparecen ya metas distritales en salud oral que se monitorean desde la Secretaria Distrital de Salud en el entendido de que con un sistema fragmentado la mayor parte de la oferta de los servicios de Salud Oral está en el régimen contributivo pero también hay que ver que se hacía en el subsidiado, pero que hacia la ciudad en el contributivo.

Desde el 2008 se empiezan a monitorear las metas de cobertura y hacer seguimiento global de la ciudad sobre la Resolución 412 y de los indicadores de cumplimento de la misma resolución.

Para Bogotá Humana lo que se busca es alcanzar una cobertura del 25\% en jóvenes menores de 19 años, para que se hace esto, para que al cabo de cuatro años el 100\% de los niños y niñas y jóvenes hubieran sido atendidos completamente para poder ir generando cohortes de pacientes sanos.

Al comenzar el monitoreo las coberturas fueron bajas, después va mejorando el reporte del dato, lo que ocurre también es que se logra ver una gran brecha entre contributivo y 
subsidiado es dos o tres veces más el acceso de consulta odontológica de primera vez en el contributivo que en el subsidiado y es una representación de la inequidad en el acceso, a pesar de que el plan de benéficos tiene los mismos servicios en salud oral entonces esa evidencia es lo que empieza a presentarles a las EPS, en este caso a los hospitales públicos en su gran mayoría para que mejoren su oferta en salud oral para mejorar coberturas para posteriormente mejorar indicadores de salud oral, esa es la idea. Eso en cuanto a aseguramiento.

En cuanto a Salud Pública los servicios de salud oral se ubican en la atención primaria, están en los equipos de respuesta secundaria en territorios y digamos que las promotoras de salud oral visitan las casas y orientan al paciente, lo remiten de acuerdo a categorización de rojo si es urgente, amarillo intermedio y verde que puede esperar para que solicite cita en los hospitales públicos o en los servicios de salud oral de la EPS, la idea es canalizar el $100 \%$ de los que se detectan con algún problema.

Entrevistador. Con respecto a estas acciones Ud. considera que ha dado el resultado del deber ser

Encuestado: Lo que ocurre digamos que Bogotá tiene además de lo que se está haciendo , logro desarrollar un Sistema de Vigilancia Epidemiológica en Salud Oral único que opera en Colombia, es el único que permite a través de unidades centinela 
monitorear los eventos de salud oral casi en tiempo real, hay unidades notificadoras en régimen contributivo y en régimen subsidiado y eso nos permite mirar la ciudad más rápido, también eso ha permitido una metodología de análisis de caso y hemos hecho análisis de caso por ejemplo hospitalizados por casos de información temprana con alertas epidemiológicas que son por ejemplo maternas de más de dos caries, se reporta por el sistema de vigilancia, esta alerta debe ser atendida en el menor tiempo posible, para que la materna que fue al odontólogo, cumpla su proceso de atención antes, al igual sucede en niños.

Digamos que articular todos estos componentes nos ha permitido en estos cerca diez años tener una mejor lectura de la ciudad en el hoy y a pesar de los múltiples dificultades que hay en el sistema nosotros hemos venido construyendo cosas que permiten tener atención y a pesar de los múltiples problemas que hay en el sistema podríamos echarnos a llorar, nosotros hemos venido construyendo cosas que permiten tener atención y tener esperanza, a la gente si se está atendiendo tal vez no en la totalidad que quisiéramos pero si la están atendiendo, gradualmente debe mejorar o pagar la deuda social que hay en salud oral, esa es la idea.

Otra es vigilar que los recursos que se asignen se vuelvan servicios de salud oral, entonces digamos en ese doble juego uno esperaría que haya habido un mejor acceso porque antes de esa información no existía nada.

Página 195 de 228

Rutty Adriana Abril Vivas. Odontóloga. Especialista Administración Hospitalaria. Auditoria de la Calidad. Nubia Astrid Duarte Pinzón. Enfermera. Especialista en Gerencia de Salud. 
Entrevistador. Dr. Considera Ud. ¿que existe articulación adecuada en los procesos PICPOSS en los hospitales públicos?

Entrevistado. ¿A qué te refieres en articulación?

Entrevistador: A la ejecución de las actividades de demanda inducida desde los territorios, en las canalizaciones efectivas y sus seguimientos.

Entrevistado: Hay un problema mental en los hospitales públicos cuando se desarrollan todo lo que acciones del PIC y las acciones del POSS para los colegas, los trabajadores se vuelve el de acceso Es la misma institución la que canaliza y la misma institución luego niega los servicios, pero ese problema debe ser superado primero en la mente de los personas ahí es una de las dificultades es un problema que arranca en lo mental este problema no debiera existir porque se está pagando, que si el paciente está en el régimen subsidiado y esta capitado con el hospital y se detecta por los equipos territoriales debe ser atendido, pero ahí ocurre que dentro de la contratación captada y si una verdadera auditoria y cumplimento de metas por parte del a segurador se convierte en que , la entidad pública o privada opera como seguro y restringe el acceso por un lado realiza inducción a la demanda para él se vuelve gasto y entonces niega servicios y el mismo hospital tiene eso en la forma de contratar porque además como no los evalúan por logros en salud sino por gasto o inversión o por no estar quebrados es toda 
una antítesis por un lado induce demanda y por otro lado restringe los servicios para que la cápita según ellos alcance.

2.- Conoce Ud. el seguimiento de indicadores de calidad, que se realizan a los programas de salud oral.

Como tal la estructura y la concepción de Programa desafortunadamente la desmontaron con las normas, con la 412, con lo que paso con el Sistema de Seguridad Social.

Los programas tenían un objetivo, una población específica y eso lo diluyeron desde el año 90. En Salud oral que queda, queda el servicio sea a través de prestadores públicos o a través de prestadores privados al interior del servicio está el componente preventivo, individual y colectivo y el componente individual de atención. La idea es que debe articularse y solucionar el problema de salud a los pacientes.

En el contributivo no son islas entonces las personas del contributivo viven en los mismos barrios donde opera la atención primaria para la gente del subsidiado pero los recursos y la operación del contributivo es más lejana de los lugares de vivienda de las personas, a pesar de tener el mismo plan, los mismo servicio, los mismos indicadores la accesibilidad de los pacientes es diferencial de acuerdo a como hayan contratado el servicio de salud oral en la EPS del contributivo a la persona, en el subsidiado es un poco más equitativo pero hay la restricción por la cápita, por las forma de contratar a 
pesar que el servicio de salud es idéntico los servicios no son de la misma calidad y contenido en cualquier punto donde lo atiendan en salud oral.

Arrancando que no hay una clara definición ni estandarización de la misma oferta, cuantos sillones por afiliado, cuantos odontólogos por afiliados el número de horas de odontólogos y equipos de salud oral, odontólogos, higienistas, metros cuadrados.

El consultorio no es un consultorio de operatoria ,digamos el consultorio debiera estar claramente definido y estandarizado un consultorio odontológico sin equipo de rayos $\mathrm{x}$ no lo es sin embargo en la red pública y en algunos puntos de atención hay unidades odontológicas para operatoria porque si no hay equipo de Rayos x y las guías dicen que deben tomarse rayos $\mathrm{x}$ periapical o rayos $\mathrm{x}$ coronales para diagnósticos de caries y no está la oferta seria de operatoria y sería un servicio parcial, pero como el Ministerio como tal no lo reglamento Ud. no podría sancionar por eso entonces desde la estructura del servicio el servicio tiene diferenciales grandes de acuerdo a como se haya diseñado cada uno de los operadores EPS o el mismo servicio de la Secretaria de Bogotá tiene ese problema.

3.- Considera Ud. que el sistema en el país, y específicamente el distrito, cuenta con infraestructura suficiente para la atención primaria, secundaria y terciaria en salud oral.

Página 198 de 228

Rutty Adriana Abril Vivas. Odontóloga. Especialista Administración Hospitalaria. Auditoria de la Calidad. Nubia Astrid Duarte Pinzón. Enfermera. Especialista en Gerencia de Salud. 
En Bogotá teníamos a septiembre hace como dos años más de 5.000 prestadores de servicios que habilitaron el servicio de consulta de odontología general y otro montón que habilitaron diferentes subespecialidades, pero como la, puerta de entrada es odontología general hay 5700 tanto en IPS como en institución que no se habilitan, , instituciones objeto social diferente son creo 164 y pico lo que ocurre es que están ubicadas en unas zonas donde se concentran, en Chapinero, en Teusaquillo, en Usaquén, en el sur hay menor oferta y hay menor oferta hacia el borde occidental de la ciudad que es donde la ciudad está creciendo, esa inequidad espacial tiene problemas para el acceso, hay algunas EPS por ejemplo COMPENSAR diseño sus servicios de salud un poco como centro periferia , tiene como 80 sillones en la 43 con 13 entonces todo el mundo tendría que ir allá cuando viven en diferentes localidades, esto es lo que se está tratando de orientarlos para que haya una redistribución de la oferta de tal manera que sea más accesible de donde la gente vive y trabaja, como no hay forma sancionatoria ni obligatoriedad que así se haga lo único que se puede hacer desde la entidad territorial es orientarlo e informarlo.

Bogotá podría llegar a necesitar no sé si somos 8.500 , con 1.700 sillones nada más la ciudad podría ofertar un sillón por cada 5.000 personas solo necesita 1.700 sillones y necesitaría también en teoría ofertando un odontólogo por cada 3.500 el problema es que hay demasiados odontólogos, necesitaríamos 2.428 odontólogos en sillones , 2.700 y

\footnotetext{
Página 199 de 228

Rutty Adriana Abril Vivas. Odontóloga. Especialista Administración Hospitalaria. Auditoria de la Calidad. Nubia Astrid Duarte Pinzón. Enfermera. Especialista en Gerencia de Salud.
} 
pico en sillones y 2.500 odontólogos con eso estaríamos ofertando a la gente 2.000 horas hombre, horas de odontólogo para necesidades de salud oral eso alcanza a dar coberturas por ahí del $20 \%$ más o menos por que no tiene que atender todos entonces hay sobreoferta porque si hay 5000 además todo lo que está en el POSS lo puede hacer un odontólogo generales ese es el rollo.

4.- Considera usted, que las entidades involucradas en el SGSSS (EPS IPS y Aseguradoras) ofertan y garantizan servicios en salud oral con los atributos de oportunidad, accesibilidad, continuidad, efectividad y pertinencia.

Los atributos de calidad son un mito y en salud oral peor en el entendido de que reportan las consultas y se reportan cosas, pero para llegar allá y tener un esquema de calidad los mismos estudiosos de eso hablan de que uno primero diseña la estructura, después se diseñan las guías que son las que tienen que ver con los procesos y al final se ven los resultados.

Si el Ministerio no exigió a las EPS en estructura la obligatoriedad de ofertar el sillón por 5.000 o menos y el odontólogo por 3.500 personas o menos según estándar que defina el ministerio o más o como se le haya ocurrido ya desde ahí hay un problema serio en definir cuantas personas van a ir, tampoco definió una cobertura, lo que quedo allí es la demanda espontánea; el POSS está calculado sobre demanda espontánea de la 
población y la demanda espontanea no está por encima del 8\% entonces ya perce es un servicio bien restringido porque si uno lo hubiera programado de otra manera se le habría podido exigir más, entonces no se exigió que en los territorios se ubiquen de manera equitativa para ofertar donde viven las familias entonces ahí hay un problema ya, después hay que mirar donde están ofertando en donde y los tiempos de espera y el desplazamiento.

En una ciudad una persona no debiera gastarse 30 minutos entre el lugar de residencia y el lugar de oferta de los servicios básicos de salud, consulta de medicina general y consulta odontológica, entonces si aumenta el gasto del transporte.

Entrevistador: ¿gasto de bolsillo?

Entrevistado: gasto que no es gasto en salud curiosamente; pero entonces hay momentos en que la gente hace todos esos cálculos y entonces va al odontólogo particular que puede salir más barato en un momento dado frente a las citas todo eso problemático

5.-Qué opina de los resultados y del lapso de tiempo trascurrido para la realización de las últimas encuestas en el tema de salud oral correspondientes a ENSB 3 Y ENSB 4 de fechas 1999 y 2014 respectivamente.

Página 201 de 228

Rutty Adriana Abril Vivas. Odontóloga. Especialista Administración Hospitalaria. Auditoria de la Calidad. Nubia Astrid Duarte Pinzón. Enfermera. Especialista en Gerencia de Salud. 
Que ocurre, Colombia es un país que tiene cuatro estudios de morbilidad oral es uno de los países que mayor información tiene digamos si uno lo mira en tiempos institucionales la reforma realmente arranca en el 95 es decir la ley 100 la sacan en el 93 las EPS se constituyen en el 95 y se comienza la afiliación masiva de la gente en finales del 95 y 96.

El tercer estudio se hace en el año 98 realmente es muy buen momento para poder mirar como quedo la población con el marchitamiento del Sistema Nacional de Salud y lo que fue en su momento la seguridad social pública representada en el Seguro Social y CAJANAL ya después viene el proceso de implementación de la reforma y se invisibilidad el servicio de Salud Oral y las necesidades de salud oral al interior del Ministerio por que todo se volvió POSS, todo se volvió reforma y por eso se invisibilidad entonces el Ministerio arranca y para sacar la contratación se tarda casi 3 años por eso el estudio se hace 16 años después sale con fecha 16 años después pero en realidad fueron 15 por que los datos se toman 2013- 2014 y se inicia en octubre 2013 culmina la recolección de la muestra en el 2014. Fueron 15 años, tres lustros una generación lo que ahora metieron ahí que forma parte del estudio regular y cada 10 años es obligatorio que se haga porque es una manera interesante de evaluar el desarrollo.

Entrevistador: ¿por norma?

Página 202 de 228

Rutty Adriana Abril Vivas. Odontóloga. Especialista Administración Hospitalaria. Auditoria de la Calidad. Nubia Astrid Duarte Pinzón. Enfermera. Especialista en Gerencia de Salud. 
Entrevistado: No está por norma, pero está incluido en estudios regulares el problema es que el mismo gremio, la academia no exige al gobierno el cumplimiento de estos tiempos como ciudadanos como interesados no le exigieron al gobierno que lo hiciera al décimo, año.

Pero mire la paradoja en el 98 se cuenta con estudio para entrar al siglo 21 para que más datos con ese estudio tu sabias cual era la línea de que corte, que pocos países lo tienen para entrar al siglo 21 con tres lustros se esperaría que todo lo que se ha hecho el sistema mejorara muchísimo, pero si ha mejorado pero no en las condiciones esperadas uno tendría que mirar ya con un análisis de cuanto invertimos y cuanto ganamos en salud, ese análisis no lo tiene el ENSAB en teoría cuanto debió haberse invertido en salud oral, cuanta ganancia en salud oral hubo y si hubiese podido obtenerse más ganancia en salud oral no en plata; pero ese estudio no está habría que mirar si es posible halar estos datos de ahí .

Entrevistador. ¿Cree Ud. que sería importante un análisis de RIPS para que la información aportara a los resultados de la situación en Salud oral de la población del distrito?

Página 203 de 228

Rutty Adriana Abril Vivas. Odontóloga. Especialista Administración Hospitalaria. Auditoria de la Calidad. Nubia Astrid Duarte Pinzón. Enfermera. Especialista en Gerencia de Salud. 
No sirve por dos razones lo que va por RIPS es demanda espontánea y demanda atendida no las necesidades poblacionales, en RIPS van los que están enfermos los que se sienten enfermos en realidad los sanos pocos van.

Si en salud oral solo se está atendiendo; solo va un $8,5 \%$ de la población entonces lo que tiene allí es el consumo general, es importante porque desde allí se puede ver mayor prevenibilidad, una disminución en el tamaño de las obturaciones mayor número de endodoncias que exodoncias, pero la población que demanda no es el grueso de la población que podría estar sana sin ir al odontólogo ese es el rollo.

6.-Cual considera Ud. cuál sería la estrategia para garantizar la disminución de las patologías prevalentes del sistema estomatognatico?

La gente está mejorando, hay mejoras diferenciales y eso es otra cosa que habrá que analizar a mayor profundidad y el mismo ENSAP lo aporta cuando hace estudios de determinación social con estudios de caso y es que hay segmentos de población que tiene mejores condiciones de salud oral incluso no por ir al odontólogo sino por la formación por la preocupación por su propio cuidado, a que nosotros en verdad estemos produciendo una mayor salud es una cuestión compleja pero las prevalencias han disminuido el problema es que se concentran en los grupos más excluidos lo que se llama polarización de la caries .Ahora hay prevalencias del 40 del 55 \% una disminución

Página 204 de 228

Rutty Adriana Abril Vivas. Odontóloga. Especialista Administración Hospitalaria. Auditoria de la Calidad. Nubia Astrid Duarte Pinzón. Enfermera. Especialista en Gerencia de Salud. 
grande del COP pero cuando uno va y mira del contributivo los estratos altos y el estrato bajo eso es como si los del estrato alto estuvieran en el siglo 21 y los del estrato bajo en los años 65 con exodoncias, edentulismo, raíces abandonadas entonces en un país que en teoría tiene el mismo plan para todos la inequidad es la que hay que controlar en la medida en que se logre el desarrollo, del concepto del derecho la gente estaría consultando más al odontólogo y las prevalencias digamos del cáncer de boca, es decir lo de la caries es controlable debiera bajar más lo mismo que la enfermedad periodontal, digamos que el cáncer tiene sus variables diferentes, pero digamos las que nos mueve la caja lo que hace que la gente demande debiera bajar y entonces tiene que ver más que uno pudiera trabajar una estrategia de comunicaciones masivas para que la gente demande el servicio a la seguridad social al contributivo y al subsidiado.

Pero eso también se vuelve un problema por que dejaría por fuera del mercado laboral la oferta privada porque todos los servicios están en el POSS y uno no sabe por qué no se hace, eso sí ayudaría a la gente haciéndose consciente, que consulte con mayor oportunidad y en una primera fase, se aguantaría la prevalencia porque son más consultando pero disminuiría la severidad del daño es decir sacaríamos menos dientes, haríamos más endodoncias y no haríamos tantas prótesis, esa es como la idea pero habrá que esperar.

Página 205 de 228

Rutty Adriana Abril Vivas. Odontóloga. Especialista Administración Hospitalaria. Auditoria de la Calidad. Nubia Astrid Duarte Pinzón. Enfermera. Especialista en Gerencia de Salud. 
7.- ¿Considera usted que se ha logrado cobertura efectiva e integral en acciones de salud oral en Colombia, en el distrito?

En Colombia quién sabe (risa...) Al menos en Bogotá nosotros hemos logrado monitorear que al parecer si se está yendo en la medida que se ha hecho demanda, la gente sí pareciera que está obteniendo y mejorando los datos, al menos consulta de primera vez porque no sabemos si le terminaron el tratamiento.

Entrevistador: ¿Se han hecho esos seguimientos? ¿Es muy complicado?

Entrevistado: Muy complicado la definición de tratamiento en salud oral y en odontología es una locura porque te lo dan por operatoria, por endodoncia, por cirugía y se vuelve loco, en todo caso las coberturas que se están alcanzando son como del $28 \%$ entre $25 \%$ entonces uno dice listo fue al odontólogo ya eso es un paso.

Datos que tenía la red pública indicaban que el índice de continuidad que es el que indica de que una persona inicia y termina el tratamiento al menos en el sector público ese indicador por ejemplo no lo pregunta la Superintendencia no está dentro de los indicadores de calidad entonces hay que definirlo, paciente que ingresa y que termino todo el tratamiento no operatoria , ese índice de continuidad estaba a cercano al $70 \%$ entonces si uno llega y dice que llego a coberturas del 30\% para ser optimista es decir que fueron y realmente le estarían terminando tratamiento entre 15 y el $20 \%$ de las personas pero cuando teníamos coberturas del $8 \%$ del 10 solo le hacían tratamiento terminado al 7 es decir si nosotros no empujamos una mayor cobertura y lo obligamos 
normativamente al monitorear el índice de continuidad pues no va a haber habría manera de ver en verdad evaluar acceso y que los tratamientos se terminen por que todos pueden ir al odontólogo, al tratamiento y si tienes tales cosas y si no terminan el tratamiento?

El servicio se abandonó por que incluso se pregunta por las camas Ud. sabe cuántas camas tiene el país como casi 60 mil camas talvez más las conoces por servicios las puedes bajar por la web.

Pero no sabes de los consultorios odontológicos de los servicios de salud oral de las EPS y de los diferentes prestadores públicos, privados, profesionales independientes cuantos sillones instalados hay y cuantos equipos de radiología hay a uno le toca cuando hace esos análisis decir que donde hay un odontólogo hay un sillón.

El país reporta camas por 1.000 habitantes, pero no se reporta sillón por 1.000 habitantes y eso que solamente es agregar en el campo de registro que lo hace la Superintendencia en el campo de cuando se habilita un sillón dos sillones en el entendido de que la unidad básica nuestra de trabajo es el sillón odontológico.

8.- Considera Ud. ¿Que los recursos asignados para salud oral en salud pública y resolutivo son los adecuados? 
Depende de la negociación. Los datos de la UPC según el Cooperativa Nacional de odontólogos que le ofertaba como por el $4 \%$ del valor de la UPC Nacional y estaba contratando cuando SALUDCOOP ordeno vender el valor de la UPC Nacional están a 700 ósea $\$ 28.000$.

Entrevistador: ¿Cree Ud. que es suficiente?

Toca mirar la estructura de la demanda, digamos que si fuera el 4\%, digamos que está en $\$ 700$ el $10 \%$ que descuenta el contributivo lo que queda es $\$ 630$, si se multiplica por .04 que es el $4 \%$ tendríamos 25.000 pesos por persona año, a un sillón de 5.000 personas, le cargas 5.000 personas estarías asignando de presupuesto a un sillón de 25 personas 126 mil millones de pesos y tendrías que atender 5.000 personas con una cobertura del $20 \%$, si tienes 5.000 y coberturas de $20 \%$ son 1.000 y estas asignando por cada tratamiento en teoría en teoría como si estuviera comprando el mercado $\$ 1.260$ pesos, mil personas cada una tendría un valor de 1.260 .

Estos datos en 5.000 horas voy a atender 1.000 estoy ofreciendo 5 horas de tratamiento de las personas para hacerle lo básico, 15 citas para hacer básicas de odontología , preventivas, sellantes, profilaxis, operatoria, endodoncia y se paga por ese valor, en términos generales se paga $\$ 1.200 .00$ por persona en teoría no estaría mal, si el odontólogo quiere ganar más plata aunque no sea así dice que se va a poner un salario 
de \$ 6 millones 6 × 12 setenta y dos la mitad de la plata está ahí es suficiente dinero si este es el valor los colegas no han entendido no riesgos compensados no les están diciendo que atiendan los 5.000 porque tampoco caben en el sillón, en la medida que sean menos las necesidades tendrían que atender más gente, acá estaríamos planeando a las personas que están muy enfermas y que cada uno necesita 5 horas pero si necesita tres podría atender 1.700 , si le baja el valor promedio de la atención hace una mayor cobertura, esto es lo que no se enseña en la universidad, el problema es donde está la plata y si la pagaron e hicieron los servicios.

Encuestador: ¿Considera Ud. que la calidad de los servicios es un problema?

Entrevistado: La Calidad es un mito en últimas el país habilitó los odontólogos entonces nosotros tenemos colegas que trabajan en hospitales públicos incluso algún día podríamos preguntar a las EPS que nos den las cédulas de sus odontólogos, él puede decir que el servicio que presta en el hospital público es de mala calidad y en el consultorio particular de buena calidad, un poco esto es lo que hacemos con el sistema es eso, pero nadie cuando hacen trasplante de médula, de hígado de pulmón de riñón el que paga es el sistema esos si son buenos y son malos los servicios más sencillo de hacer que son los de odontología no cuadra y se incluyen todos los materiales esta todo incluido 
La pregunta es esa se paga la seguridad social y toca aguantarse la colita pero si los servicios estuvieran estandarizados y debían estarlo y hay auditoria y se verifica que lo que está en los anaqueles es de buena calidad la amalgama o la resina de última generación, la mejor resina que hay.

9.-Considera usted que el tipo de contratación actual afecta las curvas de aprendizaje del talento humano y la efectividad de este, para la ejecución de los programas en salud oral en el país, y específicamente en el Distrito.

Lo que pasa es que una de las mayores pérdidas para los profesionales en Colombia fue la pérdida de los años sociales ya que no hay plazas.

Entrevistador: ¿No hay plazas?

Entrevistado: ¿pues para el número de egresados de 2000 que haya 200 o 300 plazas?, por eso están haciendo los sorteos. ¿Es cuando a él solo le toca comenzar a desenvolverse, a resolver los problemas con lo que aprendió y el rural le servía para soltar las manos, para ser más autónomo para tener más confianza, pero si no hay plazas de rural?

¿Y dos en las universidades en algunos programas el concepto del requisito de competencias mínimas básicas a veces no se hacen todas, en algunas universidades es un mito que todo va a la subespecialidad y están remitiendo y si no les enseñaron a hacer 
endodoncias, exodoncias de incluidos y si no les enseñaron que van a poder desplegar después en la práctica clínica como independiente o como odontólogos de la seguridad social?

El problema está en la academia que no les enseñan las habilidades a pesar de todo lo que pagan. Las universidades tienen la obligación además de poner el sillón de comprar los equipos de rotación para endodoncia, todos los equipos para que el pelado pueda estar allí con los pacientes, eso lo guardan y se lo piden al estudiante para que lo lleve al posgrado.

El problema está en que la academia está formando mal y si el Ministerio de Educación no vigila por la Ley 30 del 92 y el Ministerio de Salud no hace evaluación de competencias de los trabajadores y salud y educación no obliga a que se forme un mejor profesional las familias terminan un poco digamos estafadas porque uno paga un valor para que le enseñen unas cosas con las cuales va a derivar un sustento.

Entrevistador: ¿Dr. y en el área de Salud Pública?

Entrevistado: Bueno en PIC hay un problema, en todas partes hay problemas, las universidades están aisladas y no se forman al interior de los servicios entonces nunca van a poder mirar y esto es problema de salud oral todo se centra en el sillón en 
actividades intramurales y no se trabaja en los territorios no se conoce como se opera en lo colectivo.

Nosotros cuando desarrollamos el SISVESO nos hacíamos ilusiones los trabajadores de acá, era que habían pocos odontólogos que sabían manejar programas de vigilancia epidemiológica en Salud oral, creíamos que esos 4 o 5 colegas que lo hacían iban a ser contratados por las mismas universidades y las universidades iban a enseñar cómo se opera el SISVESO como le enseñan a uno en los posgrados o le enseñan a enfermeras y médicos a manejar el SIVIGILA y no, en ninguna facultad de odontología se ha adoptado como parte de formación integral de los odontólogos al menos en Bogotá el manejo del SISVESO y que se aplique como es .

Las Universidades tampoco enseñan a los muchachos a manejar los RIPS a analizarlos entonces el problema está más en la formación entonces salen escépticos y a ellos no les sirve nada.

10.-Existe vigilancia y acompañamiento técnico del gremio odontológico de los estudios actuariales los que dentro del sistema de aseguramiento se encargan de definir los recursos, frecuencias de uso, población a atender y número de odontólogos que la seguridad social empleara cada año.

Página 212 de 228

Rutty Adriana Abril Vivas. Odontóloga. Especialista Administración Hospitalaria. Auditoria de la Calidad. Nubia Astrid Duarte Pinzón. Enfermera. Especialista en Gerencia de Salud. 
El gremio no, el gremio digamos no ha desarrollado una participación masiva y de control social sobre los recursos se salud oral en la seguridad social. ¿Por qué? Porque la Federación Odontológica representa a profesionales independientes que viven de la práctica liberal y el único sindicato de odontólogos que había era ASDOAS que con la desaparición del Instituto de Seguro Social desaparece, no hay una organización gremial que agrupe a los odontólogos que le laboran a la seguridad social sea contrato o sea a través de algún tipo de vinculación de contrato en planta. Los pocos odontólogos que están en servicios de salud pública están afiliados a sindicatos de empresas no a sindicatos de odontólogos entonces sin una estructura clara de gremio como odontólogo dependiente pero digamos odontólogos de seguridad a contrato y con una clara competencia de unos odontólogos de práctica liberal pues La Federación se ha dedicado a trabajar con lo de la práctica liberal, no ejerce control social sobre los recursos que para la Salud Oral asigne el sistema de seguridad social.

La práctica liberal se ha dedicado más a la estética, cada uno está en el curso de estética en la subespecialización de operatoria, en la subespecialización de estética, Los servicios básicos que están todos contemplados en el POSS no se desarrollan y la misma Federación no ha desarrollado el concepto de que eso es un derecho, si no es un derecho la salud para los pacientes o para los colombianos pues ahí sí que menos van a ir al público ni al privado donde les cobran yo creería que ese es el problema.

\footnotetext{
Página 213 de 228

Rutty Adriana Abril Vivas. Odontóloga. Especialista Administración Hospitalaria. Auditoria de la Calidad. Nubia Astrid Duarte Pinzón. Enfermera. Especialista en Gerencia de Salud.
} 
Si no conocen eso tampoco conocen de las metodologías actuariales de como inciden en las políticas públicas. Para que el gobierno tenga una estandarización de regulación de la práctica profesional: los españoles tienen una cosa que se llama el númerus clausus, es decir que el país hace un acuerdo social con los egresados para el control de la oferta profesional, significa control de la oferta educativa, en Colombia no pueden salir egresados más de 800 odontólogos año así dupliquen el valor de la matrícula, si es por plata que no pierdan las universidades.

Que la gente se jubile, se cancelan las tarjetas profesionales y se regula un número de profesionales en el país, no debe ser mayor a 22 mil y hay como 45 mil. De una vez el 50 \% está desempleado o subempleado o trabajando en condiciones precarias, si no se hace esto menos aún se va a trabajar en lo de actuaría en lo que tiene que ver con la incidencia ante el organismo de regulación que es el Ministerio.

Si el odontólogo tampoco reporta los datos de lo que atienden por RIPS pues nunca tú vas a saber cuál es la verdadera demanda de los servicios de salud oral para que aparezca un mayor valor asignado y una mayor frecuencia de uso (indicador de consumo) del servicio de odontología, si eso no se articula, si decimos que los RIPS no sirven estamos escondiendo información y nunca aparecerá el dato ese es el problema.

Entrevistador: ¿Existen inconsistencias en el reporte de los datos tomados de los RIPS?

Página 214 de 228

Rutty Adriana Abril Vivas. Odontóloga. Especialista Administración Hospitalaria. Auditoria de la Calidad. Nubia Astrid Duarte Pinzón. Enfermera. Especialista en Gerencia de Salud. 
Entrevistado: Además de todas las inconsistencias que puedan tener, pero al menos existe un dato y algo se puede hacer pero si no, si todos se rehúsan a llenarlo, pero si lo llenan y no lo verifican y cuando se verifica no se agrega entonces tú no saber en verdad cuantos es el gasto de bolsillo de odontología, cuanta gente fue al odontólogo sea al público o al privado, cuanta gente está en subsidiado y en contributivo o en prestadores de odontología independientes por ejemplo y en qué servicios.

Entrevistador: Dr. le toco liderar el gremio.

Entrevistado: risas....... 


\section{Bibliografía}

1. Agencia para sustancias tóxicas y el registro de intoxicaciones. (2013). Fluoruros, Fluoruro de Hidrógeno y Flúor. Recuperado a partir de http://www.atsdr.cdc.gov/es/toxfaqs/es_tfacts11.html

2. Alcaldía Mayor de Bogotá. (2008). Plan de Desarrollo Bogotá Positiva. Para vivir mejor. $\begin{array}{llll}\text { Recuperado } & \text { a } & \text { partir }\end{array}$ http://portel.bogota.gov.co/secretariageneral/imadocumentos/Plan\%20de\%20desarrollo \%20BOGOTA\%20FINAL\%20web.pdf

3. Alcaldía Mayor de Bogotá. (2012a). Modelo humano de atención en salud en Bogotá. $\begin{array}{llll}\text { Recuperado } & \text { a } & \text { de }\end{array}$ http://www.saludcapital.gov.co/Formatos\%20Captura\%20Territorios\%20Saludables/LINE AMIENTOS\%20TECNICOS/DOCUMENTO\%20MARCO\%20TERRITORIOS\%20SALUD ABLES.pdf

4. Alcaldía Mayor de Bogotá. (2012b). Plan de desarrollo de Bogotá 2012-2016. Bogotá $\begin{array}{llll}\text { Humana. } & \text { Recuperado } & \text { a }\end{array}$ http://www.canalcapital.gov.co/images/planeacion_pdf/Plan-de-Desarrollo-2012-2016.pdf

5. Amparo Constanza Varón de Gaitán, Juan Carlos Bustamante Mesa, Ana Catalina Hoyos Galvis, Andrés Felipe Zapata Suárez, \& Sonia Patricia Plaza Ruiz. (2014). Determinación tomográfica de la prevalencia de forma y tamaño de los rebordes residuales en pacientes $\begin{array}{lllll}\text { edentados. } & \text { Recuperado } & \text { a } & \text { partir }\end{array}$ http://www.scielo.org.co/pdf/rfoua/v25n2/v25n2a03.pdf 
6. Ana Cristina Mafla, Doris Lucía Córdoba Urbano, \& Maritza Natalia Rojas Caicedo. (2014). Prevalencia de defectos del esmalte dental en niños y adolescentes colombianos., 16. $\begin{array}{llll}\text { Recuperado } & \text { a } & \text { partir }\end{array}$ http://aprendeenlinea.udea.edu.co/revistas/index.php/odont/article/view/15345/16883

7. Anderson Rocha Buelvas. (2013). Análisis sobre el acceso a los servicios de la salud bucal: un indicador de equidad. Recuperado a partir de http://www.scielo.org.co/pdf/rgps/v12n25/v12n25a08.pdf

8. Bascones Martínez A, G. G. V. (2009). Cáncer oral:Puesta al día, 5. Recuperado a partir de http://scielo.isciii.es/pdf/odonto/v25n5/original1.pdf

9. Bermejo Fenoll, \& López Jornet. (2005). Diagnóstico diferencial lesiones exofíticas. Recuperado a partir de http://scielo.isciii.es/scielo.php?script=sci_arttext\&pid=S169844472005000500015

10. Blanca M. Chávez G, \& Luis E. Velásquez. (2011). Análisis de la gestión territorial: Encuesta Nacional de Salud 2007, Colombia 2011. Recuperado a partir de http://www.scielo.org.co/pdf/rfnsp/v30n1/v30n1a07.pdf

11. Carmen Lucia Velásquez Maya. (2011). Boletín epidemiológico temático. La salud oral por redes de vigilancia . Recuperado a partir de http://www.saludcapital.gov.co/sitios/vigilanciasaludpublica/Protocolos\%20de\%20Vigilan cia\%20en\%20Salud\%20Publica/BOLETIN\%20EPI\%20SISVESO\%20IV\%20TRIM\%2020 11.pdf 
12. Catalina Arévalo, María Claudia Castro, Sergio Losada, Martha Serrano, Carlos Serrano, \& Diego Sabogal. (2012). Guía de atención enfermedad gingival. Recuperado a partir de http://www.odontologia.unal.edu.co/docs/habilitacion/guia_sistema_clasificacion_periodo ntal_gingival.pdf

13. CDC de Atlanta. (2002). Recomendaciones sobre el uso de fluoruros para prevenir y controlar la caries dental en los Estados Unidos. Recuperado a partir de http://www.scielosp.org/pdf/rpsp/v11n1/7900.pdf

14. Departamento Administrativo Nacional de Estadistica .DANE. (2009). Proyecciones nacionales y departamentales de población 2005-2020. Recuperado a partir de http://www.dane.gov.co/files/investigaciones/poblacion/proyepobla06_20/7Proyecciones _poblacion.pdf

15. Conferencia Internacional sobre Atención Primaria de Salud,. (1978). Declaración de $\begin{array}{lllll}\text { ALMA } & \text { ATA. } & \text { Recuperado }\end{array}$ http://www.promocion.salud.gob.mx/dgps/descargas1/promocion/1_declaracion_deALM A_ATA.pdf

16. Constanza Pardo Ramos, \& , Ricardo Cendales Duarte. (2015). Incidencia, mortalidad y prevalencia de Cáncer en Colombia.pdf. Recuperado a partir de http://www.cancer.gov.co/files/libros/archivos/incidencia1.pdf

17. Damián Guillermo Lanza Echeveste. (12d. C.). Tratamiento odontológico integral del paciente oncológico. Recuperado a partir de http://www.scielo.edu.uy/pdf/ode/v15n22/v15n22a06.pdf 
18. Defensoría del Pueblo. (2015). Sigue creciendo el número de tutelas en salud. Recuperado a partir de http://www.defensoria.gov.co/es/nube/noticias/3414/Siguecreciendo-el-n\%C3\%BAmero-de-tutelas-en-salud-Tutelas-salud-D\%C3\%ADa-Mundialde-la-salud-justicia-Plan-Obligatorio-de-Salud-Fallos-de-tutela-Derechos-HumanosEPS.htm

19. Departamento Nacional de Planeación DNP. (2015). Objetivos de Desarrollo del Milenio. Recuperado el 30 de abril de 2016, a partir de https://www.dnp.gov.co/programas/desarrollo-social/pol\%C3\%ADticas-socialestransversales/Paginas/objetivos-de-desarrollo-del-milenio.aspx

20. Fondo Colombiano de enfermedades de alto costo. (2014). Situacion del VIH-SIDA en $\begin{array}{llll}\text { Colombia. } & \text { Recuperado } & \text { partir }\end{array}$ http://www.cuentadealtocosto.org/patologias/VIH/docs/Situacion\%20del\%20VIHSIDA\%20en\%20Colombia\%202013.pdf

21. Fundación Corona, \& Fundación Santa Fe de Bogotá. (2015). Análisis aseguramiento georeferenciado. Recuperado a partir de https://www.asivamosensalud.org/inidicadores/aseguramiento/grafica.ver/15

22. Fundación Saldarriaga Concha. (2007). Diagnóstico de los adultos mayores de Colombia. Recuperado a partir de http://www.sdp.gov.co/portal/page/portal/PortalSDP/SeguimientoPoliticas/Politicas Poblacionales/Envejecimiento y Vejez/Documentacion/A31ACF931BA329B4E040 
23. García García V, \& Bascones Martínez A. (2009). Cáncer oral: Puesta al día. Recuperado a partir de http://scielo.isciii.es/scielo.php?script=sci_arttext\&pid=S021312852009000500002

24. Gino Montenegro Martínez. (2011). Un nuevo enfoque de la salud oral: una mirada desde la salud pública. Recuperado a partir de http://www.redalyc.org/pdf/2312/231218581013.pdf

25. Gino Montenegro Martínez, Ana Lucia Sarralde Delgado, \& Claudia Patricia Lamby Tovar. (2013). La educación como determinante de la salud oral. Recuperado a partir de http://revistas.javeriana.edu.co/index.php/revUnivOdontologica/article/view/SICl\%3A\%20 2027-3444\%28201307\%2932\%3A69\%3C115\%3AECDDSO\%3E2.0.CO\%3B2-F/5291

26. Grupo funcional de salud oral. (2014). Oferta de servicios Odontológicos habilitados en Bogotá, D.C. Recuperado a partir de Inédito

27. Grupo técnico de la Secretaria Distrital de Salud. (2012). Seguimiento metas distritales de salud oral 2008-2012. Recuperado a partir de Inédito.

28. Hospital general de México. (2014). Manual de Procedimientos del servicio de $\begin{array}{lllll}\text { estomatología. } & \text { Recuperado } & \text { a } & \text { de }\end{array}$ http://www.hgm.salud.gob.mx/descargas/pdf/area_medica/estomato/ManProcEstomatolo gia.pdf

29. Instituto Nacional de Salud. (2015). Análisis RIPS Salud Bucal. Recuperado a partir de http://www.ins.gov.co/lineas-de-accion/Subdireccion-Vigilancia/Lineamientos Documentos/Anexo_12 Analisis de RIPS en salud bucal.pdf?Mobile=1\&Source=\%2 
30. Jairo Hernán Ternera. (2012). Seguimiento metas distritales de salud oral 2012-2016. Recuperado a partir de Inédito

31. Jorge Martín Rodríguez Hernández, Diana Patricia Rodríguez Rubiano, \& Juan Carlos Corrales Barona. (2013). Barreras de acceso administrativo a los servicios de salud en población Colombiana, 20. Recuperado a partir de http://www.scielo.br/pdf/csc/v20n6/1413-8123-csc-20-06-1947.pdf

32. Juan Carlos Uribe López. (2011). Mortalidad en Colombia por Cáncer oral en el 2008. Recuperado a partir de https://dialnet.unirioja.es/descarga/articulo/3818095.pdf

33. Julio Franco Corzo. (2013). Diseño de Politicas Públicas. Recuperado a partir de https://www.iexe.edu.mx/nuestras-publicaciones/libro-diseno-de-politicas-publicas.html

34. María del Carmen Jiménez Malagón, Luis Fang, \& Antonio Díaz Caballero. (2012). Perfil epidemiológico oral y necesidad de tratamiento odontológico de pacientes VIH/SIDA. Recuperado a partir de http://scielo.isciii.es/scielo.php?script=sci_arttext\&pid=S1699$695 \times 2012000200004$

35. Martin Hobdel, Poul Erik Petersen, John Clarkson, \& Newell Johnson. (2013). GlobalGoals-for-Oral-Health-2020. Recuperado a partir de http://www.who.int/oral_health/media/en/orh_goals_2020.pdf

36. Ministerio de la Protección social. (2005). Plan Nacional de Salud bucal 2005-2008. Recuperado a partir de http://www1.paho.org/hq/dmdocuments/2009/OH_COL_PlanNacSalBuc2005.pdf 
37. Ministerio de la Protección Social, COLCIENCIAS, Cendex, S.E.I. S.A, \& Pontificia Universidad Javeriana. (2009). Encuesta Nacional de Salud. Recuperado a partir de https://www.minsalud.gov.co/Documentos\%20y\%20Publicaciones/ENCUESTA\%20NACI ONAL.pdf

38. Ministerio de la Protección Social de Colombia. (2010). Documento técnico línea de base con atlas versión 3. Recuperado a partir de https://www.minsalud.gov.co/Documentos\%20y\%20Publicaciones/DOCUMENTO\%20T \%C3\%89CNICO\%20L\%C3\%8DNEA\%20DE\%20BASE\%20CON\%20ATLAS\%20VERSI \%C3\%93N\%203\%20-\%20ABRIL\%202010.pdf

39. Ministerio de la Protección Social, \& Universidad de Antioquia. (2010). Analisis de la situacion de salud en Colombia 2002-2007. Recuperado a partir de https://www.minsalud.gov.co/Documentos\%20y\%20Publicaciones/ASIS-Tomo\%20III-Morbilidad\%20y\%20mortalidad\%20de\%20la\%20poblaci\%C3\%B3n\%20colombiana.pdf

40. Ministerio de Salud. (1999). Estudio Nacional de Salud Bucal. Tomo VII. Recuperado a partir de http://www.visitaodontologica.co/ARCHIVOS/ARCHIVOSNORMAS/Salud\%20Publica_P_y_P/II_ESTUDIO_NACIONAL_SALUD_BUCAL.pdf

41. Ministerio de Salud ., \& Protección Social - Instituto Nacional de Cancerología, ESE. (2012). Plan decenal para el control del cancer en Colombia, 2012-2021. Recuperado a partir de http://www.iccpportal.org/sites/default/files/plans/PlanDecenal_ControlCancer_2012-2021.pdf 
42. Ministerio de Salud. Colombia. (2014). Taller ENSAB última Versión.pdf. Recuperado el 17 de enero de 2016, a partir de https://www.minsalud.gov.co/sites/rid/Lists/BibliotecaDigital/RIDE/VS/PP/ENT/TALLER\% 20ENSAB\%20ULTIMA\%20VERSION.pdf

43. Ministerio de Salud y Protección Social. (2015). Normativa. Recuperado a partir de https://www.minsalud.gov.co/Paginas/normativa-inicio.aspx

44. Ministerio de Salud y Protección Social. (2013). Perfil y competencias profesionales del odontólogo en Colombia. Recuperado a partir de https://www.minsalud.gov.co/sites/rid/Lists/BibliotecaDigital/RIDE/VS/TH/Odontologia_O ctubre2014.pdf

45. Ministerio de Salud y Protección Social. (2013). Plan Decenal de Salud Pública. Recuperado el 1 de noviembre de 2015, a partir de https://www.minsalud.gov.co/plandecenal/Paginas/home2013.aspx

46. Ministerio de Salud y Protección Social. (2014). Analisis de la situacion de salud en $\begin{array}{llll}\text { Colombia. } & \text { Recuperado } & \text { partir } & \text { de }\end{array}$ http://www.paho.org/col/index.php?option=com_docman\&task=doc_download\&gid=434\& Itemid=

47. Ministerio de Salud y Protección social., \& Pontificia Universidad Javeriana. (2014). ENSAB-IV-Situacion-Bucal-Actual.pdf. Recuperado el 28 de octubre de 2015, a partir de https://www.minsalud.gov.co/sites/rid/Lists/BibliotecaDigital/RIDE/VS/PP/ENSAB-IVSituacion-Bucal-Actual.pdf

Página 223 de 228

Rutty Adriana Abril Vivas. Odontóloga. Especialista Administración Hospitalaria. Auditoria de la Calidad. Nubia Astrid Duarte Pinzón. Enfermera. Especialista en Gerencia de Salud. 
48. National Institute of Dental and Craniofacial ResearchNational Oral Health Information Clearinghouse. (2013). Enfermedad de las encías o enfermedad periodontal. Recuperado a partir de http://www.nidcr.nih.gov/

49. OPS. (2008). Sistemas de salud basados en la atención primaria de salud. Recuperado a partir de http://www1.paho.org/hq/dmdocuments/2010/APSEstrategias_Desarrollo_Equipos_APS.pdf

50. Organización Mundial de la Salud. (2012). Salud bucodental. Recuperado a partir de http://www.who.int/mediacentre/factsheets/fs318/es/

51. Organización Mundial de la Salud. (2016). OMS | Salud bucodental. Recuperado el 29 de abril de 2016, a partir de http://www.who.int/mediacentre/factsheets/fs318/es/

52. Organización Mundial de la Salud OPS/OMS Colombia, R. M. (2009). Análisis del perfil de la salud urbana de Bogotá. Recuperado a partir de www.paho.org/col/index.php?option...gid..

53. Organización Panamericana de la salud. (1997). Salud oral. Recuperado a partir de http://apps.who.int/iris/bitstream/10665/165421/1/25288.pdf

54. Procuraduría general de la Nación de Colombia. (2012). Financiamiento del Sistema General de Seguridad Social en Salud. Seguimiento y control preventivo a las políticas $\begin{array}{lllll}\text { públicas. } & \text { Recuperado } & \text { a } & \text { partir }\end{array}$ http://www.procuraduria.gov.co/portal/media/file/Publicaci\%C3\%B3n\%20-

\%20Finanzas\%20en\%20Salud.pdf 
55. PROFAMILIA. (2013). Envejecimiento y vejez en Colombia. Recuperado a partir de http://www.profamilia.org.co/docs/estudios/imagenes/3\%20\%20ENVEJECIMIENTO\%20Y\%20VEJEZ\%20EN\%20COLOMBIA.pdf

56. Secretaria de educacion. (2013). Caracterización del sector educativo de Bogotá. $\begin{array}{llll}\text { Recuperado a } & \text { partir } & \text { de }\end{array}$ http://www.educacionbogota.edu.co/archivos/SECTOR_EDUCATIVO/ESTADISTICAS_E DUCATIVAS/2013/BoletinEstadisticoAnual2013.pdf

57. Secretaria de Salud de Bogotá. (s/f). politic_salud_oral_bogota_2011-2021.pdf. Recuperado el 7 de febrero de 2016, a partir de http://acfo.edu.co/educacion/pdf/Guias/politic_salud_oral_bogota_2011-2021.pdf

58. Secretaria de Salud de los Estados Unidos Mexicanos. (2012). Manual de Procedimientos Estandarizados para la Vigilancia Epidemiológica de las patologias bucales.pdf. $\begin{array}{llll}\text { Recuperado } & \text { a } & \text { partir } & \text { de }\end{array}$ http://www.epidemiologia.salud.gob.mx/dgae/infoepid/vig_epid_manuales.html

59. Secretaria Distrital de Salud. (2007). Guia de práctica clinica en salud oral. Recuperado a partir de http://acfo.edu.co/educacion/pdf/Guias/guia_caries.pdf

60. Secretaria Distrital de Salud. (2011). Política pública de salud oral con participación social para el decenio 2011 - 2021. Recuperado a partir de http://acfo.edu.co/educacion/pdf/Guias/politic_salud_oral_bogota_2011-2021.pdf 
61. Secretaria Distrital de Salud. (2011). Politica salud oral de Bogotá con participación social para el decenio 2011-2021. Recuperado a partir de http://acfo.edu.co/educacion/pdf/Guias/politic_salud_oral_bogota_2011-2021.pdf

62. Secretaria Distrital de Salud. (2011). Proyecto de desarrollo de autonomia de salud oral. Recuperado el 18 de enero de 2016, a partir de http://www.saludpublicabogota.com/wiki/index.php?title=Salud_oral

63. Secretaria Distrital de Salud. (2012). Informe final seguimiento metas distritales de salud oral 2008-2011. Recuperado a partir de Inédito

64. Secretaria Distrital de Salud. (2012). Informe parcial Isemestre 2012 seguimiento metas distritales de salud oral 2012-2016. Recuperado a partir de Inédito

65. Secretaria Distrital de Salud. (2012). Proyecto de desarrollo de autonomía salud oral, desarrolladas a través del PIC 2012. Recuperado a partir de http://www.grupofergusson.org/biblioteca/2012/Mayo\%202012\%20a\%20Julio\%202012/D ocumentos\%20tecnicos\%20PDA,\%20TV\%20Equipo\%20Poblacional/DT_PDA_SALUD_ ORAL.pdf

66. Secretaria Distrital de Salud. (2015). Proyecto de desarrollo de autonomía de salud oral en territorios saludables 2015. Recuperado a partir de http://www.magacinodontologico.com/index.php/eventos-y-mercadeo-febrero2015/dentales-xcellent-colombia/item/107-bogota-hacia-la-construccion-de-una-culturade-la-salud-oral 
67. Secretaria Distrital de Salud. Bogotá. (2012). Documento técnico para orientar las respuestas en salud pública del proyecto de desarrollo de autonomía salud oral, desarrolladas a través del PIC 2012.

68. Secretaría Distrital de Salud de Bogotá D.C. Fondo Financiero Distrital de Salud de Bogotá D.C. (2013). Balance Social 2012. Recuperado a partir de http://www.saludcapital.gov.co/Informes\%20de\%20Gestin/Balance\%20Social/Balance\% 20Social\%202012.pdf

69. Secretaria Distrital de Salud de Bogotá, Martha Lucía Hincapié Molina, \& Nirley Stella Vargas Díaz. (2014). Morbilidad en salud oral en la población vinculada, desplazada y del Régimen Subsidiado no pos, periodo 2011-2012. Revist Seg Social-16-1. Recuperado a partir de Inédito

70. Souza Coelho Soares, Santos Gusmão, Soares Hordonho Santillo, \& Henriques Simoni. (2016). Impacto del edentulismo en la calidad de vida de individuos brasileños. Recuperado a partir de http://www.actaodontologica.com/ediciones/2013/3/art9.asp

71. Stambuk, H., Karimi,S., Lee S, Patel,S. (2007). Tumores de la cavidad oral y orofaringe. Recuperado a partir de http://apps.elsevier.es/watermark/ctl_servlet?_f=10\&pident_articulo=13122721\&pident_u suario $=0 \&$ pcontactid $=\&$ pident_revista $=505 \&$ ty $=10 \&$ accion $=$ L\&origen=zona

72. Superintendencia Nacional de Salud. (2012). Indicadores de oportunidad reportados por las entidades administradoras de planes de beneficios a la Superintendencia Nacional de Salud. Recuperado a partir de http://www.wma.net/es/20activities/30publichealth/ 
73. Universidad de Antioquia. Facultad de Odontología. (2014). Determinación tomográfica de la prevalencia de forma y tamaño de los rebordes residuales en pacientes edentados. Recuperado a partir de http://www.scielo.org.co/pdf/rfoua/v25n2/v25n2a03.pdf

74. Universidad de Antioquia Facultad Nacional de Salud Pública Héctor Abad Gómez, \& COLCIENCIAS. (2014). Tensiones en las decisiones en Salud Pública en el sistema de salud colombiano: El bién común en confrontación con los intereses y prácticas particulares. Medellín. Colombia: L.Vieco. S.A.S. Recuperado a partir de http://cosesam.co/wp-content/uploads/2014/07/GloriaMolina-

TensionesDecisionesSaludPublica-2.pdf

75. Universidad Nacional de Colombia, S. de S. de B. (2012). Barreras geográficas y equidad en el acceso a los servicios de salud en el Distrito. Presentación_Barreras_geográficas_equidad_acceso_2012.pdf. Recuperado a partir de http://www.saludcapital.gov.co/Investigaciones\%20Observatorio/Presentaci\%C3\%B3n_B arreras_geogr\%C3\%A1ficas_equidad_acceso_2012.pdf

76. U.S. National Library of Medicine. (2015). Cáncer de cabeza y cuello: MedlinePlus en $\begin{array}{lllll}\text { español. } & \text { Recuperado } & \text { a } & \text { de }\end{array}$ https://www.nlm.nih.gov/medlineplus/spanish/headandneckcancer.html 